UNIVERSIDADE DE SÃO PAULO

ESCOLA POLITÉCNICA

PAULO TORRES DE CARVALHO CORDOVIL

Modelagem e aspectos construtivos de geradores síncronos multifásicos para turbinas eólicas offshore 
PAULO TORRES DE CARVALHO CORDOVIL

\section{Modelagem e aspectos construtivos de geradores síncronos multifásicos para turbinas eólicas offshore}

Dissertação apresentada à Escola Politécnica da Universidade de São Paulo para obtenção do título de Mestre em Ciências em Engenharia Elétrica.

Área de concentração: Sistemas de Potência

Orientador: Prof. Dr. Ivan Eduardo Chabu

São Paulo

2018 


\section{FICHA CATALOGRÁFICA}

Este exemplar foi revisado e alterado em relação à versão original, sob responsabilidade única do autor e com a anuência de seu orientador.

São Paulo, de .de 2018

Assinatura do autor

Assinatura do orientador

Cordovil, Paulo

Modelagem e aspectos construtivos de geradores síncronos multifásicos para turbinas eólicas offshore/P. Cordovil -- versão corr. São Paulo, 2018.

$167 \mathrm{p}$.

Dissertação (Mestrado) - Escola Politécnica da Universidade de São Paulo. Departamento de Energia e Automação Elétricas.

1. Máquinas Elétricas 2. Máquinas Síncronas 3. Energia Eólica I. Universidade de São Paulo. Escola Politécnica. Departamento de Engenharia de Energia e Automação Elétricas. II.t. 


\section{SUMÁRIO}

1 INTRODUÇÃO

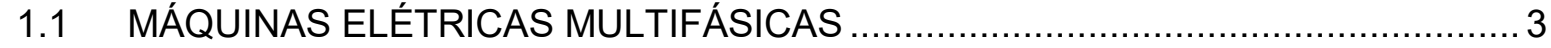

1.1.1 Trem de potência para turbinas eólicas offshore. ......................................... 3

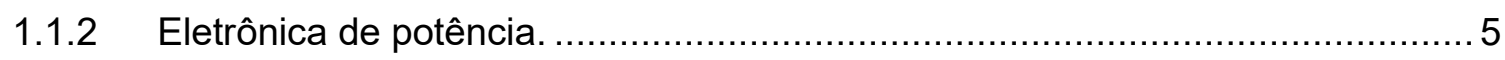

1.1.3 Oportunidades para máquinas elétricas multifásicas ................................... 5

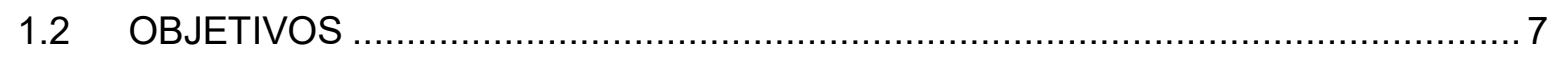

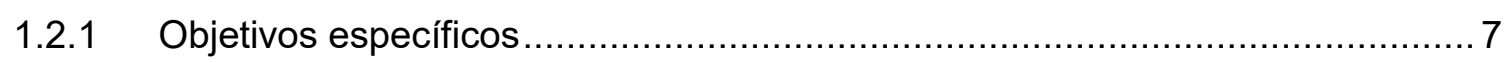

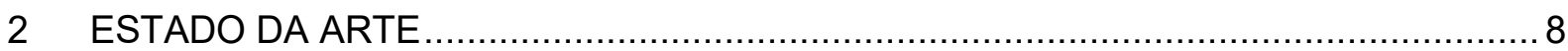

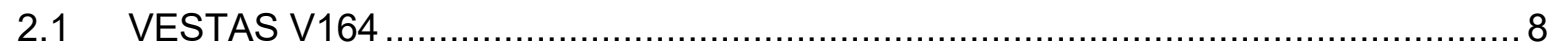

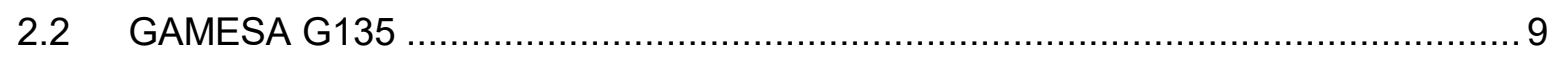

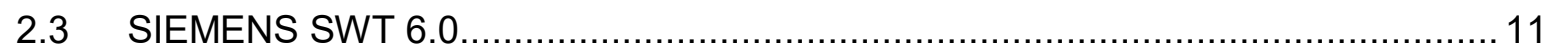

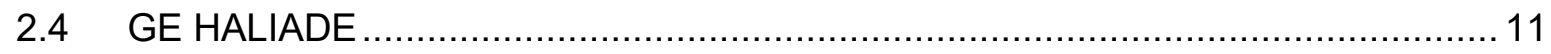

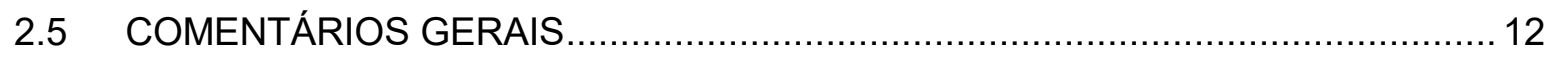

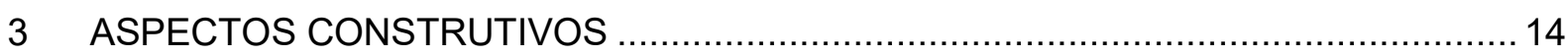

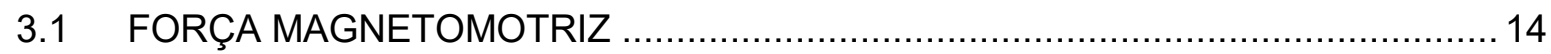

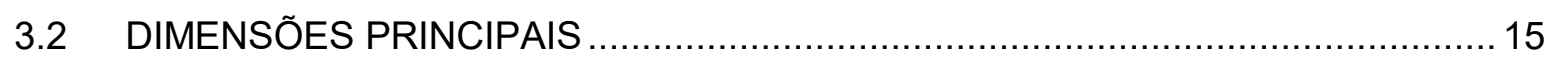

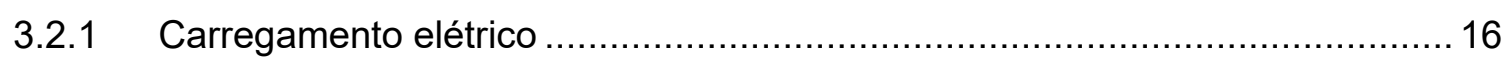

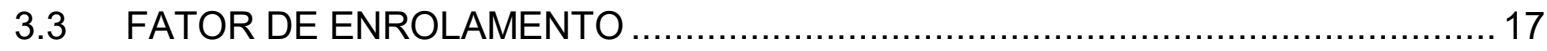

3.3.1 Fator de distribuição ................................................................... 17

3.3.2 Fator de encurtamento de passo ....................................................... 19

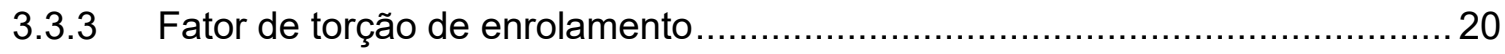

3.4 PARÂMETROS EM FUNÇÃO DAS DIMENSÕES PRINCIPAIS .......................... 21

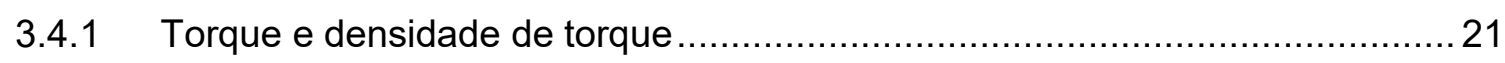

3.4.2 Força e densidade de força normal ............................................................. 22

3.4.3 Dimensões de ranhura e fluxo magnético no dente ..................................... 23

3.4.4 Dimensões das coroas estatórica e rotórica ................................................ 26

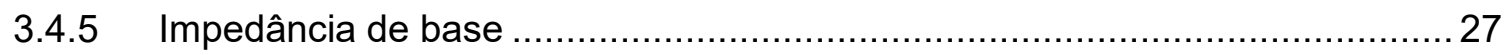

3.4.6 Corrente e indutância de magnetização.................................................. 28

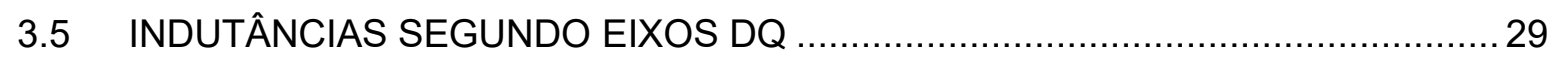

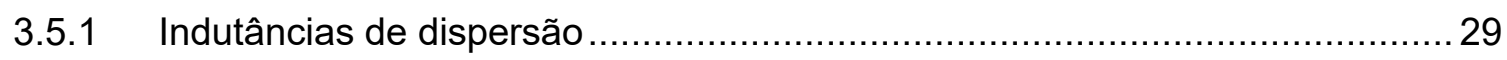

3.5.2 Indutâncias de magnetização segundo eixos d e q................................... 30

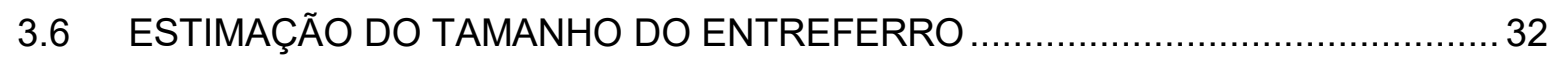

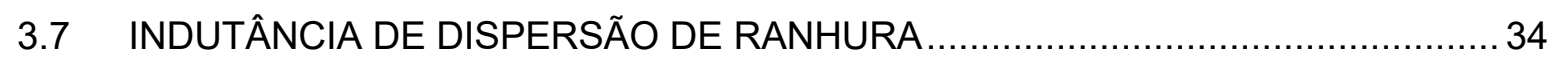

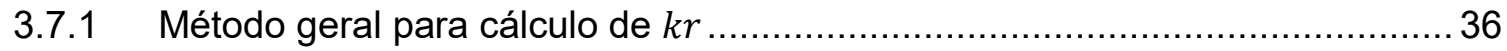

3.7.2 Cálculo de $k r$ para máquinas elétricas trifásicas. ........................................ 36

3.7.3 Cálculo de $k r$ para máquinas elétricas de 5, 6 e 7 fases ............................... 38

3.7.4 Cálculo de $k r$ para máquinas elétricas de nove ou mais fases .......................41

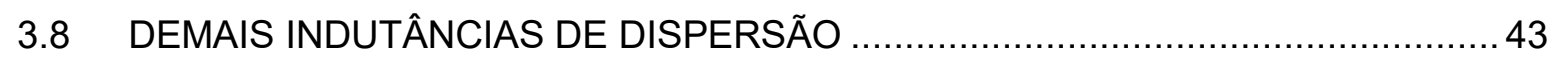


3.8.1 Indutância de dispersão de topo de dente. ............................................... 43

3.8.2 Indutância de dispersão harmônica ........................................................... 44

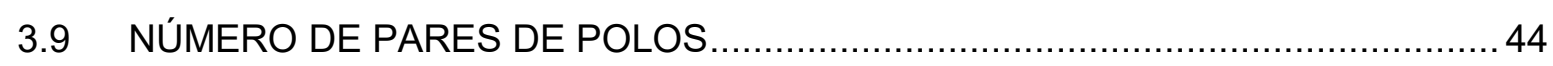

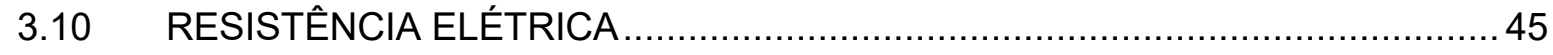

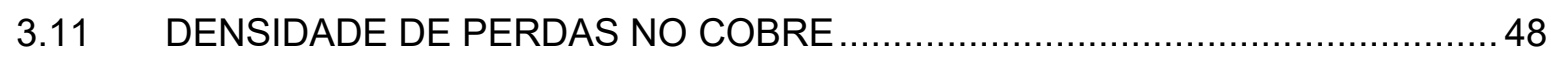

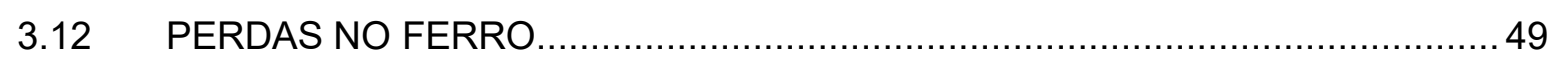

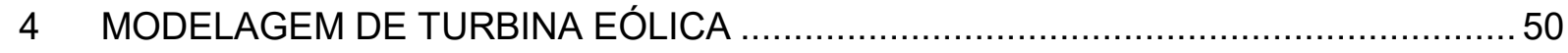

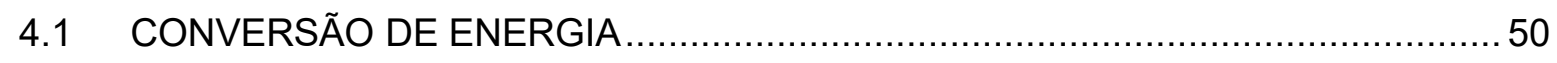

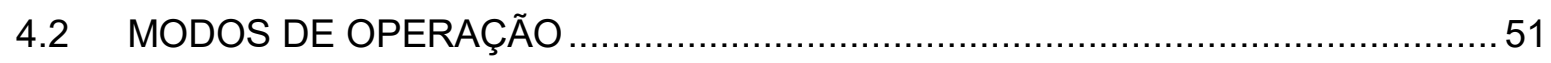

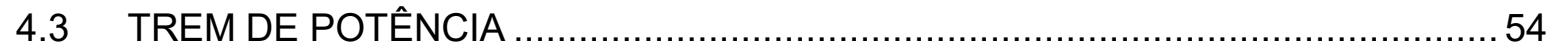

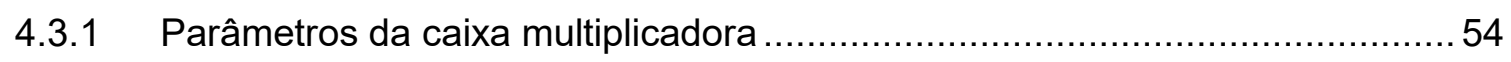

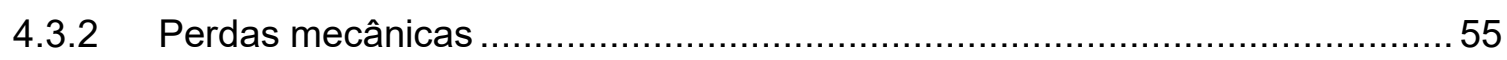

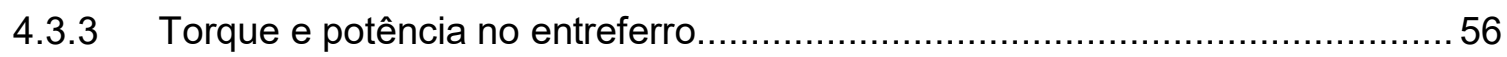

4.4 INTERFACE GERADOR - ELETRÔNICA DE POTÊNCIA ................................. 57

4.4.1 Solução 1 - Gerador trifásico com conversores em paralelo ...........................57

4.4.2 Solução 2 - Gerador de 6 fases com conversores em paralelo .........................58

4.4.3 Solução 3 - Gerador de 9 fases com conversores em paralelo .......................59

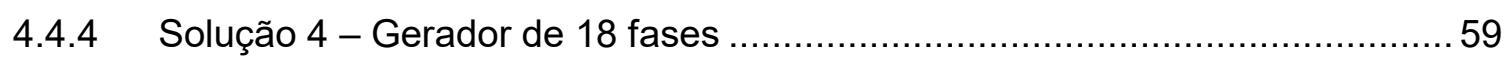

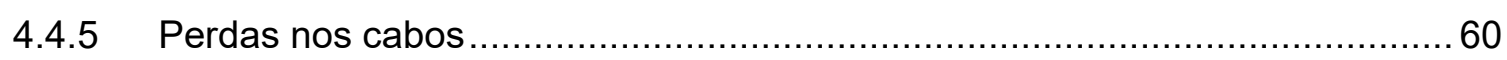

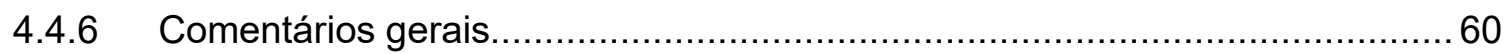

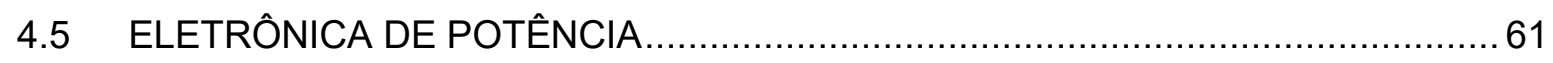

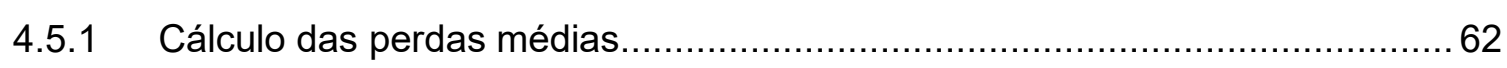

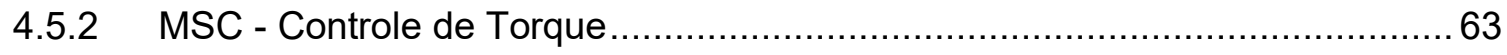

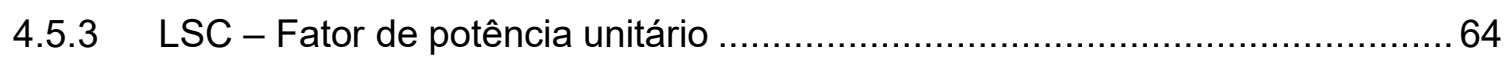

4.6 RENDIMENTO E COEFICIENTE DE POTÊNCIA ELÉTRICO ............................... 64

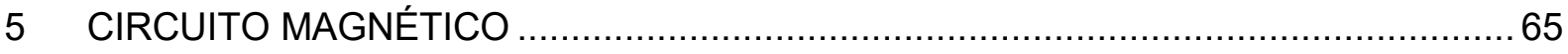

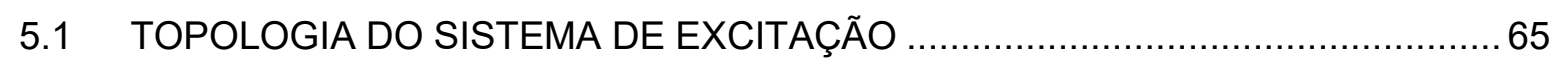

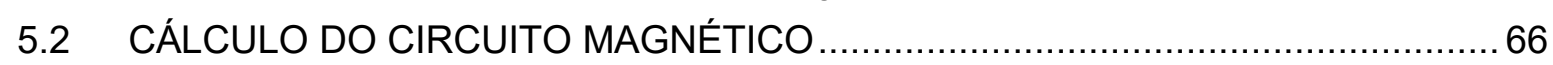

5.2.1 Fluxo e indução magnética no imã ........................................................ 67

5.2.2 Fluxo e indução magnética na coroa do rotor ...............................................6 68

5.2.3 Fluxo e indução magnética na coroa do estator...........................................68

5.2.4 Fluxo e indução magnética no dente ..................................................... 68

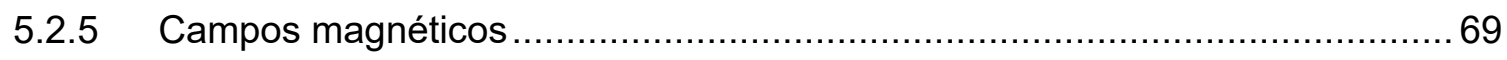

6 COMPARAÇÃO ENTE DIFERENTES TOPOLOGIAS ......................................... 71

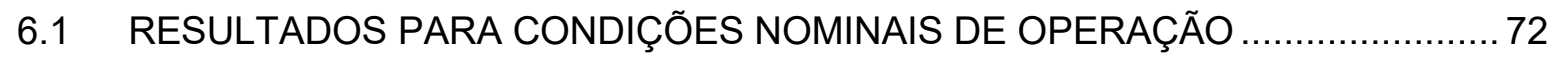

6.2 RESULTADOS EM FUNÇÃO DA VELOCIDADE DO VENTO ........................... 75

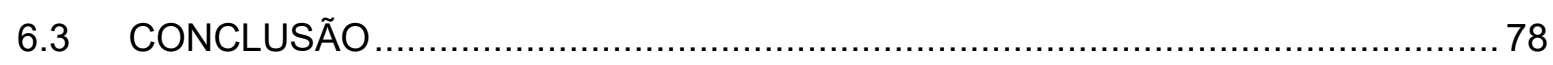

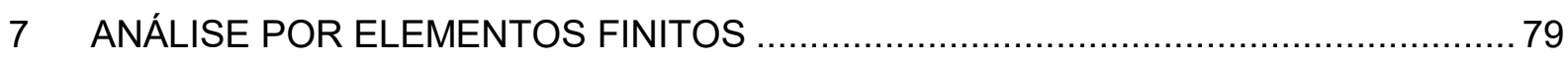

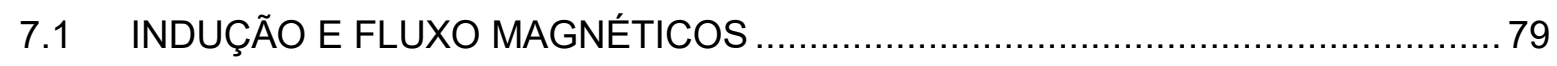




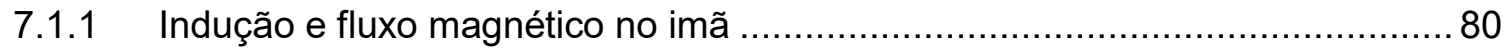

7.1.2 Indução e fluxo magnético no entreferro..................................................... 81

7.1.3 Indução e fluxo magnético na altura média das ranhuras ............................. 81

7.1.4 Indução magnética na coroa estatórica ..................................................... 83

7.1.5 Indução magnética na coroa rotórica .................................................... 83

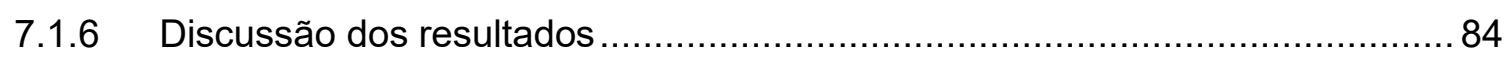

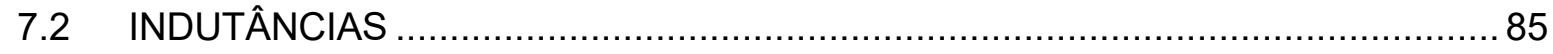

7.2.1 Variação Ld e Lq com posição angular do rotor.......................................... 85

7.2.2 Variação Ld e Lq com id e iq. ........................................................... 87

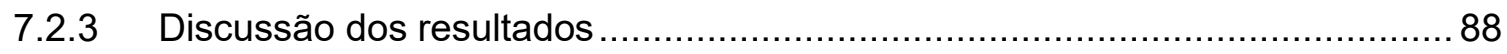

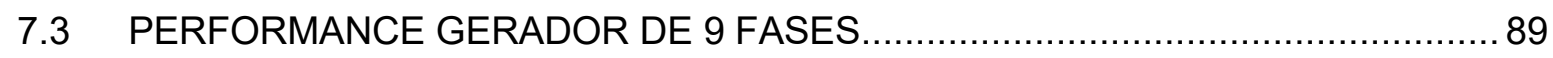

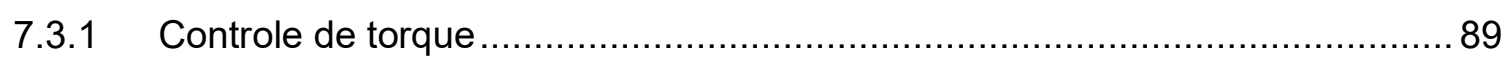

7.3.2 Comparação dos resultados ................................................................ 90

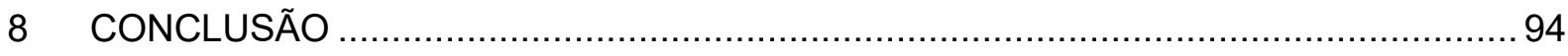

8.1 PROJETO E MODELAGEM DE MÁQUINAS ELÉTRICAS MULTIFÁSICAS .........94

8.2 GERADOR DE NOVE FASES PARA TURBINA EÓLICA DE 10MW ...................96

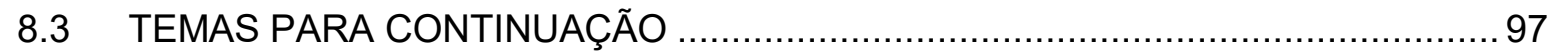

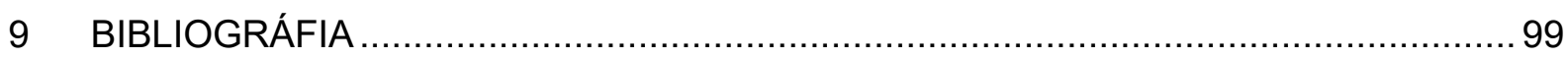

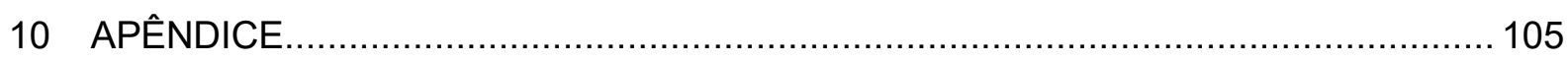

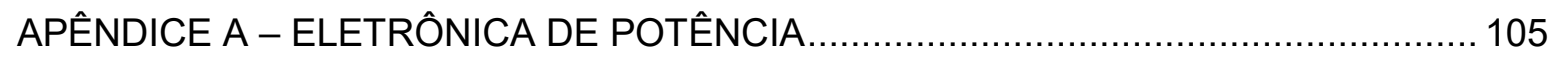

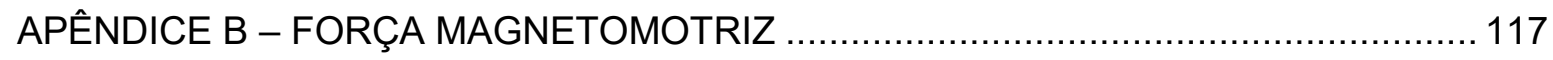

APÊNDICE C - FATORES DE PROJETO DE MÁQUINAS ELÉTRICAS ....................... 130

APÊNDICE D - TEORIA GERAL DE MÁQUINAS ELÉTRICAS ............................... 137

APÊNDICE E - TEORIA DE COMPONENTES SIMÉTRICAS ................................. 144

APÊNDICE F - DRIVETRAIN PARA TURBINAS EÓLICAS .................................. 148 


\section{LISTA DE FIGURAS}

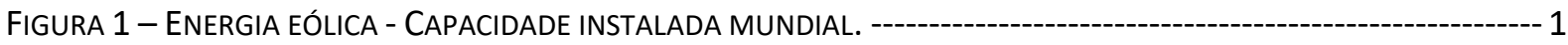

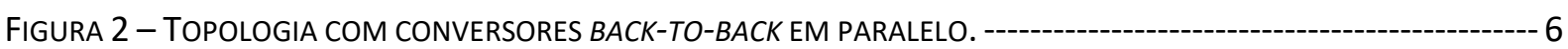

FIGURA 3 - TOPOLOGIA COM CONVERSORES BACK-TO-BACK TRIFÁSICOS PARA CADA SET TRIFÁSICO DO GERADOR. ------ 6

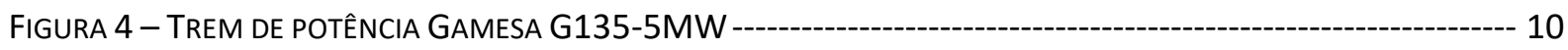

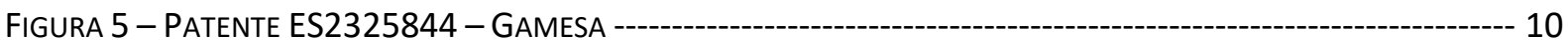

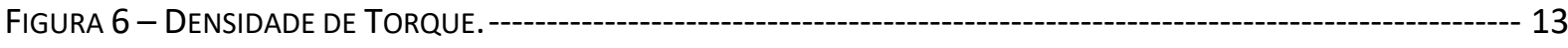

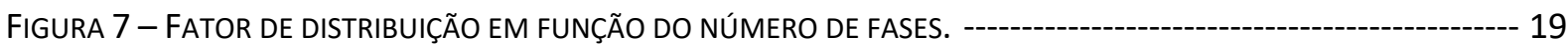

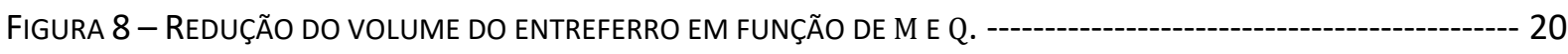

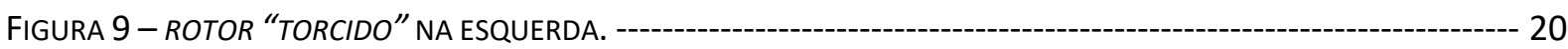

FIGURA 10 - DIFERENTES CONFIGURAÇÕES DE MÁQUINAS DE IMÃS PERMANENTES. A) SURFACE MAGNETS. B) INSET MAGNETS C) PM WITH MILD STEEL POLE SHOES D) BURIED MAGNETS. -

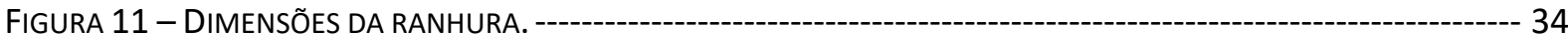

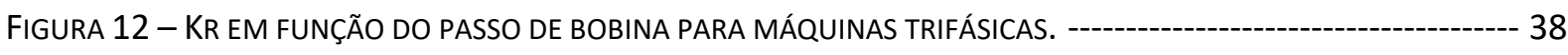

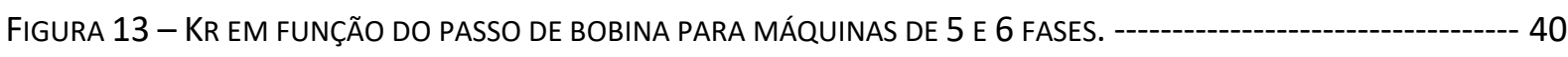

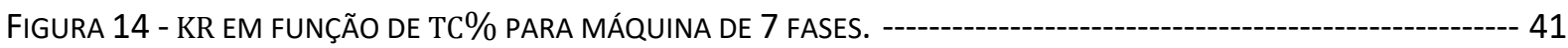

FIGURA 15 - KR EM FUNÇÃO DO PASSO DE BOBINA PARA MÁQUINAS ELÉTRICAS DE 9 FASES SIMÉTRICA OU ASSIMÉTRICA

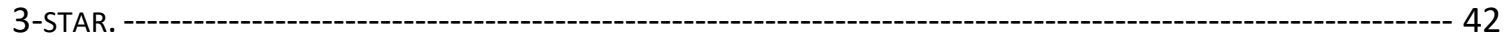

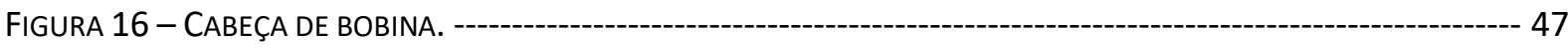

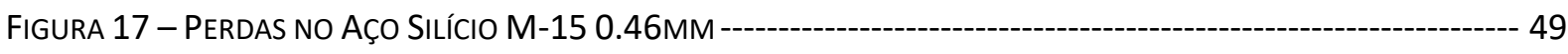

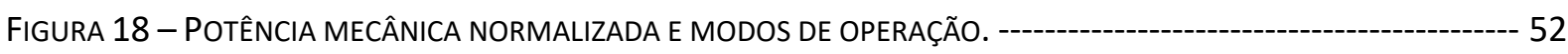

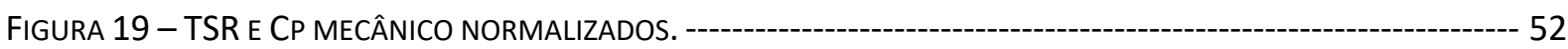

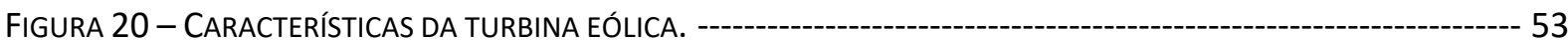

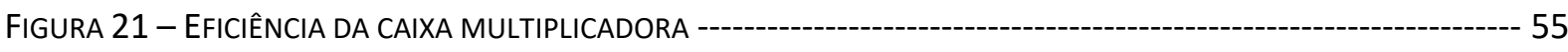

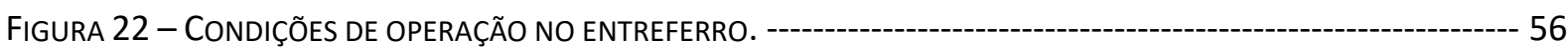

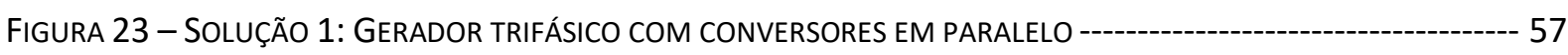

FIGURA 24 - SOLUÇÃO 2: GERADOR DE 6 FASES COM CONVERSORES EM PARALELO --------------------------------- 58

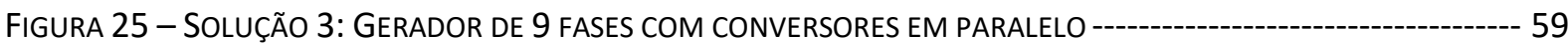

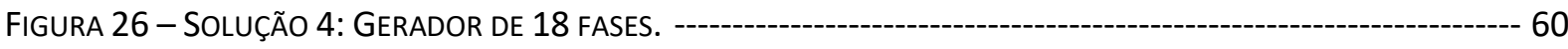

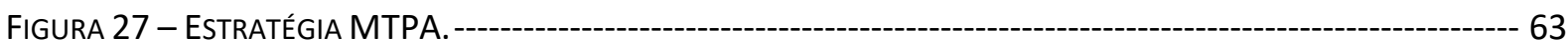

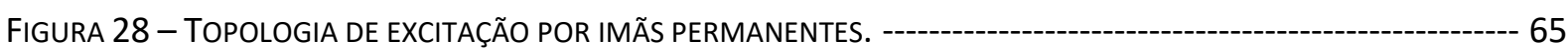

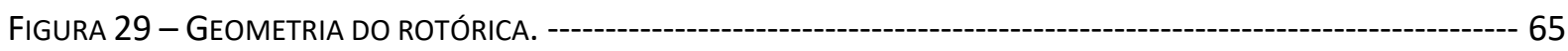

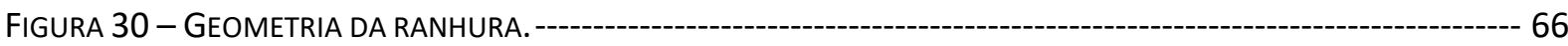

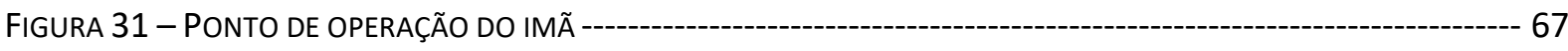

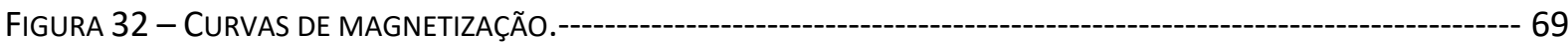

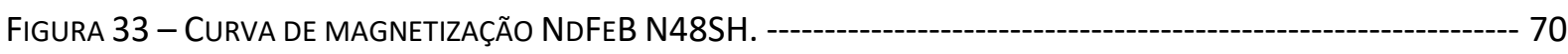

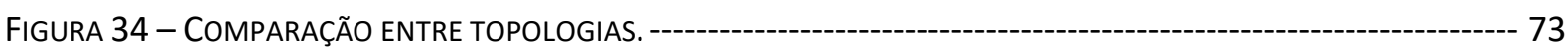




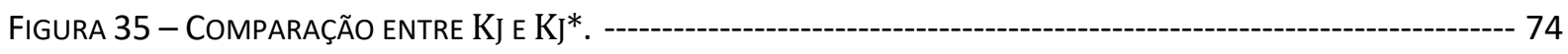

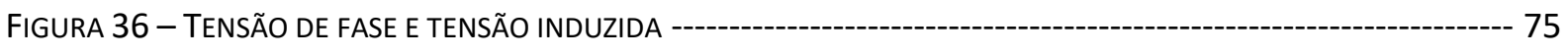

FIGURA 37 - CORRENTE POR CONVERSOR E FATOR DE POTÊNCIA --- 76

FIGURA 38 - RENDIMENTOS --- 77

FIGURA 39 - COEFICIENTE DE POTÊNCIA. -- 77

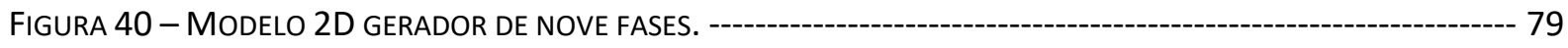

FIGURA 41 - MODELO GERADOR DE NOVE FASES EM FEMM. ---

FIGURA 42 - MODELO GERADOR DE NOVE FASES EM FEMM. -

FIGURA 43 - INDUÇÃO MAGNÉTICA NO ENTREFERRO. -

FIGURA 44 - INDUÇ̃̃o MAGNÉTICA NOS DENTES (ALTURA MÉDIA).

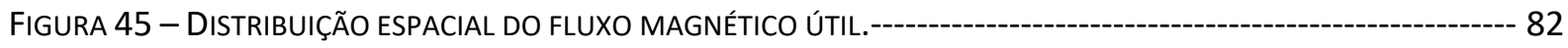

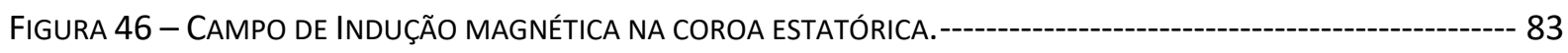

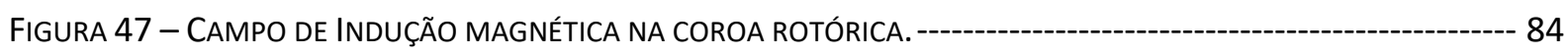

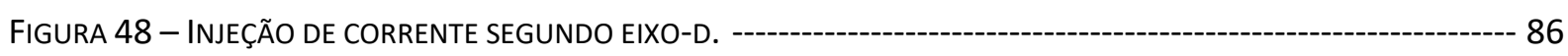

FIGURA 49 - INJEÇÃO DE CORRENTE SEGUNDO EIXO-Q. - 86

FIGURA 50 - LDQ $(\Theta)$---- 87

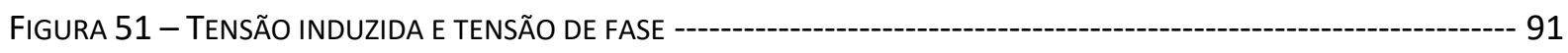

FIGURA 52 - CORRENTE DE FASE E FATOR DE POTÊNCIA --- 92

FIGURA 53 - RENDIMENTOS -- 92

FIGURA 54 - POTÊNCIA E COEFICIENTE DE POTÊNCIA. - 93

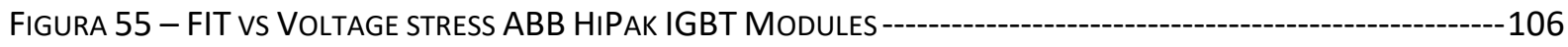

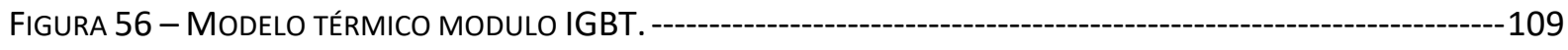

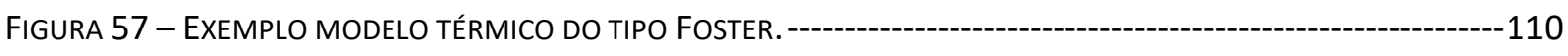

FIGURA 58 - IMPEDÂNCIA TÉRMICA FZ3600R17HP4. ---

FIGURA 59 - PERDAS MÉDIAS EM FUNÇÃO DO FATOR DE POTÊNCIA. -

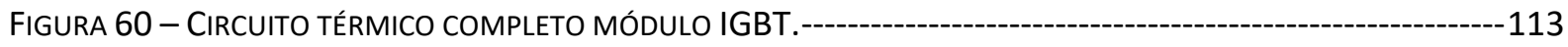

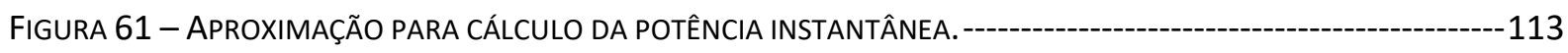

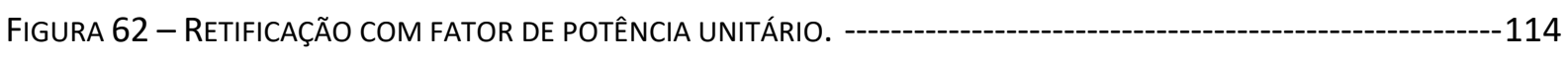

FIGURA 63 - INVERSÃO COM FATOR DE POTÊNCIA UNITÁRIO.---

FIGURA 64 - TVJ PARA DIFERENTES VALORES DE FREQUÊNCIA. ---

FIGURA 65 - REDUÇÃO DA CAPACIDADE DE CORRENTE PARA BAIXOS VALORES DE FREQUÊNCIA ELÉTRICA. -----------116

FIGURA 66 - HARMÔNICAS ESPACIAIS NA FMM EM MÁQUINAS DE 9 FASES, SEQUÊNCIA POSITIVA. ----------------125

FIGURA 67 - HARMÔNICAS ESPACIAIS NA FMM EM MÁQUINAS DE 9 FASES, SEQUÊNCIA NEGATIVA.------------126

FIGURA 68 - COMPARAÇÃO ENTRE HARMÔNICAS ESPACIAIS DA FMM DE MÁQUINAS SIMÉTRICAS E N-STAR. --------127

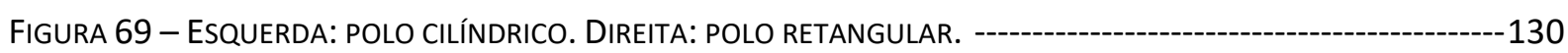

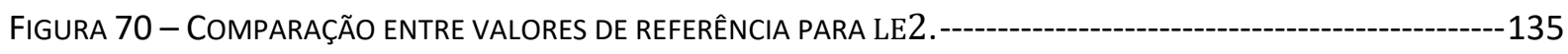

FIGURA 71 - APROXIMAÇÃO DE CABEÇA DE BOBINA. - 
FIGURA 72 - FATORES EMPÍRICOS PARA CÁLCULO DE INDUTÂNCIA DE DISPERSÃO DE CABEÇA DE BOBINA.

FIGURA 73 - TRANSFORMAÇÃO REAL DERIVADA DA TRANSFORMAÇÃO COMPLEXA DE COMPONENTES SIMÉTRICAS. --146

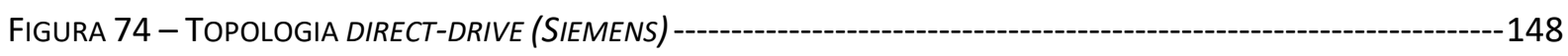

FIGURA 75 - TOPOLOGIA DE MÉDIA VELOCIDADE (VESTAS) -

FIGURA 76 - TREM DE POTÊNCIA TíPICO DE ALTA VELOCIDADE. 


\section{LISTA DE TABELAS}

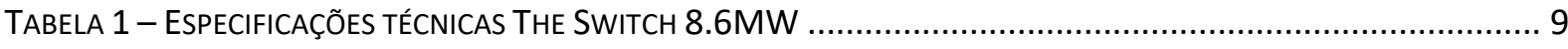

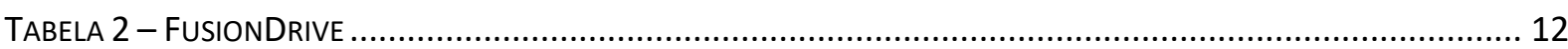

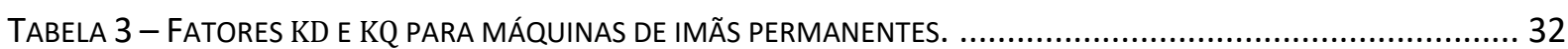

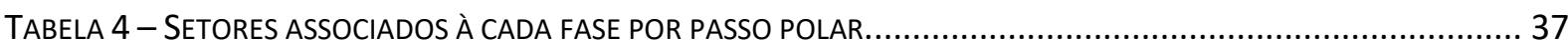

TABELA 5 - FASES ASSOCIADAS À CADA SETOR POR PASSO POLAR PARA MÁQUINA DE 5 FASES. .......................... 38

TABELA 6 - POSSÍVEIS CONFIGURAÇÕES DE RANHURA PARA FASE 1 E VALORES DE OR PARA MÁQUINA DE 5 FASES. .... 38

TABELA 7 - FASES ASSOCIADAS À CADA SETOR POR PASSO POLAR PARA MÁQUINA DE 7 FASES..............................39

TABELA 8 - POSSÍVEIS CONFIGURAÇÕES DE RANHURA PARA FASE 1 E VALORES DE @R PARA MÁQUINAS DE 7 FASES.... 39

TABELA 9 - FASES ASSOCIADAS À CADA SETOR DO PASSO POLAR, MÁQUINA DE 6 FASES SIMÉTRICAS, FAIXA DE FASE DE 30

TABELA 10 - FASES ASSOCIADAS À CADA SETOR DO PASSO POLAR, MÁQUINA DE 6 FASES SIMÉTRICAS, FAIXA DE FASE DE 60 은.

TABELA 11 - FASES ASSOCIADAS À CADA SETOR POR PASSO POLAR PARA MÁQUINA DE 6 FASES 2-STAR. 40

TABELA 12 - POSSÍVEIS CONFIGURAÇÕES DE RANHURA PARA FASE 1 E VALORES DE @R PARA MÁQUINAS DE 6 FASES 2STAR.

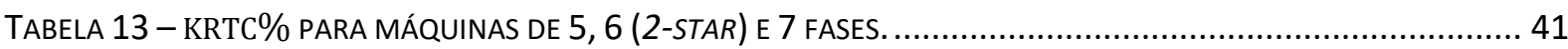

TABELA 14 - FASES ASSOCIADAS À CADA SETOR POR PASSO POLAR PARA MÁQUINA DE 9 FASES SIMÉTRICA. 42

TABELA 15 - POSSÍVEIS CONFIGURAÇÕES DE RANHURA PARA FASE 1 E VALORES DE @R PARA MÁQUINAS DE 9 FASES SIMÉTRICA.

TABELA 16 - FASES ASSOCIADAS À CADA SETOR POR PASSO POLAR PARA MÁQUINA DE 9 FASES 3-STAR.

TABELA 17 - POSSÍVEIS CONFIGURAÇÕES DE RANHURA PARA FASE 1 E VALORES DE OR PARA MÁQUINAS DE 9 FASES 3 STAR.

TABELA 18 - VALORES DE REFERÊNCIA PARA KJ (PELLEGRINO, 2016, P. 29) ..........................................48

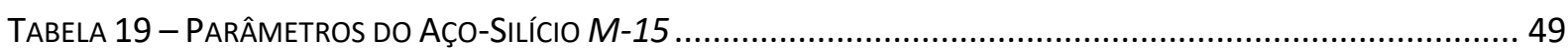

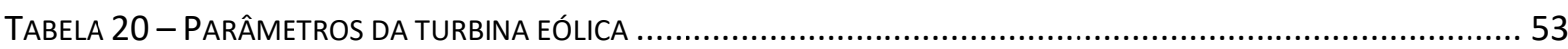

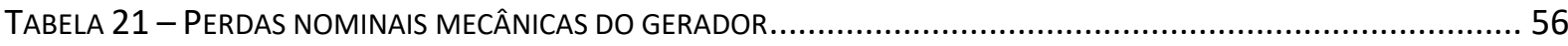

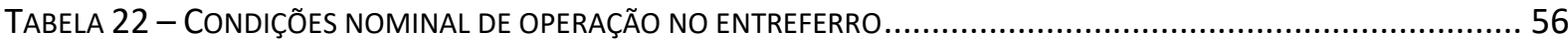

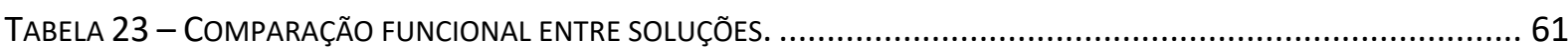

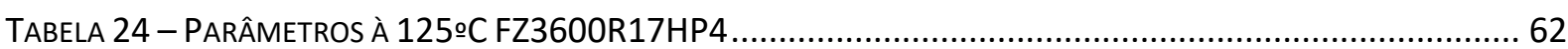

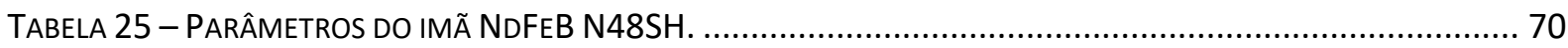

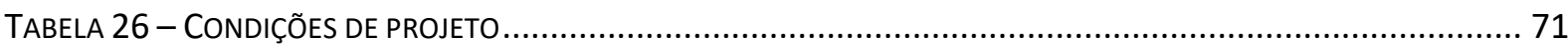

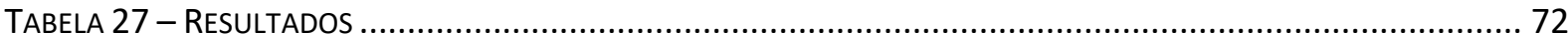

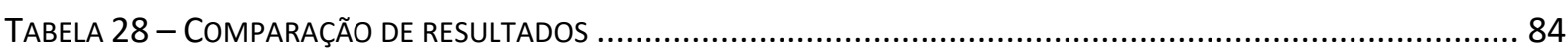

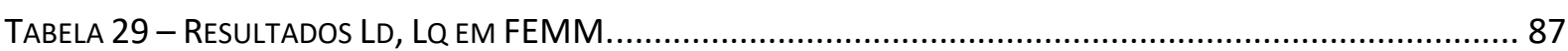

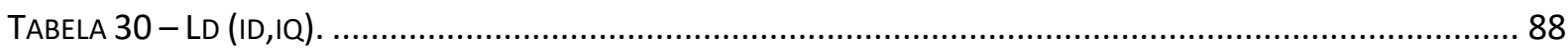

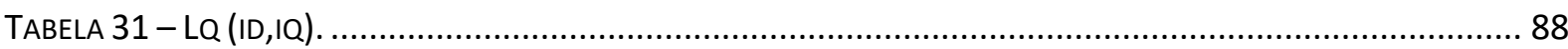

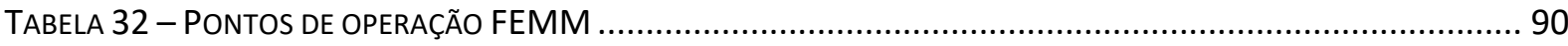


TABELA 33 - CONDIÇÕES NOMINAIS DE OPERAÇÃO. 91

TABELA 34 - POTÊNCIA E COEFICIENTE DE POTÊNCIA. . 93

TABELA 35 - PARÂMETROS DE MÓDULOS IGBT ABB HIPAK (ABB, 2016)... 106

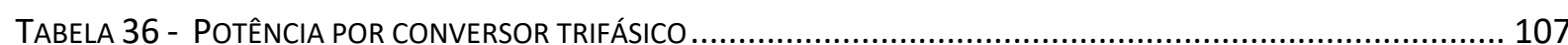

TABELA 37 - VALORES DE REFERÊNCIA PARA LE2 (LIWSCHITZ-GARIK E WHIPPLE, 1947, P. 71) ........ 134 


\section{LISTA DE ABREVIATURAS E SIGLAS}

$\begin{array}{ll}\text { 2L-BTB } & \text { 2 Level Back-to-Back } \\ \text { AC } & \text { Alternating Current } \\ \text { DC } & \text { Direct Current } \\ \text { DFIG } & \text { Double Feed Induction Generator } \\ \text { EWEA } & \text { European Wind Energy Association } \\ \text { FEMM } & \text { Finite Element Method Magnetics } \\ \text { FIT } & \text { Failures in Time } \\ \text { FMM } & \text { Força Magnetomotriz } \\ \text { GE } & \text { General Electric } \\ \text { GTO } & \text { Gate turn-off thyristor } \\ \text { GWEC } & \text { Global Wind Energy Council } \\ \text { IEA } & \text { International Energy Agency } \\ \text { IGBT } & \text { Insulated Gate Bipolar Transistor } \\ \text { IGCT } & \text { Integrated Gate Commutated Thyristor } \\ \text { IPOSIM } & \text { Infineon power simulation program } \\ \text { LCOE } & \text { Levelized Cost of Energy } \\ \text { LSC } & \text { Line Side Converter } \\ \text { MSC } & \text { Machine Side Converter } \\ \text { MTPA } & \text { Maximum Torque per Ampere } \\ \text { MTPV } & \text { Maximum Torque per Voltage } \\ \text { NPC } & \text { Neutral-Point-Clamped } \\ \text { RPM } & \text { Rotações por minuto } \\ \text { THD } & \text { Total Harmonic Distortion } \\ \text { TSR } & \text { Tip Speed Ratio } \\ \text { VSD } & \text { Vector Space Decomposition } \\ & \end{array}$




\section{LISTA DE SÍMBOLOS}

\begin{tabular}{|c|c|c|}
\hline Símbolo & Unidade & Descrição \\
\hline$\alpha$ & - & Fator de Steinmetz \\
\hline$\alpha_{s p}$ & $\circ$ & Tamanho da sapata polar em graus elétricos \\
\hline$A_{c u}$ & $m^{2}$ & Área de cobre \\
\hline$A_{d}$ & $m^{2}$ & Área do diodo \\
\hline$A_{\text {Igbt }}$ & $m^{2}$ & Área do IGBT \\
\hline$A_{p}$ & $m^{2}$ & Área polar \\
\hline$A_{q}$ & $A_{r m s} / m$ & Carregamento elétrico \\
\hline$A_{s}$ & $m m^{2}$ & Área da ranhura \\
\hline$b_{s}, b_{s 1}$ & $m m$ & Abertura mínima e máxima da ranhura \\
\hline$b_{t}$ & $\mathrm{~mm}$ & Largura mínima do dente \\
\hline$b_{v r}, b_{v s}$ & $\mathrm{~mm}$ & Largura do duto de ventilação no rotor e estator \\
\hline$B_{c}$ & $T$ & Campo de indução magnética coercivo \\
\hline$B_{g}$ & $T$ & Valor de pico do campo de indução magnética no entreferro. \\
\hline$B_{g m}$ & $T$ & Valor médio do campo de indução magnética no entreferro \\
\hline$B_{m}$ & $T$ & Campo de indução magnética do imã \\
\hline$B_{s y}$ & $T$ & Campo de indução magnética na coroa estatórica \\
\hline$B_{r y}$ & $T$ & Campo de indução magnética na coroa rotórica \\
\hline$B_{t m}$ & $T$ & Campo de indução magnética máximo no dente \\
\hline$\beta$ & $\circ$ & Ângulo de pitch das pás da turbina eólica \\
\hline$c_{g}, c_{g}^{\prime}$ & - & Fatores auxiliar para cálculo de kd e kq \\
\hline $\cos (\varphi)$ & - & Fator de potência interno \\
\hline$C_{p}$ & - & Coeficiente de potência mecânico da turbina eólica \\
\hline$C_{\text {pmax }}$ & - & Coeficiente de potência mecânico máximo \\
\hline$C_{p e}$ & - & Coeficiente de potência elétrico \\
\hline$C_{t h}$ & $J / K$ & Capacidade térmica \\
\hline$d_{0}, d_{1}, d_{2}, d_{3}, d_{4}, d_{5}$ & $\mathrm{~mm}$ & Dimensões da ranhura \\
\hline$D_{\text {ext_max }}$ & $m$ & Valor máximo para o diâmetro externo do gerador \\
\hline$D_{g}$ & $m$ & Diâmetro do entreferro \\
\hline$\delta$ & $\circ$ & Encurtamento de passo \\
\hline$\Delta$ & $\circ$ & Ângulo de inclinação da ranhura \\
\hline$E_{f}$ & $V_{r m s}$ & Tensão induzida (vazio) por fase \\
\hline$E_{n}$ & $V_{r m s}$ & Tensão em vazio nominal do gerador (linha) \\
\hline$f_{e}$ & $H_{z}$ & Frequência elétrica \\
\hline$f_{m e c}$ & $H z$ & Frequência mecânica \\
\hline$f_{g}$ & $A e$ & Força magnetomotriz no entreferro \\
\hline$f_{n}$ & $A e$ & Força magnetomotriz produzida pela fase $n$ \\
\hline$f_{r y}$ & $A e$ & Força magnetomotriz na coroa rotórica \\
\hline$f_{s y}$ & $A e$ & Força magnetomotriz na coroa estatórica \\
\hline$f_{t}$ & $A e$ & Força magnetomotriz no dente \\
\hline$f p_{\text {nom }}$ & - & Fator de potência nominal do gerador \\
\hline$F_{0}$ & $A e$ & Força magnetomotriz por polo \\
\hline$F_{h}$ & $A e$ & Força magnetomotriz resultante para harmônica de ordem $\mathrm{h}$ \\
\hline$F_{m m}$ & $A e$ & Força magnetomotriz resultante \\
\hline$F_{n x}$ & $N$ & Força normal no eixo-x \\
\hline$F_{n y}$ & $N$ & Força Normal no eixo-y \\
\hline
\end{tabular}




\begin{tabular}{|c|c|c|}
\hline$\gamma$ & - & Constante para estimação do entreferro \\
\hline$h$ & - & Harmônica de ordem h \\
\hline$h_{s}$ & $m m$ & Altura da ranhura \\
\hline$h_{r y}$ & $\mathrm{~mm}$ & Comprimento da coroa rotórica \\
\hline$h_{s y}$ & $m m$ & Comprimento da coroa estatórica \\
\hline$H_{C}$ & $A / m$ & Campo magnético coercivo \\
\hline$H_{g}$ & $A / m$ & Campo magnético no entreferro \\
\hline$H_{m}$ & $A / m$ & Campo magnético no imã \\
\hline$H_{r y}$ & $A / m$ & Campo magnético na coroa rotórica \\
\hline$H_{s y}$ & $A / m$ & Campo magnético na coroa estatórica \\
\hline$H_{t 0}, H_{t 1}, H_{t 2}, H_{t 3}$ & $A / m$ & Campos magnéticos no dente \\
\hline$i_{d}, i_{q}$ & - & Corrente de fase segundo eixos d e q em p.u \\
\hline$i_{s}$ & - & Corrente de fase em p.u \\
\hline$I_{f}$ & $A_{\text {rms }}$ & Corrente de fase \\
\hline$I_{m a g}$ & $A_{\text {rms }}$ & Corrente de magnetização \\
\hline$I_{\max }$ & $A_{r m s}$ & Corrente máxima por conversor trifásico \\
\hline$I_{n}$ & $A_{r m s}$ & Corrente de fase nominal do gerador \\
\hline$I_{r}$ & $A_{r m s}$ & Corrente eficaz na ranhura \\
\hline$J_{r}$ & $A_{r m s} / m^{2}$ & Densidade de corrente na ranhura \\
\hline$k_{1}, k_{2}$ & - & Fatores auxiliares para cálculo de perdas no ferro \\
\hline$k_{b}$ & $k W . s$ & Fator de perdas nos rolamentos do gerador \\
\hline$k_{c h}$ & - & Fator de encurtamento de passo para harmônica de ordem $\mathrm{h}$ \\
\hline$k_{c s}$ & - & Fator de Carter para estator \\
\hline$k_{d}, k_{q}$ & - & Fatores de permeância para eixos d e q \\
\hline$k_{d h}$ & - & Fator de distribuição do enrolamento para harmônica de ordem $\mathrm{h}$ \\
\hline$k_{\text {dis }}$ & - & Fator de dispersão \\
\hline$k_{e h}$ & - & Fator de enrolamento para harmônica de ordem $\mathrm{h}$ \\
\hline$k_{\text {pre }}$ & - & Fator de preenchimento da ranhura (fill factor) \\
\hline$k_{r}, k_{x t}, k_{x c o}$ & - & Parâmetros para cálculo da indutância de dispersão de ranhura \\
\hline$k_{s}$ & - & Razão entre abertura de ranhura e passo de ranhura \\
\hline$k_{\text {sat }}$ & - & Fator de saturação \\
\hline$k_{s k h}$ & - & Fator de inclinação de ranhura para harmônica de ordem $\mathrm{h}$ \\
\hline$k_{w}$ & $k W \cdot s^{2}$ & Fator de perdas de atrito viscoso \\
\hline$K_{j}$ & $k W / m^{2}$ & Densidade de perdas Joule no entreferro \\
\hline$K_{j}^{*}$ & $\mathrm{~kW} / \mathrm{m}^{2}$ & Densidade de perdas no entreferro (Cobre e Ferro) \\
\hline$\lambda, \lambda_{\text {opt }}$ & - & Tip Speed Ratio e valor ótimo de $\lambda$ \\
\hline$l_{b l}$ & $H$ & Indutância de dispersão harmônica \\
\hline$l_{b m}$ & $m$ & Comprimento médio da bobina \\
\hline$l_{\text {dis }}$ & $H$ & Indutância de dispersão \\
\hline$l_{e}$ & $m$ & Comprimento total da cabeça da bobina \\
\hline$l_{e 1}, l_{e 2}, l_{e 3}$ & $m$ & Dimensões da cabeça da bobina \\
\hline$l_{\text {ew }}$ & $H$ & Indutância de dispersão de final de enrolamento \\
\hline$l_{g}$ & $m m$ & Entreferro mínimo (eixo-d) \\
\hline$l_{g}^{\prime}$ & $m m$ & Entreferro equivalente \\
\hline$l_{m}$ & $m m$ & Altura do imã \\
\hline$l_{s y}, l_{r y}$ & $m m$ & Dimensões das coroas estatórica e rotórica \\
\hline$l_{t t}$ & $H$ & Indutância de dispersão de topo de dente \\
\hline$L_{e f}, L_{e f \_m a x}$ & $m$ & Comprimento efetivo e valor máximo para $L_{e f}$ \\
\hline
\end{tabular}




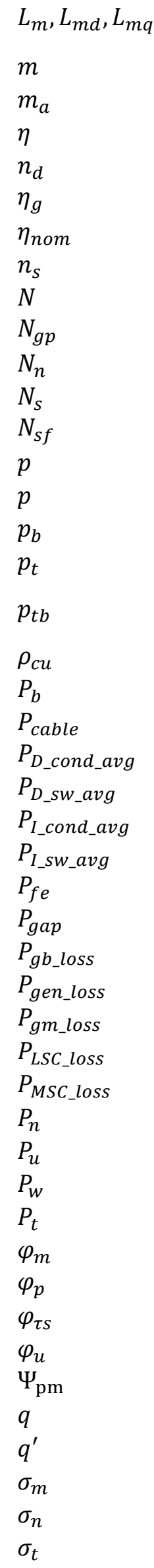

Indutância de magnetização indutâncias de magnetização segundo eixos d e q.

Número de fases

Índice de modulação em amplitude.

Rendimento

Número de dutos de ventilação

Rendimento global

Rendimento nominal do gerador

Número de condutores por ranhura

Número de estágios da caixa multiplicadora

Número de grupos em paralelo

RPM Rotação mecânica nominal do gerador

- Número total de ranhuras

- $\quad$ Número de bobinas em série por fase

- Número de pares de polos

- $\quad$ Potência em p.u da turbina (rendimento da caixa multiplicadora)

$W b / A_{e} \quad$ Permeância magnética do circuito na parte de baixo da ranhura

$W b / A_{e} \quad$ Permeância magnética do circuito no topo da ranhura

$W b / A_{e} \quad$ Permeância magnética mútua entre os circuitos no topo e na parte de

$\Omega m \quad$ Resistividade do cobre

$W \quad$ Perdas nos rolamentos

$W \quad$ Perdas nos cabeamentos

$W \quad$ Perdas por condução médias no Diodo

$W \quad$ Perdas de chaveamento médias no Diodo

$W \quad$ Perdas por condução médias no IGBT

$W \quad$ Perdas de chaveamento médias no IGBT

W Perdas no ferro

$W \quad$ Potência no entreferro

W Perdas na caixa multiplicadora

$W \quad$ Perdas no gerador elétrico

W Perdas mecânicas no gerador elétrico

$W \quad$ Perdas no inversor

$W \quad$ Perdas no retificador

$M W \quad$ Potência nominal do gerador

$W \quad$ Potência eólica

W Perdas por atrito viscoso

$W \quad$ Potência mecânica da turbina eólica

$W b \quad$ fluxo magnético produzido pelo imã

$W b \quad$ Fluxo magnético por polo

$W b \quad$ Fluxo magnético por passo de ranhura

$W b \quad$ Fluxo magnético útil

$\mathrm{V} / \mathrm{s} \quad$ Constante de fluxo magnético

- $\quad$ Número de ranhuras por polo e por fase

- Número de ranhuras por polo e por fase equivalente

$\mathrm{N} / \mathrm{m}^{2} \quad$ Magnetic shear stress

$\mathrm{N} / \mathrm{m}^{2}$ Densidade de força normal no entreferro

$\mathrm{Nm} / \mathrm{m}^{2} \quad$ Densidade de torque no entreferro 


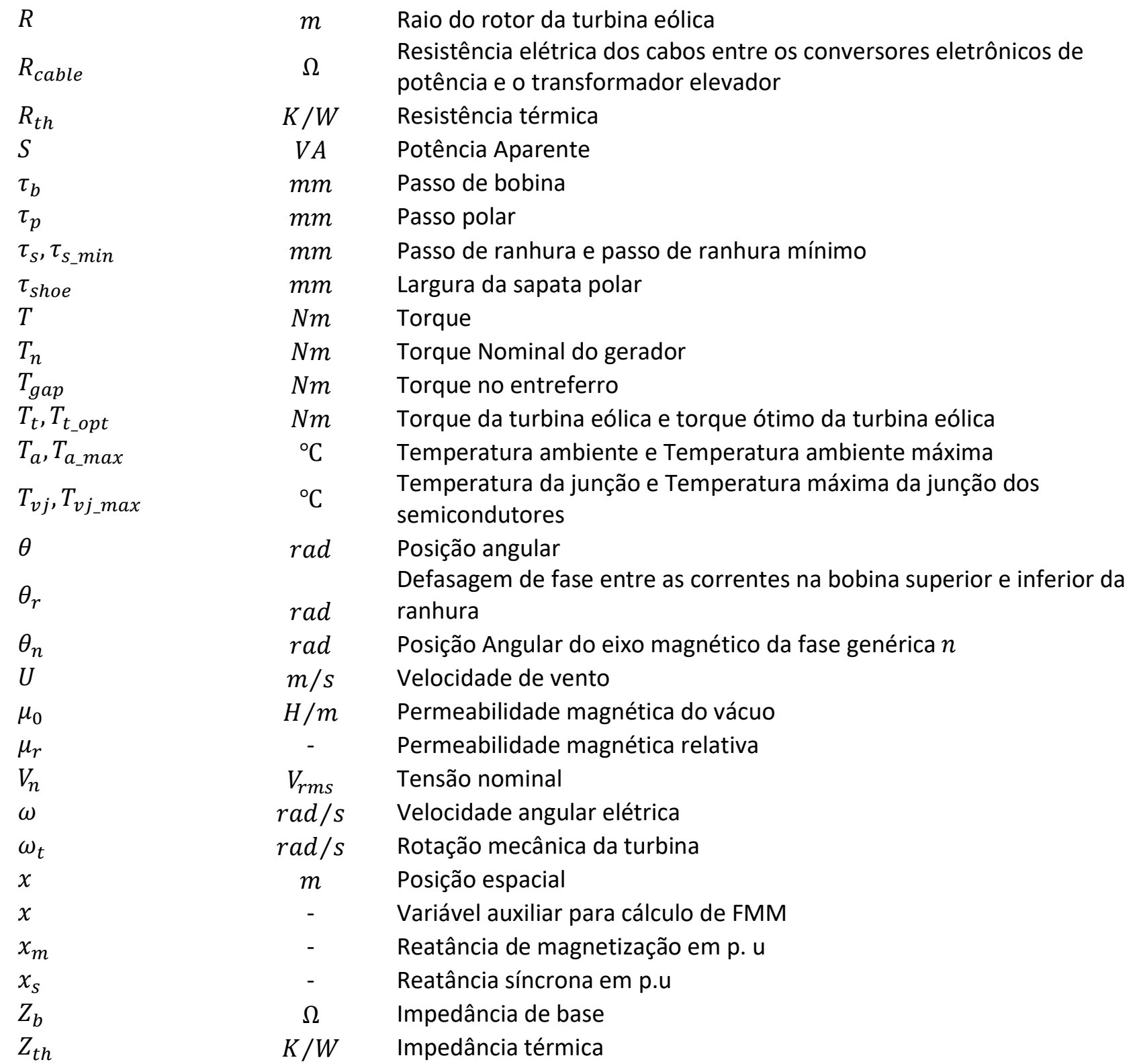




\section{RESUMO}

Neste trabalho desenvolve-se uma análise sobre o estado da arte e tendências para projeto de geradores elétricos em turbinas eólicas offshore. A conjunção dos requerimentos de alta confiabilidade e potência, criam condições adequadas para a aplicação de máquina elétricas multifásicas nesse setor. Desta forma, optou-se por estudar as características e condições de projeto de máquinas elétricas multifásicas, simétricas ou assimétricas. Com esta finalidade, os métodos analíticos de projeto de máquinas elétricas trifásicas são revisitados e estendidos, quando necessário, para diferentes configurações multifásicas. O foco do trabalho, consiste em desenvolver e explorar temas de projeto de geradores elétricos multifásicos, síncronos de imãs permanentes, com enrolamentos distribuídos de dupla camada. Para estudo de caso, realiza-se a comparação entre o projeto de quatro topologias diferentes. Nomeadamente, compara-se o projeto de geradores de três, seis, nove e dezoito fases para turbinas eólicas offshore de $10 \mathrm{MW}$. A configuração com gerador de nove fases apresenta os melhores resultados, com densidade de torque 10,96\% superior à densidade de torque desenvolvida pela máquina trifásica analisada. Por fim, a metodologia analítica desenvolvida para o projeto de máquinas elétricas multifásicas é verificada usando o método de elementos finitos bidimensional, para o gerador síncrono de imãs permanentes de nove fases.

Palavras chave: Máquinas elétricas. Máquinas elétricas multifásicas. Projeto de máquinas elétricas. Energia eólica. 


\section{ABSTRACT}

The state of the art and future trends for offshore wind turbines were reviewed. Due to its fault-tolerant characteristic, multiphase electrical generators were identified as strong candidates to meet the power and resilience targets of the offshore wind sector. In this work, the design aspects of three-phase electrical machines are reviewed and extended to different multiphase configurations. The main focus of the work is to develop an analytical design methodology for multiphase, symmetrical and asymmetrical, synchronous generators with double-layer distributed windings. As a case study, the project of a three-phase, six-phase, nine-phase and eighteen-phase permanent magnet synchronous generators were compared for a 10MW offshore wind turbine. The best results were found for the nine-phase topology, with a torque density $10.96 \%$ higher than the torque density of the analysed three-phase machine. The developed design methodology was validated with a finite element analysis of the ninephase permanent magnet generator.

Keywords: Electrical machines. Multiphase electrical machines. Design aspects of electrical machines. Wind energy. 


\section{INTRODUÇÃO}

A geração de energia elétrica por meio de turbinas eólicas cresce de forma significativa desde a década de 80, com especial expressividade após o ano 2000. De acordo com o Global Wind Energy Council (GWEC, 2016, p. 14), (GWEC, 2017, p. 18), a capacidade instalada em parques eólicos aumentou de 17.4GW no ano 2000 para 486,7 GW no final de 2016. Destes 486,7 GW, 472.4 GW correspondem a turbinas eólicas em terra firme (onshore) enquanto 14,4 GW correspondem a instalações no ambiente marinho, offshore (GWEC, 2017, p. 61). A evolução da capacidade instalada mundial em parques eólicos é apresentada na Figura 1.

Figura 1 - Energia eólica - Capacidade instalada mundial.

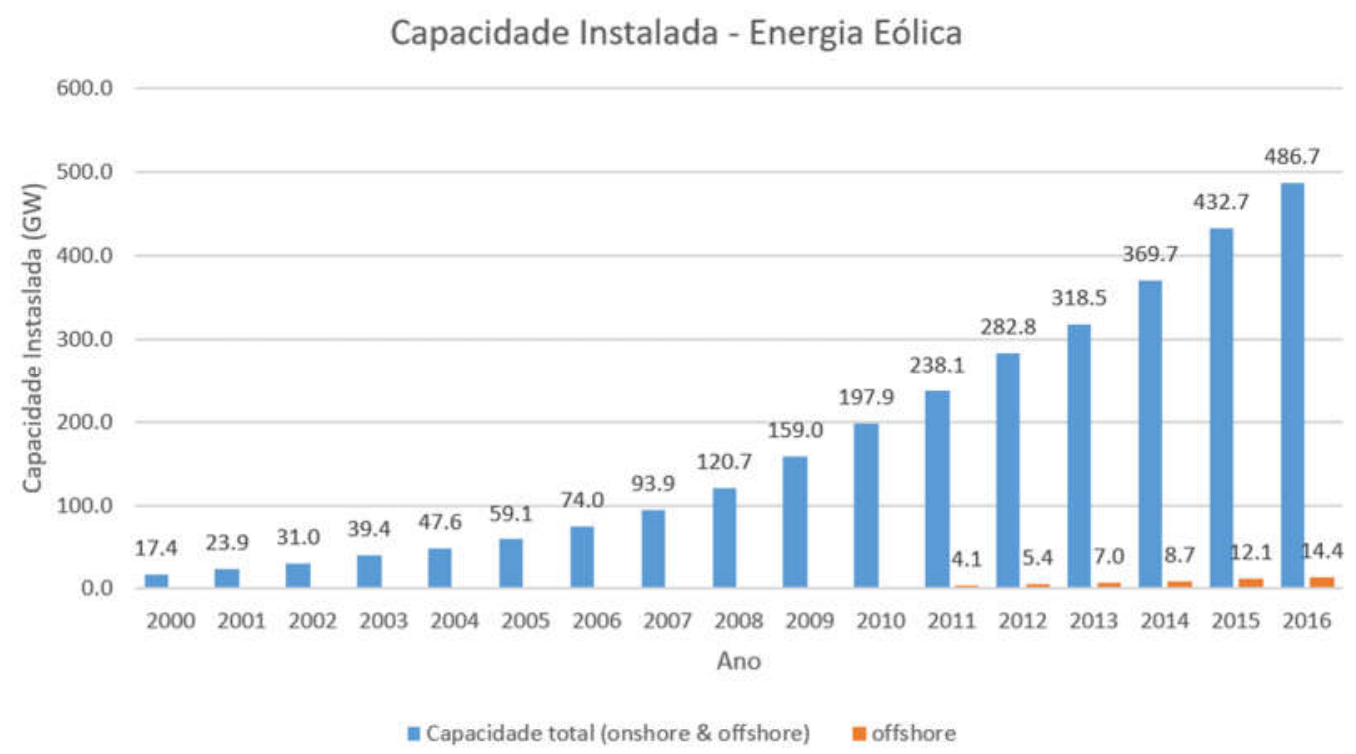

Fonte: adaptado de (GWEC, 2016), (GWEC, 2017).

A tecnologia utilizada em turbinas eólicas onshore é madura. A solução dominante utiliza turbinas eólicas de potência nominal entre 1,5 a 3,5 MW, caixa multiplicadora de 3 estágios (EUROPEAN COMMISSION, 2015, p. 24) e geradores de indução duplamente alimentados (DFIGs). DFIGs são atrativos para aplicações eólicas pois permitem operação em velocidade variável com conversor eletrônico de potência reduzida, tipicamente $30 \%$ da potência nominal do gerador (ANAYA-LARA, CAMPOS-GAMOA, et al., 2014, p. 7).

Embora a capacidade instalada em parques eólicos offshore seja ainda bastante inferior à capacidade instalada em parques onshore, este setor cresce significativamente, principalmente, após 2010. As limitações do recurso eólico em 
terra firme e o comprometimento com as metas de redução de emissões de $\mathrm{CO}_{2}$, são os principais fatores que motivam o crescimento do setor eólico offshore.

A União Europeia concentra a maior parte de instalações offshore, com 12.6 GW dos 14.4 GW instalados até o final de 2016 (EWEA, 2017, p. 6). De acordo com (WIND EUROPE, 2017), projeta-se atingir entre 49 e 99 GW de capacidade instalada em parques eólicos offshore na União Europeia até 2030. O maior desafio deste setor consiste em aumentar a sua competividade econômica em relação às outras formas de produção de eletricidade.

De acordo com (BVG ASSOCIATES, 2012, p. 48-49) e (IEA, 2016, p. 30), para parques eólicos offshore, os principais avanços tecnológicos para a redução do custo por unidade de energia (USD/MWh, Levelized Cost of Energy, LCOE) são: o aumento da potência instalada por turbina eólica e o aumento da durabilidade e de confiabilidade dos seus componentes. Nesse sentido, espera-se que uma turbina eólica offshore típica, em 2030, terá capacidade instalada de 11 MW e, para turbinas eólicas flutuantes, 9 MW (IEA, 2016, p. 25).

O aumento da capacidade instalada por turbina eólica contribui para o aumento da competitividade do projeto eólico, principalmente devido à redução dos custos de instalação e de infraestrutura (fundações, cabeamentos submarinos, transformadores...). Maior durabilidade e confiabilidade dos componentes da turbina colaboram para mitigar riscos e custos de manutenção corretiva (BVG ASSOCIATES, 2012, p. 48-49).

A mitigação dos riscos, relativos à necessidade de manutenção corretiva, é imprescindível em projetos eólicos offshore. Em primeiro lugar, por conta da complexidade das operações envolvidas, os custos com embarcações e mão de obra qualificada são elevados. Um segundo fator, que aumenta de forma indireta os custos de manutenção corretiva, é a disponibilidade de acesso ao parque. Os fatores críticos são a disponibilidade das embarcações e as condições climáticas (velocidade do vento, luminosidade, tamanho das ondas, velocidade das correntes marítimas). Em (BRAAM, 2002) estima-se que $89,4 \%$ do tempo necessário para a atividade de manutenção corresponde à espera das condições climáticas adequadas. Além disso, 
mais de $50 \%$ do custo total de manutenção é composto pela energia que não pode ser vendida no período (revenue costs) (BRAAM, 2002).

\subsection{MÁQUINAS ELÉTRICAS MULTIFÁSICAS}

Máquinas elétricas multifásicas, número de fases superior a três, são utilizadas em setores específicos da indústria onde, em geral, requer-se alta potência e confiabilidade. As duas principais características de máquinas elétricas multifásicas que justificam sua adoção no lugar de máquinas trifásicas são:

a) Capacidade de manter o campo magnético girante no entreferro, mesmo em condição de falha de uma ou, possivelmente, mais fases.

b) Divisão da corrente total da máquina em um maior número de fases.

A possibilidade de se continuar em operação, mesmo em caso de falha de um ou mais enrolamentos, é especialmente importante em aplicações onde resiliência e confiabilidade são essenciais. No caso de aplicações eólicas offshore, onde o tempo de espera para uma oportunidade de manutenção pode ser longo, essa característica pode contribuir de forma significativa para o sucesso econômico do projeto.

A possibilidade de se dividir a corrente total da máquina em um número maior de fases é, também, desejável. Para sustentar este argumento é necessário explorar as particularidades do trem de potência (drivetrain), tipicamente adotados para turbinas eólicas offshore, e as características dos conversores eletrônicos de potência.

\subsubsection{Trem de potência para turbinas eólicas offshore.}

Drivetrain ou trem de potência de uma turbina eólica consiste no sistema eletromecânico que converte a energia mecânica de rotação do rotor da turbina eólica em energia elétrica na saída do gerador. Tipicamente, o trem de potência de uma turbina eólica é composto pelos seguintes componentes: Eixo mecânico da turbina (baixa velocidade), caixa multiplicadora, eixo mecânico de alta ou média velocidade, gerador elétrico e estruturas auxiliares de suporte mecânico e de refrigeração. Mais detalhes sobre diferentes configurações de trens de potência normalmente adotados em turbinas eólicas são apresentados no Apêndice F. 
A configuração mais comum para o trem de potência de turbinas eólicas offshore utiliza geradores síncronos de imãs permanentes de baixa ou média velocidade. Uma desvantagem importante de DFIGs em aplicações eólicas de alta potência é a necessidade de caixa multiplicadora com elevada taxa de transmissão (por exemplo, 100:1). O projeto de caixas multiplicadoras de alta velocidade é extremamente complexo para turbinas eólicas offshore por conta dos níveis elevados de torque de entrada, variando, por exemplo, entre 8000 e $9900 \mathrm{kNm}$ para turbinas de 8MW (WINENERGY, 2017), (ZF, 2017).

Além disso, máquinas de indução duplamente alimentadas requerem anéis coletores que conectam os circuitos do rotor ao conversor eletrônico de potência. Os anéis coletores são componentes que precisam de manutenção frequente, o que é indesejável no ambiente marinho.

As configurações com máquinas síncronas de baixa velocidade são soluções direct-drive, que não utilizam caixa multiplicadora entre o eixo principal da turbina e o gerador elétrico. As desvantagens desta topologia são as grandes dimensões do gerador elétrico, por conta da baixa rotação mecânica, e a necessidade de se utilizar conversores eletrônicos com a mesma potência do gerador. Em aplicações eólicas offshore, as principais referências com sistemas direct-drive são as turbinas Siemens SWT 8.0, com 167 m de diâmetro e 8 MW, e a turbina da GE Haliade, com 150 m de diâmetro e 6MW (GE, 2016b) (SUN \& WIND ENERGY, 2017).

A solução intermediária consiste na adoção de caixa multiplicadora de média velocidade. Normalmente, a caixa multiplicadora é composta por dois ou três estágios planetários e tem taxa de multiplicação entre 35 e 45:1 (WINENERGY, 2017), (WIND TURBINE MODELS, 2015), (ZF, 2017). O aumento da rotação do eixo mecânico do gerador possibilita o projeto de máquinas elétricas com dimensões menores, trazendo benefícios para manufatura, manuseio e transporte do gerador. Para exemplificar este ponto comenta-se que os limites típicos de altura e largura para cargas rodoviárias, que não precisam de escolta policial, são de 4,3 m e $3 \mathrm{~m}$, respectivamente (JOCKEL, 2003, p. 129). Na mesma referência, estima-se que as dimensões externas máximas do gerador, de forma a se enquadrar nesta legislação, deverão ser inferiores a $D_{\text {ext_max }}=3,8 \mathrm{~m}$ e $L_{\max }=2,5 \mathrm{~m}$. A necessidade de escolta policial é indesejável, uma 
vez que aumenta custos, tempo e riscos (riscos de logística) para transporte do gerador.

Por conta do menor volume do gerador elétrico, reduz-se substancialmente o volume de imãs permanentes requeridos para o projeto. Desta forma, é possível mitigar a exposição aos riscos associados à flutuação dos preços destes materiais. As principais referências do setor eólico offshore, com trens de potência de média velocidade, são: a turbina Adwen AD8, com $8 \mathrm{MW}$ de capacidade instalada e 180m de diâmetro, e a turbina Vestas V164 de 9,5 MW e 164 m de diâmetro. Comenta-se, entretanto, que a turbina AD8 foi descontinuada após a aquisição da Gamesa pela Siemens (OFFSHORE WIND JOURNAL, 2017).

\subsubsection{Eletrônica de potência.}

Em termos de eletrônica de potência, neste trabalho, será considerada apenas a configuração típica adotada pela indústria, que consiste em conversores de baixa tensão $\left(V_{a c}<1000 \mathrm{~V}\right.$ e $\left.V_{d c}<1500 \mathrm{~V}\right)$, trifásicos de dois níveis, com módulos IGBT de 1700 V e 3600 A. O Apêndice A apresenta os detalhes que suportam esta escolha. Nesta configuração, cada conversor trifásico tem capacidade de potência em torno de 2 MVA.

\subsubsection{Oportunidades para máquinas elétricas multifásicas}

A solução normalmente utilizada em turbinas eólicas com drivetrains de baixa e média velocidades, consiste na conexão em paralelo de múltiplos conversores eletrônicos de potência, trifásicos e de baixa tensão. Esta estratégia, por exemplo, é adotada pela Vestas na sua turbina V164 - 8 MW (DET NORSKE VERITAS, 2015) e é apresentada na Figura 2.

Esta topologia, com conversores em paralelo, é resiliente a falhas na eletrônica de potência. Caso um dos conversores falhe, a turbina ainda pode operar com os demais conversores. Entretanto, caso exista falha nas bobinas de uma das fases do gerador, a turbina precisa ser retirada de operação.

De forma alternativa, outros fabricantes como GE e Gamesa utilizam máquinas elétricas multifásicas. A GE na sua turbina Halliade de $6 \mathrm{MW}$ utiliza um gerador de nove fases com três conversores trifásicos de 900 V (GE, 2016b). Já a Gamesa, na 
sua plataforma G135 - $5 \mathrm{MW}$, utiliza uma máquina de doze fases, com quatro conversores trifásicos de 690 V (GAMESA, 2016), (DURAN e BARRERO, 2016). Esta solução é apresentada na Figura 3.

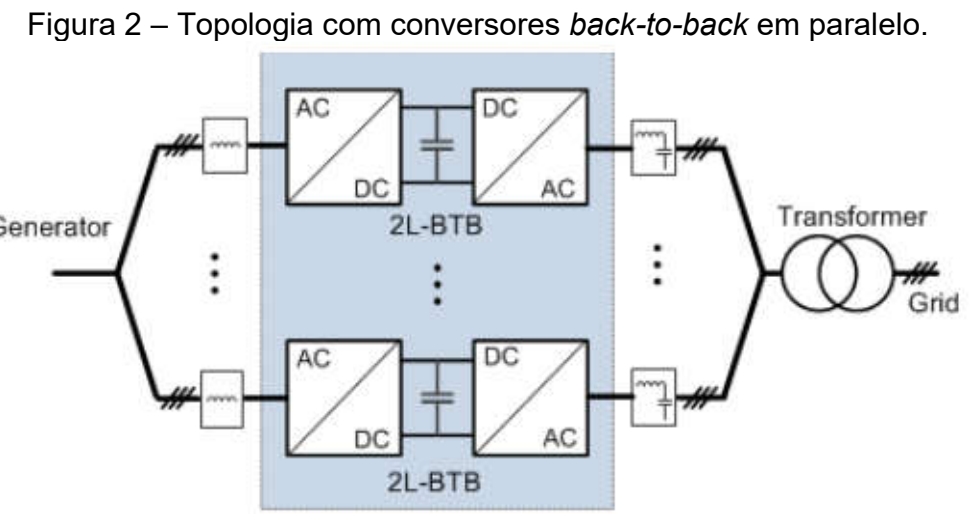

Fonte: (BLAABJERG e MA, 2013).

Figura 3 - Topologia com conversores back-to-back trifásicos para cada set trifásico do gerador.

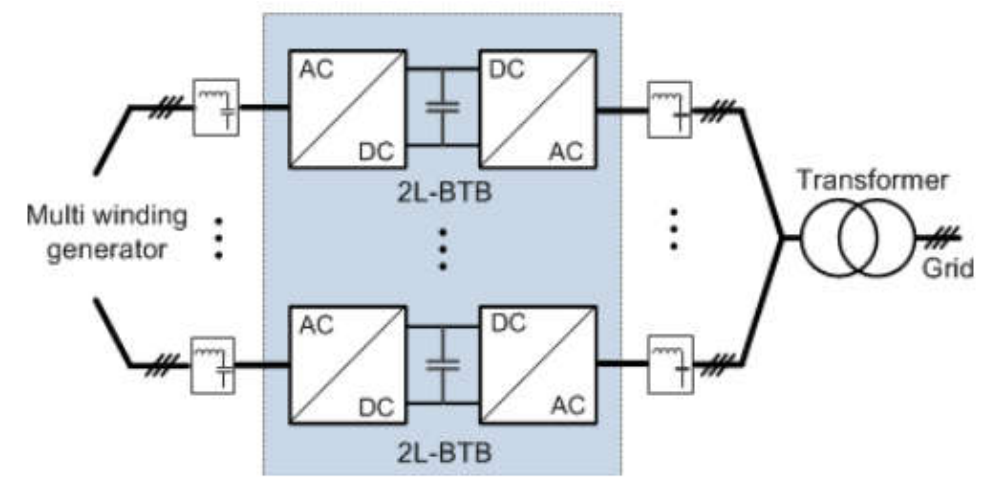

Fonte: (BLAABJERG e MA, 2013).

Com a adoção de uma máquina multifásica, a turbina torna-se também resiliente quando há falha em uma das fases do gerador. Além disso, a turbina dispõe das vantagens, em termos de desempenho, da configuração multifásica. Estas vantagens serão discutidas e detalhadas ao longo deste trabalho.

É possível afirmar, portanto, que o setor eólico offshore apresenta as principais características que motivam a utilização de máquinas elétricas multifásicas. A necessidade de elevada resiliência e confiabilidade é relacionada aos elevados custos de manutenção corretiva. A capacidade de dividir a corrente da máquina em um maior número de fases é desejada devido às limitações dos semicondutores de potência disponíveis no mercado. 


\subsection{OBJETIVOS}

O objetivo geral deste trabalho consiste em explorar tópicos de projeto, com enfoque em métodos analíticos, de máquinas elétricas multifásicas, com especial ênfase em máquinas síncronas de imãs permanentes para aplicações eólicas offshore. Uma vez desenvolvidos os métodos analíticos para o projeto básico da máquina elétrica, diferentes soluções serão exploradas e comparadas entre si. Com base nos resultados desta comparação, será escolhida a topologia com melhor desempenho para validação pelo método dos elementos finitos.

\subsubsection{Objetivos especificos}

i. Análise do estado da arte para conversão de energia em turbinas eólicas offshore, identificação das tecnologias mais prováveis a serem adotadas para turbinas eólicas de potência em torno de 10 MW.

ii. Avaliar enquadramento, vantagens e desafios, de máquinas elétricas multifásicas neste setor.

iii. Analisar as componentes fundamental e harmônicas da força magnetomotriz gerada pelo estator multifásico com enrolamentos simétricos e assimétricos.

iv. Aplicar ou extrapolar as equações analíticas tipicamente utilizadas para o projeto básico de máquinas elétricas trifásicas para máquinas multifásicas simétricas e assimétricas.

v. Aplicar ou estender a teoria geral de máquinas elétricas para topologias multifásicas simétricas e assimétricas.

vi. Comparar e discutir o projeto de diferentes geradores multifásicos para uma turbina eólica com potência de aproximadamente $10 \mathrm{MW}$.

vii. Validar, pelo método dos elementos finitos, o projeto analítico da topologia apresentada com melhor desempenho. 


\section{ESTADO DA ARTE}

Para a caracterização do estado da arte de turbinas eólicas offshore, são discutidos, com mais detalhes, os aspectos técnicos dos geradores utilizados nas turbinas Vestas V164 - 8 MW, Gamesa G135 - 5 MW, Siemens SWT 6.0 e GE Haliade 6,0 MW. As turbinas SWT 6.0 e V164 - 8 MW são exploradas por conta da falta de informação disponível na literatura dos seus modelos mais recentes SWT 8.0 e V164 $9,5 \mathrm{MW}$.

As turbinas SWT 6.0 e V164 são utilizadas como exemplos de sistemas de geração eólica de baixa e média velocidade trifásicos. As turbinas GE Haliade e G135 são discutidas para caracterização de geradores multifásicos de baixa e média velocidade, respectivamente. Por fim, serão comentados alguns aspectos gerais do estado da arte de geradores elétricos no setor eólico offshore.

\subsection{VESTAS V164}

A turbina Vestas V164 - $8 \mathrm{MW}$ utiliza caixa multiplicadora do tipo diferencial planetária de três estágios, com taxa de multiplicação de 38,3:1 (DET NORSKE VERITAS, 2015), (MONGEAU, ASHAR e DEMTRODER, 2014). Além disso, a caixa multiplicadora é conectada ao gerador elétrico por meio de um flange, drivetrain integrado (WIND POWER MONTHLY, 2013), (MONGEAU, ASHAR e DEMTRODER, 2014). O torque e peso da caixa multiplicadora são estimados em 8000 kNm e 85 toneladas, de acordo com a informação disponível em (ZF, 2017). Mais detalhes desta topologia são apresentados no Apêndice F - Figura 75.

O gerador síncrono de imãs permanentes tem rotação nominal de 400 RPM. Este gerador é fabricado pela empresa finlandesa The Switch (DET NORSKE VERITAS, 2015), consiste num gerador de baixa tensão, $710 \mathrm{~V}$ nominal, com 16 pares de polos, fator de potência nominal de 0,90 e peso de 27,7 toneladas (THE SWITCH, 2013). Os parâmetros mais relevantes deste gerador estão disponíveis na referência (THE SWITCH, 2013) e apresentados na Tabela 1. 
Tabela 1 - Especificações técnicas The Switch 8.6MW

\begin{tabular}{|c|c|c|}
\hline \multicolumn{3}{|c|}{ The Switch 8.6MW } \\
\hline Potência nominal & 8,6 & MW \\
\hline Rotação nominal/Max & $400 / 536$ & RPM \\
\hline Frequência Nominal/Max & $106,7 / 142,9$ & $\mathrm{~Hz}$ \\
\hline Pares de polos & 16 & - \\
\hline Número de fases & 3 & - \\
\hline Enrolamento & Distribuído & - \\
\hline Excitação & Imãs Permanentes & - \\
\hline Tensão nominal & 710 & $\mathrm{~V}$ \\
\hline Corrente nominal & 7800 & A \\
\hline Fator de Potência nominal & 0.90 & - \\
\hline Rendimento [25\%/ 50\%/75\%/100\%] & $96,0 / 97,6 / 98,0 / 98,1$ & $\%$ \\
\hline Peso & 27700 & $\mathrm{~kg}$ \\
\hline Refrigeração & IC8A6W7 & - \\
\hline Altura & 3034 & $\mathrm{~mm}$ \\
\hline Altura do eixo mecânico & 1500 & $\mathrm{~mm}$ \\
\hline Largura & 3310 & $\mathrm{~mm}$ \\
\hline Comprimento & 2255 & $\mathrm{~mm}$ \\
\hline $\begin{array}{l}\text { Temperatura máxima de entrada } \\
\text { do líquido de refrigeração }\end{array}$ & 40 & ${ }^{\circ} \mathrm{C}$ \\
\hline Pressão máxima do sistema de refrigeração & 4 & bar \\
\hline Vazão do sistema de refrigeração & 480 & $\mathrm{I} / \mathrm{min}$ \\
\hline Volume do sistema de refrigeração & 80 & 1 \\
\hline Classe de Proteção & IP54 & - \\
\hline Classe de Isolamento & $\mathrm{H}$ & - \\
\hline Classe Térmica & $\mathrm{F}$ & - \\
\hline
\end{tabular}

\subsection{GAMESA G135}

O trem de potência da turbina Gamesa G135, de 5 MW, possui gerador elétrico e caixa multiplicadora integrados, também conectados por meio de um flange, (GAMESA, 2016). O gerador elétrico da turbina G135 consiste num gerador síncrono de imãs permanentes de doze fases, rotação nominal de 490 RPM, caixa multiplicadora de 41,4:1 de dois estágios planetários, $690 \mathrm{~V}$, fator de potência nominal de 0,90. Este sistema é apresentado na Figura 4.

Supondo que o gerador com "módulos independentes em paralelo", Figura 4, consiste no sistema descrito na patente (ANDRESEN, 2010), o conceito do gerador da Gamesa constitui um gerador multifásico de simetria radial conforme apresentado na Figura 5. 


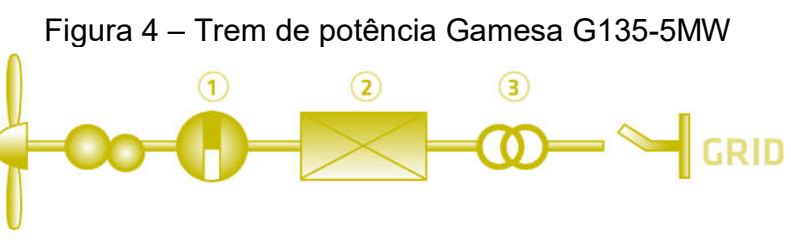

\section{Multi-pole synchronous GENERATOR with four independent modules in parallel. \\ 2. CONVERTER with four independent modules and built-in automatic circuit breaker. \\ 3. TRANSFORMER with multiple grid voltage connection options.}

Fonte: (GAMESA, 2016)

Figura 5 - Patente ES2325844 - Gamesa

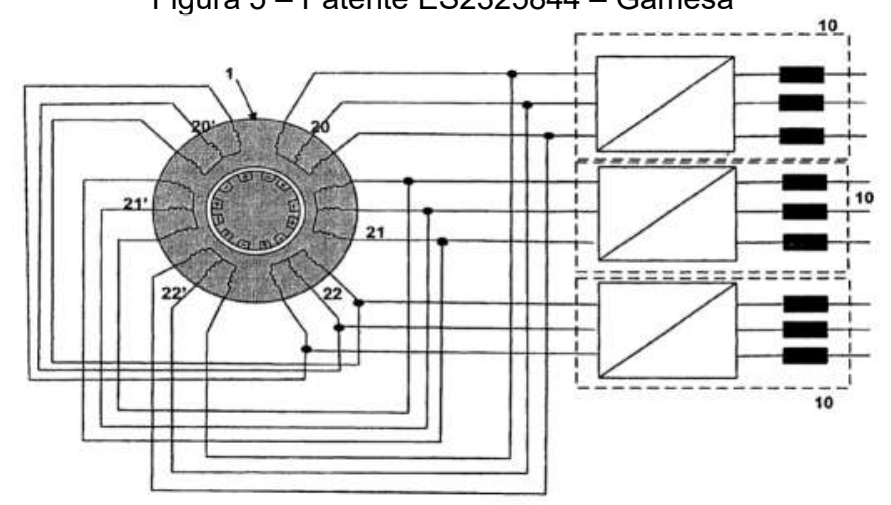

Fonte: (ANDRESEN, 2010)

Neste conceito um número fixo de pares de polos - conjunto de pares de polos - é associado a um enrolamento trifásico convencional (com fases defasadas de $120^{\circ}$ ). As fases do conjunto adjacente, de pares de polos, são independentes; elas dão origem a três fases adicionais. O número mínimo de pares de polos por grupo trifásico é dois. Por exemplo, na Figura 5 um par de polos é associado ao enrolamento trifásico 20 e um segundo par de polos é associado ao enrolamento trifásico 20'. As bobinas 20 e 22', que estão em fase, são conectadas em paralelo para produzir um grupo trifásico (ANDRESEN, 2010).

Cada conjunto trifásico do gerador é conectado a um conversor eletrônico de potência convencional. Este conceito possui resiliência a falhas em uma ou mais fases do gerador. No caso de falha em uma das fases, um dos conversores trifásicos precisa ser retirado de operação. Em termos eletromagnéticos, o gerador se comporta como uma máquina trifásica. 


\subsection{SIEMENS SWT 6.0}

O gerador direct-drive da Siemens de 6,0 MW opera com tensão nominal de 690 $\checkmark$ e rotação entre 5 e 11 RPM (SIEMENS, 2012). Segundo (STIESDAL, 2014), este gerador possui $6,5 \mathrm{~m}^{1}$ de diâmetro, pesa 100 toneladas e tem torque nominal de 5500 $\mathrm{kNm}$. Os pontos diferenciais deste gerador são o seu rotor externo, com excitação por imãs permanentes, e estator modular (STIESDAL, 2014).

Em (STIESDAL, 2014, p. 24) estima-se que geradores com rotor externo possuem diâmetro e peso aproximadamente $15 \%$ inferiores a geradores de imãs permanentes de rotor interno. O estator modular apresenta enrolamentos do tipo tooth-coil' ${ }^{2}$, para reduzir o tamanho da cabeça das bobinas, reduzindo o volume e as perdas no cobre. Em contrapartida, enrolamentos do tipo tooth-coil produzem pior forma de onda para força magnetomotriz e tensão induzida do que enrolamentos distribuídos. Estes fatores podem criar problemas de torque ripple e de qualidade de energia.

\subsection{GE HALIADE}

O gerador direct-drive de imãs permanentes da GE, Haliade, possui tensão nominal de $900 \mathrm{~V}$ (opera entre $0-990 \mathrm{~V}$ ) e tem potência nominal de 6,34 MW / 7,2 MVA (CAUBET, 2014, p. 11). Com estes valores, estima-se o fator de potência nominal em 0,88 e a corrente nominal do gerador em $1540 \mathrm{~A}$. A turbina opera com velocidades entre 4 e 11,5 RPM (GE, 2016b). Segundo (WIND POWER MONTHLY, 2013), o diâmetro externo desse gerador é de $7,5 \mathrm{~m}$.

O gerador possui nove fases, divididas em três grupos trifásicos. Cada grupo trifásico é conectado a um conversor eletrônico de potência de três níveis do tipo NPC (CAUBET, 2014). Conforme apresentado em (GE, 2016a), os enrolamentos estatóricos deste gerador são do tipo tooth-coil. Ainda em (GE, 2016a) é possível observar que, diferentemente da solução da Siemens, o gerador da GE apresenta rotor interno.

\footnotetext{
1 O autor entende que se trata do diâmetro externo do gerador.

2 Nesta configuração as bobinas são enroladas em torno de apenas um dente e depois associadas entre si. Mais detalhes sobre esta configuração são explorados em (PONOMAREV, 2013).
} 


\subsection{COMENTÁRIOS GERAIS}

Observa-se a tendência para trens de potência mais integrados e menos complexos para turbinas eólicas offshore, ao se comparar com soluções típicas de turbinas eólicas onshore (Apêndice F - Figura 76). As turbinas de média velocidade Vestas V164 - 8 MW, Gamesa G135 e a antiga Adwen AD8 (ADWEN, 2016a), dispõem de drivetrains integrados, onde o gerador e caixa multiplicadora são diretamente conectados por meio de um flange. A grande vantagem de um sistema integrado é o aumento da densidade de torque do trem de potência e a redução riscos de desalinhamento do eixo mecânico entre a caixa multiplicadora e o gerador elétrico (WIND POWER MONTHLY, 2014).

Outros exemplos de drivetrains integrados são as soluções HybridDrive (Winergy) e FusionDrive (Moventas/The Switch). O sistema HyrbidDrive está disponível para plataformas de $3 \mathrm{MW}$ com valores nominais de torque de entrada de 2000 e $2500 \mathrm{kNm}$, peso de 25 e 31 toneladas, respectivamente (WINENERGY, 2017a). A solução FusionDrive está disponível para plataformas entre 3 e 7 MW, suas principais características são apresentadas na tabela a seguir:

Tabela 2 - FusionDrive

\begin{tabular}{|l|c|c|}
\hline \multicolumn{3}{|c|}{ FusionDrive } \\
\hline Modelo & FusionDrive3 & FusionDrive7 \\
\hline Potência[MW] & $3-4.1$ & $6-7.7$ \\
\hline Torque[kNm] & 3000 & 7000 \\
\hline Peso[Ton] & 35 & $85-95$ \\
\hline Comprimento[m] & $3-3,5$ & 4 \\
\hline Diâmetro[m] & 2,3 & 2,8 \\
\hline Rendimento & 0,96 & 0,96 \\
\hline Densidade de Torque [kNm/Ton] & 86 & $74-82$ \\
\hline Densidade de Potência[kW/Ton] & $86-117$ & $71-81$ \\
\hline
\end{tabular}

Os sistemas direct-drive, por um lado, reduzem a complexidade do trem de potência ao se remover a caixa multiplicadora. Por outro lado, a complexidade com o manuseio, transporte e projeto do gerador podem aumentar de forma significativa. Além disso, como será discutido a seguir, em termos de densidade de torque, as soluções de média velocidade parecem apresentar vantagens.

$\mathrm{Na}$ Figura 6, apresentam-se os valores de densidade de torque para o subsistema - caixa multiplicadora e gerador elétrico - das soluções: HyrbidDrive 2000, 
HyrbidDrive 2500, FusionDrive3, FusionDrive7, Siemens SWT 6.0 e Vestas V164 8,0 MW. Nesta figura, observa-se que a densidade de torque para as soluções de média velocidade tem valores entre $70 \mathrm{kNm} /$ ton a $86 \mathrm{kNm} / \mathrm{ton}$. Nota-se, contudo, uma tendência para redução da densidade de torque com o aumento do torque de entrada da turbina. O gerador direct-drive analisado, a turbina SWT 6.0, apresenta o menor valor de densidade de torque, $55 \mathrm{kNm} / \mathrm{ton}$.

Figura 6 - Densidade de Torque.

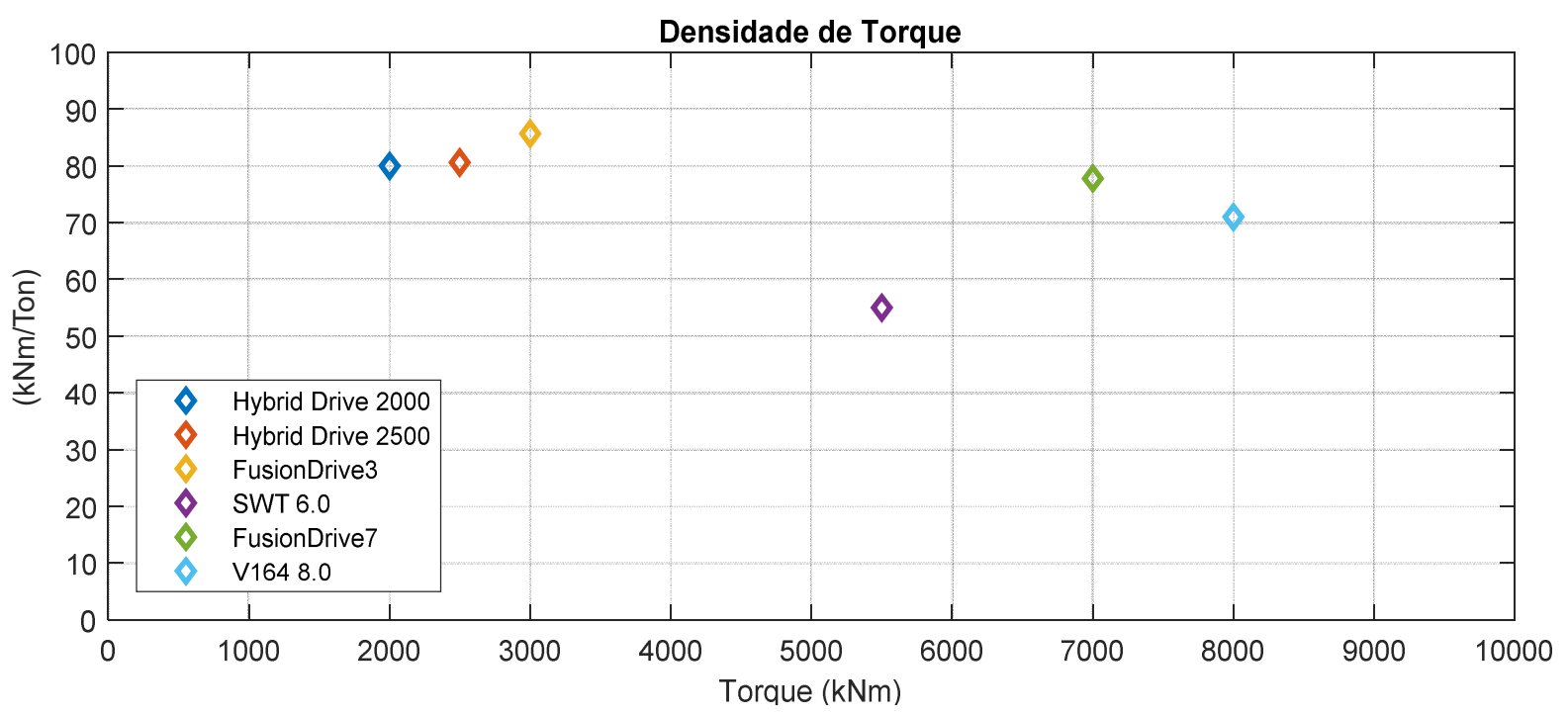

Diversas outras topologias foram sugeridas para geradores eólicos offshore como, por exemplo: máquinas de fluxo axial (BOULDER WIND POWER, 2017), (SWAY TURBINE, 2012), (GOLIATH WIND, 2016), máquinas de fluxo transversal (BANG, POLINDER, et al., 2008), máquinas com enrolamentos supercondutores (AMSC WINDTEC SOLUTIONS, 2012), máquinas com múltiplos geradores (RENEWABLE ENERGY WORLD, 2012), (CLIPPER WIND POWER PLC, 2008), entre outras soluções. Estas soluções "alternativas" não serão discutidas neste trabalho pela falta de representatividade no setor offshore. 


\section{ASPECTOS CONSTRUTIVOS}

Neste capítulo, são apresentadas as relações matemáticas que permitem o cálculo das principais dimensões mecânicas de geradores síncronos multifásicos com excitação por imãs permanentes. A maior parte da discussão aqui apresentada pode ser diretamente aplicada a outros tipos de máquinas elétricas.

\subsection{FORÇA MAGNETOMOTRIZ}

Uma vantagem da configuração multifásica, em comparação com máquinas elétricas trifásicas, é a redução das componentes harmônicas espaciais da força magnetomotriz de reação da armadura. Conforme demonstrado no Apêndice $B$, com pressuposto de corrente senoidal, a força magnetomotriz para uma máquina multifásica, simétrica ou assimétrica ( $N$-Star), possui apenas harmônicas espaciais de ordem $h=2 \mathrm{~km} \pm 1$. Esse fator tem impactos positivos na redução de torque ripple e na redução da indutância de dispersão harmônica. As harmônicas de ordem $h=$ $2 k m+1$ são de sequência positiva, enquanto as harmônicas de ordem $h=2 k m-1$ são de sequência negativa. Onde $k$ é um número inteiro positivo $k=0,1,2 \ldots$

Os termos sequência positiva e negativa, neste caso, são usados de forma generalizada. Componente harmônica de sequência positiva significa que a FMM produzida pela harmônica específica produz campo girante no entreferro com mesmo sentido de rotação do campo fundamental. Para sequência negativa, o mesmo raciocínio é válido, contudo, o campo girante se propaga no sentido contrário à onda fundamental.

Força magnetomotriz de sequência positiva $h=2 k m+1$

$$
F_{h}=\frac{m}{2} \frac{4}{\pi} N_{s f} \sqrt{2} I_{f} \frac{k_{e h}}{h}\left[\operatorname{sen}\left(w t-\frac{h \pi}{\tau_{p}} x\right)\right]
$$

Força magnetomotriz de sequência negativa $h=2 \mathrm{~km}-1$

$$
F_{h}=\frac{m}{2} \frac{4}{\pi} N_{s f} \sqrt{2} I_{f} \frac{k_{e h}}{h}\left[\operatorname{sen}\left(w t+\frac{h \pi}{\tau_{p}} x\right)\right]
$$


Em ambos os casos, máquinas simétricas ou assimétricas, do tipo $\mathrm{N}$-Star, considerou-se enrolamentos distribuídos em faixas de fase de $\frac{180^{\circ}}{m}$. Estes resultados podem não são válidos para máquinas com enrolamentos diferentes.

\subsection{DIMENSÕES PRINCIPAIS}

As dimensões principais de uma máquina elétrica, nomeadamente o diâmetro do entreferro $D_{g}$ e o seu comprimento efetivo $L_{e f}$, são definidos em função da potência aparente do gerador $S$, do carregamento elétrico $A_{q}$ e do carregamento magnético $B_{g}$.

A potência aparente $S$ é calculada pelo produto entre o número de fases $m \mathrm{e}$ os valores eficazes de tensão induzida e corrente de fase $E_{f}$ e $I_{f}$.

$$
S=m E_{f} I_{f}
$$

A tensão induzida por fase é calculada em função da frequência elétrica $f_{e}$, do número total de bobinas em série por fase $N_{s f}$, do fator de enrolamento para a harmônica fundamental $k_{e 1}$, da área polar $A_{p}$ e do valor médio do campo de indução magnética em um passo polar no entreferro $B_{g m}$.

$$
E_{f}=\frac{1}{\sqrt{2}} 2 \pi f_{e} N_{s f} k_{e 1} A_{p} B_{g m}
$$

A área polar é calculada pela seguinte relação:

$$
\begin{gathered}
A_{p}=\tau_{p} L_{e f} \\
A_{p}=\frac{\pi D_{g}}{2 p} L_{e f}
\end{gathered}
$$

Considerando que a indução magnética no entreferro possui distribuição cossenoidal, o seu valor médio em um passo polar é calculado por:

$$
B_{g m}=\int_{-\frac{\pi}{2}}^{\frac{\pi}{2}} B_{g} \cos (\theta) d \theta=\frac{2}{\pi} B_{g}
$$

Portanto, 


$$
E_{f}=\frac{1}{\sqrt{2}} 2 \pi f N_{s f} k_{e 1}\left(\frac{\pi D_{g}}{2 p} L_{e f}\right) \frac{2}{\pi} B_{g}
$$

\subsubsection{Carregamento elétrico}

O carregamento elétrico corresponde à densidade linear de corrente $\left(A_{\text {rms }} / \mathrm{m}\right)$ na circunferência delimitada pelo entreferro. O carregamento elétrico é calculado pela relação a seguir:

$$
A_{q}=\frac{m I_{f} 2 N_{s f}}{\pi D_{g}}\left[\frac{A_{e f}}{m}\right]
$$

A corrente eficaz de fase do gerador pode ser expressa em função do carregamento elétrico:

$$
I_{f}=\frac{A_{q} \pi D_{g}}{2 m N_{s f}}
$$

Ao substituir as equações (3.8) e (3.10) em (3.3), obtém-se a relação entre a potência aparente e os carregamentos elétrico e magnético:

$$
\begin{gathered}
S=m\left[\frac{1}{\sqrt{2}} 2 \pi f N_{s f} k_{e 1}\left(\frac{\pi D_{g}}{2 p} L_{e f}\right) \frac{2}{\pi} B_{g}\right] \cdot\left[\frac{A_{q} \pi D}{2 m N_{s f}}\right] \\
S=\left[\pi^{2} \frac{k_{e 1} A_{q} B_{g}}{\sqrt{2}}\right] D_{g}{ }^{2} L_{e f}\left(\frac{f_{e}}{p}\right) \\
S=\left[\pi^{2} \frac{k_{e 1} A_{q} B_{g}}{\sqrt{2}}\right] D_{g}{ }^{2} L_{e f} f_{m e c}
\end{gathered}
$$

Onde $f_{m e c}=\frac{f_{e}}{p}$, é a frequência de rotação mecânica do rotor. Desta forma, a quantidade $D_{g}{ }^{2} L_{e f}$, proporcional ao volume do entreferro, é definida em função da potência aparente, da frequência mecânica e dos carregamentos elétrico e magnético.

$$
D_{g}{ }^{2} L_{e f}=\frac{S}{\left[\pi^{2} \frac{k_{e 1} A_{q} B_{g}}{\sqrt{2}}\right] f_{m e c}}
$$


$\mathrm{Na}$ equação (3.14), observa-se que o volume do entreferro não depende, num primeiro momento, do número de fases do gerador. Os valores de $D_{g}$ e $L_{e f}$ são determinados ao se estabelecer uma razão adequada entre estas duas dimensões, levando em consideração as limitações específicas do projeto (espaço disponível, máxima velocidade periférica, condições de transporte... entre outros). Algumas sugestões são apresentadas no Apêndice $C$.

\subsection{FATOR DE ENROLAMENTO}

O fator de enrolamento, seguindo a definição de (KRISHNAN, 2010, p. 63) e (PYRHONEN, JOKINEN e HRABOVCOVÁ, 2014, p. 79), é composto por três componentes: fator de distribuição $k_{d h}$, fator de encurtamento de passo $k_{c h}$ e fator de inclinação de ranhura $k_{s k h^{3}}$.

$$
k_{e h}=k_{d h} k_{c h} k_{s k h}
$$

Conforme apresentado na equação (3.14), o valor do fator de enrolamento tem impacto direto no volume do gerador. Embora a topologia multifásica não altere a metodologia convencional para cálculo deste parâmetro, o número de fases da máquina tem impacto no fator de distribuição e, consequentemente, no valor de $k_{e h}$. As definições de $k_{d h}, k_{c h}$ e de $k_{s k h}$ serão apresentadas na sequência.

\subsubsection{Fator de distribuição}

O fator de distribuição, $k_{d h}$, para a $h$-ésima harmônica, com enrolamento com número de ranhuras por polo e por fase, $q$, inteiro é definido segundo a relação (JORDÃO, 2013, p. 45-47):

$$
k_{d h}=\frac{\operatorname{sen}\left(h \frac{q \alpha_{u}}{2}\right)}{q \operatorname{sen}\left(h \frac{\alpha_{u}}{2}\right)}
$$

\footnotetext{
${ }^{3}$ É prática comum definir fator de enrolamento apenas pelo produto entre o fator de distribuição e o fator de encurtamento de passo (CHAPMAN, 1991), (JORDÃO, 2013), (SAY, 1983). Neste caso, existindo inclinação de ranhura (skew), é necessário corrigir os valores de tensão induzida, indutância de magnetização e força magnetomotriz por conta da inclinação. Neste trabalho, optou-se por definir o fator de enrolamento já incluindo o fator de inclinação de ranhura e, dessa forma, não se faz necessário correções nos parâmetros mencionados.
} 
Onde $\alpha_{u}$ corresponde ao ângulo elétrico entre duas ranhuras adjacentes $\alpha_{u}=$ $\frac{\pi}{q m}$. Desta forma, pode-se reescrever (3.16) em função do número de fases do gerador:

$$
k_{d h}=\frac{\sin \left(\frac{h \pi}{2 m}\right)}{q \sin \left(\frac{h \pi}{2 q m}\right)}
$$

No caso de enrolamentos com $q$ fracionário onde $q=\alpha / \beta$, razão irredutível, define-se $q^{\prime}$ e $\alpha_{u}^{\prime}$ :

$$
\begin{gathered}
q^{\prime}=q \beta=\alpha \\
\alpha_{u}{ }^{\prime}=\frac{\pi}{q^{\prime} m}
\end{gathered}
$$

Neste caso, o fator de distribuição deverá ser calculado pela seguinte relação (JORDÃO, 2013, p. 52-54):

$$
k_{d h}=\frac{\sin \left(h \frac{q^{\prime} \alpha_{u}{ }^{\prime}}{2}\right)}{q^{\prime} \sin \left(h \frac{\alpha_{u}{ }^{\prime}}{2}\right)}
$$

Alternativamente, em função de $m$ :

$$
k_{d h}=\frac{\sin \left(\frac{h \pi}{2 m}\right)}{q^{\prime} \sin \left(\frac{h \pi}{2 q^{\prime} m}\right)}
$$

Portanto, independentemente do fator $q$ ser inteiro ou fracionário, é possível estabelecer a relação entre o fator de distribuição em função do número de fases. Esta relação é apresentada na figura a seguir: 
Figura 7 - Fator de distribuição em função do número de fases.

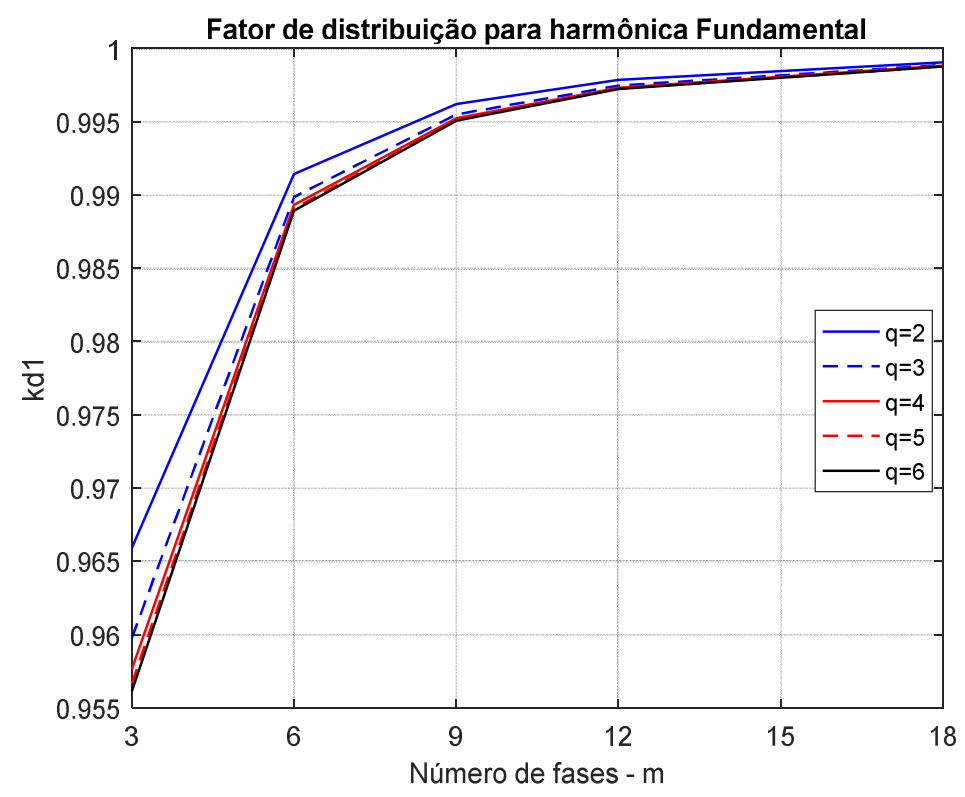

Conforme apresentado na Figura 7, para um mesmo valor de $q$ ou $q^{\prime}$, o fator de distribuição aumenta rapidamente com o número de fases da máquina para $m$ até, aproximadamente, nove. Para $m$ superior a nove, o crescimento do fator de distribuição com número de fases é reduzido.

Conclui-se, portanto, que máquinas multifásicas apresentam uma tendência para operarem com valores mais elevados de $k_{e 1}$. Desta forma um menor volume do entreferro é necessário para estabelecer a potência requerida - equação (3.14). Esta possível redução no volume do entreferro é apresentada na Figura 8. Nesta figura observa-se que uma máquina de nove fases consegue estabelecer a mesma potência no entreferro com um volume entre 3 e $4 \%$ inferior ao volume de uma máquina trifásica, assumindo-se mesmos valores de $q, B_{g}, A_{q}$ e $f_{m e c}$.

\subsubsection{Fator de encurtamento de passo}

O encurtamento de passo das bobinas estatóricas normalmente é realizado para melhorar as componentes harmônicas da tensão induzida. Tipicamente, adotase encurtamento de passo com valor próximo de $30^{\circ}$ que minimiza as componentes de quinta e sétima harmônicas (JORDÃO, 2013). Para encurtamento de passo de $\delta$ graus, o fator de encurtamento $k_{c h}$ é calculado por (JORDÃO, 2013, p. 47): 


$$
k_{c h}=\cos \left(\frac{h \delta}{2}\right)
$$

Figura 8 - Redução do volume do entreferro em função de $\boldsymbol{m}$ e $\boldsymbol{q}$.

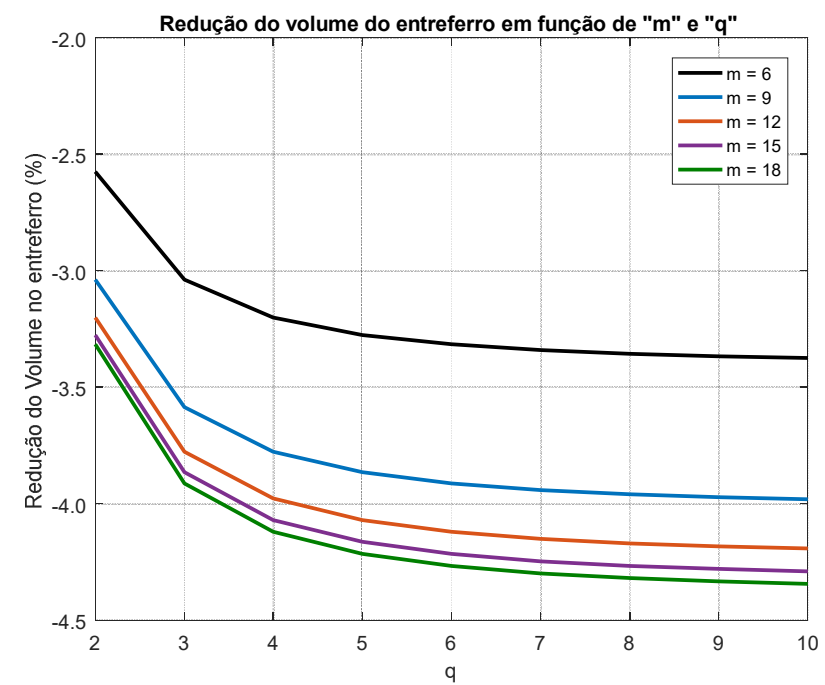

\subsubsection{Fator de inclinação de ranhura}

A variação da permeância magnética ao longo do entreferro pode provocar efeitos parasitas que resultam em pulsações de torque. Com a finalidade de atenuar estes torques parasitas, é comum aplicar uma inclinação nas ranhuras no estator, no rotor ou em ambos. Tipicamente, adota-se inclinação de um passo de ranhura ${ }^{4}$.

Figura 9 - rotor com ranhuras inclinadas na esquerda.

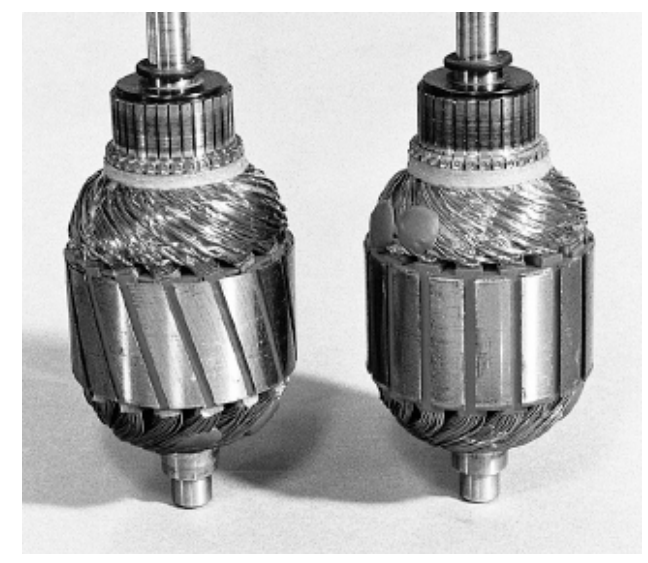

\footnotetext{
${ }^{4}$ Em máquinas de indução, o fator de inclinação de ranhura introduz ainda uma indutância de dispersão que é discutida em (LIPO, 2011, p. 241-244) e em (PYRHONEN, JOKINEN e HRABOVCOVÁ, 2014, p. 242-243).
} 
Para inclinação de $\Delta^{\circ}$, calcula-se o fator de inclinação de ranhura (skew) por (LIPO, 2011, p. 90-93), (PYRHONEN, JOKINEN e HRABOVCOVÁ, 2014, p. 239-241):

$$
k_{s k h}=\frac{\sin \left(h \frac{\Delta}{2}\right)}{h \frac{\Delta}{2}}
$$

\subsection{PARÂMETROS EM FUNÇÃO DAS DIMENSÕES PRINCIPAIS}

Com a finalidade de definir as dimensões do projeto básico do gerador elétrico, nesta secção serão apresentadas as relações entre diversos parâmetros eletromecânicos do gerador em função dos carregamentos elétrico e magnético e das dimensões principais $D_{g}$ e $L_{e f}$.

\subsubsection{Torque e densidade de torque}

O torque $T$ desenvolvido pelo gerador é igual a:

$$
T=\frac{P}{2 \pi f_{m e c}}=\frac{S \cos (\varphi)}{2 \pi f_{m e c}}
$$

Recorrendo-se a equação (3.13), o torque desenvolvido pela máquina pode ser calculado em função dos carregamentos elétrico e magnético e das dimensões principais do gerador de acordo com a seguinte relação:

$$
\begin{gathered}
T=\frac{\left[\pi^{2} \frac{k_{e 1} A_{q} B_{g}}{\sqrt{2}}\right] D_{g}{ }^{2} L_{e f} f_{m e c} \cos (\varphi)}{2 \pi f_{m e c}} \\
T=\frac{1}{2} \pi\left[\frac{k_{e 1} A_{q} B_{g}}{\sqrt{2}}\right] D_{g}{ }^{2} L_{e f} \cos (\varphi)
\end{gathered}
$$

A Tensão de cisalhamento magnético (Magnetic shear-stress) é definida por:

$$
\sigma_{m}=\frac{k_{e 1} A_{q} B_{g}}{\sqrt{2}}\left[N / m^{2}\right]
$$

Substituindo a equação (3.26) em (3.25), o torque desenvolvido pelo gerador é escrito em função de $\sigma_{m}$. 


$$
T=\frac{1}{2} \pi \cdot \sigma_{m} D_{g}^{2} L_{e f} \cos (\varphi)
$$

Ao se dividir (3.27) por $\pi D_{g} L$, obtém-se a densidade de torque no entreferro $\sigma_{T}$ :

$$
\begin{gathered}
\sigma_{T}=\frac{\frac{1}{2} \pi \cdot \sigma_{m} D_{g}^{2} L_{e f} \cos (\varphi)}{\pi D_{g} L} \\
\sigma_{T}=\frac{1}{2} \sigma_{m} D_{g} \frac{L_{e f}}{L} \cos (\varphi)
\end{gathered}
$$

No caso de retificação ativa, é possível controlar as correntes de fase do gerador para operação com fator de potência interno - $\cos (\varphi)$ - unitário. Nestas condições, consegue-se maximizar o torque desenvolvido pela máquina. A relação (3.28) mostra que, para mesmos valores de carregamentos elétrico e magnético, a densidade de torque na área limitada pelo entreferro aumenta linearmente com o diâmetro do gerador.

\subsubsection{Força e densidade de força normal}

Um fator relevante, especialmente para máquinas de grandes dimensões ${ }^{5}$, é a força de atração entre estator e rotor da máquina elétrica. A densidade de força normal à superfície do rotor é calculada por:

$$
\sigma_{n}(\theta)=\frac{B(\theta)^{2}}{2 \mu_{0}}\left[N / m^{2}\right]
$$

A força resultante normal à superfície do rotor é calculada pela integral de $\sigma_{n}(\theta)$ ao longo da superfície rotórica (WALLIN, 2013, p. 9):

$$
\begin{aligned}
& F_{n x}=\frac{D_{g} L_{e f}}{2} \int_{0}^{2 \pi} \sigma_{n}(\theta) \cos (\theta) d \theta \\
& F_{n y}=\frac{D_{g} L_{e f}}{2} \int_{0}^{2 \pi} \sigma_{n}(\theta) \operatorname{sen}(\theta) d \theta
\end{aligned}
$$

${ }^{5}$ Este fator pode ser crítico para geradores do tipo direct-drive (JOCKEL, 2003), (MUELLER e POLINDER, 2013) 
Caso o rotor e o estator sejam perfeitamente centralizados, a força normal será nula. Entretanto, devido às tolerâncias mecânicas, assimetrias de instalação e vibrações em operação, é esperado que o sistema opere com excentricidades. O suporte mecânico do gerador deve ser suficientemente robusto evitar o choque entre rotor e estator. Os custos e a complexidade do sistema de suporte mecânico crescem com o aumento do diâmetro do gerador (GRAUERS, 1996, p. 24) (ZAVVOS, MCDONALD e MUELLER, 2010).

\subsubsection{Dimensões de ranhura e fluxo magnético no dente}

\subsubsection{Largura de ranhura $b_{s}$}

A largura de ranhura $b_{s}$ pode ser relacionada com o passo de ranhura $\tau_{s}$, segundo (3.32), onde $k_{s}$ assume valores entre 0 e 1. Para uma aproximação inicial é comum considerar que o passo de ranhura é dividido igualmente entre a ranhura e o dente. Neste caso: $b_{s}=b_{t}$ e $k_{s}=0,5$.

$$
b_{s}=k_{s} \tau_{s}
$$

O produto entre o número total de ranhuras, $N_{s}=2 p q m$, e o passo de ranhura é igual ao comprimento da circunferência interna do estator, aproximadamente igual ao comprimento da circunferência delimitada pelo entreferro $\pi D_{g}$. Desta forma, calcula-se a largura da ranhura em função de $\pi D_{g}, N_{s}$ e $k_{s}$, por:

$$
\begin{aligned}
& N_{s} \tau_{s} \cong \pi D_{g} \\
& b_{s} \cong \frac{k_{s} \pi D_{g}}{2 p q m}
\end{aligned}
$$

\subsubsection{Corrente e densidade de corrente por ranhura}

O módulo da corrente eficaz por ranhura, $I_{r}$, é calculado em função do carregamento elétrico $A_{q}$, segundo a equação (3.35).

$$
I_{r}=\frac{A_{q} \pi D_{g}}{2 p q m}\left[A_{r m s}\right]
$$


A densidade de corrente na ranhura, $J_{r}$, é função de $I_{r}$, da área e do fator de preenchimento da ranhura $A_{s}$ e $k_{\text {pre }}$.

$$
\begin{gathered}
J_{r}=\frac{I_{r}}{A_{s} k_{\text {pre }}}\left[\frac{A_{r m s}}{m^{2}}\right] \\
J_{r}=\frac{A_{q} \pi D_{g}}{2 p q m A_{s} k_{\text {pre }}}\left[\frac{A_{r m s}}{m^{2}}\right]
\end{gathered}
$$

Considerando-se ranhuras retangulares $A_{s}=h_{s} b_{s}$.

$$
J_{r}=\frac{A_{q} \pi D_{g}}{2 p q m h_{s} b_{s} k_{p r e}}
$$

Tipicamente, $J_{r}$ assume valores entre 2 e $5 A_{r m s} / \mathrm{mm}^{2}$, enquanto o fator de preenchimento $k_{\text {pre }}$ varia entre 0,45 e 0,60. O fator de preenchimento tende a diminuir com o aumento da tensão nominal da máquina.

\subsubsection{Altura de ranhura $h_{s}$}

Substituindo as equações (3.34) e (3.35) em (3.38), observa-se que a altura da ranhura $h_{s}$ é função de $A_{q}, k_{s}, k_{\text {pre }}$ e $J_{r}$, segundo (3.39).

$$
\begin{gathered}
J_{r}=\frac{\frac{A_{q} \pi D_{g}}{2 p q m}}{h_{s} \frac{k_{s} \pi D_{g}}{2 p q m} k_{p r e}} \\
J_{r}=\frac{A_{q}}{h_{s} k_{s} k_{p r e}} \\
h_{s}=\frac{A_{q}}{J_{r} k_{s} k_{\text {pre }}}
\end{gathered}
$$

O valor de $h_{s}$ normalmente assume valores entre uma a cinco vezes a largura da ranhura $b_{s}$ (UPADHYAY, 2008, p. 120). 


\subsubsection{Fluxo magnético no passo de ranhura}

O valor médio do fluxo magnético por passo de ranhura é função do valor médio do campo de indução magnética no entreferro $B_{g m}=\frac{2}{\pi} B_{g}$ e da área do passo de ranhura $A_{\tau_{s}}=\tau_{s} L_{e f}$

$$
\varphi_{\tau_{s}}=\frac{2}{\pi} B_{g} \tau_{s} L_{e f}
$$

\subsubsection{Campo de indução magnética máximo no dente}

Escrevendo $\tau_{s}$ em função do diâmetro do entreferro $D_{g}$, do número de ranhuras por polo e por fase $q$, do número de fases $m$ e do número total de polos $2 p$, o fluxo magnético por passo de ranhura é calculado segundo a relação (3.41).

$$
\begin{gathered}
\tau_{s}=\frac{\tau_{p}}{q m} \\
\tau_{s}=\frac{\pi D_{g}}{2 p q m} \\
\varphi_{\tau_{s}}=\frac{2}{\pi} B_{g} \frac{\pi D_{g} L_{e f}}{2 p q m} \\
\varphi_{\tau_{s}}=\frac{B_{g} D_{g} L_{e f}}{p q m}
\end{gathered}
$$

Considerando que o fluxo magnético do passo de ranhura passa exclusivamente pelo dente, o campo de indução magnética máximo no dente $B_{t m}$ é calculado em função de $k_{e m p}, \varphi_{\tau_{s}}, b_{t}$ e $L_{e f}$ :

$$
\begin{gathered}
B_{t m}=\frac{\varphi_{\tau_{s}}}{k_{e m p} b_{t} L_{e f}} \\
B_{t m}=\frac{\frac{B_{g} D_{g} L_{e f}}{p q m}}{k_{e m p} b_{t} L_{e f}}
\end{gathered}
$$




$$
B_{t m}=\frac{B_{g} D_{g}}{k_{\text {emp }} b_{t} p q m}
$$

Escrevendo $b_{t}$ em função de $k_{s}$ e de $\tau_{s}$, obtém-se:

$$
\begin{gathered}
B_{t m}=\frac{B_{g} D_{g}}{k_{e m p}\left(1-k_{s}\right) \tau_{s} p q m} \\
B_{t m}=\frac{B_{g} D_{g}}{k_{e m p}\left(1-k_{s}\right) \frac{\pi D_{g}}{2 p q m} p q m} \\
B_{t m}=\frac{2 B_{g}}{\pi k_{e m p}\left(1-k_{s}\right)}
\end{gathered}
$$

Tipicamente, o valor máximo da indução magnética no dente varia entra 1,5 e 1,9 T. A equação (3.42) pressupõe que o fluxo magnético por passo polar é dividido igualmente por cada dente do estator. Para máquinas de polos salientes, entretanto, o fluxo magnético tende a se concentrar nos dentes mais alinhados com a sapata polar do rotor. Desta forma, para máquinas de polos salientes, sugere-se corrigir a equação (3.42) pela razão entre a sapata polar e o passo polar, de acordo com a equação a seguir:

$$
B_{t m}=\frac{2 B_{g}}{\frac{\tau_{\text {shoe }}}{\tau_{p}} \pi k_{e m p}\left(1-k_{s}\right)}
$$

A equação (3.43), assume que a área efetiva dos dentes por passo polar igual a $\frac{\tau_{\text {shoe }}}{\tau_{p}} b_{t} L_{e f} q m$.

\subsubsection{Dimensões das coroas estatórica e rotórica}

As dimensões das coroas estatórica e rotórica, $h_{s y}$ e $h_{r y}$, são definidas, normalmente, pelo valor do campo de indução magnética desejado nestas estruturas. De acordo com (UPADHYAY, 2008, p. 123), tipicamente, utiliza-se valores de indução magnética entre 1,3 e 1,5 T. 
Assumindo os valores de indução magnética desejados na coroa estatórica e rotórica, $B_{s y}$ e $B_{r y}, h_{s y}$ e $h_{r y}$ são calculados de forma semelhante. Considerando que metade do fluxo magnético por polo atravessa a coroa estatórica, $h_{s y}$ é calculado segundo a relação (3.44).

$$
\begin{gathered}
h_{s y}=\frac{\varphi_{p} / 2}{B_{s y} k_{e m p} L_{e f}} \\
h_{s y}=\frac{\left(\frac{\pi D_{g}}{2 p} L_{e f}\right) \frac{2}{\pi} B_{g} / 2}{B_{s y} k_{e m p} L_{e f}} \\
h_{s y}=\frac{D_{g} B_{g}}{2 p B_{s y} k_{e m p}}
\end{gathered}
$$

Para o cálculo $h_{r y}$ é necessário adicionar o fator de dispersão $k_{d i s}$ relativo ao fluxo magnético disperso no sistema de excitação.

$$
\begin{gathered}
h_{r y}=\frac{k_{d i s} \varphi_{p} / 2}{B_{r y} k_{e m p} L_{e f}} \\
h_{r y}=\frac{k_{d i s} D_{g} B_{g}}{2 p B_{r y} k_{e m p}}
\end{gathered}
$$

\subsubsection{Impedância de base}

Adotando-se como tensão de base $V_{b}=E_{f}$ e corrente de base $I_{b}=I_{f}$, a impedância de base $Z_{b}$ é calculada segundo (3.46).

$$
Z_{b}=\frac{V_{b}}{I_{b}}=\frac{E_{f}}{I_{f}}
$$

Recorrendo-se às equações (3.8) e (3.10), escreve-se $Z_{b}$ pela relação (3.47):

$$
Z_{b}=\frac{\frac{1}{\sqrt{2}} 2 \pi f N_{s f} k_{e 1}\left(\frac{\pi D_{g}}{2 p} L_{e f}\right) \frac{2}{\pi} B_{g}}{\frac{A_{q} \pi D_{g}}{2 m N_{s f}}}
$$




$$
Z_{b}=\frac{2 m \sqrt{2} k_{e 1} N_{s f}{ }^{2} L_{e f} B_{g}}{A_{q}} f_{m e c}
$$

\subsubsection{Corrente e indutância de magnetização}

\subsubsection{Corrente de magnetização}

Recorrendo-se à equação (3.1), é possível relacionar a corrente de magnetização da máquina $I_{\text {mag }}$ com a FMM por polo, $F_{0}$, requerida para magnetizar o entreferro.

$$
\begin{gathered}
F_{0}=\frac{F_{m m}}{2 p}=\frac{\left(\frac{m}{2}\right) \frac{4}{\pi} N_{s f} \sqrt{2} I_{m a g} k_{e 1}}{2 p} \\
I_{m a g}=\frac{F_{0} p}{\frac{m \sqrt{2}}{\pi} N_{s f} k_{e 1}}
\end{gathered}
$$

A força magnetomotriz por polo, $F_{0}$, pode ser escrita em função de $B_{g}$ e $l_{g}{ }^{\prime}$ segundo (3.50). Desta forma, $I_{m a g}$ pode ser calculada pela equação (3.51):

$$
\begin{gathered}
F_{0}=\frac{B_{g}}{\mu_{0}} l_{g}{ }^{\prime} \\
I_{m a g}=\frac{\frac{B_{g}}{\mu_{0}} l_{g}{ }^{\prime} p}{\frac{m \sqrt{2}}{\pi} N_{s f} k_{e 1}}
\end{gathered}
$$

3.4.6.2 Indutância de magnetização

A indutância de magnetização é calculada pela relação:

$$
L_{m}=\frac{1}{2 \pi f} \frac{E_{f}}{I_{m a g}}
$$

Substituindo as equações (3.8) e (3.51) em (3.52), obtém-se (3.53): 


$$
L_{m}{ }^{6}=\frac{m}{2} \frac{8}{\pi}\left(\frac{N_{s f} k_{e 1}}{2 p}\right)^{2} \frac{\mu_{0} D_{g} L_{e f}}{l_{g}^{\prime}}
$$

A reatância de magnetização, em valor por unidade, é obtida ao se dividir $2 \pi f L_{m}$ pela impedância de base $Z_{b}(3.47)$ :

$$
x_{m}=\frac{\mu_{0} A_{q} \sqrt{2} k_{e 1}}{2 B_{g}} \cdot \frac{D_{g}}{l_{g}{ }^{\prime} p}
$$

\subsection{INDUTÂNCIAS SEGUNDO EIXOS DQ}

As indutâncias, para os eixos direto e de quadratura, são calculadas pela soma da indutância de dispersão por fase e as indutâncias de magnetização segundo os eixos direto e de quadratura:

$$
\begin{aligned}
& L_{d}=l_{d i s}+L_{m d} \\
& L_{q}=l_{d i s}+L_{m q}
\end{aligned}
$$

\subsubsection{Indutâncias de dispersão}

Tipicamente, a indutância de dispersão por fase da máquina, $l_{\text {dis }}$, é calculada pela soma de quatro componentes: dispersão de ranhura, $l_{s}$, dispersão de topo de dente, $l_{t t}$, dispersão de final de enrolamento, $l_{e w}$, e dispersão harmônica $l_{b l}$.

$$
l_{d i s}=l_{s}+l_{t t}+l_{b l}+l_{e w}
$$

O enrolamento multifásico produz impactos diretos e indiretos no cálculo de todas as componentes de dispersão. A metodologia para o cálculo de $l_{s}, l_{t t}$ e $l_{b l}$ para máquinas elétricas multifásicas será apresentada nas secções a seguir.

A indutância de dispersão de final de enrolamento é normalmente calculada de forma empírica. Considera-se fora do escopo desse trabalho a elaboração de equações empíricas para $l_{e w}$ para máquinas multifásicas. Desta forma, para $l_{e w}$, as

\footnotetext{
${ }^{6}$ Salienta-se que $L_{m}$ já considera o acoplamento magnético das $\mathrm{m}$ fases no estator, portanto a indutância síncrona é $L_{s}=l_{\text {dis }}+L_{m}$. Em alguns livros é comum usar a notação $L_{m}$ para uma fase isolada no estator, neste segundo caso $L_{s}=l_{\text {dis }}+\frac{m}{2} L_{m}$.
} 
equações tipicamente utilizadas para máquinas elétricas trifásicas são apresentadas no Apêndice C.

\subsubsection{Indutâncias de magnetização segundo eixos $d$ e $q$}

Uma vez determinada a indutância de magnetização, aplica-se a teoria da dupla reação para determinar a indutância de magnetização segundo os eixos direto e de quadratura, através dos fatores de correção $k_{d}$ e $k_{q}$ (GIERAS e WING, 2002) e (KOSTENKO e PIOTROVISK, 1979, p. 190-201). Para geradores de polos salientes eletricamente excitados, calcula-se $k_{d}$ e $k_{q}$ em função do tamanho da sapata polar em graus elétricos $\alpha_{s p}$.

$$
\begin{aligned}
& k_{d}=\frac{\alpha_{s p} \pi+\sin \left(\alpha_{s p} \pi\right)}{\pi} \\
& k_{q^{7}}=\frac{\alpha_{s p} \pi-\sin \left(\alpha_{s p} \pi\right)}{\pi}
\end{aligned}
$$

Para máquinas de imãs permanentes, os fatores $k_{d}$ e $k_{q}$ dependem da topologia/geometria do sistema de excitação. A Figura 10 apresenta configurações típicas de máquinas excitadas por imãs permanentes. Gieras em (GIERAS e WING, 2002, p. 187-191) sugere as relações, apresentadas na Tabela 3, para o cálculo de $k_{d}$ e $k_{q}$ para máquinas de imãs permanentes.

Define-se:

$$
\begin{gathered}
c_{g} \approx 1-\frac{l_{m}}{l_{g}} \\
c_{g}^{\prime} \approx 1-\frac{d_{p}}{l_{g q}}
\end{gathered}
$$

Onde $l_{m}$ é a altura do imã, $d_{p}$ é a altura do material ferromagnético para concentração de campo e $l_{g q}$ corresponde ao comprimento do entreferro segundo o eixo de quadratura.

\footnotetext{
${ }^{7}$ (BOLDEA, 2006, p. 4-17) sugere $k_{q}=\frac{\alpha_{s p} \pi-\operatorname{sen}\left(\alpha_{s p} \pi\right)}{\pi}+\frac{2}{3 \pi} \cos \left(\alpha_{s p} \frac{\pi}{2}\right)$
} 
Figura 10 - Diferentes configurações de máquinas de imãs permanentes. a) surface magnets. b) Inset magnets c) PM with mild steel pole shoes d) Buried magnets.

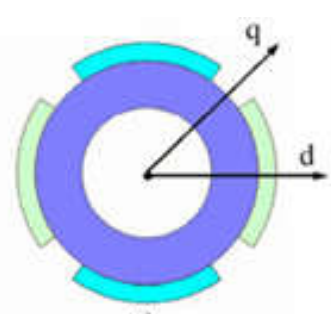

a)

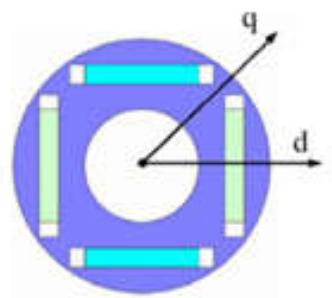

c)

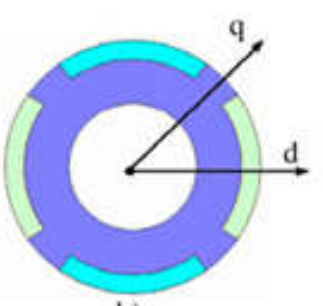

b)

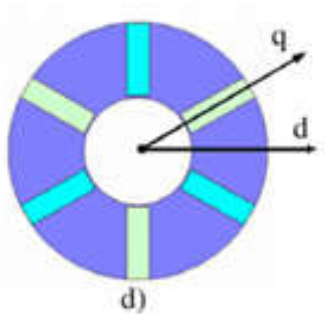

Fonte: Adaptado de (GERLING, 2015, p. 219).

As indutâncias de magnetização segundo os eixos direto e de quadradura $L_{m d}$ e $L_{m q}$ são calculadas por:

$$
\begin{aligned}
& L_{m d}=L_{m} k_{d} \\
& L_{m q}=L_{m} k_{q}
\end{aligned}
$$

Salienta-se que o método apresentado para estimação de $L_{m d}$ e $L_{m q}$ apresenta, tipicamente, bons resultados para máquinas eletricamente excitadas. Para máquinas de imãs permanentes o método analítico não possui a mesma performance pois há maior influência das características especificas (geometria) da máquina em questão na distribuição do campo magnético.

Desta forma, recomenda-se a validação/correção desses parâmetros através do método de elementos finitos (GIERAS, SANTINI e WING, 1998). Em ambos os casos, máquinas eletricamente excitadas ou com excitação por imãs permanentes, as impedâncias operacionais são estimadas por meio de ensaios experimentais. 
Tabela 3 - Fatores $\boldsymbol{k}_{\boldsymbol{d}}$ e $\boldsymbol{k}_{\boldsymbol{q}}$ para máquinas de imãs permanentes.

\begin{tabular}{|c|l|}
\hline Topologia & \multicolumn{1}{c|}{ Fatores } \\
\hline Inset magnets & $k_{d}=\frac{\alpha_{s p} \pi+\operatorname{sen}\left(\alpha_{s p} \pi\right)+c_{g}\left[\pi\left(1-\alpha_{s p}\right)-\operatorname{sen}\left(\alpha_{s p} \pi\right)\right]}{\pi}$ \\
\hline $\begin{array}{c}\text { PM with mild steel } \\
\text { pole shoes }\end{array}$ & $k_{q}=\frac{\left(1 / c_{g}\right)\left[\alpha_{s p} \pi-\operatorname{sen}\left(\alpha_{s p} \pi\right)\right]+\pi\left(1-\alpha_{s p}\right)+\operatorname{sen}\left(\alpha_{s p} \pi\right)}{\pi}$ \\
\hline $\begin{array}{c}\text { Buried Magnets } \\
\text { Surface magnets }\end{array}$ & $k_{d}=\frac{\alpha_{s p} \pi+\operatorname{sen}\left(\alpha_{s p} \pi\right)+c_{g}^{\prime}\left[\pi\left(1-\alpha_{s p}\right)-\operatorname{sen}\left(\alpha_{s p} \pi\right)\right]}{\pi}$ \\
\hline & $k_{d}=\frac{4}{\pi} \frac{\alpha_{s p}}{1-\alpha_{s p}{ }^{2}} \cos \left(\frac{\alpha_{s p} \pi}{2}\right) ; k_{q}=\frac{\alpha_{s p} \pi-\operatorname{sen}\left(\alpha_{s p} \pi\right)}{\pi}$ \\
\hline
\end{tabular}

\subsection{ESTIMAÇÃO DA DIMENSÃO DO ENTREFERRO}

A dimensão do entreferro é estabelecida através de um compromisso entre os sistemas mecânico, térmico e o projeto eletromagnético do gerador. Quando se sabe a priori valores típicos da reatância síncrona $x_{s}$ para a máquina em questão, é possível estimar o comprimento do entreferro necessário para atingir aproximadamente o valor desejado de $x_{s}$. Para tal, assume-se que a reatância de dispersão é desprezível, neste caso, a reatância síncrona é igual à reatância de magnetização $x_{m}$.

$$
\begin{gathered}
x_{s} \cong x_{m} \\
x_{s} \cong \frac{\mu_{0} A_{q} \sqrt{2} k_{e 1}}{2 B_{g}} \cdot \frac{D_{g}}{l_{g}{ }^{\prime} p}
\end{gathered}
$$

Para geradores com imãs permanentes, tipicamente utiliza-se a seguinte aproximação:

$$
l_{g}{ }^{\prime}=\left(k_{c s} k_{s a t} l_{g}+\frac{l_{m}}{\mu_{r}}\right)
$$


$\mathrm{Na}$ equação (3.65), supõe-se um caminho médio para o fluxo magnético, produzido pelos enrolamentos do estator, que cruza o entreferro e o imã. Essa aproximação é razoável, principalmente, para máquinas com imãs na superfície do rotor. Dependendo da geometria do sistema de excitação, entretanto, podem existir caminhos alternativos para a passagem de fluxo magnético pelo ferro. Neste caso, a equação (3.65) apresentará resultados menos precisos. Com base na relação (3.65), é possível estimar $l_{g}$ de acordo com a relação:

$$
l_{g}=\frac{1}{k_{c s} k_{s a t}}\left(\frac{\mu_{0} A_{q} \sqrt{2} k_{e 1} D_{g}}{2 p B_{g} x_{s}}-\frac{l_{m}}{\mu_{r}}\right)
$$

Para gerador eletricamente excitado:

$$
l_{g}^{\prime}=k_{c s} k_{s a t} l_{g}
$$

Portanto, estima-se o tamanho do entreferro por:

$$
l_{g}=\frac{1}{k_{c s} k_{s a t}}\left(\frac{\mu_{0} A_{q} \sqrt{2} k_{e 1} D_{g}}{2 p B_{g} x_{s}}\right)
$$

De forma alternativa, em (UPADHYAY, 2008, p. 114) sugere-se $l_{g}$ entre $1 \%$ e $1,5 \%$ de $\tau_{p}$ para geradores hidroelétricos e entre $2 \%$ e $2,5 \%$ de $\tau_{p}$ para turbogeradores. A referência (PYRHONEN, JOKINEN e HRABOVCOVÁ, 2014, p. 307) discute a necessidade de se estabelecer um entreferro mínimo de forma a limitar o impacto do fluxo magnético de reação na densidade de campo magnético no entreferro e sugere a seguinte relação:

$$
l_{g} \geq \gamma \tau_{p} \frac{A_{q}}{B_{g}}
$$

Onde $\gamma=7.10^{-7}$ para máquinas de polos salientes de entreferro constante, $\gamma=4.10^{-7}$ para máquinas de polos salientes com entreferro cossenoidal e $\gamma=3.10^{-7}$ para máquinas síncronas de polos lisos. Outro valor de referência, tipicamente encontrado na literatura, é a relação $l_{g} \geq 0,1 \% D_{g}$ para geradores eólicos do tipo directdrive (POLINDER, BANG, et al., 2007), (GRAUERS, 1996). 


\subsection{INDUTÂNCIA DE DISPERSÃO DE RANHURA}

A indutância de dispersão de ranhura, $l_{s}$, de um enrolamento de dupla camada (configuração apresentada na Figura 11), é calculada em função das permeâncias específicas das bobinas superior $p_{t}$, inferior $p_{b}$, da permeância específica referente ao fluxo mútuo entre elas, $p_{t b}=p_{b t}$, quando ambas as bobinas pertencem à mesma fase (enrolamento de passo pleno), e do fator $k_{r}$ que quantifica a redução de $p_{t b}$ por conta de encurtamento de passo (LIWSCHITZ-GARIK e WHIPPLE, 1950, p. 118-123).

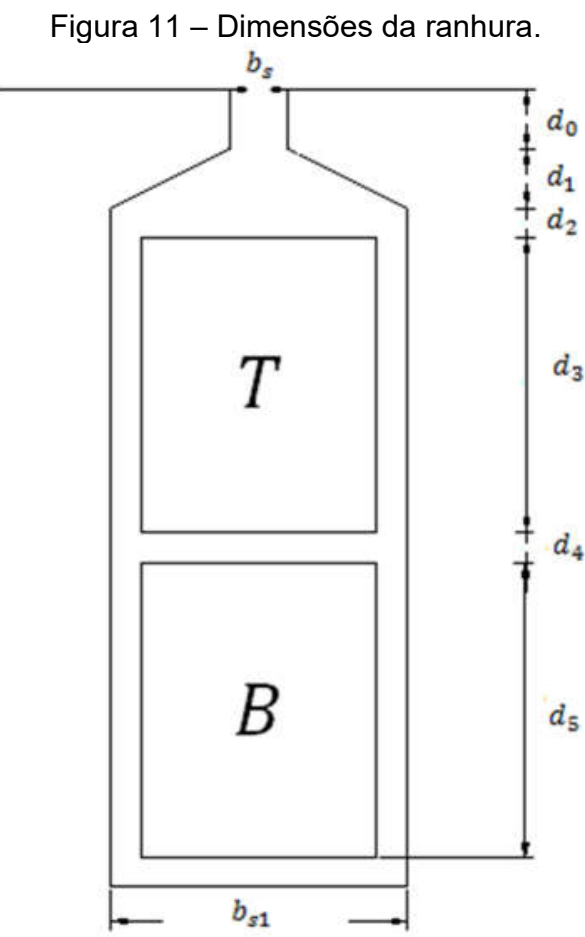

Fonte: adaptado de (LIPO, 2011, p. 175).

$$
\begin{gathered}
l_{s}=l_{s b}+l_{s t} \\
l_{s b}=\frac{4}{2 p q}\left(\frac{N_{s f}}{2}\right)^{2} L_{e f}\left(p_{b}+k_{r} p_{b t}\right) \\
l_{s t}=\frac{4}{2 p q}\left(\frac{N_{s f}}{2}\right)^{2} L_{e f}\left(p_{t}+k_{r} p_{t b}\right) \\
l_{s}=\frac{4}{2 p q}\left(\frac{N_{s f}}{2}\right)^{2} L_{e f}\left(p_{b}+p_{t}+2 k_{r} p_{t b}\right)
\end{gathered}
$$

As permeâncias específicas são calculadas de acordo com as relações a seguir (LIPO, 2011, p. 175-177), (LIWSCHITZ-GARIK e WHIPPLE, 1950, p. 118-123): 


$$
\begin{gathered}
p_{b}=\mu_{0}\left[\frac{d_{5}+3 d_{3}}{3 b_{s 1}}+\frac{d_{2}+d_{4}}{b_{s 1}}+\frac{d_{1}}{b_{s 1}-b_{s}} \ln \left(\frac{b_{s 1}}{b_{s}}\right) 8+\frac{d_{0}}{b_{s}}\right] \\
p_{t}=\mu_{0}\left[\frac{d_{3}}{3 b_{s 1}}+\frac{d_{2}}{b_{s 1}}+\frac{d_{1}}{b_{s 1}-b_{s}} \ln \left(\frac{b_{s 1}}{b_{s}}\right)+\frac{d_{0}}{b_{s}}\right] \\
p_{t b}=\mu_{0}\left[\frac{d_{0}}{b_{s}}+\frac{d_{1}}{b_{s 1}-b_{s}} \ln \left(\frac{b_{s 1}}{b_{s}}\right)+\frac{d_{2}}{b_{s 1}}+\frac{d_{3}}{2 b_{s 1}}\right]
\end{gathered}
$$

Substituindo (3.74), (3.75) e (3.76) em (3.73):

$$
l_{s}=\frac{4 \mu_{0}}{2 p q} N_{s f}^{2} L_{e f}\left[\left(\frac{1}{4}\right)\left(\frac{d_{5}+d_{3}\left(4+3 k_{r}\right)}{3 b_{s 1}}\right)+\frac{d_{4}}{4 b_{s 1}}+\left(\frac{2 k_{r}+2}{4}\right)\left(\frac{d_{2}}{b_{s 1}}+\frac{d_{1}}{b_{s 1}-b_{s}} \ln \left(\frac{b_{s 1}}{b_{s}}\right)+\frac{d_{0}}{b_{s}}\right)\right]
$$

Para $d_{3}=d_{5}$, escreve-se (3.77) por:

$$
l_{s}=\frac{4 \mu_{0}}{2 p q} N_{s f}^{2} L_{e f}\left[\left(\frac{5+3 k_{r}}{8}\right)\left(\frac{2 d_{3}}{3 b_{s 1}}\right)+\frac{d_{4}}{4 b_{s 1}}+\left(\frac{2 k_{r}+2}{4}\right)\left(\frac{d_{2}}{b_{s 1}}+\frac{d_{1}}{b_{s 1}-b_{s}} \ln \left(\frac{b_{s 1}}{b_{s}}\right)+\frac{d_{0}}{b_{s}}\right)\right]
$$

Usando a nomenclatura de Liwschitz em (LIWSCHITZ-GARIK e WHIPPLE, 1947) e em (LIWSCHITZ-GARIK e WHIPPLE, 1950)9:

$$
\begin{aligned}
& k_{x c o}=\left(\frac{5+3 k_{r}}{8}\right) \\
& k_{x t}=\left(\frac{2+2 k_{r}}{4}\right)
\end{aligned}
$$

A equação (3.78) é reescrita em função de $k_{x c o}$ e $k_{x t}$ por:

$$
l_{s}=\frac{4 \mu_{0}}{2 p q} N_{s f}^{2} L_{e f}\left[k_{x c o}\left(\frac{2 d_{3}}{3 b_{s 1}}\right)+\frac{d_{4}}{4 b_{s 1}}+k_{x t}\left(\frac{d_{2}}{b_{s 1}}+\frac{d_{1}}{b_{s 1}-b_{s}} \ln \left(\frac{b_{s 1}}{b_{s}}\right)+\frac{d_{0}}{b_{s}}\right)\right]
$$

$8 \frac{d_{1}}{b_{s 1}-b_{s}} \ln \left(\frac{b_{s 1}}{b_{s}}\right)$ Corresponde à permeância específica do trecho $d_{1}$ pela integral da força magnetomotriz no trecho, conforme apresentado em (LIPO, 2011, p. 166-168). Liwschitz em (LIWSCHITZ-GARIK e WHIPPLE, 1947, p. 6465) considera a queda de força magnetomotriz no caminho médio, portanto, considera a permeância especifica do trecho $d_{1}=\frac{2 d_{1}}{b_{s 1}+b_{s}}$

9 Para o cálculo da indutância de dispersão de ranhura, Liwschitz em (LIWSCHITZ-GARIK e WHIPPLE, 1950, p. 120), despreza o termo $h^{\prime}=d_{4}$, desta forma o termo $\frac{d_{4}}{4 b_{s 1}}$ não aparece em (4-13) - página 123. Esta consideração é, entretanto, explicita na versão em italiano do livro (LIWSCHITZ-GARIK, 1964, p. 53) e levada em consideração em (PYRHONEN, JOKINEN e HRABOVCOVÁ, 2014, p. 253-255), equação (4.83). 
No caso de ranhura retangular e aberta, $b_{s 1}=b_{s}$ e $d_{1}=d_{0}=0$.

$$
l_{s}=\frac{4 \mu_{0}}{2 p q} N_{s f}^{2} L_{e f}\left[k_{x c o}\left(\frac{2 d_{3}}{3 b_{s 1}}\right)+\frac{d_{4}}{4 b_{s 1}}+k_{x t}\left(\frac{d_{2}}{b_{s 1}}\right)\right]
$$

\subsubsection{Método geral para cálculo de $k_{r}$}

Assumindo $k_{r}{ }^{\prime}$ um fator de correção para a permeância específica mútua, devido à diferença entre as correntes nas bobinas superior e inferior na ranhura. Para cada ranhura, conforme sugerido em (LIWSCHITZ-GARIK e WHIPPLE, 1950) $k_{r}{ }^{\prime}=$ $\cos \left(\theta_{r}\right)$. Onde $\theta_{r}$ é a defasagem entre as correntes da bobina superior e inferior da ranhura. Para cálculo da indutância de dispersão de ranhura por fase considera-se o valor médio de $k_{r}$ 'para cada grupo de simetria do enrolamento. Portanto, $k_{r}=$ média $\left(k_{r}{ }^{\prime}\right)$.

No caso de máquinas com $q$ inteiro os enrolamentos são simétricos para cada dois polos e o número de ranhuras por fase por conjunto de simetria é igual $2 q$. Para $q$ fracionário, $q=\alpha / \beta$, os enrolamentos são simétricos a cada $\beta$ polos. Neste caso, o número total de ranhuras por fase por conjunto de simetria é igual $\alpha=\beta q$. Desta forma $k_{r}$ é calculado, independentemente do número de fases da máquina, por:

$$
\begin{gathered}
k_{r}=\frac{1}{2 q} \sum_{r=1}^{2 q} \cos \left(\theta_{r}\right), q \text { inteiro } \\
k_{r}=\frac{1}{\beta q} \sum_{r=1}^{\beta q} \cos \left(\theta_{r}\right), q=\frac{\alpha}{\beta}
\end{gathered}
$$

A defasagem entre as correntes na bobina superior e inferior da ranhura, entretanto, dependerá do número de fases e do encurtamento de passo.

\subsubsection{Cálculo de $k_{r}$ para máquinas elétricas trifásicas.}

Nesta secção, descreve-se a metodologia para cálculo de $k_{r}$ em função do passo de bobina (em percentagem do passo polar) para máquinas elétricas trifásicas. A metodologia aqui apresentada é estendida, nas secções seguintes, para máquinas elétricas com mais de três fases. Considerando enrolamento trifásico, o passo polar 
da máquina é dividido em $m=3$ setores (phase-belts, faixas de fase) conforme apresentado na Tabela 4.

Tabela $4-$ Setores associados à cada fase por passo polar.
\begin{tabular}{|c|c|c|c|}
\hline Setor $\left[{ }^{\circ}\right]$ & $0-60$ & $60-120$ & $120-180$ \\
\hline Fase & 1 & -3 & 2 \\
\hline Setor $\left[{ }^{\circ}\right]$ & $180-240$ & $240-300$ & $300-360$ \\
\hline Fase & -1 & 3 & -2 \\
\hline
\end{tabular}

Para máquinas trifásicas, três situações são possíveis:

i. Ranhura com bobinas das camadas superior e inferior de mesma fase. Neste caso $k_{r}{ }^{\prime}=1$. Este caso acontece para encurtamentos de passo no intervalo $] 0^{\circ}: 60^{\circ}$.

ii. Ranhura com bobinas das camadas superior e inferior com defasagem de $60^{\circ}$. Neste caso $k_{r}{ }^{\prime}=\cos \left(60^{\circ}\right)$. Tomando como exemplo a fase 1 , isto acontece quando bobinas da fase 1 compartilham a ranhura com bobinas da fase 3 com polaridade negativa $\left(60^{\circ}=240^{\circ}-180^{\circ}\right)$. Este caso acontece quando o encurtamento de passo pertence ao intervalo entre ] $0^{\circ}: 120^{\circ}[$.

iii. Ranhura com bobinas das camadas superior e inferior com defasagem de $120^{\circ}$. Neste caso $k_{r}{ }^{\prime}=\cos \left(120^{\circ}\right)$. Tomando como exemplo a fase 1 , isto acontece quando as bobinas da fase 1 compartilham ranhura com bobinas da fase 2. Isso acontece para encurtamentos de passo no intervalo entre [ $120^{\circ}: 180^{\circ}[$.

Para encurtamento de passo múltiplo de $180^{\circ} / \mathrm{m}$, neste caso $60^{\circ}$, todas as bobinas de uma fase compartilham ranhura com bobinas de outra fase. Por exemplo, para um encurtamento de passo de $60^{\circ}$, todas as bobinas da fase 1 compartilham ranhura com bobinas da fase -3 . Desta forma $k_{r}=\cos \left(60^{\circ}\right)$. Para encurtamento de passo igual a $120^{\circ}$ as bobinas da fase 1 compartilham todas as ranhuras com bobinas da fase 2 e, portanto, $k_{r}=\cos \left(120^{\circ}\right)$.

Caso o encurtamento de passo esteja entre múltiplos de $180 \% \mathrm{~m}$, duas situações são possíveis. Por exemplo, para um encurtamento de passo de $30^{\circ}$, metade das bobinas da fase 1 compartilham ranhura com bobinas, também, da fase 1 e a outra metade compartilha ranhura com bobinas da fase -3. Desta forma: $k_{r}=$ $\left[\cos \left(0^{\circ}\right)+\cos \left(60^{\circ}\right)\right] / 2$. A figura a seguir apresenta $k_{r}$ em função do passo de bobina $k_{c \%}$ : 
Figura 12 - Kr em função do passo de bobina para máquinas trifásicas.

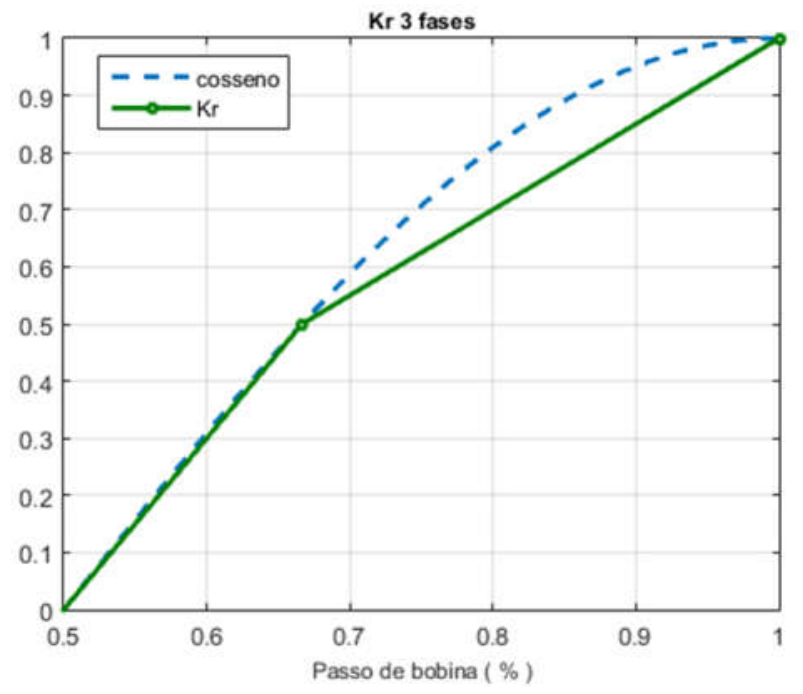

Considerando valores típicos de encurtamento de passo, descreve-se, normalmente, $k_{r}$ pela seguinte equação:

$$
k_{r}\left(\tau_{c \%}\right)=\frac{1}{2}\left(3 \tau_{c \%}-1\right) ; \frac{2}{3} \leq \tau_{c \%}<1
$$

Salienta-se, entretanto, que a equação (3.85) é apenas a equação da reta entre os pontos $(1,1)$ e $(2 / 3,0.5)$ da Figura 12 . A curva tracejada em azul corresponde à função cosseno de acordo com:

$$
f\left(\tau_{c \%}\right)=\cos \left[\pi\left(1-\tau_{c \%}\right)\right]
$$

\subsubsection{Cálculo de $k_{r}$ para máquinas elétricas de 5, 6 e 7 fases}

Para máquinas de cinco e sete fases, os setores associados a cada fase são apresentados nas tabelas a seguir:

Tabela 5 - Fases associadas à cada setor por passo polar para máquina de 5 fases.

\begin{tabular}{|c|c|c|c|c|c|}
\hline Setor $\left[{ }^{\circ}\right]$ & $0-36$ & $36-72$ & $72-108$ & $108-144$ & $144-180$ \\
\hline Fase & 1 & -4 & 2 & -5 & 3 \\
\hline Setor $\left[{ }^{\circ}\right]$ & $180-216$ & $216-252$ & $252-288$ & $288-324$ & $324-360$ \\
\hline Fase & -1 & 4 & -2 & 5 & -3 \\
\hline
\end{tabular}

Tabela 6 - Possíveis configurações de ranhura para fase 1 e valores de $\boldsymbol{\theta}_{\boldsymbol{r}}$ para máquina de 5 fases.

\begin{tabular}{|c|c|c|c|c|c|}
\hline Ranhura & $1 \& 1$ & $1 \&-4$ & $1 \& 2$ & $1 \&-5$ & $1 \& 3$ \\
\hline $\boldsymbol{\theta}_{\boldsymbol{r}}\left[^{\circ}{ }^{\circ}\right.$ & 0 & 36 & 72 & 108 & 144 \\
\hline
\end{tabular}


Tabela 7 - Fases associadas à cada setor por passo polar para máquina de 7 fases.

\begin{tabular}{|c|c|c|c|c|c|c|c|}
\hline Setor $\left[{ }^{\circ}\right]$ & $0-25.7$ & $25.7-51.4$ & $51.4-77.1$ & $77.1-102.9$ & $102.9-128.6$ & $128.6-154.3$ & $154.3-180$ \\
\hline Fase & 1 & -5 & 2 & -6 & 3 & -7 & 4 \\
\hline Setor $\left[{ }^{\circ}\right]$ & $180-205.7$ & $205.7-231.4$ & $231.4-257.1$ & $257.1-282.9$ & $282.9-308.6$ & $308.6-334.3$ & $334.3-360$ \\
\hline Fase & -1 & 5 & -2 & 6 & -3 & 7 & -4 \\
\hline
\end{tabular}

Tabela 8 - Possíveis configurações de ranhura para fase 1 e valores de $\boldsymbol{\theta}_{\boldsymbol{r}}$ para máquinas de 7 fases.

\begin{tabular}{|c|c|c|c|c|c|c|c|}
\hline Ranhura & $1 \& 1$ & $1 \&-5$ & $1 \& 2$ & $1 \&-6$ & $1 \& 3$ & $1 \&-7$ & $1 \& 4$ \\
\hline $\boldsymbol{\theta}_{\boldsymbol{r}}\left[{ }^{\circ}{ }^{\circ}\right.$ & 0 & 25.71 & 51.43 & 77.14 & 102.86 & 128.57 & 154.29 \\
\hline
\end{tabular}

Em ambos os casos, é possível provar que este é um resultado geral para máquinas com faixa de fase $180 \% \mathrm{~m}$, os possíveis valores de $\theta_{r}$ são definidos pela seguinte relação:

$$
\boldsymbol{\theta}_{\boldsymbol{r}}=\left[0, \frac{\pi}{m}, 2 \frac{\pi}{m},(m-1) \frac{\pi}{m}\right]
$$

Para máquinas de seis fases, a configuração simétrica com faixa de fase de $180 \%$ pode não ser possível ou desejável. Para máquinas elétricas com número par de fases a configuração simétrica com faixa de fase de $180 \% \mathrm{~m}$ é inconveniente pois o mesmo setor do passo polar teria que ser compartilhado entre duas fases distintas e o setor adjacente ficaria vazio. Para exemplificar este aspecto é apresentada na tabela a seguir como seria a distribuição fases por setor do passo polar para máquina de seis fases simétricas com faixa de fase de $30^{\circ}$.

Tabela 9 - Fases associadas à cada setor do passo polar, máquina de 6 fases simétricas, faixa de fase de $30^{\circ}$.

\begin{tabular}{|c|c|c|c|c|c|c|}
\hline Setor $\left[{ }^{\circ}\right]$ & $0-30$ & $30-60$ & $60-90$ & $90-120$ & $120-150$ & $150-180$ \\
\hline Fase & $1 /-4$ & & $2 /-5$ & & $3 /-6$ & \\
\hline Setor $\left[{ }^{\circ}\right]$ & $180-210$ & $210-240$ & $240-270$ & $270-300$ & $300-330$ & $330-360$ \\
\hline Fase & $4 /-1$ & & $5 /-2$ & & $6 /-3$ & \\
\hline
\end{tabular}

Tabela 10 - Fases associadas à cada setor do passo polar, máquina de 6 fases simétricas, faixa de fase de $60^{\circ}$.

\begin{tabular}{|c|c|c|c|}
\hline Setor $\left[{ }^{\circ}\right]$ & $0-60$ & $60-120$ & $120-180$ \\
\hline Fase & $1 /-4$ & $2 /-5$ & $3 /-6$ \\
\hline Setor $\left[{ }^{\circ}\right]$ & $180-240$ & $240-300$ & $300-360$ \\
\hline Fase & $4 /-1$ & $5 /-2$ & $6 /-3$ \\
\hline
\end{tabular}

Na prática constrói-se máquinas de seis fases simétricas com faixa de fase de $60^{\circ}\left(360^{\circ} / \mathrm{m}\right)$, neste caso as fases associadas a cada setor do passo polar estarão de acordo com a Tabela 10: 
Para construção de máquinas elétricas de seis fases com faixa de fase de $180 \%$, tipicamente, utiliza-se a configuração assimétrica do tipo $N$-star. Esta configuração é composta por $\mathrm{N}$ grupos de enrolamentos trifásicos defasados entre si por uma faixa de fase. Desta maneira, para a máquina de seis fases assimétrica, 2star, as fases associadas por setor e os possíveis valores de $\theta_{r}$ são apresentados nas tabelas a seguir:

Tabela 11 - Fases associadas à cada setor por passo polar para máquina de 6 fases 2-star.

\begin{tabular}{|c|c|c|c|c|c|c|}
\hline Setor $\left[{ }^{\circ}\right]$ & $0-30$ & $30-60$ & $60-90$ & $90-120$ & $120-150$ & $150-180$ \\
\hline Fase & 1 & 4 & -3 & -6 & 2 & 5 \\
\hline Setor $\left[{ }^{\circ}\right]$ & $180-210$ & $210-240$ & $240-270$ & $270-300$ & $300-330$ & $330-360$ \\
\hline Fase & -1 & -4 & 3 & 6 & -2 & -5 \\
\hline
\end{tabular}

Tabela 12 - Possíveis configurações de ranhura para fase 1 e valores de $\theta_{r}$ para máquinas de 6 fases 2-star.

\begin{tabular}{|c|c|c|c|c|c|c|}
\hline Ranhura & $1 \& 1$ & $1 \& 4$ & $1 \&-3$ & $1 \&-6$ & $1 \& 2$ & $1 \& 5$ \\
\hline $\boldsymbol{\theta}_{\boldsymbol{r}}\left[{ }^{\circ}\right]$ & 0 & 30 & 60 & 90 & 120 & 150 \\
\hline
\end{tabular}

Observa-se que os possíveis valores $\theta_{r}$ para máquina de seis fases 2-star são descritos pela relação (3.87). Aplicando a mesma metodologia apresentada para o caso trifásico pode-se estabelecer a relação entre $k_{r}$ e $\tau_{c \%}$, conforme apresentado nas figuras a seguir:

Figura $13-\mathrm{Kr}$ em função do passo de bobina para máquinas de 5 e 6 fases.
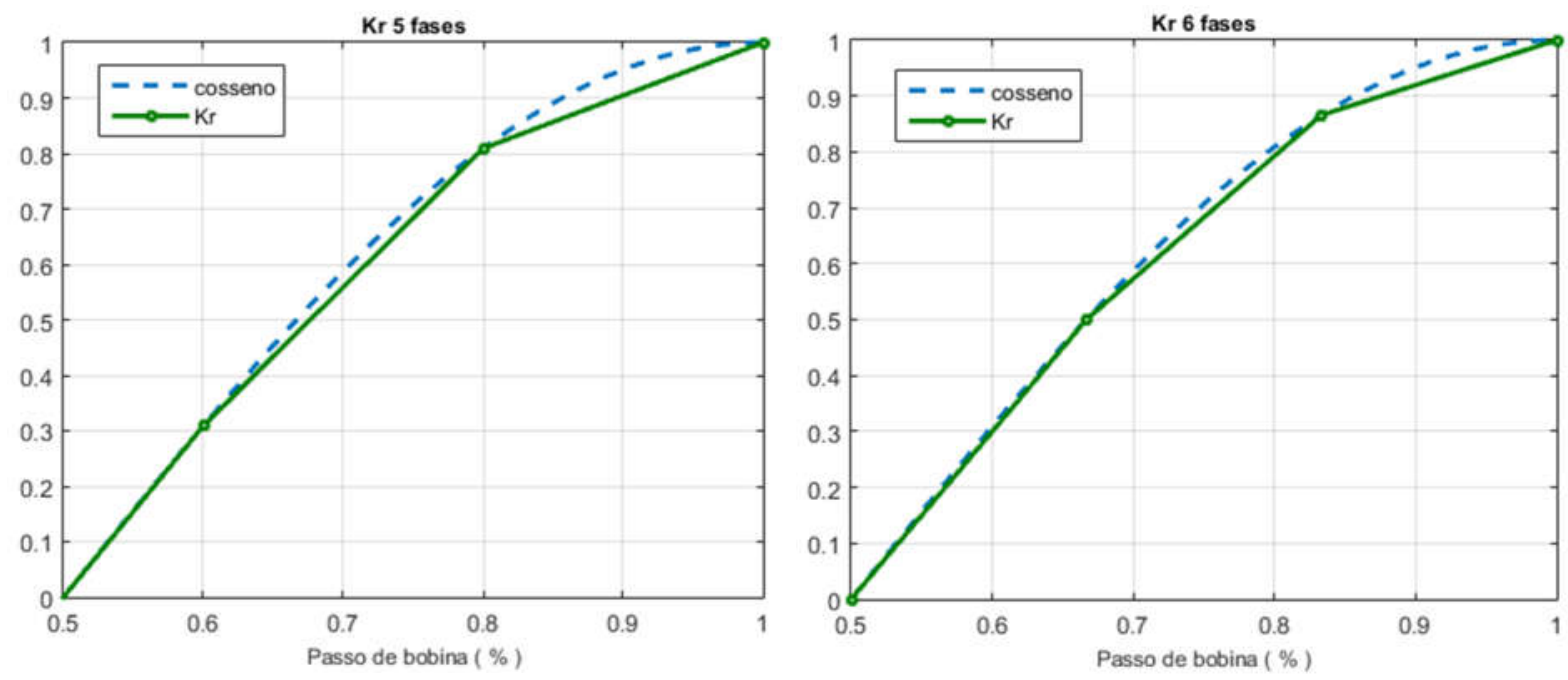
Figura $14-\boldsymbol{k}_{\boldsymbol{r}}$ em função de $\boldsymbol{\tau}_{\boldsymbol{c} \%}$ para máquina de 7 fases.

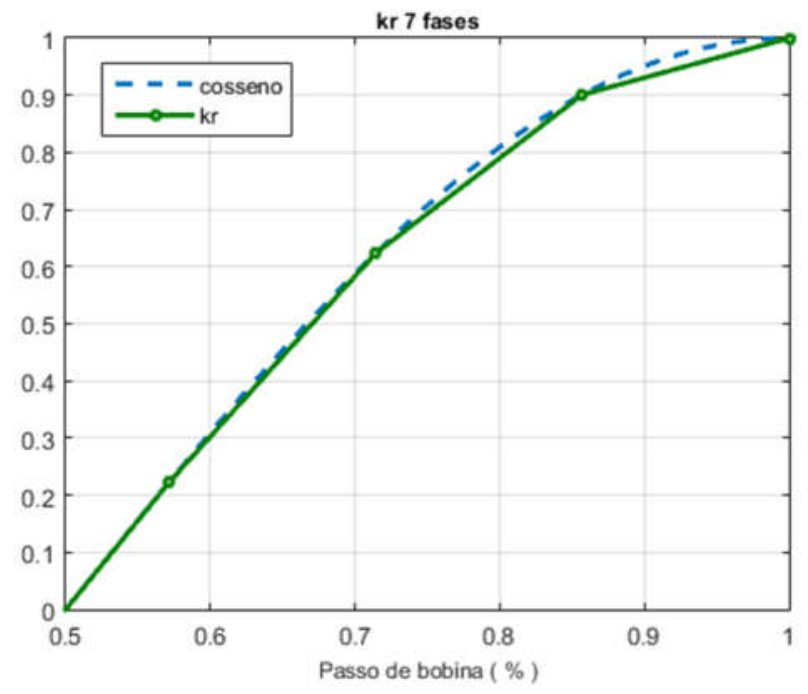

Analisando-se as figuras 25 e 26 , observa-se que a função $k_{r}\left(\tau_{c \%}\right)$ consiste na discretização da função cosseno, equação (3.86), em passos de 1/m.

Para valores típicos de encurtamento de passo, calcula-se $k_{r}\left(\tau_{c \%}\right)$ para máquinas de 5, 6 (2-star) e 7 fases de acordo com as relações apresentadas na tabela a seguir:

Tabela $13-k_{r}\left(\tau_{c \%}\right)$ para máquinas de 5,6 (2-star) e 7 fases.

\begin{tabular}{|c|c|c|}
\hline № Fases & $\boldsymbol{k}_{\boldsymbol{r}}\left(\boldsymbol{\tau}_{\boldsymbol{c} \%}\right)$ & $\boldsymbol{\tau}_{\boldsymbol{c} \%}$ Intervalo \\
\hline 5 & $\begin{array}{l}f_{1}=0,9549 \tau_{c \%}+0,0451 \\
f_{2}=2,5 \tau_{c \%}-1,1910\end{array}$ & $\begin{array}{l}\text { 1. }[4 / 5 ; 1,00] \\
\text { 2. }[3 / 5 ; 4 / 5]\end{array}$ \\
\hline ,6 (2-STAR) & $\begin{array}{l}f_{1}=3(2-\sqrt{3}) \tau_{c \%}+3 \sqrt{3}-5 \\
f_{2}=3(\sqrt{3}-1) \tau_{c \%}+2.5-2 \sqrt{3}\end{array}$ & $\begin{array}{l}\text { 1. }[5 / 6 ; 1,00] \\
\text { 2. }[4 / 6 ; 5 / 6]\end{array}$ \\
\hline 7 & $\begin{array}{l}f_{1}=0,9549 \tau_{c \%}+0,0451 \\
f_{2}=2,5 \tau_{c \%}-1,1910\end{array}$ & $\begin{array}{l}\text { 1. }[6 / 7 ; 1,00] \\
\text { 2. }[5 / 7 ; 6 / 7]\end{array}$ \\
\hline
\end{tabular}

3.7.4 Cálculo de $k_{r}$ para máquinas elétricas de nove ou mais fases

Para máquinas de nove fases, as configurações simétrica e assimétrica (3-star) são possíveis. Seguindo a mesma metodologia aplicada às máquinas com menor número de fases é possível demonstrar que os valores de $\theta_{r}$ são iguais para ambos os casos e estão de acordo com a expressão (3.87). Este resultado significa que para o mesmo encurtamento de passo, a máquina simétrica e assimétrica terá o mesmo valor de $k_{r}$. 
Tabela 14 - Fases associadas à cada setor por passo polar para máquina de 9 fases simétrica.

\begin{tabular}{|c|c|c|c|c|c|c|c|c|c|}
\hline Setor $\left[{ }^{\circ}{ }\right]$ & $0-20$ & $20-40$ & $40-60$ & $60-80$ & $80-100$ & $100-120$ & $120-140$ & $140-160$ & $160-180$ \\
\hline Fase & 1 & -6 & 2 & -7 & 3 & -8 & 4 & -9 & 5 \\
\hline Setor $\left[{ }^{\circ}\right]$ & $180-200$ & $200-220$ & $220-240$ & $240-260$ & $260-280$ & $280-300$ & $300-320$ & $320-340$ & $340-360$ \\
\hline Fase & -1 & 6 & -2 & 7 & -3 & 8 & -4 & 9 & -5 \\
\hline
\end{tabular}

Tabela 15 - Possíveis configurações de ranhura para fase 1 e valores de $\theta_{r}$ para máquinas de 9 fases simétrica.

\begin{tabular}{|c|c|c|c|c|c|c|c|c|c|}
\hline Ranhura & $1 \& 1$ & $1 \&-6$ & $1 \& 2$ & $1 \&-7$ & $1 \& 3$ & $1 \&-8$ & $1 \& 4$ & $1 \&-9$ & $1 \& 5$ \\
\hline $\boldsymbol{\theta}_{\boldsymbol{r}}\left[{ }^{\circ}\right]$ & 0 & 20 & 40 & 60 & 80 & 100 & 120 & 140 & 160 \\
\hline
\end{tabular}

Tabela 16 - Fases associadas à cada setor por passo polar para máquina de 9 fases 3-star.

\begin{tabular}{|c|c|c|c|c|c|c|c|c|c|}
\hline Setor $\left[{ }^{\circ}\right]$ & $0-20$ & $20-40$ & $40-60$ & $60-80$ & $80-100$ & $100-120$ & $120-140$ & $140-160$ & $160-180$ \\
\hline Fase & 1 & 4 & 7 & -3 & -6 & -9 & 2 & 5 & 8 \\
\hline Setor $\left[{ }^{\circ}\right]$ & $180-200$ & $200-220$ & $220-240$ & $240-260$ & $260-280$ & $280-300$ & $300-320$ & $320-340$ & $340-360$ \\
\hline Fase & -1 & -4 & -7 & 3 & 6 & 9 & -2 & -5 & -8 \\
\hline
\end{tabular}

Tabela 17 - Possíveis configurações de ranhura para fase 1 e valores de $\theta_{r}$ para máquinas de 9 fases 3-star.

\begin{tabular}{|c|c|c|c|c|c|c|c|c|c|}
\hline Ranhura & $1 \& 1$ & $1 \& 4$ & $1 \& 7$ & $1 \&-3$ & $1 \&-6$ & $1 \&-9$ & $1 \& 2$ & $1 \& 5$ & $1 \& 8$ \\
\hline $\boldsymbol{\theta}_{\boldsymbol{r}}\left[{ }^{\circ}\right]$ & 0 & 20 & 40 & 60 & 80 & 100 & 120 & 140 & 160 \\
\hline
\end{tabular}

Figura 15 - Kr em função do passo de bobina para máquinas elétricas de 9 fases simétrica ou assimétrica 3-star.

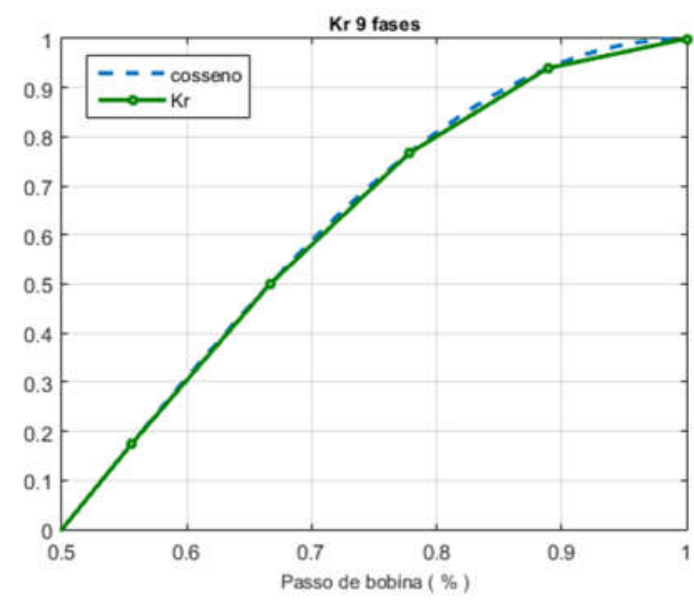

Conforme o número de fases aumenta a diferença entre $k_{r}\left(\tau_{c \%}\right)$ e a função cosseno torna-se desprezível. Desta forma:

$$
k_{r}\left(\tau_{c \%}\right) \approx \cos \left[\pi\left(1-\tau_{c \%}\right)\right]
$$

O autor em (CORDOVIL e CHABU, 2016) recomenda a utilização da equação (3.88) para máquinas de 9 ou mais fases. É possível demonstrar que ao se utilizar esta simplificação o erro de cálculo em $k_{x c o}$ e $k_{x t}$ é sempre inferior a $1 \%$. Este 
resultado é valido para máquinas elétricas multifásicas com número de fases ímpar, simétricas ou $\mathrm{N}$-star, e para máquinas elétricas multifásicas, com número par do tipo N-star.

Alternativamente, pode-se recorrer a um grupo de equações lineares para a caracterização de $k_{r}\left(\tau_{c \%}\right)$, conforme apresentado para máquinas de 3, 5, 6 (2-star) e 7 fases. Para máquinas com faixa de fase de $180 \% \mathrm{~m}$ e possíveis valores de $\theta_{r}$ de acordo com (3.87), o grupo genérico de equações lineares para caracterização de $k_{r}\left(\tau_{c \%}\right)-f_{1}, f_{2} \ldots f_{n}$ - é calculado por:

$$
\begin{gathered}
f_{n+1}=a_{n+1} \tau_{c \%}+b_{n+1} \\
a_{n+1}=m\left[\cos \left(\pi \frac{n}{m}\right)-\cos \left(\pi \frac{n+1}{m}\right)\right] \\
b_{n+1}=\cos \left(\pi \frac{n}{m}\right)-a_{n+1}\left(1-\frac{n}{m}\right) \\
n=0,1,2 \ldots(m-1)
\end{gathered}
$$

Onde $k_{r}\left(\tau_{c \%}\right)$ é igual a $f_{n+1}$ para $\tau_{c \%}$ no intervalo $\left[1-\frac{n+1}{m}, 1-\frac{n}{m}\right]$.

\subsection{DEMAIS INDUTÂNCIAS DE DISPERSÃO}

3.8.1 Indutância de dispersão de topo de dente.

A indutância de dispersão de topo de dente é calculada de acordo com a seguinte relação (LIWSCHITZ-GARIK e WHIPPLE, 1947, p. 69-70):

$$
l_{t t}=\frac{4 \mu_{0}}{2 p q} N_{s f}^{2} L_{e f}\left[\left(\frac{5 \frac{l_{g}}{b_{s}}}{5+4 \frac{l_{g}}{b_{s}}}\right) k_{x t} \frac{\tau_{\text {shoe }}}{\tau_{p}}\right]
$$

No caso de enrolamento de camada simples ou de passo pleno $k_{x t}=1$. Para máquinas de polos lisos $\tau_{\text {shoe }}=\tau_{p}$. Embora a equação (3.93) seja idêntica a equação utilizada para máquinas elétricas trifásicas, o impacto do enrolamento multifásico ocorre no cálculo de $k_{x t}$, conforme discutido na secção anterior. 


\subsubsection{Indutância de dispersão harmônica}

A indutância de dispersão harmônica é calculada de acordo com (3.94) (LIPO, 2011, p. 201-204):

$$
l_{b l}=L_{m} \frac{1}{k_{e 1}^{2}}\left[\sum_{h=2}^{\infty}\left(\frac{k_{e h}}{h}\right)^{2}\right]
$$

Caso a máquina possua enrolamentos amortecedores, ou gaiola de esquilo, a (PONOMAREV, ALEXANDROVA, et al., 2014), (LIPO, 2011, p. 204) indutância de dispersão harmônica é em geral desprezível, uma vez que os enrolamentos amortecedores estabelecem um caminho de impedância aproximadamente zero para as componentes harmônicas de campo. A indutância de dispersão harmônica é mais relevante para máquinas de pequeno entreferro (elevada indutância de magnetização).

Para máquinas elétricas multifásicas ou com $q$ fracionário, o autor desconhece equações analíticas para o somatório apresentado em (3.94). Nestes casos, portanto, para o cálculo da indutância de dispersão harmônica considera-se suficiente o cálculo do somatório até a harmônica de ordem $\sim 50$. Um método analítico para o cálculo do somatório (3.94) para máquinas trifásicas com $q$ inteiro é apresentado em (GIERAS e WING, 2002, p. 548-549).

Conforme comentado anteriormente, máquinas elétricas multifásicas com enrolamentos distribuídos e com onda de FMM simétrica, só apresenta harmônicas espaciais de ordem $h=2 \mathrm{~km} \pm 1$ (pressuposto de corrente senoidal). Desta forma, a redução da indutância de dispersão harmônica torna-se evidente.

\subsection{NÚMERO DE PARES DE POLOS}

Ao se aumentar o número de fases da máquina, em geral, existirá uma tendência para projetar geradores com passos polares maiores. Como consequência, o número de pares de polos que podem ser acomodados um certo valor de $D_{g}$ será reduzido. Isso pode ser compreendido, de forma simples, ao se analisar a seguinte relação entre $\tau_{p}, q$ e $\tau_{s}:$ 


$$
\tau_{p}=m q \tau_{s}
$$

Evidentemente, há um valor mínimo para o passo de ranhura uma vez que a ranhura precisa ter espaço suficiente para os enrolamentos do gerador. Desta forma, para $q$ fixo, $\tau_{p}$ será tanto maior quanto maior o número de fases da máquina. $\mathrm{A}$ equação (3.95) pode ser reescrita de forma a se estabelecer um limite superior para o número de pares de polos, considerando valores específicos para $D_{g}, q$ e para o passo de ranhura mínimo $\tau_{S_{-} \text {min }}$ :

$$
p<\frac{\pi D_{g}}{2 m q \tau_{s \_m i n}}
$$

A tendência para a redução do número de pares de polos que o gerador pode acomodar com o aumento do seu número de fases é uma desvantagem de máquinas elétricas multifásicas para turbinas eólicas do tipo direct-drive. Geradores síncronos de baixa velocidade precisam ter um número elevado de pares de polos por conta da redução da performance dos conversores eletrônicos de potência em baixos valores de frequência elétrica. Este aspecto é comentado com mais detalhes no Apêndice $A$.

Tipicamente dimensiona-se geradores direct-drive para atingirem frequência elétrica nominal de pelo menos $15 \mathrm{~Hz}$. Assumindo rotação nominal entre $9.0 \mathrm{e}$ 9.5RPM, o número de pares de polos requeridos para aplicações de $10 \mathrm{MW}$ será em torno de $p=100$.

O projeto a máquina com passo polar maior pode ainda aumentar a massa ativa do gerador e, consequentemente, reduzir a sua densidade de torque/potência. Isso pode ser observado ao se analisar as relações (3.44) e (3.45), onde é explícito que as dimensões das coroas estatórica e rotórica são inversamente proporcionais ao número de pares de polos.

\subsection{RESISTÊNCIA ELÉTRICA}

A resistência elétrica por fase do estator da máquina é calculada em termos do número de espiras conectadas em série por fase $N_{s f}$, do número de grupos conectados em paralelo $N_{g p}$, da resistividade elétrica do cobre $\rho_{c u}$, do comprimento médio da bobina $l_{b m}$ e da área do cobre na ranhura $A_{c u}$ (LIPO, 2011, p. 264). 


$$
R_{f}=\frac{N_{s f}}{N_{g p}} \rho_{c u} \frac{l_{b m}}{A_{c u}}
$$

A área do cobre é definida em função da área da ranhura, do fator de preenchimento e do número de condutores por ranhura $n_{s}$.

$$
\begin{gathered}
A_{c u}=\frac{A_{s} k_{\text {pre }}}{n_{s}} \\
A_{c u}=\frac{A_{s} k_{p r e}}{\frac{2 N_{g p} N_{s f}}{2 p q}} \\
A_{c u}=\frac{p q A_{s} k_{p r e}}{N_{g p} N_{s f}}
\end{gathered}
$$

Desta forma, a resistência elétrica por fase pode ser calculada por:

$$
R_{f}=\frac{N_{s f}^{2}}{p q} \rho_{c u} \frac{l_{b m}}{A_{s} k_{p r e}}
$$

O valor de $A_{s} k_{\text {pre }}$ pode ser substituído por $I_{r} / J_{r}$, segundo (3.36):

$$
\begin{gathered}
R_{f}=\frac{N_{s f}^{2}}{p q} \rho_{c u} \frac{l_{b m}}{\left(\frac{I_{r}}{J_{r}}\right)} \\
R_{f}=\frac{N_{s f}^{2}}{p q} \rho_{c u} \frac{l_{b m} J_{r}}{\left(\frac{A_{q} \pi D_{g}}{N_{s}}\right)} \\
R_{f}=\frac{2 m N_{s f}^{2}}{\pi D_{g}} \frac{J_{r}}{A_{q}} \rho_{c u} l_{b m}
\end{gathered}
$$

O comprimento médio da bobina é estimado pela seguinte relação:

$$
l_{b m}=2 L+4\left(l_{e 2}+l_{e 3}\right)
$$

Os parâmetros $l_{e 2}$ e $l_{e 3}$ são definidos na Figura 16 . 
Figura 16 - Cabeça de bobina.

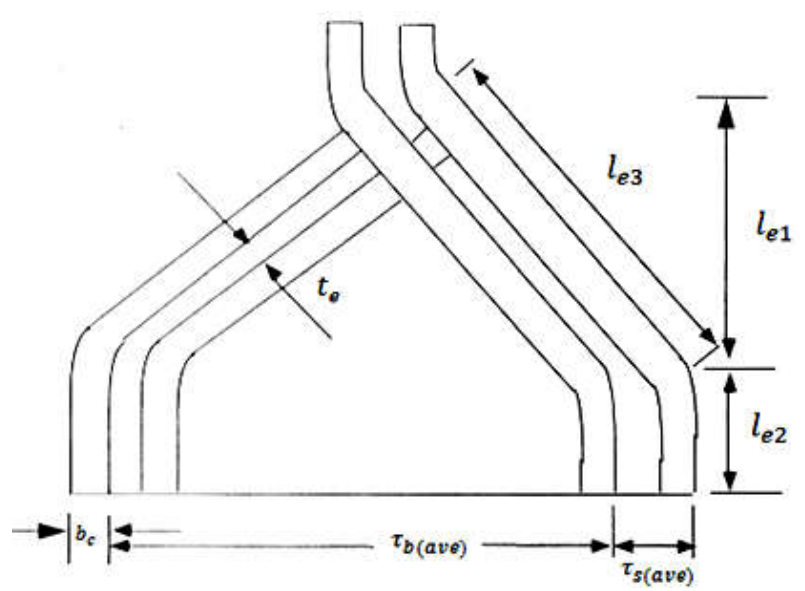

Fonte: adaptado de (LIPO, 2011, p. 199).

O valor de $l_{e 2}$ pode ser estimado segundo (10.63) ou (10.64), $l_{e 3}$ é calculado por (LIPO, 2011, p. 261):

$$
l_{e 3}=\frac{\tau_{b(\text { ave })}}{2} \frac{\tau_{s(\text { ave })}}{\sqrt{\tau_{s(\text { ave })}{ }^{2}-\left(b_{c}+t_{e}\right)^{2}}}
$$

De forma alternativa, para o projeto inicial da máquina, pode-se recorrer às seguintes equações (UPADHYAY, 2008, p. 124):

$$
\begin{gathered}
l_{b m}=2\left(L+1.25 \tau_{p}+\frac{V_{n}+3}{100}\right) \\
l_{b m}=2\left(L+1.25 \tau_{p}+\frac{3 V_{n}+10}{100}\right)
\end{gathered}
$$

Onde (3.103) é usada para máquinas de tensão inferior a $3 k V$ e (3.104) para máquinas de tensão superior à $3 \mathrm{kV}$. Em (3.103) e em (3.104), a tensão nominal da máquina $V_{n}$ deve ser expressa em escrito em $k V$ eficaz.

O valor da resistividade elétrica do cobre $\rho_{c u}$ deve ser utilizado para a temperatura nominal de operação da máquina, tipicamente entre 75 e $120^{\circ} \mathrm{C}$. A resistividade do cobre em função da temperatura é calculada por (FEUP):

$$
\rho_{c u}(T)=\rho_{c u 0}(1+\alpha \Delta T)
$$


Onde, $\rho_{c u 0}$ é a resistividade do cobre para $T=0^{\circ} \mathrm{C}, 1.6 \Omega \mathrm{m} 10^{-8}, \alpha=0.0039$ $\Omega \mathrm{m} 10^{-8} / K$, e $\Delta T$ é a diference de temperatura em relação a $0^{\circ} \mathrm{C}$. A resistência elétrica pode ainda ser calculada em seu valor por unidade $r_{f}$ dividindo-se (3.100) por (3.47):

$$
\begin{gathered}
r_{f}=\frac{\frac{2 m N_{s f}^{2}}{\pi D_{g}} \frac{J_{r}}{A_{q}} \rho_{c u} l_{b m}}{\frac{2 m \sqrt{2} k_{e 1} N_{s f}{ }^{2} L_{e f} B_{g}}{A_{q}} f_{m e c}} \\
r_{f}=\frac{J_{r}}{\sqrt{2} k_{e 1} \pi D_{g} B_{g} f_{m e c}} \rho_{c u} \frac{l_{b m}}{L_{e f}}
\end{gathered}
$$

\subsection{DENSIDADE DE PERDAS NO COBRE}

Nesta secção é definido o parâmetro $K_{j}$ que corresponde à densidade de perdas no cobre do estator em relação à área delimitada pelo entreferro da máquina. Este parâmetro é relacionado com a capacidade de dissipação de calor da máquina elétrica e é aproximadamente constante, independentemente das dimensões da máquina, para uma estratégia específica de refrigeração (PELLEGRINO, 2016, p. 30).

$$
\begin{gathered}
K_{j}=\frac{m R_{p h} I_{f}^{2}}{\pi D_{g} L} \\
K_{j}=\frac{m\left[\frac{2 m N_{s f}^{2}}{\pi D_{g}} \frac{J_{r}}{A_{q}} \rho_{c u} l_{b m}\right]\left(\frac{A_{q} \pi D_{g}}{2 m N_{s f}}\right)^{2}}{\pi D_{g} L} \\
K_{j}=\rho_{c u} J_{r} A_{q} \frac{l_{b m}}{2 L}\left[\frac{W}{m^{2}}\right]
\end{gathered}
$$

Valores de referência para $K_{j}$ são apresentados na tabela a seguir:

Tabela 18 - Valores de referência para $\boldsymbol{K}_{\boldsymbol{j}}$ (PELLEGRINO, 2016, p. 29)

\begin{tabular}{|l|l|}
\hline $\boldsymbol{K}_{\boldsymbol{j}}\left(\boldsymbol{k W} / \boldsymbol{m}^{\mathbf{2}}\right)$ & Refrigeração \\
\hline $1.5-3.0$ & Fechada \\
\hline $5.0-12.0$ & Ventilação forçada \\
\hline $12.0-20.0$ & Líquido \\
\hline
\end{tabular}




\subsection{PERDAS NO FERRO}

Para cálculo das perdas no ferro recorre-se a seguinte relação:

$$
P_{f e}=k_{1} f_{e} B^{\alpha}+k_{2} f_{e}^{2} B^{2}[W / k g]
$$

O primeiro termo corresponde às perdas por histerese, onde $\alpha$ assume valores entre 1.5 e 2.2. O segundo termo corresponde às perdas Foucault. $O$ valor das perdas no ferro total no ferro para condições específicas de frequência elétrica e indução magnética são normalmente fornecidos pelos fabricantes das chapas de aço.

Neste trabalho, assume-se $\alpha=2$ e considera-se para o estator da máquina o aço-silício do tipo $M-15(0.46 \mathrm{~mm})$ com os parâmetros descritos na tabela a seguir (AK STEEL, 2007):

Tabela 19 - Parâmetros do Aço-Silício M-15

\begin{tabular}{|c|c|c|}
\hline \multicolumn{3}{|c|}{ Aço Silício - M15 (0.46mm) } \\
\hline Parâmetro & Valor & Unidade \\
\hline Densidade $\left(\rho_{f e}\right)$ & 7.65 & $\mathrm{~g} / \mathrm{cm}^{3}$ \\
\hline$P_{f e}(50 \mathrm{~Hz}, 1.5 \mathrm{~T})$ & 2.79 & $\mathrm{~W} / \mathrm{kg}$ \\
\hline$P_{f e}(60 \mathrm{~Hz}, 1.5 \mathrm{~T})$ & 3.53 & $\mathrm{~W} / \mathrm{kg}$ \\
\hline$k_{1}$ & 0.017977 & - \\
\hline$k_{2}$ & 0.0001359 & - \\
\hline
\end{tabular}

Figura 17 - Perdas no Aço Silício M-15 0.46mm

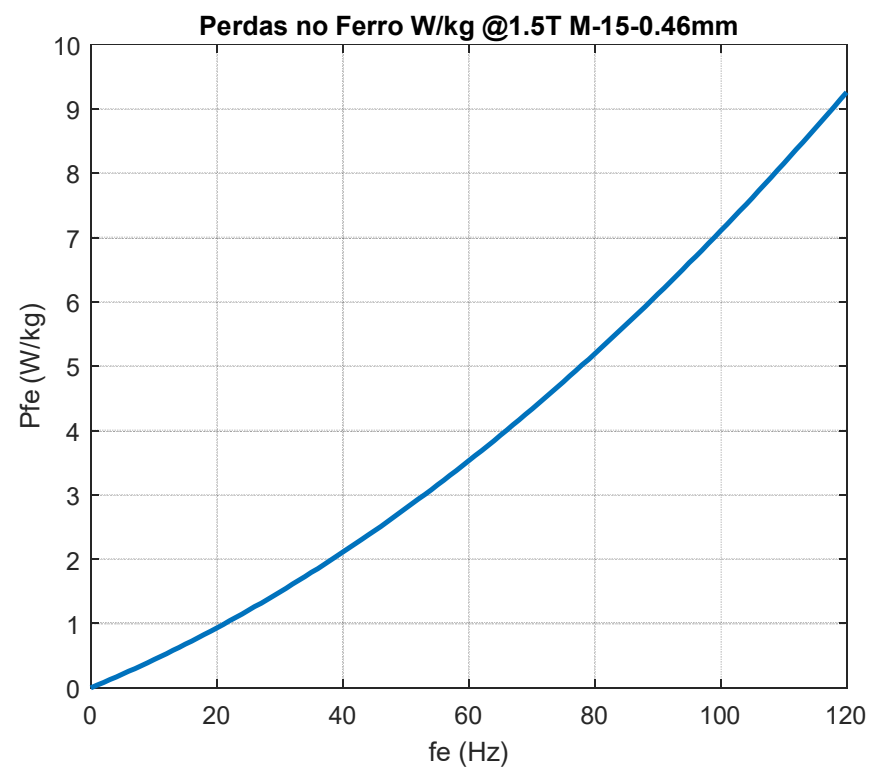




\section{MODELAGEM DE TURBINA EÓLICA}

Neste capítulo serão apresentadas as considerações adotadas para modelagem da turbina eólica de 10MW. Estes parâmetros definem as hipóteses iniciais para o projeto dos geradores elétricos que serão estudados nos capítulos a seguir.

\subsection{CONVERSÃO DE ENERGIA}

Primeiramente é necessário introduzir os principais fatores que permitem a modelagem da turbina eólica. A potência eólica disponível no volume de ar que cruza, perpendicularmente, a área do rotor da turbina é calculada por (MANWELL, MCGOWAN e ROGERS, 2002):

$$
P_{u}=\frac{1}{2} \rho \pi R^{2} U^{3}
$$

Onde $\rho$ é a massa específica do ar, $R$ é o raio do rotor da turbina e $U$ é a velocidade do vento. A razão entre a potência mecânica extraída pela da turbina $\left(T_{t} \omega_{t}\right)$ e a potência disponível no vento é conhecida por coeficiente de potência $C_{p}$. Desta forma (BURTON, SHARPE, et al., 2001, p. 44-45):

$$
P_{t}=C_{p} \frac{1}{2} \rho \pi R^{2} U^{3}
$$

O coeficiente de potência mecânico da turbina eólica é função do ângulo de pitch $\beta$ das pás da turbina e do parâmetro $\lambda$ - Tip speed ratio - corresponde à razão entre a velocidade da ponta da pá $\left(\omega_{t} R\right)$ e a velocidade do vento $U$ (HEIER, 2006, p. 40-44).

$$
\lambda=\frac{\omega_{t} R}{U}
$$

Assumindo operação com $\beta$ constante, há uma rotação ótima da turbina eólica que maximiza a extração da energia mecânica do vento. Em outras palavras, existe um valor ótimo de $\lambda=\lambda_{\text {opt }}$ para o qual $C_{p}=C_{\text {pmax }}$. $\mathrm{O}$ valor máximo teórico para o coeficiente de potência é igual a 59.3\% (16/27), conhecido como limite de Betz (BURTON, SHARPE, et al., 2001, p. 45). 
A equação da potência da turbina pode ser escrita em função de $\lambda$ :

$$
\begin{gathered}
P_{t}=C_{p}(\beta, \lambda) \frac{1}{2} \rho \pi R^{2}\left(\frac{\omega_{t} R}{\lambda}\right)^{3} \\
P_{t}=C_{p}(\beta, \lambda) \frac{1}{2} \frac{\rho \pi R^{5}}{\lambda^{3}} \omega_{t}^{3}
\end{gathered}
$$

Uma vez que $P_{t}=T_{t} \omega_{t}$ :

$$
T_{t}=C_{p}(\beta, \lambda) \frac{1}{2} \frac{\rho \pi R^{5}}{\lambda^{3}} \omega_{t}^{2}
$$

Para operação com $\beta$ constante, é possível estabelecer uma relação, entre torque e rotação da turbina eólica, ótima para máxima extração de energia do vento (MANWELL, MCGOWAN e ROGERS, 2002, p. 360).

$$
T_{\text {opt }}=C_{p_{-} \max } \frac{1}{2} \frac{\rho \pi R^{5}}{\lambda_{\text {opt }}{ }^{3}} \omega_{t}^{2}
$$

Como será discutido na secção a seguir, a equação (4.7) é tipicamente utilizada para o controle da turbina eólica em condições de vento de baixa velocidade.

\subsection{MODOS DE OPERAÇÃO}

Turbinas eólicas de velocidade variável, normalmente, apresentam três modos distintos de operação, Figura 18, (MANWELL, MCGOWAN e ROGERS, 2002, p. 361363), (BURTON, SHARPE, et al., 2001, p. 481-486). O primeiro modo é utilizado para velocidades de vento entre a velocidade inicial de operação da turbina eólica ("cut-in", assumido $=4 \mathrm{~m} / \mathrm{s}$ ) e uma velocidade de vento intermediária, inferior à velocidade de vento nominal $U_{n}$. Neste trabalho, assume-se que o valor desta velocidade de vento intermediária é de $80 \%$ da velocidade de vento nominal.

Neste estágio a turbina eólica opera com $\lambda$ constante e igual ao seu valor ótimo $\lambda_{\text {opt }}$. Além disso, o ângulo $\beta$ é constante, com valor próximo de zero, para acelerar o tanto quanto for possível o rotor da turbina. A turbina é controlada para manter a relação ótima entre torque e rotação da turbina de acordo com (4.7). 
O segundo modo de operação consiste na transição entre a operação com $\lambda_{\text {opt }}$ e a operação em potência nominal. Neste modo de operação, a turbina opera com rotação constante e, desta forma, $\lambda$ decai de forma inversamente proporcional à velocidade do vento - Figura 19.

Conforme comentado na secção anterior, o coeficiente de potência da turbina eólica é função de $\lambda$, portanto durante o segundo modo de operação não é possível manter $C_{p}=C_{p \max }$. Neste trabalho, considera-se a aproximação apresentada na Figura 19.

Figura 18 - Potência mecânica normalizada e modos de operação.

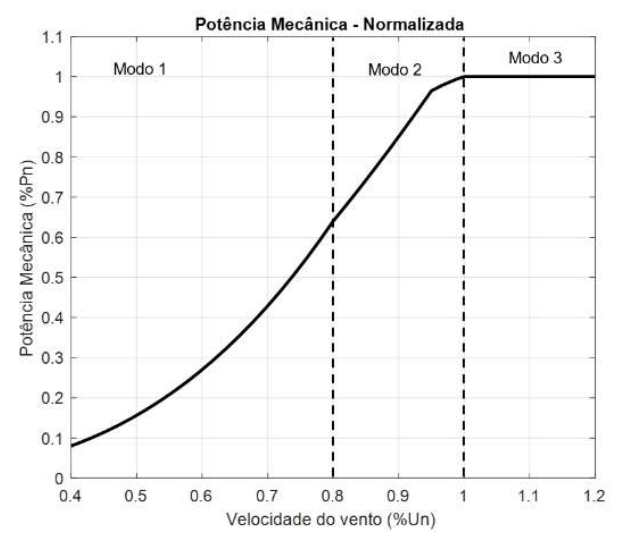

No terceiro modo de operação, a turbina opera em potência nominal, o controle de passo (pitch $-\beta$ ) é encarregado por manter a turbina em condições nominais de torque e rotação para velocidades de vento de até $25 \mathrm{~m} / \mathrm{s}$. Quando a velocidade de vento ultrapassa $25 \mathrm{~m} / \mathrm{s}$ a turbina eólica é desligada (cut-off).

Figura 19 - TSR e Cp mecânico normalizados.
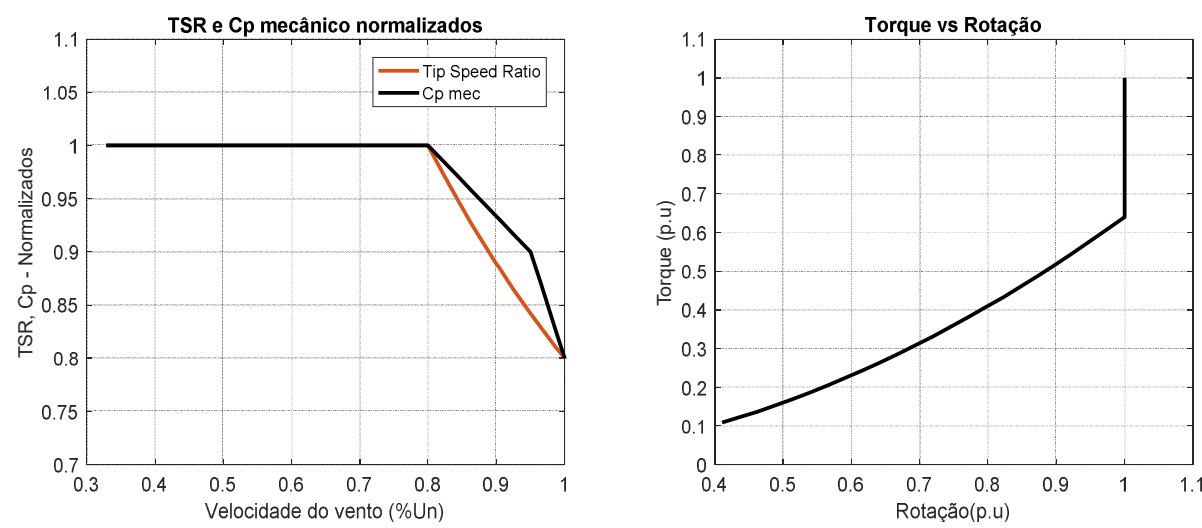

Com as simplificações apresentadas é possível modelar a relação entre torque e rotação da turbina eólica (Figura 19) de forma razoavelmente realística para uma 
turbina eólica offshore. Os valores de diâmetro, $C_{P \max }$ e velocidade de ponta de pá são baseados no estudo - "DTU 10MW reference wind turbine" - (BAK, ZAHLE, et al., 2013). Os principais parâmetros da turbina eólica são apresentados Tabela 20.

Tabela 20 - Parâmetros da turbina eólica

\begin{tabular}{|l|c|c|}
\hline Parâmetro & Valor & Unidade \\
\hline Diâmetro do Rotor & 180 & $\mathrm{~m}$ \\
\hline Velocidade de ponta de pá & 90 & $\mathrm{~m} / \mathrm{s}$ \\
\hline Velocidade de vento nominal & 12.17 & $\mathrm{~m} / \mathrm{s}$ \\
\hline Rotação Nominal & 9.55 & $\mathrm{RPM}$ \\
\hline Tip Speed Ratio ótimo $\left(\lambda_{\text {opt }}\right)$ & 9.24 & - \\
\hline Tip Speed Ratio nominal & 7.40 & - \\
\hline$C_{P \max }$ & 0.494 & - \\
\hline$C_{P n}$ & 0.395 & - \\
\hline Torque Nominal & 11096 & $\mathrm{kNm}$ \\
\hline Potência Nominal Mecânica & 11096 & $\mathrm{~kW}$ \\
\hline
\end{tabular}

Figura 20 - Características da turbina eólica.
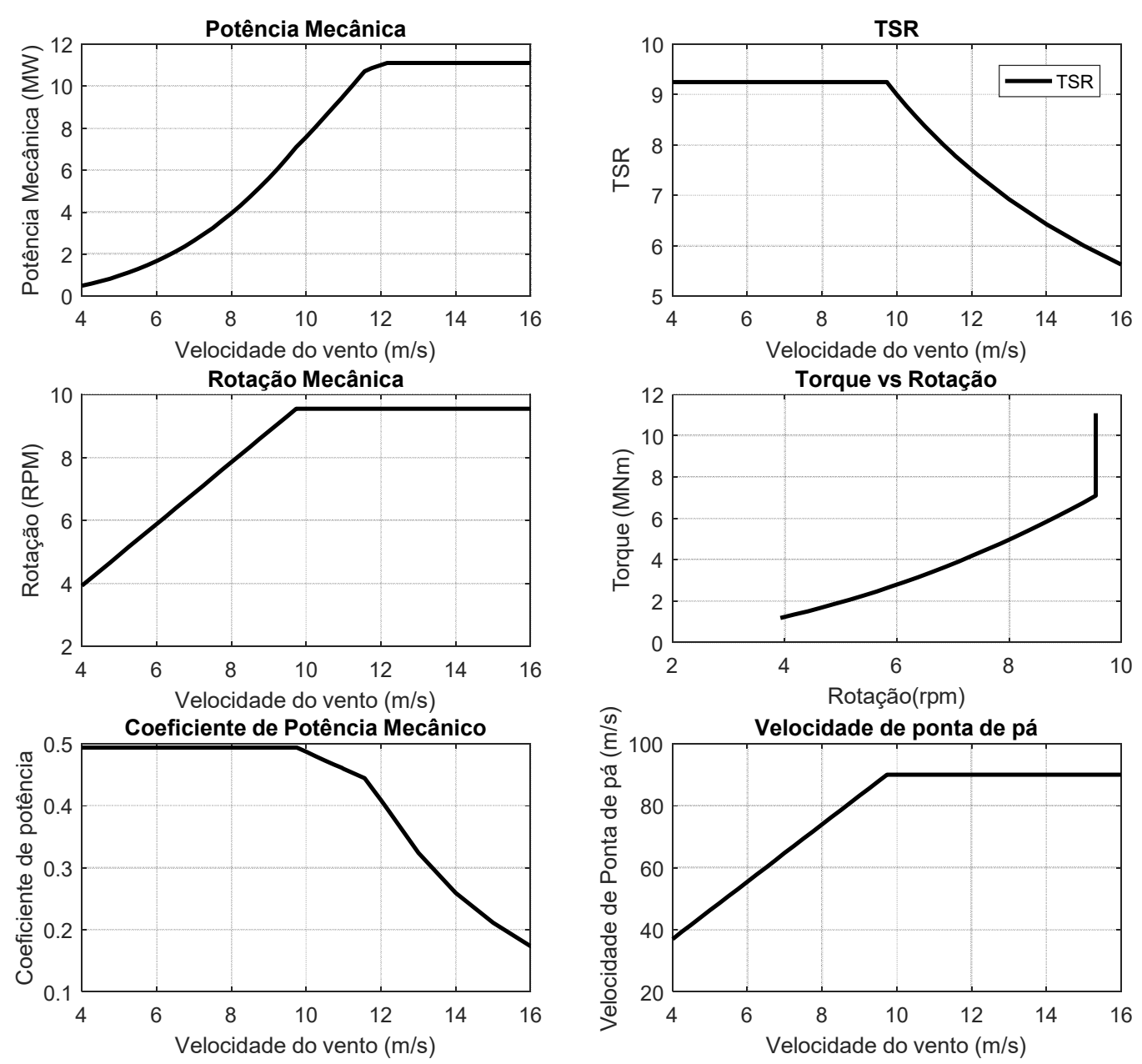


\subsection{TREM DE POTÊNCIA}

Para o trem de potência considera-se gerador síncrono multifásico de média velocidade com excitação por imãs permanentes. Opta-se por um sistema de média velocidade ao invés de um sistema de baixa velocidade (direct-drive) pelos seguintes motivos:

i. Gerador multifásico com enrolamentos distribuídos tem menor capacidade de acomodar pares de polos do que soluções trifásicas. A solução multifásica, com enrolamentos distribuídos, portanto, é mais adequada para máquinas de média velocidade (conforme discutido na secção 3.9).

ii. A solução de média velocidade beneficia a operação do conversor eletrônico de potência em termos de performance, fiabilidade e custos (Apêndice A).

iii. Por conta do menor volume do gerador elétrico, a solução de média velocidade será menos susceptível a flutuação de custo dos imãs permanentes, o que reduz o risco econômico do projeto.

iv. Devido à caixa multiplicadora, os componentes envolvidos no trem de potência apresentam menores dimensões, o que reduz custos para manuseio, transporte, logística e manufatura da turbina.

v. Conforme apresentado no estado da arte deste trabalho, Figura 6, espera-se que a solução de média velocidade tenha densidade de torque $(\mathrm{kNm} / \mathrm{ton})$ superior a soluções de baixa velocidade. Em turbinas eólicas offshore, o peso total da Nacelle tem impacto significativo nos custos globais da turbina. Desta forma, é desejável utilizar tecnologias de alta densidade de torque para reduzir LCOE da turbina.

\subsubsection{Parâmetros da caixa multiplicadora}

Assume-se caixa multiplicadora de dois estágios com taxa de transmissão de 6:1 por estágio. A eficiência da caixa multiplicadora é calculada segundo (JAMIESON, 2011, p. 122):

$$
\eta=1-\frac{\left(\frac{10}{3}+2 N\right)}{1000 p}-\frac{5 N}{1000}
$$


Onde, $\eta$ é o rendimento da caixa multiplicadora, $N$ é o número de estágios e $p$ é a potência da turbina em p.u. Para caixa multiplicadora de dois estágios, as perdas nominais são de $1.733 \%$. Equivalente a $192.3 \mathrm{~kW}$ para $11096 \mathrm{~kW}$ de potência de entrada.

Figura 21 - Eficiência da caixa multiplicadora

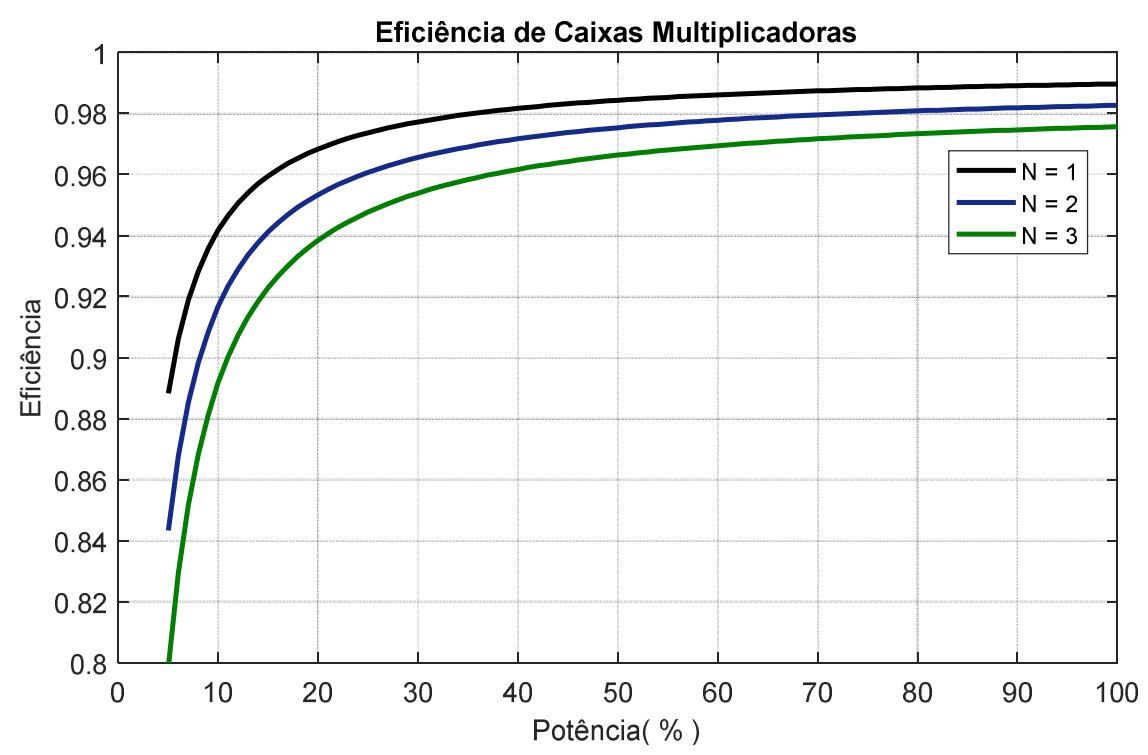

Fonte: Adaptado de (JAMIESON, 2011, p. 123).

\subsubsection{Perdas mecânicas}

As perdas mecânicas do gerador, em velocidade nominal, são estimadas em $1 \%$ da potência nominal de entrada. Este valor de perdas é decomposto em duas componentes, a primeira consiste nas perdas nos rolamentos $P_{b}$ e a segunda consiste nas perdas por atrito viscoso $P_{w}$.

$$
\begin{gathered}
P_{g m_{-} l o s s}=P_{b}+P_{w} \\
P_{b}=k_{b} \omega \\
P_{w}=k_{w} \omega^{2}
\end{gathered}
$$

Assume-se que $70 \%$ das perdas mecânicas do gerador, em condições nominais, correspondem às perdas no rolamento e $30 \%$ às perdas por atrito viscoso. Desta forma, considerando-se as perdas da caixa multiplicadora, chega-se aos resultados apresentados na tabela a seguir: 
Tabela 21 - Perdas nominais mecânicas do gerador

\begin{tabular}{|c|c|c|}
\hline \multicolumn{3}{|c|}{ Perdas mecânicas do gerador } \\
\hline Parâmetro & Valor & Unidade \\
\hline$P_{g m \_l o s s}$ & 109 & $\mathrm{~kW}$ \\
\hline$k_{b}$ & 2.120 & $\mathrm{kWs}$ \\
\hline$k_{W}$ & 0.025 & $\mathrm{kWs}^{2}$ \\
\hline
\end{tabular}

\subsubsection{Torque e potência no entreferro}

Uma vez definido o sistema mecânico de acionamento do gerador elétrico, tornase possível calcular os valores de potência e torque que precisam ser desenvolvidos no entreferro do gerador - Figura 22. As condições nominais de operação são apresentadas na Tabela 22.

Figura 22 - Condições de operação no entreferro.
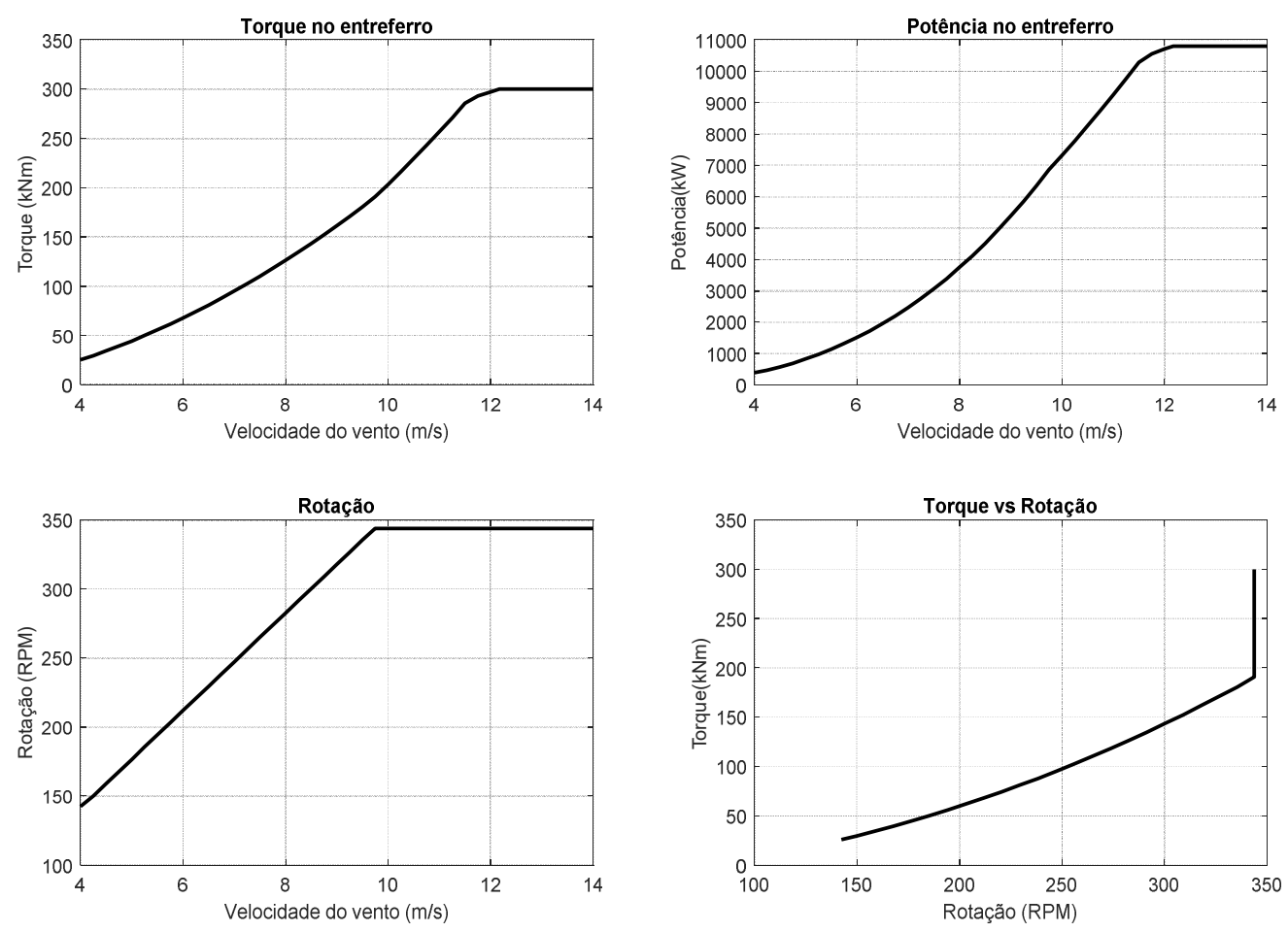

Tabela 22 - Condições nominal de operação no entreferro

\begin{tabular}{|c|c|c|}
\hline \multicolumn{3}{|c|}{ Condições de operação no entreferro } \\
\hline Parâmetro & Valor & Unidade \\
\hline$P_{\text {gap }}$ & 10795 & $\mathrm{~kW}$ \\
\hline$T_{\text {gap }}$ & 299.85 & $\mathrm{kNm}$ \\
\hline$N_{\text {mec }}$ & 343.8 & $\mathrm{RPM}$ \\
\hline
\end{tabular}




\subsection{INTERFACE GERADOR - ELETRÔNICA DE POTÊNCIA}

Para o conversor eletrônico de potência adota-se a solução convencional conversores trifásicos de dois níveis com módulos IGBT de 1700V/3600A. Conforme discutido no Apêndice $A$, cada conversor trifásico tem capacidade de potência em torno de 2MVA. Desta forma, seis conversores trifásicos são adotados.

As seguintes soluções para interface entre gerador e conversor eletrônico de potência serão analisadas:

\subsubsection{Solução 1 - Gerador trifásico com conversores em paralelo}

A primeira solução a ser analisada é a solução tradicional da indústria, composta por um gerador elétrico trifásico de baixa tensão com múltiplos conversores trifásicos conectados em paralelo - Figura 23.

Esta solução apresenta como vantagens: topologia convencional para o gerador elétrico, resiliência a falhas nos conversores eletrônicos de potência. Entretanto, uma estratégia especial de controle precisa ser adotada para mitigar as correntes circulantes entre conversores e, conforme já comentado, esta solução não é resiliente a falhas nos enrolamentos do gerador.

Figura 23 - Solução 1: Gerador trifásico com conversores em paralelo

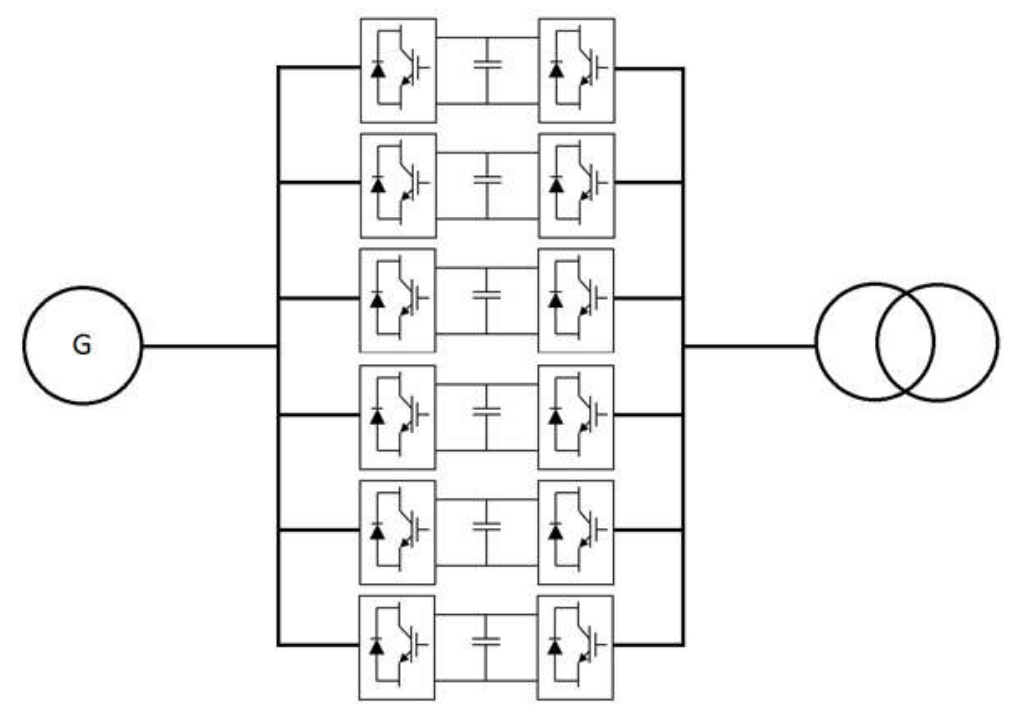




\subsubsection{Solução 2 - Gerador de 6 fases com conversores em paralelo}

De forma alternativa, pode-se utilizar um gerador de seis fases onde cada grupo trifásico do gerador é acoplado a três conversores eletrônicos de potência trifásicos em paralelo. Os neutros de cada grupo trifásico da máquina elétrica devem ser desacoplados para evitar correntes circulantes entre grupos trifásicos do gerador.

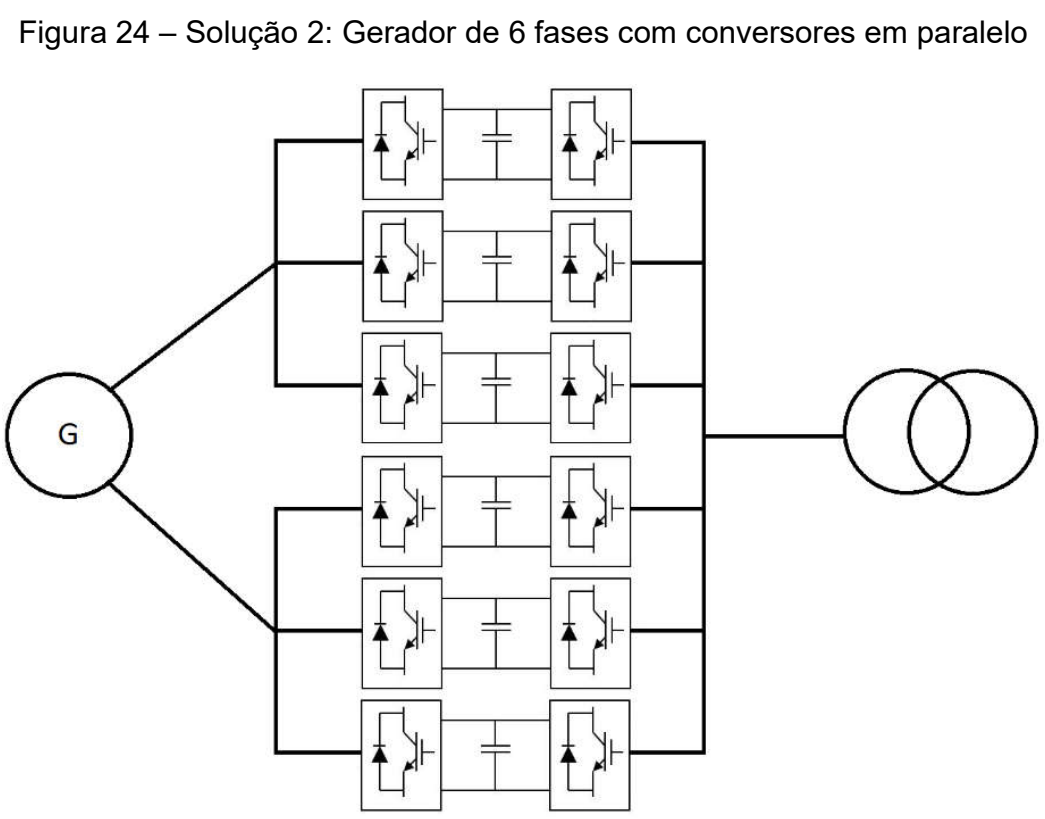

A solução 2, quando comparada com a solução 1, possui a vantagem de poder continuar em operação caso exista falha nos enrolamentos de um dos grupos trifásicos do gerador. Ademais, a solução 2 continua capaz de operar caso exista falha em um dos conversores eletrônicos de potência.

Correntes circulantes, entretanto, vão aparecer entre os conversores e o neutro de cada grupo trifásico. Desta forma, uma estratégia de controle especifica precisa ser adotada para mitigar os impactos destas correntes indesejadas. Salienta-se, contudo, que a complexidade desta estratégia de controle será reduzida, uma vez que existem menos conversores em paralelo.

Há, ainda, maior complexidade para o sistema de controle de torque e, complexidade adicional relativa ao controle do sistema para operação quando há falha em um dos enrolamentos estatóricos. 


\subsubsection{Solução 3 - Gerador de 9 fases com conversores em paralelo}

A solução 3 utiliza um gerador elétrico de nove fases com dois conversores trifásicos conectados em paralelo por grupo trifásico do gerador. Esta solução é resiliente caso exista falha nos enrolamentos de até dois grupos trifásicos do gerador elétrico e, também, é resiliente a falhas nos conversores eletrônicos de potência.

Em relação à solução 2, a estratégia de controle das correntes circulantes por grupo trifásico do gerador será mais simples, uma vez que apenas dois conversores estão em paralelo por grupo trifásico.

Figura 25 - Solução 3: Gerador de 9 fases com conversores em paralelo

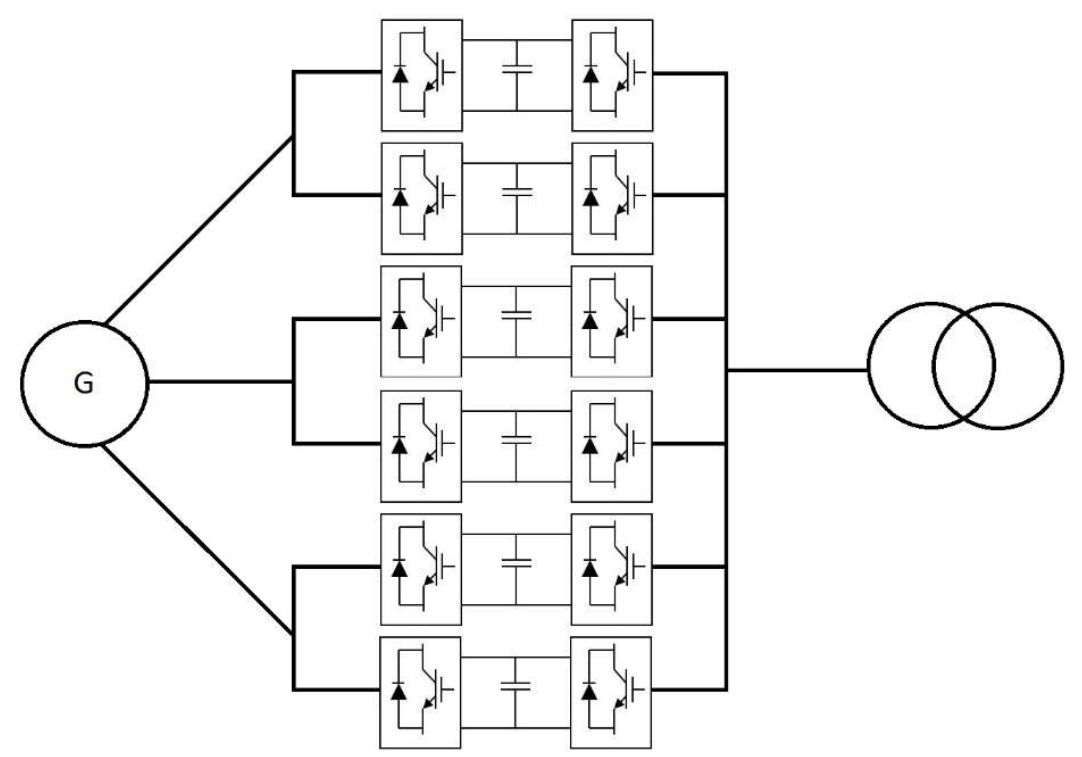

\subsubsection{Solução 4 - Gerador de 18 fases}

A solução 4 é a mesma adotada nas turbinas G135 da Gamesa e na turbina Haliade da GE. Nesta solução, cada conversor eletrônico de potência é associado a um grupo trifásico do gerador, cada grupo trifásico possui neutro independente. Além do mais, esta solução pode continuar a operar, com potência reduzida, quando há falha nos enrolamentos de até cinco grupos trifásicos.

A grande vantagem desta solução, em relação às soluções anteriores, é o não aparecimento de correntes circulantes entre conversores. Evita-se, portanto, a estratégia de controle para mitigação destas correntes indesejadas. Por outro lado, por se tratar de uma máquina com número muito elevado de fases, a complexidade geral de controle do gerador aumenta. 
Figura 26 - Solução 4: Gerador de 18 fases.

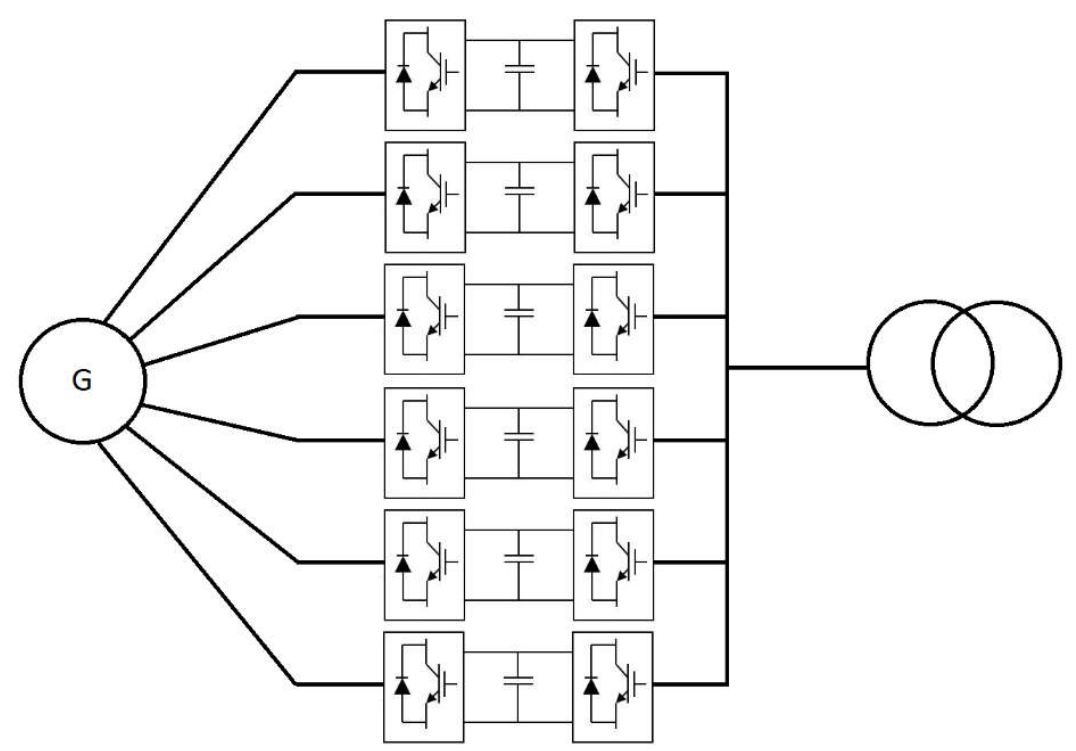

\subsubsection{Perdas nos cabos}

Para turbinas eólicas offshore, normalmente situa-se o transformador elevador na base da turbina. Desta forma, os cabeamentos de baixa tensão ( $690 \mathrm{~V})$ podem ter comprimento em torno de $100 \mathrm{~m}$, contribuindo de forma significativa para as perdas totais da turbina. Assume-se que a resistência por fase destes cabos pode ser estimada por:

$$
R_{\text {cable }}=0.005 m \frac{E_{f}^{2}}{P_{\text {gap }}}
$$

\subsubsection{Comentários gerais}

Neste estudo foi assumido que cada conversor eletrônico de potência (retificador ou inversor) é composto por três braços em meia-ponte com seis módulos IGBT com os seus respectivos diodos em antiparalelo. É possível, entretanto, projetar chaves (switch) com mais de um módulo IGBT em paralelo. Por exemplo, a solução 3 poderia ser composta por três conversores, onde cada chave seria composta por dois módulos IGBT em paralelo, resultando em 12 módulos IGBT por conversor. Esta solução, por um lado pode facilitar o disparo simultâneo das chaves e possibilita a utilização de um único banco de capacitores para "dois conversores". Quando os conversores são colocados em paralelo, ao invés das chaves, há a vantagem de se utilizar componentes off-the-shelf, o disparo simultâneo, entretanto, torna-se mais 
complicado e as diferenças nas tensões entre links-DC favorecem o surgimento de correntes circulantes.

Caso exista falha em um dos conversores das soluções 1 e 4 é simples de observar que o sistema pode continuar em operação em regime equilibrado. Para as soluções 2 e 3 , isso também é verdadeiro e é demonstrado no Apêndice B.

Tabela 23 - Comparação funcional entre soluções.

\begin{tabular}{|l|l|l|l|l|}
\hline \multicolumn{1}{|c|}{ Funcionalidade } & \multicolumn{1}{|c|}{ Solução 1 } & \multicolumn{1}{|c|}{ Solução 2 } & \multicolumn{1}{c|}{ Solução 3 } & \multicolumn{1}{c|}{ Solução 4 } \\
\hline $\begin{array}{l}\text { É resiliente a falha em pelo menos } \\
\text { um enrolamento estatórico? }\end{array}$ & Não & Sim & Sim & Sim \\
\hline $\begin{array}{l}\text { É resiliente a falha nos conversores } \\
\text { eletrônicos de potência? }\end{array}$ & Sim & Sim & Sim & Sim \\
\hline $\begin{array}{l}\text { Necessita de estratégia de controle } \\
\text { para correntes circulantes? }\end{array}$ & $\begin{array}{l}\text { Sim } \\
\text { maior } \\
\text { complexidade }\end{array}$ & $\begin{array}{l}\text { Sim } \\
\text { complexidade } \\
\text { intermediária }\end{array}$ & $\begin{array}{l}\text { Sim } \\
\text { menor } \\
\text { complexidade }\end{array}$ & Não \\
\hline
\end{tabular}

\subsection{ELETRÔNICA DE POTÊNCIA}

Para os conversores eletrônicos de potência, adota-se tensão nominal do link DC igual a $V_{D C} 1150 \mathrm{~V}, k_{v}=67,65 \%$. Os conversores são parametrizados com base no módulo IGBT da Infineon 1700V/3600A FZ3600R17HP4 (INFINEON, 2013). Assumese frequência de chaveamento de $2,5 \mathrm{kHz}$. Para projeto e operação da máquina adotam-se as seguintes restrições:

1. Valor de pico da corrente nominal de fase deve ser inferior a $65 \%$ da corrente nominal do semicondutor. Desta forma, o valor máximo da corrente de fase do conversor eletrônico de potência deve ser inferior a 1655 Arms.

2. O valor da tensão alternada de fase máxima que o conversor é capaz de estabelecer é de 445,7 Vrms. É equivalente à um índice de modulação em amplitude, "modulation index", de $95 \%$ ou $1,097(100 \%=1,1547)$.

3. Frequência elétrica fundamental deverá ser superior a $40 \mathrm{~Hz}$, portanto $p \geq 7$.

Os impactos térmicos destes pressupostos de operação são explorados no Apêndice A. 


\subsubsection{Cálculo das perdas médias}

As perdas médias em um período de condução são calculadas assumindo um pior caso, onde a temperatura da junção dos IGBTs e diodos é constante e igual a $125^{\circ} \mathrm{C}$. Essa aproximação é feita para simplificar o cálculo analítico e, ao mesmo tempo, apresentar resultados conservativos. Nestas condições, os módulos da Infineon FZ3600R17HP4 são modelados por:

Tabela 24 - Parâmetros à $125^{\circ} \mathrm{C}$ FZ3600R17HP4

\begin{tabular}{|c|c|c|c|c|c|}
\hline \multicolumn{3}{|c|}{ IGBT @ $125^{\circ} \mathrm{C}$} & \multicolumn{3}{c|}{ Diodo @125 ${ }^{\circ} \mathrm{C}$} \\
\hline Parâmetro & Valor & Unidade & Parâmetro & Valor & Unidade \\
\hline$V_{C E 0}$ & 0,940 & $\mathrm{~V}$ & $V_{f 0}$ & 0,920 & $\mathrm{~V}$ \\
\hline$R_{I 0}$ & 0,00039 & $\Omega$ & $R_{f 0}$ & 0,00029 & $\Omega$ \\
\hline$E_{\text {on }}$ & 800 & $\mathrm{~mJ}$ & $E_{r e c}$ & 950 & $\mathrm{~mJ}$ \\
\hline$E_{\text {off }}$ & 1450 & $\mathrm{~mJ}$ & \multicolumn{3}{c}{} \\
\cline { 2 - 5 }
\end{tabular}

Os valores nominais $I_{n o m}$ e $V_{d c n}$ utilizados para derivação dos dados apresentados no datasheet deste componente são 3600 A e $900 \mathrm{~V}$. As perdas médias são calculadas de acordo com a metodologia utilizada pela Infineon no seu programa IPOSIM (INFINEON, 2006). Para o módulo IGBT as perdas por condução são modeladas de acordo com a equação (4.13) e as perdas de chaveamento conforme a relação (4.14) :

$$
\begin{gathered}
P_{I_{-} \text {cond_avg }}=\frac{1}{2}\left(V_{C E 0} \frac{I_{p k}}{\pi}+R_{I 0} \frac{I_{p k}^{2}}{4}\right)+m_{a} \cos (\varphi)\left(V_{C E 0} \frac{I_{p k}}{8}+R_{I 0} \frac{I_{p k}^{2}}{3 \pi}\right) \\
P_{I_{-} s w \_a v g}=\frac{1}{\pi} f_{s w}\left(E_{\text {on }}+E_{\text {off }}\right) \frac{I_{p k}}{I_{\text {nom }}} \frac{V_{d c}}{V_{d c n}}
\end{gathered}
$$

Onde $m_{a}$ é o índice de modulação em amplitude, corresponde à razão entre o valor de pico da tensão $\mathrm{AC}$ e $\frac{V_{d c}}{2}$. As perdas médias por condução e chaveamento para o diodo são calculadas por:

$$
P_{D_{-} \text {cond_avg }}=\frac{1}{2}\left(V_{f 0} \frac{I_{p k}}{\pi}+R_{f 0} \frac{I_{p k}^{2}}{4}\right)-m_{a} \cos (\varphi)\left(V_{f 0} \frac{I_{p k}}{8}+R_{f 0} \frac{I_{p k}^{2}}{3 \pi}\right)
$$




$$
P_{D_{-} s w \_a v g}=f_{s w} E_{r e c}\left(\frac{0.96}{\pi} \sqrt{\frac{I_{p k}}{I_{n o m}}}+0.1\right) \frac{V_{d c}}{V_{d c n}}
$$

O conversor que opera do lado do gerador (Machine Side Converter - MSC) opera com retificador e, neste caso, $\cos (\varphi)$ nas equações (4.13) e (4.15) é negativo. O contrário é valido para o conversor do lado da rede (Line Side Converter - LSC).

\subsubsection{MSC - Controle de Torque}

A fim de minimizar as perdas do sistema, adota-se, sempre que possível, a estratégia de controle que maximiza a eficiência da máquina. Esta estratégia é conhecida por MTPA - Maximum Torque per Ampere. Onde, é possível estabelecer uma relação ótima entre $i_{d}$ e $i_{q}$ para a produção de torque. A trajetória (Figura 27) ótima é calculada por (KANG, KO, et al., 2010):

$$
i_{d}=\frac{\Psi_{P M}}{2\left(L_{q}-L_{d}\right)}-\sqrt{\frac{\Psi_{P M}{ }^{2}}{4\left(L_{q}-L_{d}\right)^{2}}+i_{q}{ }^{2}}
$$

Figura 27 - Estratégia MTPA.
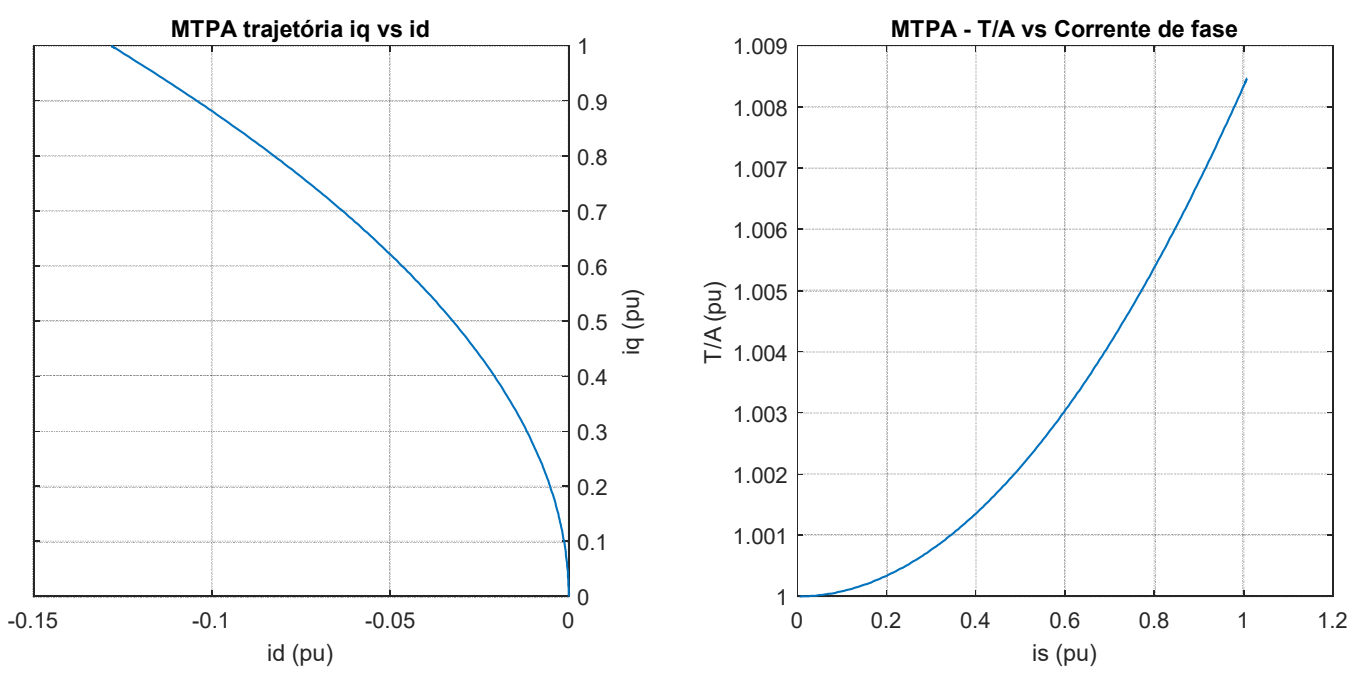

Caso não seja possível utilizar esta estratégia devido à tensão máxima $A C$ que o conversor consegue estabelecer aos terminais da máquina, adota-se a estratégia MTPV - Maximum Torque per Voltage. De forma similar a estratégia MTPA, a relação entre $i_{d}$ e $i_{q}$, neste caso, é dada por (KANG, KO, et al., 2010): 


$$
i_{d}=-\frac{\Psi_{P M}}{L_{d}}+\frac{1}{L_{d}} \sqrt{\frac{V_{\max }^{2}}{\omega_{e}^{2}}+\left(L_{q} i_{q}\right)^{2}}
$$

Os pontos de operação do gerador e do $M S C$, são definidos, portanto, pela relação $T(\omega)$ apresentada na secção 4.3 .3 em conjunção com as equações (4.17) ou (4.18). As equações diferenciais que relacionam tensão, corrente, fluxo magnético, torque e rotação são apresentadas no Apêndice D.

\subsubsection{LSC - Fator de potência unitário}

Com a finalidade de calcular a eficiência global do sistema, assume-se que o LSC opera com tensão nominal, 690 Vrms, e fator de potência unitário.

\subsection{RENDIMENTO E COEFICIENTE DE POTÊNCIA ELÉTRICO}

Neste trabalho, utiliza-se o termo "rendimento global" $n_{g}$ para se referir à eficiência entre a potência mecânica disponível no eixo de baixa rotação da turbina e a potência elétrica de saída, antes do transformador. Desta forma, é $n_{g}$ calculado por:

$$
n_{g}=1-\frac{P_{g b \_l o s s}+P_{g e n \_l o s s}+P_{\text {cable }}+P_{M S C_{\_} \text {loss }}+P_{L S C_{\_} l o s s}}{P_{m e c}}
$$

Onde, $P_{g b_{-} l o s s}$ são as perdas na caixa multiplicadora, $P_{g e n \_l o s s}$ corresponde às perdas no gerador elétrico, $P_{\text {cable }}$ refere-se às perdas nos cabeamentos de baixa tensão, $P_{M S C_{-} l o s s}$ e $P_{L S C_{-} l o s s}$ são as perdas nos conversores eletrônicos de potência (retificador e inversor), $P_{m e c}$ é a potência mecânica da turbina eólica $\left(T_{t} \omega_{t}\right)$.

O coeficiente de potência elétrico da turbina eólica, é a razão entre a potência elétrica de saída, antes do transformador, e a potência disponível no recurso eólico.

$$
C_{p e}=\frac{n_{g} P_{m e c}}{P_{u}}=n_{g} C_{p}
$$




\section{$5 \quad$ CIRCUITO MAGNÉTICO}

\subsection{TOPOLOGIA DO SISTEMA DE EXCITAÇÃO}

Adota-se sistema de excitação de imãs permanentes do tipo c), conforme a classificação da Figura 10. A topologia adotada é baseada no gerador da empresa The Switch, apresentado em (THE SWITCH, 2010) - Figura 28.

Figura 28 - Topologia de excitação por imãs permanentes.

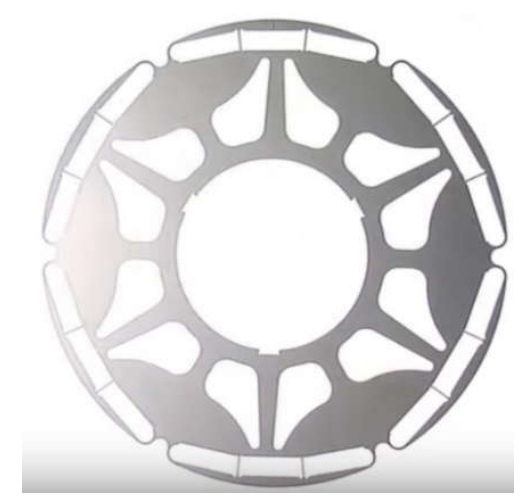

Fonte: (THE SWITCH, 2010).

Assume-se que o imã, para passo polar centrado no eixo-y, é horizontal. A camada de material ferromagnético para conformação de campo tem como intuito estabelecer entreferro aproximadamente cossenoidal. Os vazamentos do rotor serão estabelecidos de forma a guiar o fluxo magnético pela área delimitada pela dimensão da coroa rotórica $h_{r y}$ e o comprimento efetivo da máquina $L_{e f}$.

Para cálculo eletromagnético do gerador, a geometria rotórica é simplificada e parametrizada de acordo com a figura a seguir:

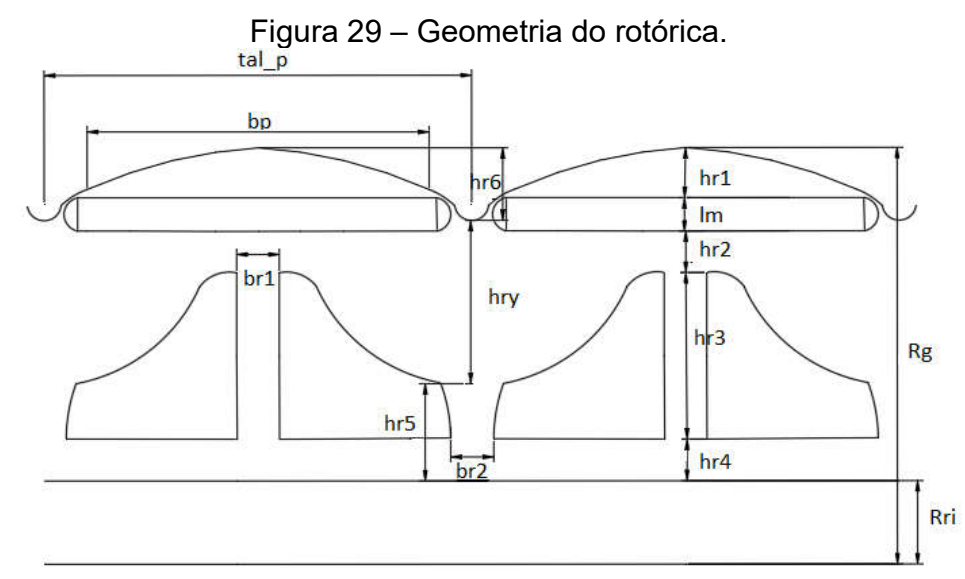




\subsection{CÁLCULO DO CIRCUITO MAGNÉTICO}

A força magnetomotriz produzida pelo imã deverá ser suficiente para vencer a força magnetomotriz requerida para magnetização do entreferro e das estruturas ferromagnéticas, portanto:

$$
\begin{aligned}
& 2 H_{m} l_{m}=2 H_{g} k_{c s} l_{g}+2 f_{t}+H_{s y} l_{s y}+H_{r y} l_{r y} \\
& H_{m} l_{m}=H_{g} k_{c s} l_{g}+f_{t}+\frac{1}{2} H_{s y} l_{s y}+\frac{1}{2} H_{r y} l_{r y}
\end{aligned}
$$

Onde $k_{c s}$ é o fator de Carter para ranhuras do estator e $f_{t}$ corresponde à queda de força magnetomotriz no dente da armadura.

Para cálculo da queda da força magnetomotriz nos dentes do estator divide-se o dente em quatro secções de acordo com a Figura 30. Para open slots com dentes retangulares $b_{t 0}=b_{t 1}=b_{t 2}=b_{t 3}$. No caso de ranhura retangular $b_{t 0} \neq b_{t 1} \neq b_{t 2} \neq$ $b_{t 3}$.

Figura 30 - Geometria da ranhura.

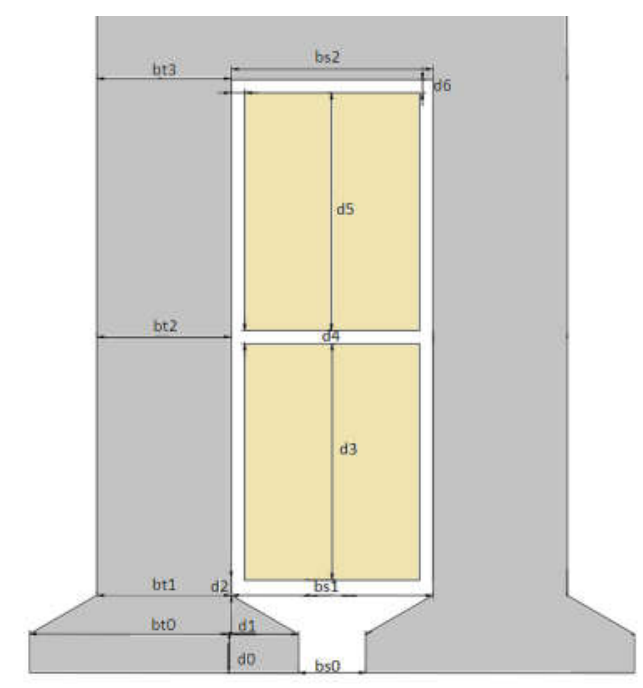

A queda de força magnetomotriz total no dente é calculada pela soma da força magnetomotriz por secção:

$$
f_{t}=H_{t 0} l_{t 0}+H_{t 1} l_{t 1}+H_{t 2} l_{t 2}+H_{t 3} l_{t 3}
$$


Onde:

$$
\begin{gathered}
l_{t 0}=d_{0} \\
l_{t 1}=d_{1} \\
l_{t 2}=l_{t 3}=\frac{\left(d_{3}+d_{4}+d_{5}+d_{6}\right)}{2}
\end{gathered}
$$

\subsubsection{Fluxo e indução magnética no imã}

O fluxo e a indução magnética no imã, $\varphi_{m}$ e $B_{m}$, são calculados pelas seguintes relações:

$$
\begin{gathered}
\varphi_{m}=\varphi_{g} k_{d i s} \\
B_{m}=\frac{2}{\pi} B_{g} \frac{\tau_{p}}{b_{m}} k_{d i s} \\
B_{m}=B_{C}\left(1-\frac{H_{m}}{H_{C}}\right)
\end{gathered}
$$

Onde $k_{\text {dis }}$ corresponde à dispersão magnética do sistema de excitação, $b_{m}$ é a largura do imã, $B_{c}$ e $H_{C}$ correspondem à indução e campo magnéticos coercitivos do imã. O ponto de operação da máquina é encontrado quando a indução magnética do imã quando calculada por (5.4) e (5.5) convergem para o mesmo valor (Figura 31).

Figura 31 - Ponto de operação do imã

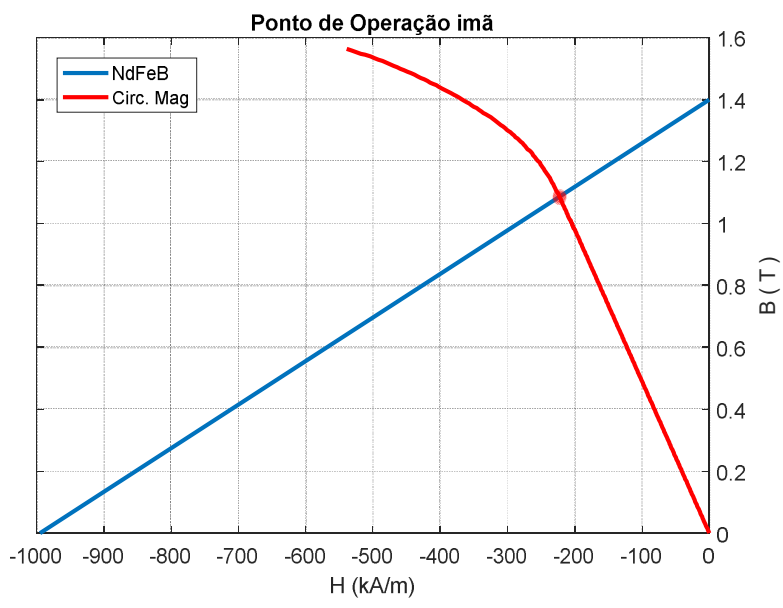


5.2.2 Fluxo e indução magnética na coroa do rotor

Metade do fluxo produzido pelo imã é conduzido pela coroa do rotor, desta forma $\varphi_{r y}$ e $B_{r y}$ são calculados de acordo com:

$$
\begin{gathered}
\varphi_{r y}=\frac{\varphi_{m}}{2} \\
B_{r y}=\frac{B_{m}}{2} \frac{b_{m}}{h_{r y}}
\end{gathered}
$$

5.2.3 Fluxo e indução magnética na coroa do estator

De forma análoga, metade do fluxo magnético do entreferro é conduzido pela coroa estatórica:

$$
\begin{gathered}
\varphi_{s y}=\frac{\varphi_{g}}{2} \\
B_{s y}=\frac{2}{\pi} B_{g} \frac{\tau_{p}}{h_{s y}}
\end{gathered}
$$

5.2.4 Fluxo e indução magnética no dente

Assume-se que o fluxo magnético do entreferro passa apenas pela área igual a $\frac{\tau_{s h o e}}{\tau_{p}}$ vezes a área total de dentes do passo polar, matematicamente escreve-se:

$$
\varphi_{t}=\frac{\varphi_{g}}{q m \frac{\tau_{s h o e}}{\tau_{p}}}
$$

A indução magnética é calculada assumindo-se a área média de cada secção do dente de acordo com a Figura 30:

$$
B_{t 0}=\frac{\frac{2}{\pi} B_{g} \tau_{p}}{q m b_{t 0} \frac{\tau_{s h o e}}{\tau_{p}}}
$$




$$
\begin{aligned}
& B_{t 1}=\frac{\frac{2}{\pi} B_{g} \tau_{p}}{q m \frac{\left(b_{t 0}+b_{t 1}\right)}{2} \frac{\tau_{\text {shoe }}}{\tau_{p}}} \\
& B_{t 2}=\frac{\frac{2}{\pi} B_{g} \tau_{p}}{q m \frac{\left(b_{t 1}+b_{t 2}\right)}{2} \frac{\tau_{\text {shoe }}}{\tau_{p}}} \\
& B_{t 3}=\frac{\frac{2}{\pi} B_{g} \tau_{p}}{q m \frac{\left(b_{t 2}+b_{t 3}\right)}{2} \frac{\tau_{\text {shoe }}}{\tau_{p}}}
\end{aligned}
$$

\subsubsection{Campos magnéticos}

Uma vez que as induções magnéticas são calculadas para cada parte do circuito magnético, os campos magnéticos são calculados ao se recorrer às curvas de magnetização dos materiais de cada parte do circuito magnético e à permeabilidade magnética do $\operatorname{ar}\left(H_{g}=\frac{B_{g}}{\mu_{0}}\right)$.

Para o estator da máquina considera-se aço silício do tipo $M-15$ e, para o rotor, aço carbono "US Steel Type 2-S0.018 inch". As curvas de magnetização dos aços são apresentadas na Figura 32.

Figura 32 - Curvas de magnetização.

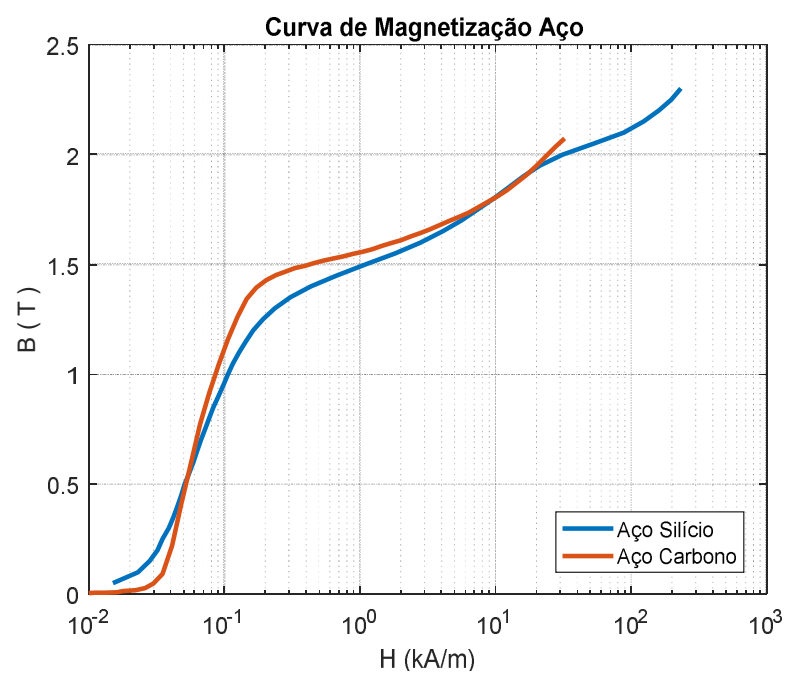

O imã é de $\mathrm{NdFeB}$ do tipo $\mathrm{N} 48 \mathrm{SH}$, com curvas de desmagnetização para $20^{\circ} \mathrm{C}$ e $100^{\circ} \mathrm{C}$ apresentadas na Figura 33. Para o projeto da máquina consideram-se as 
características do imã à $100^{\circ} \mathrm{C}$. Os parâmetros do imã N48SH são apresentados na Tabela 25.

Figura 33 - Curva de desmagnetização NdFeB N48SH.

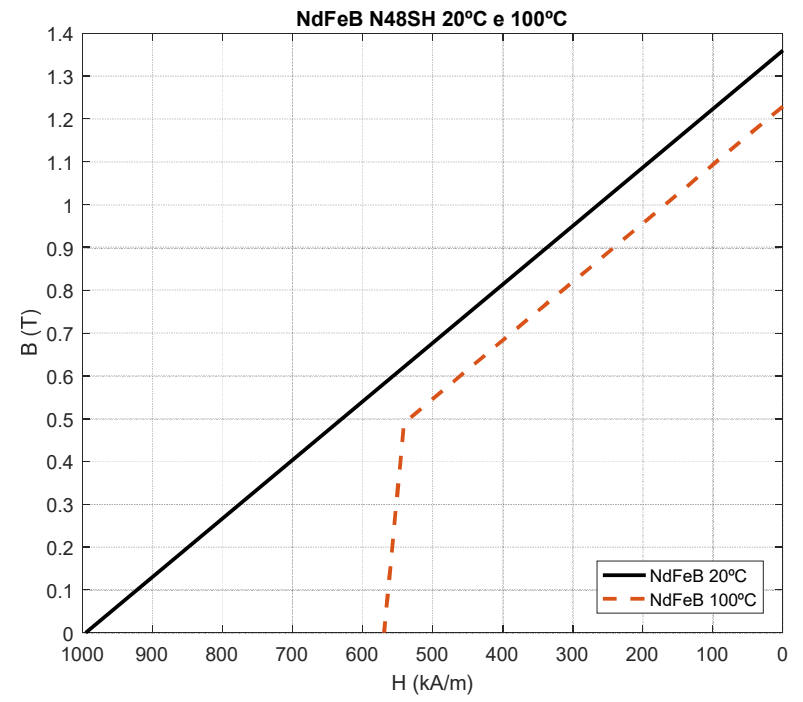

Tabela 25 - Parâmetros do imã NdFeB N48SH.

\begin{tabular}{|l|c|c|}
\hline \multicolumn{1}{|c|}{ Parâmetro } & Valor & Unidade \\
\hline Campo remanente $20^{\circ} \mathrm{C}$ & 1.390 & $T$ \\
\hline Campo remanente $100^{\circ} \mathrm{C}$ & 1.229 & $T$ \\
\hline Campo coercitivo $20^{\circ} \mathrm{C}$ & 995 & $\mathrm{kA} / \mathrm{m}$ \\
\hline Campo coercitivo $100^{\circ} \mathrm{C}$ & 569 & $\mathrm{kA} / \mathrm{m}$ \\
\hline
\end{tabular}




\section{COMPARAÇÃO ENTRE DIFERENTES TOPOLOGIAS}

Neste capítulo, primeiramente, são apresentadas as características de projeto adotadas para cada gerador elétrico estudado neste trabalho. Nomeadamente, para o gerador de três fases (Solução 1), gerador de seis fases (Solução 2), gerador de nove fases (Solução 3), e gerador de dezoito fases (Solução 4).

As condições mecânicas de operação, incluindo perdas, são consideradas constantes para todas as topologias. Estas condições são detalhas nas secções 4.2 e 4.3. Na Tabela 26 são apresentados os parâmetros de projeto que são comuns em todos os casos analisados.

Tabela 26 - Condições de projeto

\begin{tabular}{|c|c|c|c|}
\hline \multicolumn{4}{|c|}{ Condições de projeto } \\
\hline Parâmetro & Valor & Unidade & Comentário \\
\hline$P_{\text {gap }}$ & 10,795 & MW & Potência ativa no entreferro \\
\hline$T_{\text {gap }}$ & 299,85 & $\mathrm{kNm}$ & Torque no entreferro \\
\hline$f p_{\text {gap }}$ & 1,0 & - & Fator de potência interno \\
\hline$f_{m e c}$ & 5,73 & $\mathrm{~Hz}$ & Frequência mecânica (343,8 RPM) \\
\hline$B_{g}$ & 0,903 & $T$ & Carregamento magnético \\
\hline$A_{q}$ & 64000 & Arms $/ \mathrm{m}$ & Carregamento elétrico \\
\hline$J_{r}$ & 5,0 & Arms $/ \mathrm{mm} 2$ & Densidade de corrente na ranhura \\
\hline$D_{g} / L_{e f}$ & 2,6 & - & Relação de aspecto (aspect ratio) \\
\hline$l_{g}$ & 5,0 & $\mathrm{~mm}$ & Entreferro mínimo (eixo-d) \\
\hline$l_{m}$ & 14,0 & $\mathrm{~mm}$ & Espessura do imã \\
\hline $\boldsymbol{k}_{s}$ & 0,50 & - & Razão entre abertura da ranhura e passo de ranhura \\
\hline$B_{r y}$ & 1,30 & $T$ & Indução magnética na coroa rotórica \\
\hline$B_{s y}$ & 1,20 & $T$ & Indução magnética na coroa estatórica \\
\hline $\boldsymbol{k}_{\text {ench }}$ & 0,50 & - & fator de preenchimento da ranhura \\
\hline $\boldsymbol{k}_{\text {emp }}$ & 0,98 & - & fator de empacotamento do aço (rotor e estator) \\
\hline $\boldsymbol{k}_{\text {dis }}$ & 1,15 & - & fator de dispersão \\
\hline$\tau_{\text {shoe }} / \tau_{p}$ & 0,76 & - & Razão entre sapata polar e passo polar \\
\hline$N_{s f}$ & 8 & - & Número de bobinas em série por fase \\
\hline$I_{\max }$ & 1655 & Arms & Corrente máxima por conversor \\
\hline$V_{f \max }$ & 445,7 & Vrms & Tensão de fase máxima \\
\hline$\tau_{s_{\_} \min }$ & 25,0 & $\mathrm{~mm}$ & Passo de ranhura mínimo \\
\hline$D_{\text {ext_max }}$ & 3,0 & $m$ & Diâmetro externo máximo \\
\hline$L_{\text {ef_max }}$ & 1,5 & $m$ & Comprimento efetivo máximo \\
\hline $\boldsymbol{k}_{\text {skh }}$ & 1 & № de ranhuras & Assume-se inclinação (skew) de uma ranhura. \\
\hline
\end{tabular}




\subsection{RESULTADOS PARA CONDIÇÕES NOMINAIS DE OPERAÇÃO}

Com base no projeto analítico, chega-se aos resultados apresentados na Tabela 27 e na Figura 34.

Tabela 27 - Resultados

\begin{tabular}{|c|c|c|c|c|c|}
\hline & Sol. 1 & Sol. 2 & Sol. 3 & Sol. 4 & Unidade \\
\hline$P_{n}$ & 10,709 & 10,711 & 10,711 & 10,697 & MW \\
\hline$f_{e}$ & 68,75 & 68,75 & 80,21 & 45,84 & $\mathrm{~Hz}$ \\
\hline$m$ & 3 & 6 & 9 & 18 & - \\
\hline$V_{n}$ & 764,80 & 764,90 & 745,73 & 769,75 & Vrms \\
\hline$E_{n}$ & 635,6 & 637,4 & 642,0 & 647,0 & Vrms \\
\hline$I_{f}$ & 9,702 & 4,836 & 3,209 & 1,649 & kA rms \\
\hline$f p_{\text {nom }}$ & 0,833 & 0,836 & 0,861 & 0,817 & - \\
\hline$n_{\text {nom }}$ & $98,21 \%$ & $98,23 \%$ & $98,24 \%$ & $98,10 \%$ & $\%$ \\
\hline$n_{\text {global }}$ & $93,79 \%$ & $93,81 \%$ & $93,81 \%$ & $93,64 \%$ & $\%$ \\
\hline$p$ & 12 & 12 & 14 & 8 & Pares de polos \\
\hline$N_{s}$ & 288 & 288 & 288 & 288 & Ranhuras \\
\hline $\boldsymbol{K}_{j}^{*}$ & 12,986 & 12,732 & 12,830 & 15,101 & $\mathrm{~kW} / \mathrm{m} 2$ \\
\hline$D_{g}$ & 2,341 & 2,334 & 2,317 & 2,300 & $m$ \\
\hline$D_{\text {out }}$ & 2,603 & 2,596 & 2,557 & 2,633 & $m$ \\
\hline$L_{e f}$ & 0,900 & 0,898 & 0,891 & 0,884 & $m$ \\
\hline Massa Ativa & 13123 & 12980 & 11848 & 15818 & $\mathrm{~kg}$ \\
\hline Massa em ferro & 10461 & 10383 & 9338 & 12901 & $\mathrm{~kg}$ \\
\hline Massa em Cobre & 2134 & 2071 & 1992 & 2407 & $\mathrm{~kg}$ \\
\hline Massa em Imãs & 528 & 525 & 518 & 510 & $\mathrm{~kg}$ \\
\hline $\mathrm{kNm} /$ ton & 22.8 & 23.1 & 25.3 & 19.0 & $\mathrm{kNm} / \mathrm{ton}$ \\
\hline kW/ton & 816,0 & 825,2 & 904,1 & 676,2 & $\mathrm{~kW} / \mathrm{ton}$ \\
\hline$r_{s}$ & 0,005 & 0,005 & 0,005 & 0,006 & p.u. \\
\hline$L_{\text {dis }}$ & 0,064 & 0,056 & 0,064 & 0,039 & p.u. \\
\hline$L_{d}$ & 0,55 & 0,55 & 0,51 & 0,83 & p.u. \\
\hline$L_{q}$ & 0,67 & 0,67 & 0,62 & 1,03 & p.u. \\
\hline$\Psi_{P M}$ & 1,20 & 1,20 & 1,04 & 1,83 & $\mathrm{~V} / \mathrm{s}$ \\
\hline $\boldsymbol{B}_{t m}$ & 1,54 & 1,54 & 1,54 & 1,54 & $T$ \\
\hline$q$ & 4 & 2 & $1+1 / 7$ & 1 & - \\
\hline $\boldsymbol{k}_{e 1}$ & 0,947 & 0,955 & 0,972 & 0,999 & - \\
\hline Enc. Passo & 15 & 30 & 22.5 & 0 & ${ }^{\circ}$ \\
\hline$I_{\text {conv }}$ & 1616,9 & 1612,1 & 1604,6 & 1649,3 & Arms \\
\hline
\end{tabular}

Em termos de rendimento, a solução 4, gerador de dezoito fases, tem o pior resultado com eficiência $0,11 \%$ inferior à solução trifásica (Sol. 1). Encontra-se a maior eficiência do gerador ao se optar pela máquina de nove fases, com rendimento $0,03 \%$ superior ao rendimento do gerador trifásico. Justifica-se esta pequena diferença entre a eficiência das diferentes topologias estudadas, pelo fato de todas as 
máquinas serem projetadas para a mesma potência no entreferro, com os mesmos valores de carregamentos elétrico, magnético e densidade de corrente por ranhura. $A$ eficiência ligeiramente inferior da máquina de dezoito fases, decorre da necessidade de operação em modo MTPV para condições nominais de torque.

Figura 34 - Comparação entre topologias.
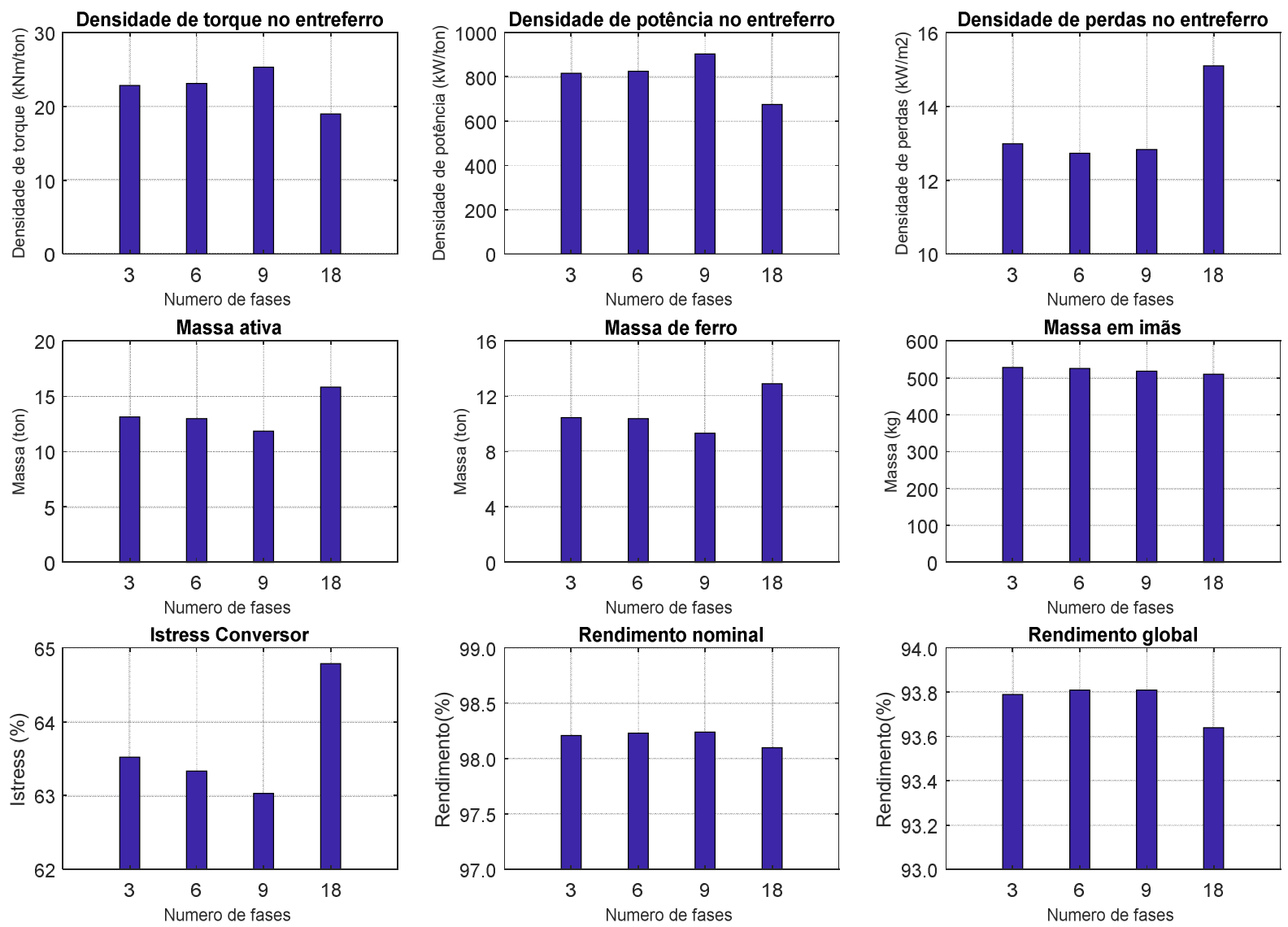

Em termos de densidade de torque/potência e massa ativa, observa-se que a terceira solução, com máquina de nove fases, apresenta os melhores resultados. A massa ativa desta topologia é $1275 \mathrm{~kg}$ inferior à massa ativa da solução de três fases, uma redução de 9,7 \%. O maior número de pares de polos, que, por sua vez, tende a reduzir a dimensão das coroas rotóricas e estatóricas, e o melhor fator de enrolamento são os principais fatores que justificam esta melhoria.

A solução 3, com máquina de nove fases, é, também, aquela que se integra melhor com os conversores eletrônicos de potência, uma vez que precisa de uma menor corrente por conversor para desenvolver o torque requerido no entreferro ( 1605 Arms). Além disso, conforme, discutido no Apêndice A, a maior frequência elétrica fundamental contribui para o aumento da fiabilidade do conversor. 
O gerador de dezoito fases, embora possua o maior fator de enrolamento e menor área no entreferro, apresenta maior massa ativa e piores valores de densidade de torque e potência. Isso é justificado pelo o aumento das dimensões das coroas estatóricas e rotóricas devido ao menor número de pares de polos. Nesse sentido, observa-se, que mesmo com o menor valor de $D_{g}, 2,30 \mathrm{~m}$, o gerador de dezoito fases apresenta o maior diâmetro externo $D_{\text {ext }}=2,63 \mathrm{~m}$. Em relação à solução com máquina trifásica, a solução 4 precisa de uma massa ativa $20 \%$ superior para desenvolver a mesma potência no entreferro.

Em relação à densidade de perdas no entreferro, parâmetro $K_{j}{ }^{*}$, inclui não apenas as perdas no cobre, mas, também, as perdas no ferro. Por conta disso, utilizase o símbolo "*" para diferenciar do parâmetro $K_{j}$ apresentado na secção 3.11. Com os resultados da Figura 34, observa-se que há pequena variação neste parâmetro para as topologias de três, seis e nove fases. Contudo, para o gerador de dezoito fases, $K_{j}{ }^{*}$ aumenta de $\sim 13 \mathrm{~kW} / \mathrm{m}^{2}$ para $15,1 \mathrm{~kW} / \mathrm{m}^{2}$, um aumento de $16 \%$ em relação à máquina trifásica. Na figura a seguir apresenta-se $K_{j}$ e $K_{j}{ }^{*}$ para cada topologia analisada:

Figura 35 - Comparação entre $\boldsymbol{K}_{\boldsymbol{j}}$ e $\boldsymbol{K}_{\boldsymbol{j}}{ }^{*}$.

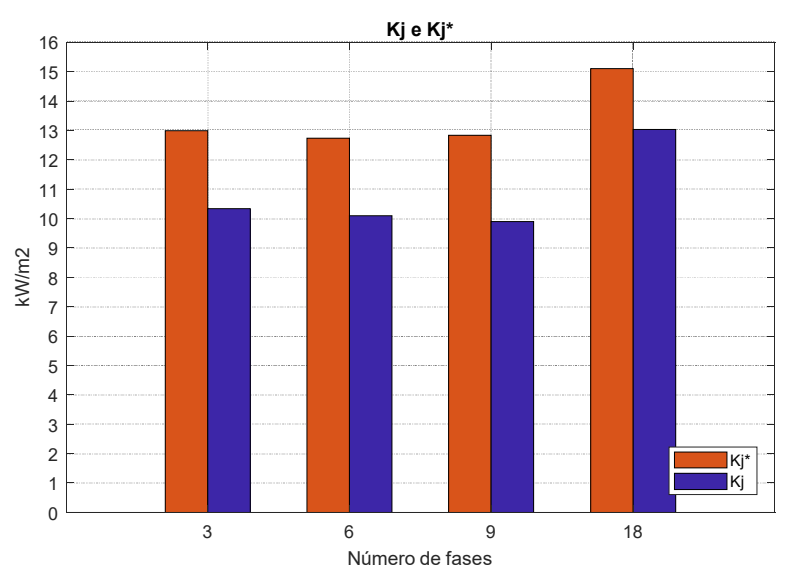

A solução 2, máquina hexafásica, possui resultados intermediários, com densidades de torque e potência ligeiramente superiores àquelas atingidas pelo gerador trifásico. 


\subsection{RESULTADOS EM FUNÇÃO DA VELOCIDADE DO VENTO}

Nas figuras a seguir são apresentados os resultados para cada topologia estuada, para diferentes valores de velocidade de vento.

Na Figura 36, apresenta-se a relação entre tensão de fase e tensão induzida de cada gerador. Observa-se que, para máquina de dezoito fases e para velocidades de vento superior a $10 \mathrm{~m} / \mathrm{s}$, o gerador opera com tensão de fase máxima, com modo de operação MTPV. Isso ocorre, pois, a máquina de dezoito fases apresenta valores maiores de $L_{d}, L_{q}$ em relação às demais topologias (menor número de pares de polos). Desta forma, pode-se dizer que este é o principal fator que deteriora a performance da solução 4 em relação às demais máquinas para velocidades de vento superiores a $10 \mathrm{~m} / \mathrm{s}$.

Figura 36 - Tensão de fase e tensão induzida
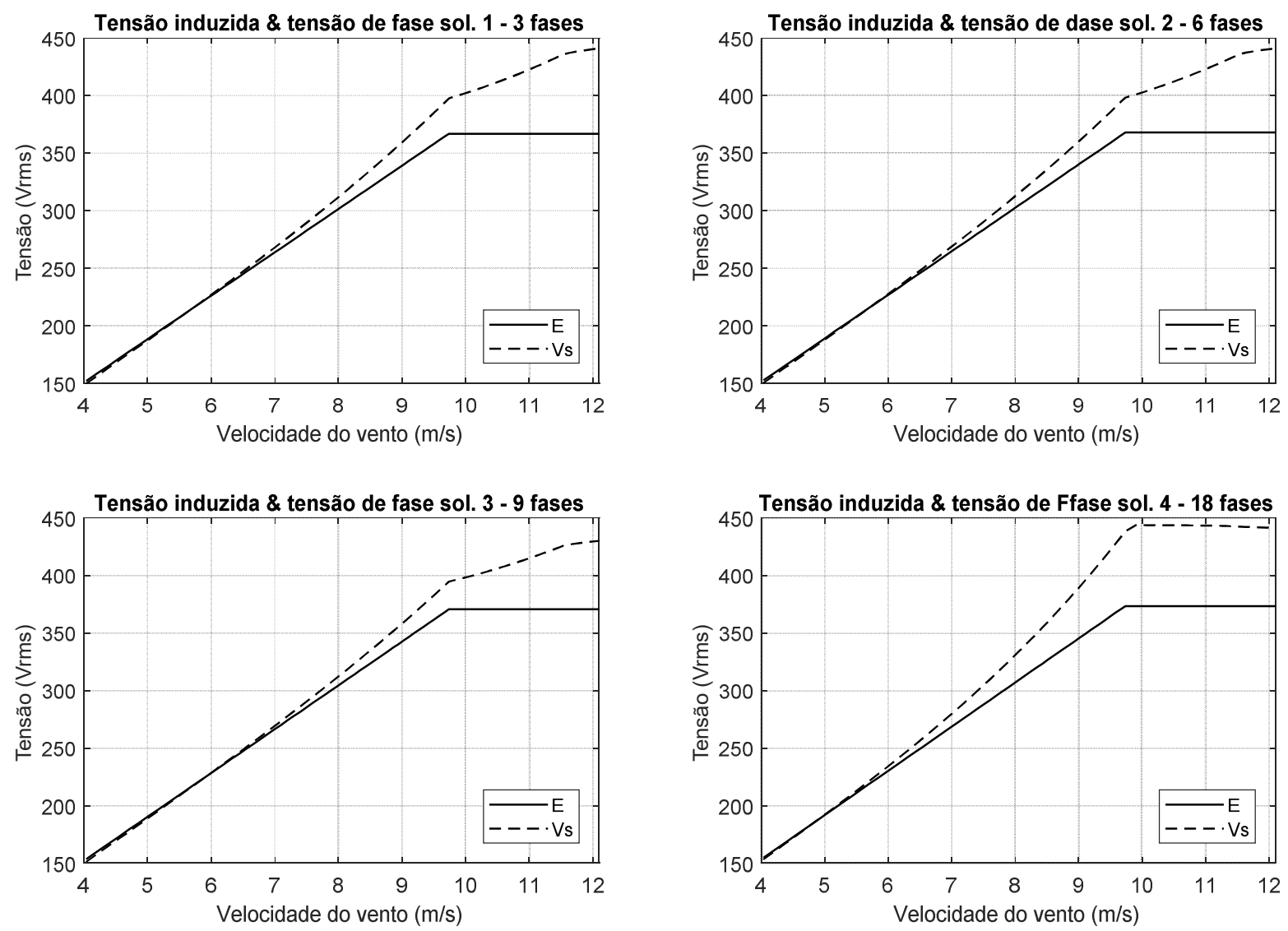

As relações entre corrente de fase, torque e velocidade de vento são apresentadas na sequência, onde é possível constatar uma relação praticamente linear entre torque e corrente. Isso ocorre, pois, o torque de relutância da topologia 
selecionada é relativamente pequeno (pequena diferença entre $L_{d}$ e $L_{q}$ ), desta forma $T \cong \frac{3 p}{2} \Psi_{p m} i_{q}$. Observa-se, entretanto, que quando a máquina de dezoito fases entra em modo de operação MTPV, há um aumento $\frac{d i_{s}}{d T}$.

A diferença entre os valores da corrente por conversor, necessários para estabelecer o mesmo torque no entreferro é relativamente pequena entre todas as topologias, tendo como base o gerador trifásico, esta diferença se encontra entre aprox. $\pm 1,85 \%$ (30A). Nota-se, entretanto, que para velocidades de vento menores que $11 \mathrm{~m} / \mathrm{s}$, a corrente por conversor requerida pelo gerador de dezoito fazes é inferior às correntes requeridas pelas demais topologias. O que se traduz numa eficiência ligeiramente maior quando a turbina opera em baixas velocidades de vento - Figura 38.

Figura 37 - Corrente por conversor e fator de potência
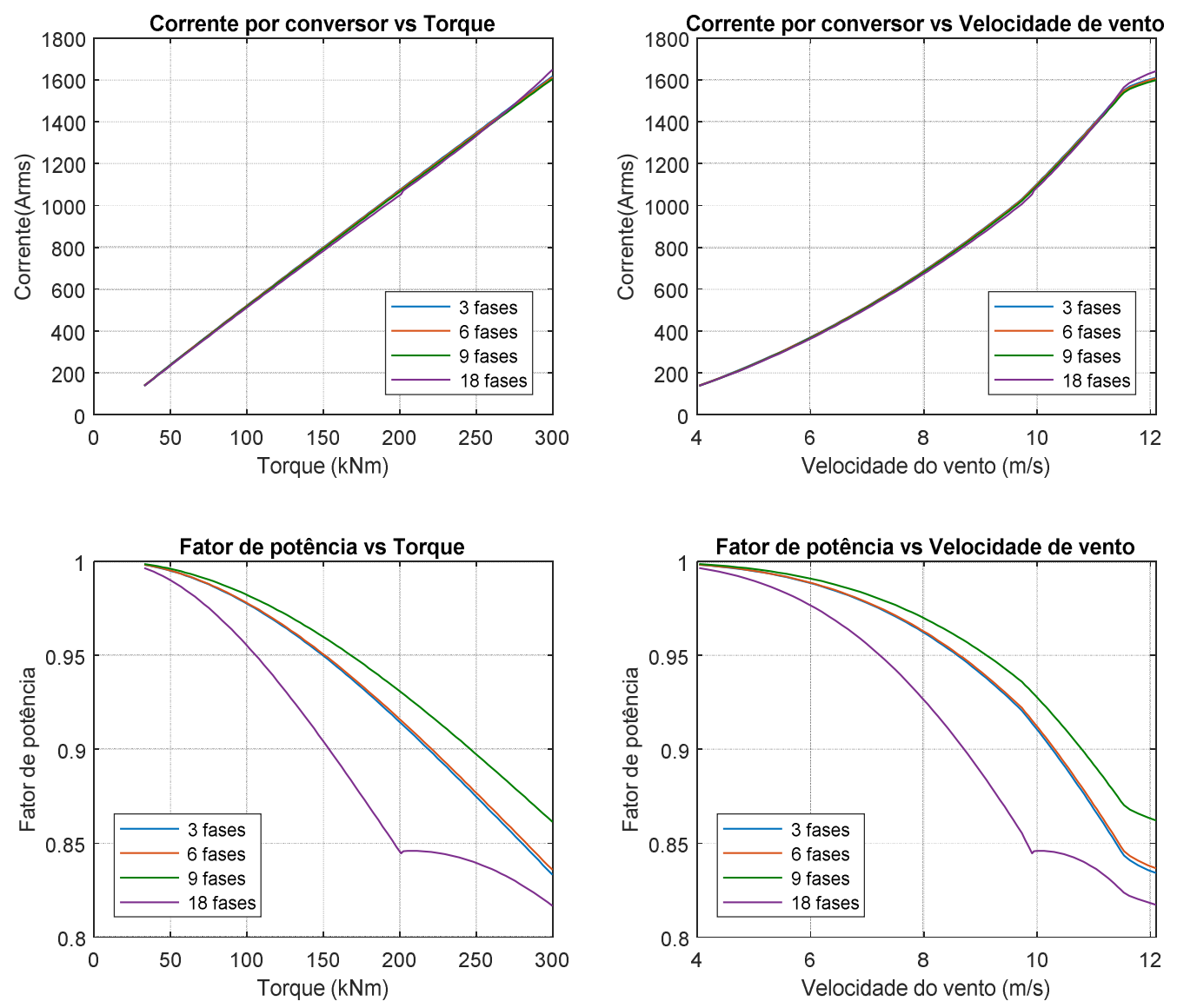
Em termos de rendimento e coeficiente de potência, pode-se afirmar que todas as topologias têm performance similar. Conforme, já comentado, isso é resultado do projeto com as mesmas condições de contorno $\left(B_{g}, A_{q}, J_{r}, \frac{D_{g}}{L_{e f}}\right)$.

Figura 38 - Rendimentos
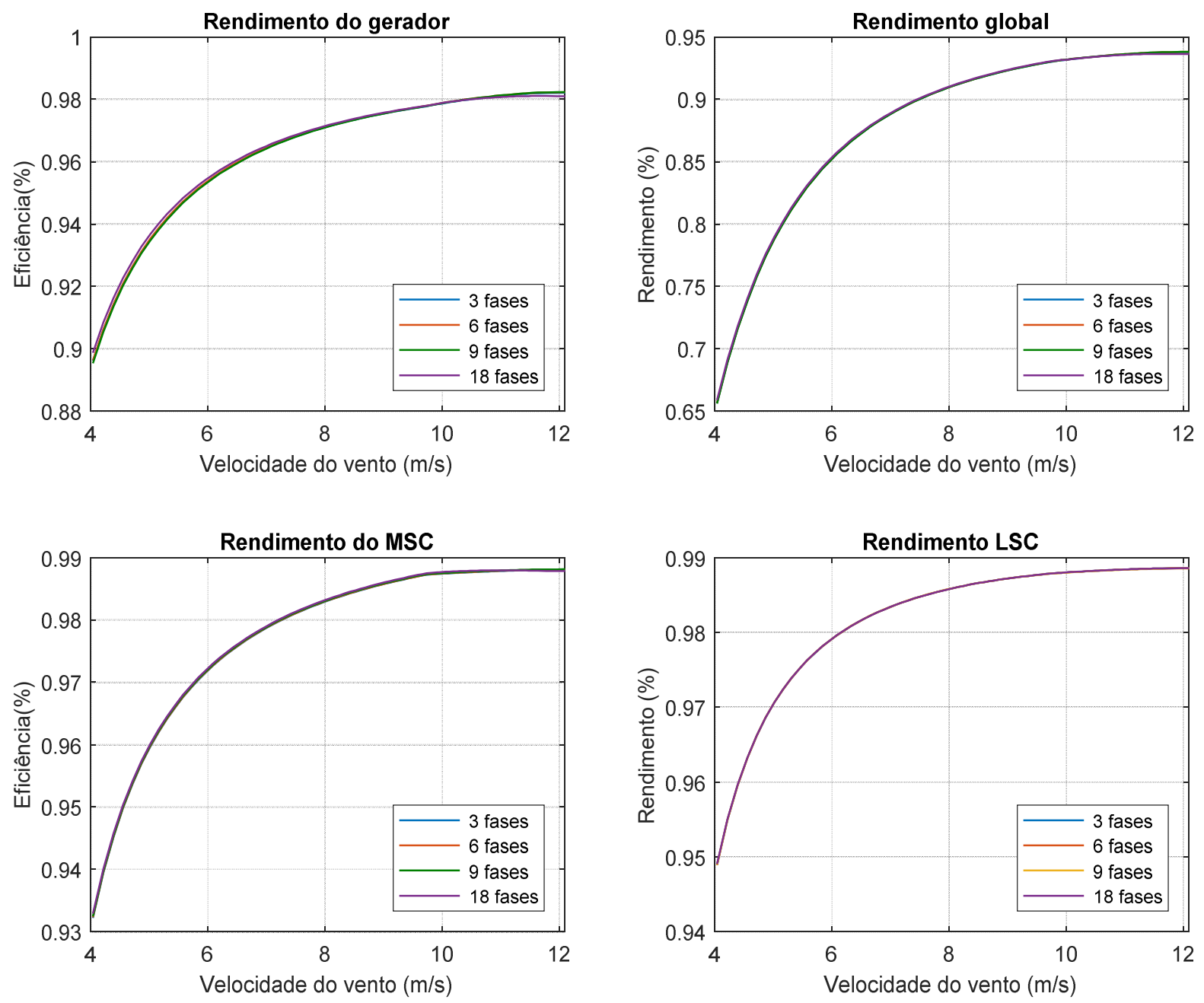

Figura 39 - Coeficiente de potência.

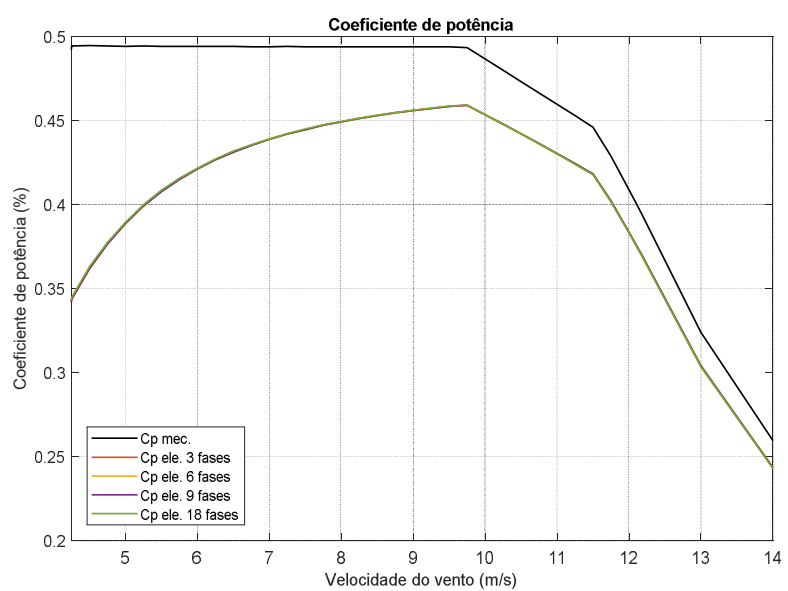


As diferenças entre os valores de fator de potência (Figura 37) entre as topologias analisadas, decorrem, principalmente, por conta da diferença entre as impedâncias internas de cada máquina $\left(L_{d}, L_{q}\right)$. Observa-se claramente a tendência para o MSC de operar com valores mais elevados de fator de potência com o aumento do número de pares de polos da máquina. Conforme, comentado anteriormente, isso decorre, pois, a indutância de magnetização é inversamente proporcional ao número de pares de polos, equação (3.54).

\subsection{CONCLUSÃO}

Com a análise dos resultados apresentados, opta-se por seguir adiante com o projeto detalhado do gerador de nove fases - solução 3. Embora todas as topologias tenham performance semelhante em termos rendimento, o projeto com gerador de nove fases tem vantagens significativas em termos de densidade de torque/potência, com uma redução de massa ativa esperada em torno de 9,7 \% em relação à massa ativa da solução trifásica.

O melhor fator de potência e menor valor de tensão nominal, são também desejáveis para que a estratégia de controle do MSC tenha maior margem para lidar com variações dos parâmetros internos do gerador (resistência/indutância), que resultam das tolerâncias/imperfeições durante o processo de fabricação. Ademais, o gerador de nove fases opera com maior frequência elétrica (maior número de pares de polos) e corrente por conversor nominal ligeiramente inferior. Estes fatores são também positivos para o projeto e fiabilidade do conversor retificador. 


\section{ANÁLISE POR ELEMENTOS FINITOS}

Neste capítulo modela-se o gerador escolhido, solução 3, pelo método de elementos finitos com a finalidade de validar e aumentar a precisão dos resultados apresentados anteriormente para esta topologia. A análise pelo método de elementos finitos tem os seguintes objetivos:

i. Avaliar a performance do método analítico para a estimação das condições de operação da máquina elétrica.

ii. Corrigir parâmetros da máquina $-\Psi_{p m}, L_{d}$ e $L_{q}$ e reavaliar a performance do gerador.

O projeto do estator e rotor da máquina são efetuados em AUTOCAD e a simulação magnetostática é conduzida através do software FEMM. Na figura a seguir apresenta-se o modelo 2D da máquina.

Figura 40 - Modelo 2D gerador de nove fases.

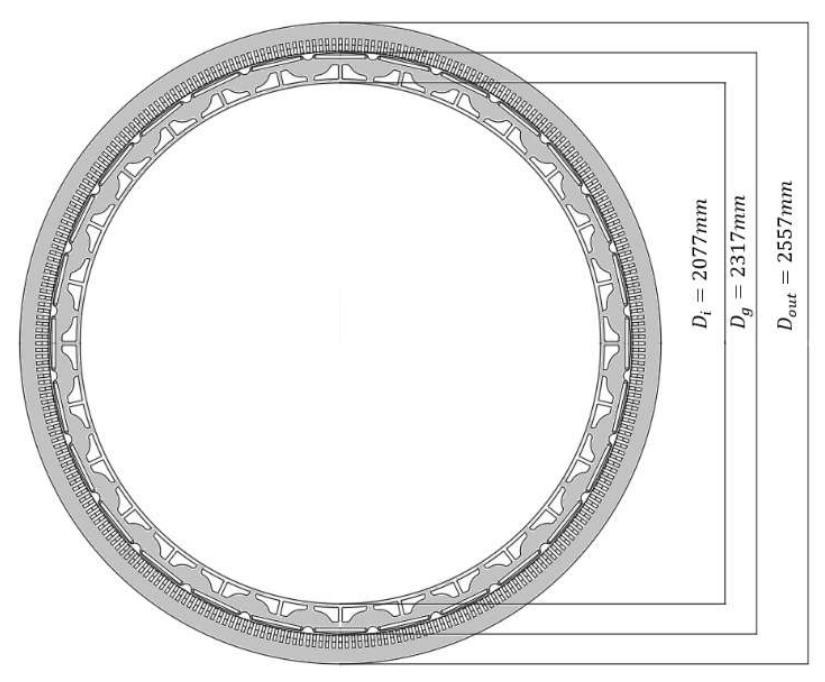

\subsection{INDUÇÃO E FLUXO MAGNÉTICOS}

Nesta secção são apresentados os resultados para indução e fluxo magnéticos provenientes das simulações por elementos finitos para as diferentes regiões da máquina elétrica. Assume-se que o fluxo magnético útil, é aquele que cruza a altura média dos dentes do estator. A Figura 43 mostra os resultados da simulação em FEMM para o campo de indução magnética nas diferentes regiões da máquina. 
Figura 41 - Modelo gerador de nove fases em FEMM.

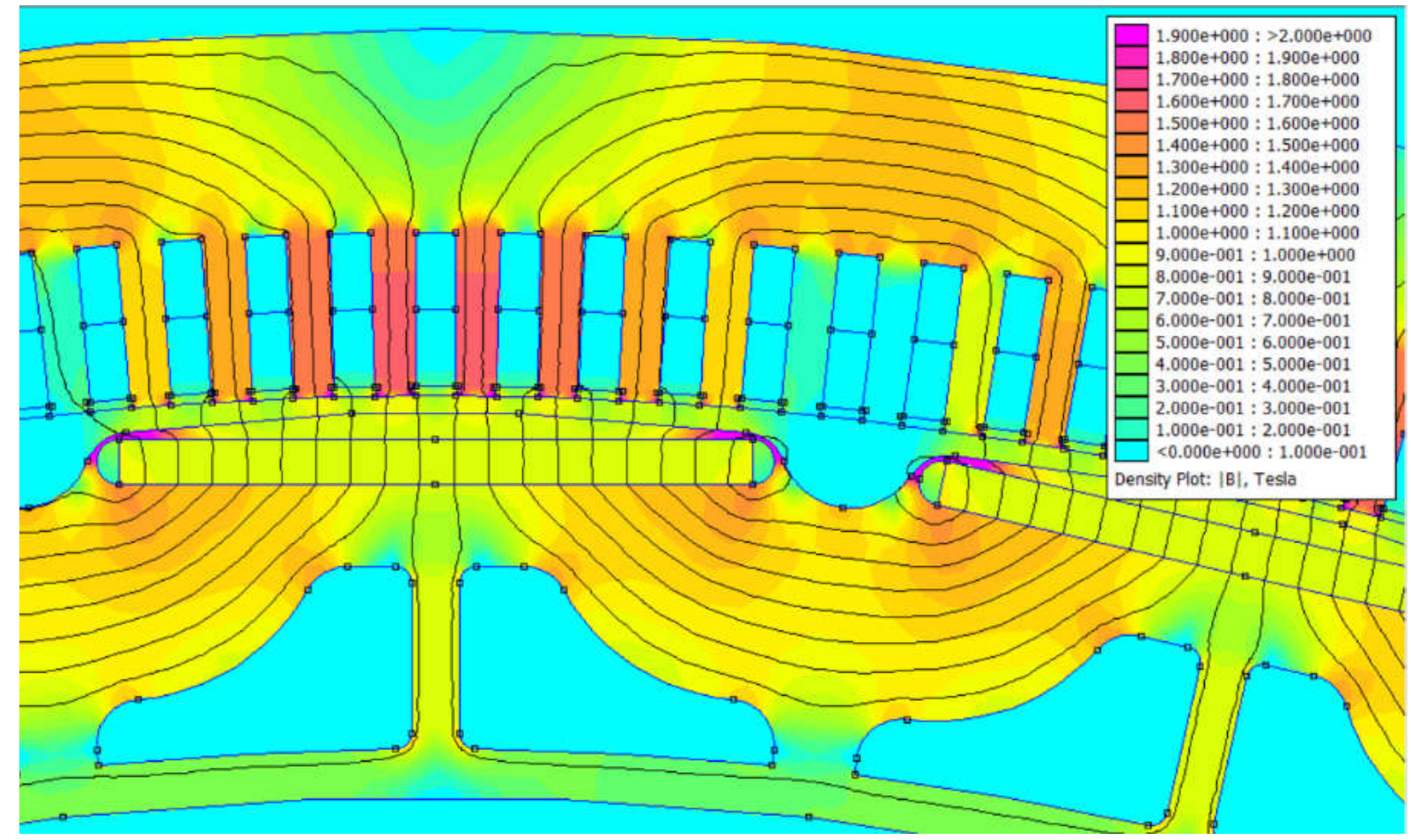

\subsubsection{Indução e fluxo magnético no imã}

O campo de indução magnética na altura média do imã é apresentado na figura a baixo. Observa-se uma diferença entre o valor médio $B_{m}$ de $\sim 0,9 \%$ entre o valor calculado pelo método analítico e o valor obtido pela simulação em FEMM $(0,870 \mathrm{~T}$ método analítico e 0,862 T - FEMM). Consequentemente, o fluxo magnético produzido pelo imã é de $\varphi_{m}=0,152 \mathrm{~Wb}$, também, 0,9\% inferior ao calculado pelo método analítico $0,153 \mathrm{~Wb}$.

Figura 42 - Modelo gerador de nove fases em FEMM.

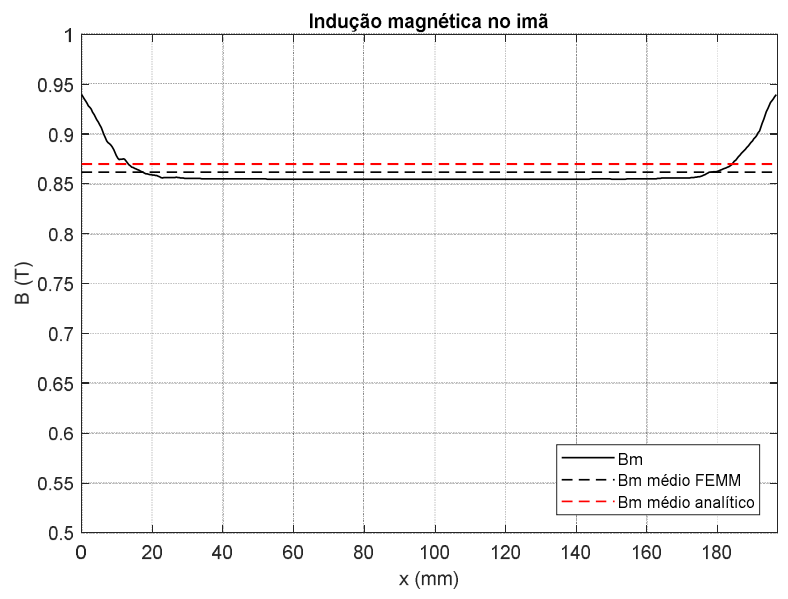




\subsubsection{Indução e fluxo magnético no entreferro}

Na Figura 43 apresenta-se a distribuição do campo de indução magnética no entreferro com a sua respectiva decomposição harmônica. $O$ valor da harmônica fundamental é de 0,9466 T, 4,8\% superior ao valor de projeto 0,903 T. A distorção harmônica total (THD) da forma de onda da indução magnética no entreferro é de 19,42 \%. A harmônica de maior amplitude é a nona harmônica com valor de 0,0905 T (9,56 \% em relação à harmônica fundamental).

Figura 43 - Indução magnética no entreferro.
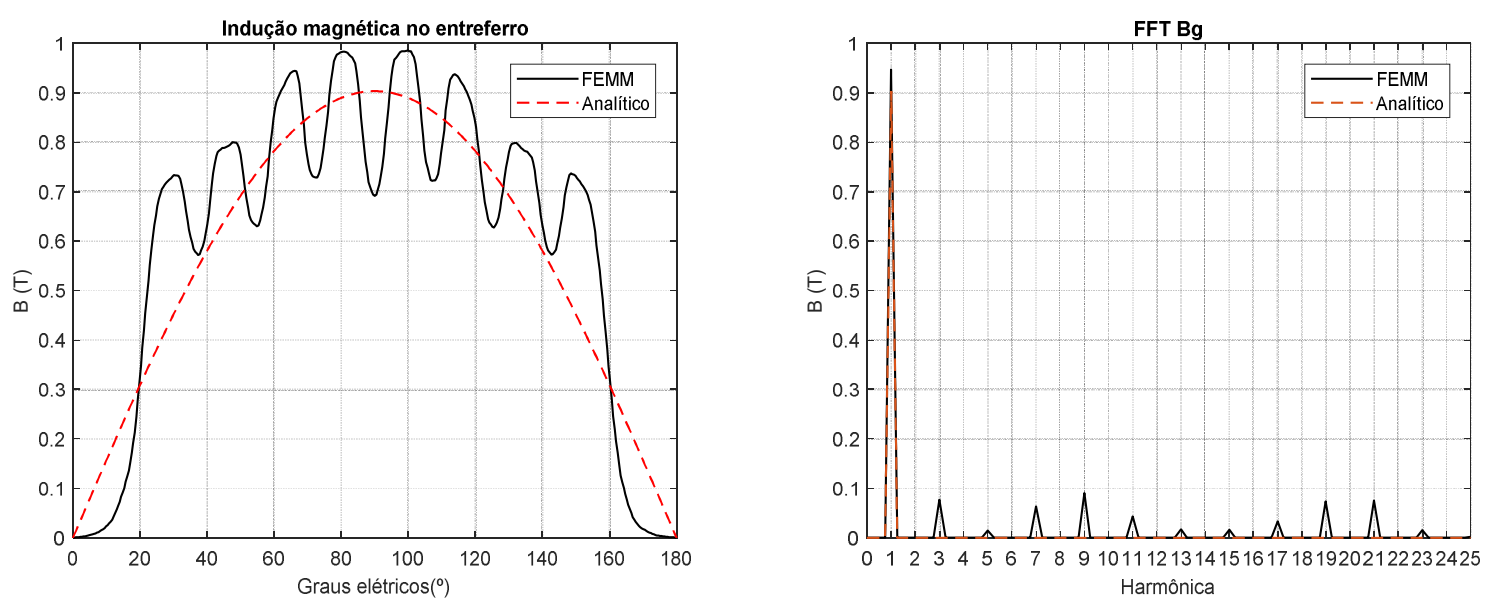

O valor médio da indução magnética no entreferro é de 0,604 T (FEMM), 5\% superior ao valor estimado pelo projeto analítico $-0,575 \mathrm{~T}$.

\subsubsection{Indução e fluxo magnético na altura média das ranhuras}

Conforme comentado previamente, assume-se que o fluxo magnético útil para produção de tensão induzida é aquele que cruza a área do passo polar na altura média das ranhuras. A distribuição do campo de indução magnética na altura média dos dentes do estator é apresentada na Figura 44. Observa-se que o valor máximo da indução magnética chega a 1,63 T para os dentes alinhados com o eixo-d. $O$ valor médio do campo de indução magnética nesta região é de 0,599 T.

O fluxo magnético é calculado para passos polares na altura média das ranhuras. Como o número de ranhuras por polo não é inteiro ( $q$ fracionário), mede-se o fluxo magnético ao longo de um grupo de simetria do estator (sete polos). $O$ resultado da distribuição espacial do fluxo magnético útil, incluindo a sua decomposição harmônica, é apresentado na Figura 45. 
Figura 44 - Indução magnética nos dentes (altura média).

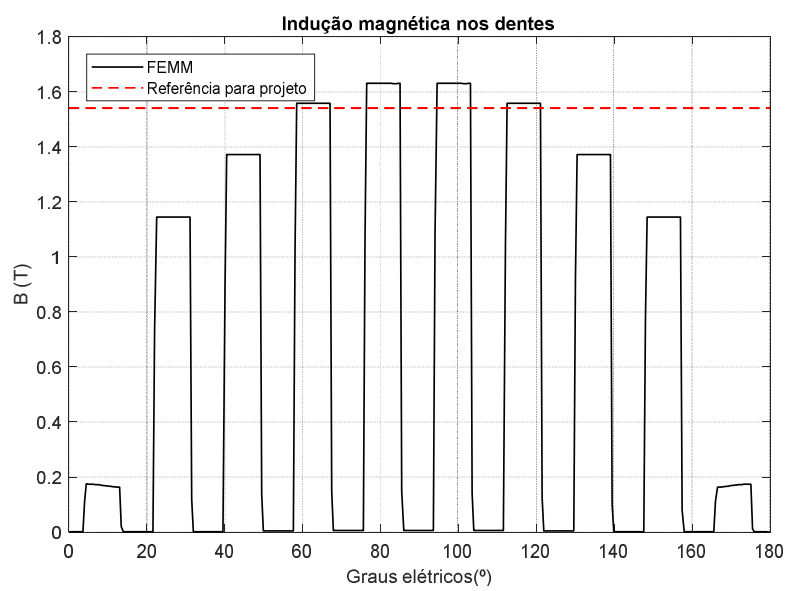

Figura 45 - Distribuição espacial do fluxo magnético útil.
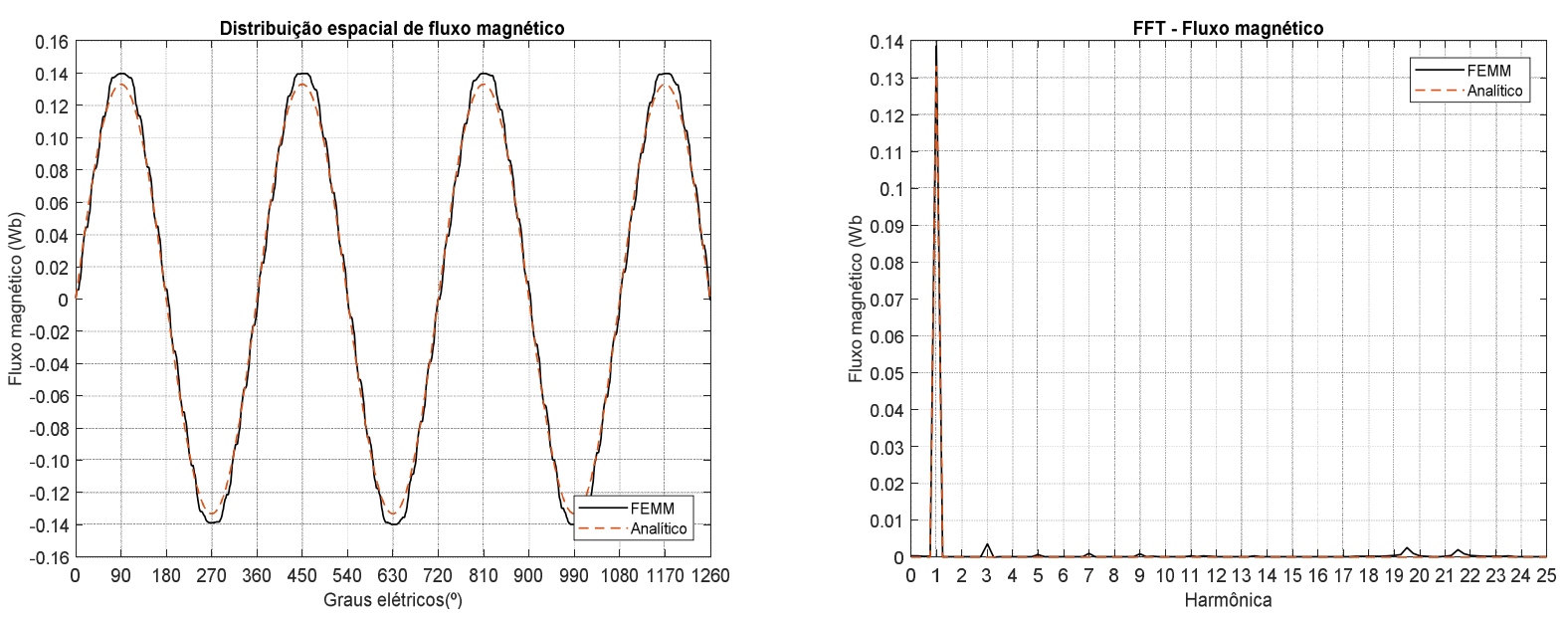

A primeira harmônica do fluxo magnético útil calculado em FEMM é de $0,1387 \mathrm{~Wb}$, o que resulta num fator de dispersão $k_{d i s}=1,095$, quando comparado ao fluxo produzido pelo imã de $0,152 \mathrm{~Wb}$ (secção 7.1.1). Conforme observado na Figura 45 as harmônicas presentes na distribuição de fluxo magnético são bastante reduzidas, com THD de 3,86 \%. Portanto, valida-se a aproximação analítica de se considerar apenas a harmônica fundamental para cálculo da tensão induzida pelo gerador.

Para o projeto analítico do gerador, considerou-se $k_{\text {dis }}=1,15$, uma diferença de $5 \%$ em relação ao valor obtido pelas simulações em FEMM. Esta discrepância é um dos fatores principais para justificar as diferenças entre os valores do campo de indução magnética e fluxo magnético, nas diferentes regiões da máquina, entre o projeto analítico e as simulações por elementos finitos. 
Para melhorar a precisão do projeto analítico, seria possível alterar o valor $k_{d i s}$, de forma a obter uma melhor correlação com os resultados obtidos em FEMM. Salienta-se, entretanto, que por se tratar de um modelo 2D, alguns fatores que contribuem para dispersão do fluxo magnético, como, por exemplo, a dispersão frontal entre sapatas polares adjacentes, não são contemplados. Desta forma, é recomendável que $k_{d i s}$ seja ligeiramente sobrestimado, no projeto analítico na expectativa de se obter melhor correlação com os valores reais de operação.

\subsubsection{Indução magnética na coroa estatórica}

O valor estimado pelo projeto analítico para a indução magnética na coroa estatórica é de 1,2 T, enquanto o valor médio obtido pela simulação em FEMM é de 1,23 T. A distribuição do campo de indução magnética ao longo da coroa estatórica é apresentada na Figura 46.

Figura 46 - Campo de Indução magnética na coroa estatórica.

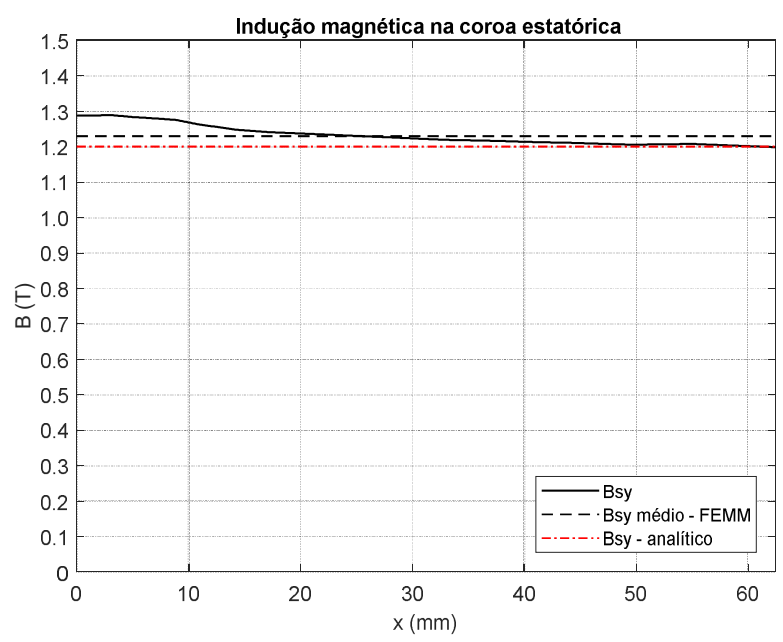

\subsubsection{Indução magnética na coroa rotórica}

O campo de indução magnética na coroa rotórica é apresentado na figura a seguir. O valor médio $B_{r y}$ segundo as simulações em FEMM é de 1,24 T, enquanto o valor de projeto é de 1,30 T. Para o projeto analítico, assume-se que todo o fluxo magnético do imã passa pela área $h_{r y} L_{e f}$, enquanto no projeto específico existem outros caminhos para passagem do fluxo magnético. Desta o projeto analítico, em geral, tende a sobrestimar o campo de indução magnética média nesta região. 
Figura 47 - Campo de Indução magnética na coroa rotórica.

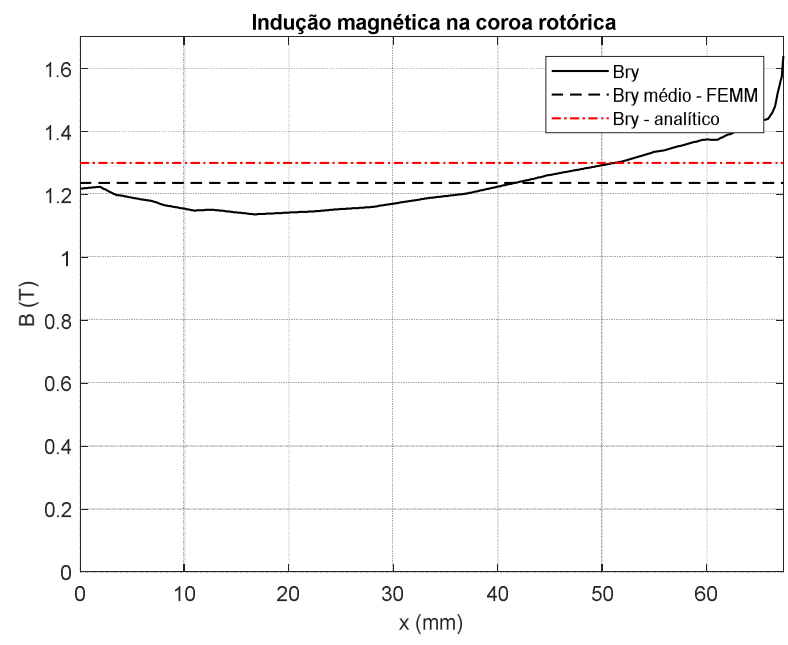

\subsubsection{Discussão dos resultados}

Com os resultados apresentados entre as secções 7.1.1 e 7.1.5, pode-se afirmar que os resultados do projeto analítico do gerador são capazes de providenciar uma base sólida para o projeto eletromagnético da máquina elétrica. A tabela a seguir sumariza os principais resultados apresentados:

Tabela 28 - Comparação de resultados

\begin{tabular}{|c|c|c|c|c|}
\hline Parâmetro & Método analítico & FEMM & Unidade & Diferença \\
\hline$B_{m}$ & 0,870 & 0,862 & $T$ & $0.9 \%$ \\
\hline$\varphi_{m}$ & 0,153 & 0,152 & $W b$ & $0.7 \%$ \\
\hline$B_{g}$ & 0,903 & 0,947 & $T$ & $-4.6 \%$ \\
\hline$B_{g m}$ & 0,575 & 0,604 & $T$ & $-4.8 \%$ \\
\hline$B_{t m}$ & 1,54 & 1,64 & $T$ & $-6.1 \%$ \\
\hline$\varphi_{u}$ & 0,133 & 0,139 & $W b$ & $-3.9 \%$ \\
\hline$B_{s y}$ & 1,20 & 1,23 & $T$ & $-2.4 \%$ \\
\hline$B_{r y}$ & 1,30 & 1,24 & $T$ & $4.8 \%$ \\
\hline$k_{\text {dis }}$ & 1,15 & 1,095 & - & $5.0 \%$ \\
\hline
\end{tabular}

A diferença mais elevada refere-se ao valor máximo da indução magnética no dente. Comenta-se, entretanto, que no cálculo analítico $B_{t m}$ é utilizado como um valor de referência para cálculo da queda de força magnetomotriz nesta região, sem a intenção de especificar um valor máximo, absoluto. Portanto, para o projeto analítico é importante garantir que $B_{t m}$ tenha uma margem de $\sim 10 \%$ em relação a valores aceitáveis de indução magnética no ferro.

Espera-se que as diferenças encontradas nos resultados de $B_{g}, B_{g m}, \varphi_{u}$ e $k_{d i s}$, em torno de $5 \%$, sejam reduzidas no projeto real da máquina, uma vez que o modelo 
2D não é capaz de incorporar fenômenos tridimensionais e outras imperfeições. Portanto, na perspetiva do autor, esta diferença é desejável e serve como uma margem de segurança para garantir que o projeto é capaz de atingir a performance esperada.

\subsection{INDUTÂNCIAS}

Para cálculo das indutâncias, os enrolamentos do gerador são modelados em FEMM para um grupo de simetria (sete polos). Além disso, os imãs são retirados do circuito magnético.

A metodologia para cálculo das indutâncias consiste em se injetar corrente no eixo direto ou no eixo em quadratura e medir os fluxos ligados em cada fase. O fluxo magnético ligado por fase é então transformado para o referencial $d q 0$ e, então,

calcula-se $L_{d}=\frac{\Psi_{d}}{I_{d}}+l_{e w}+l_{b l}, \quad L_{q}=\frac{\Psi_{q}}{I_{q}}+l_{e w}+l_{b l}$. Onde $l_{e w}$ é a indutância de dispersão de final de enrolamento e $l_{b l}$ é a indutância de dispersão harmônica.

\subsubsection{Variação Ld e Lq com posição angular do rotor.}

Para estimação de $L_{d}$ aplica-se $I_{d}=I_{n} / 4$ e $I_{q}=0$, simula-se apenas um grupo de simetria da máquina, os 4 grupos de simetria do gerador são conectados em paralelo. Defasa-se o rotor de $3^{\circ}$ elétricos e repete-se o procedimento.

Afim de converter os valores de referência no referencial $d q 0$ para coordenadas de fase, aplica-se a transformação invariante em amplitude - conforme discutido no Apêndice D. Este procedimento é descrito pela relação a seguir:

$$
I_{1 \ldots 9}=\frac{9}{2} T_{\alpha \beta 0}{ }^{T} T_{d q 0}{ }^{-1} I_{d q 0}
$$

Com os resultados da simulação os valores de fluxo magnético no referencial $d q 0$ são calculados por:

$$
\Psi_{d q 0}=T_{d q 0} T_{\alpha \beta 0} \Psi_{1 \ldots 9}
$$


Figura 48 - Injeção de corrente segundo eixo-d.

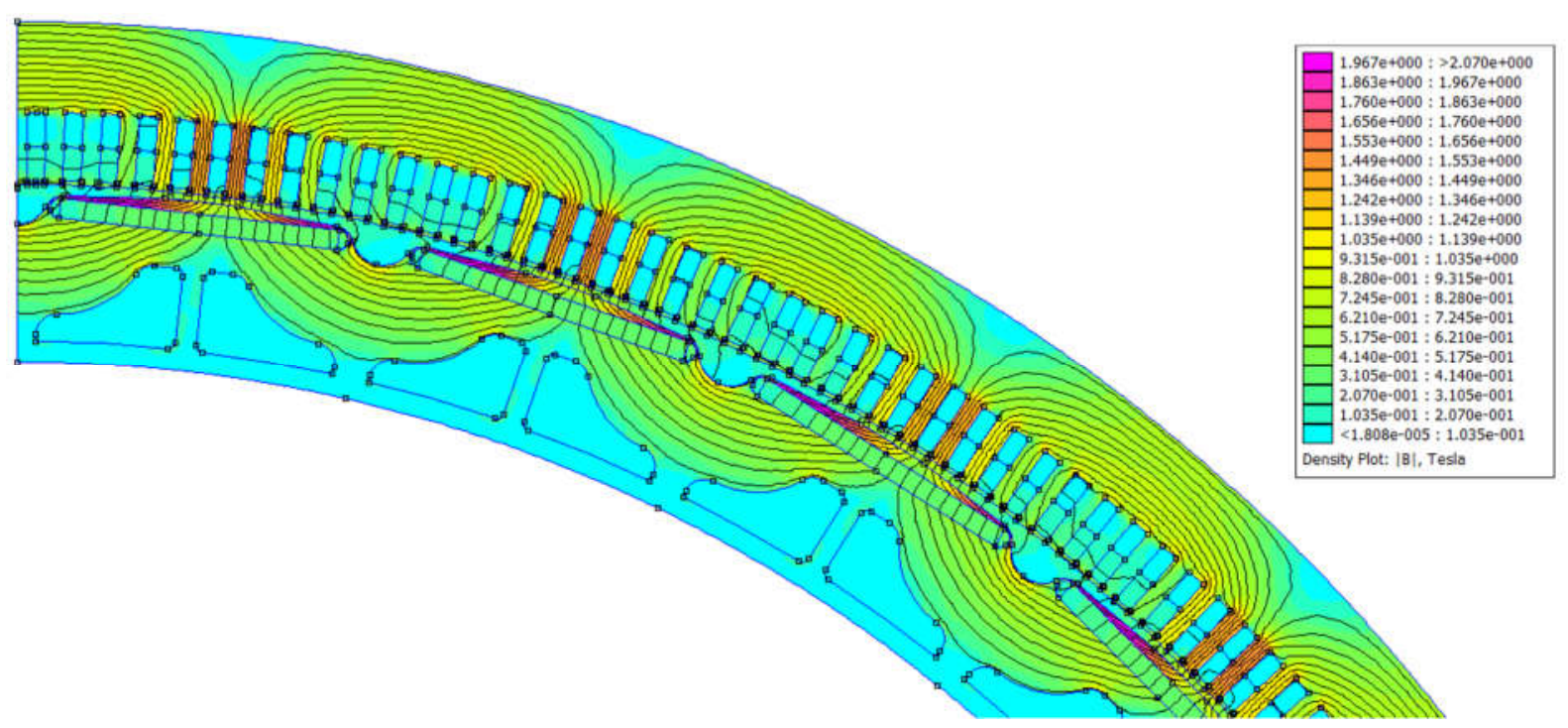

Figura 49 - Injeção de corrente segundo eixo-q.

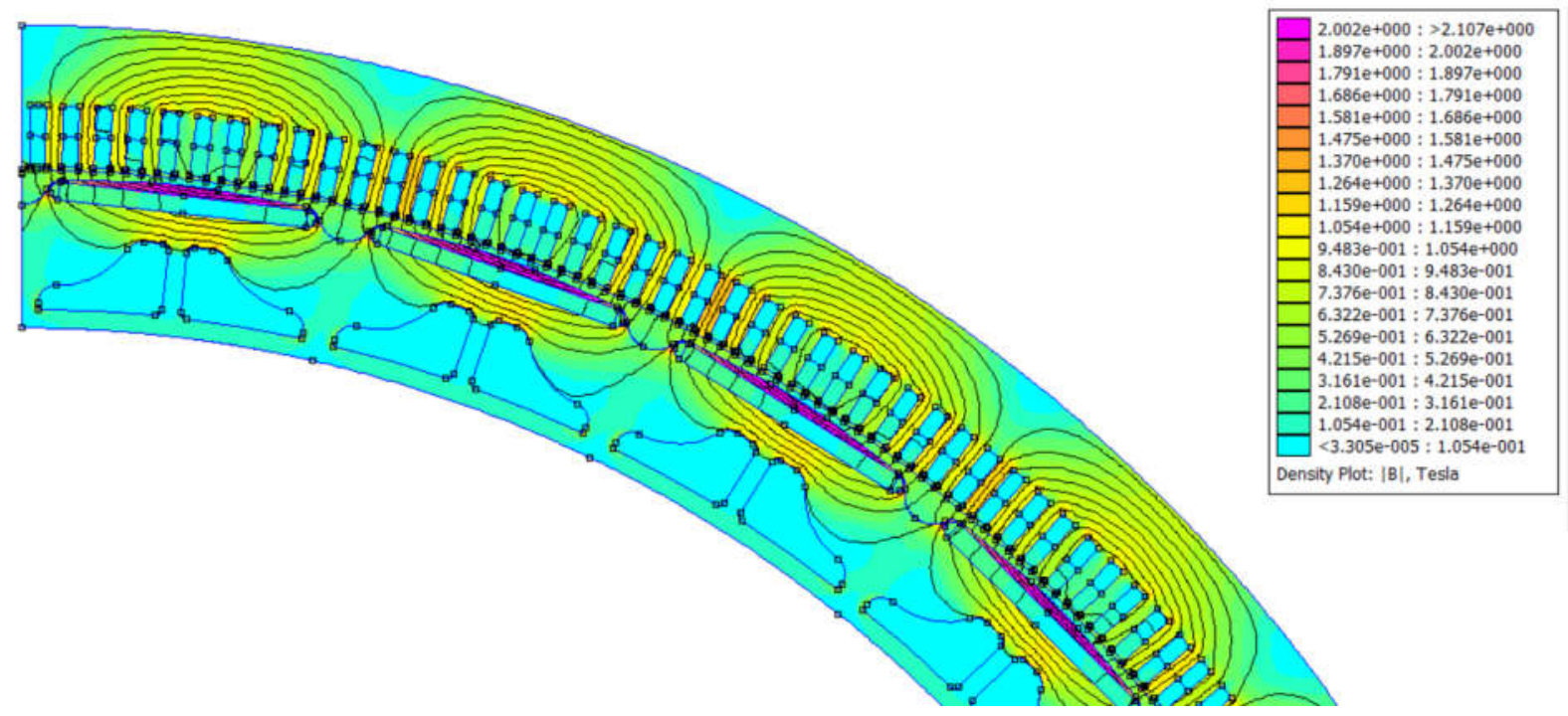

Os resultados são apresentados na Figura 50. Observa-se, que os valores de $L_{d}$ e $L_{q}$ são aproximadamente constantes, independente da posição angular do rotor. Nota-se, entretanto, uma oscilação de quarta-harmônica espacial com amplitude de $6,9 \mu \mathrm{H}(4.4 \%)$. Os valores médios de $L_{d}$ e $L_{q}$ são iguais: $L_{d}=L_{q}=156,45 \mu \mathrm{H}$.

Na Tabela 29 apresenta-se a comparação entre os valores de $L_{d}$ e $L_{q}$ quando calculados em FEMM e os valores estimados pelo método analítico. 
Figura $50-L_{d q}(\theta)$

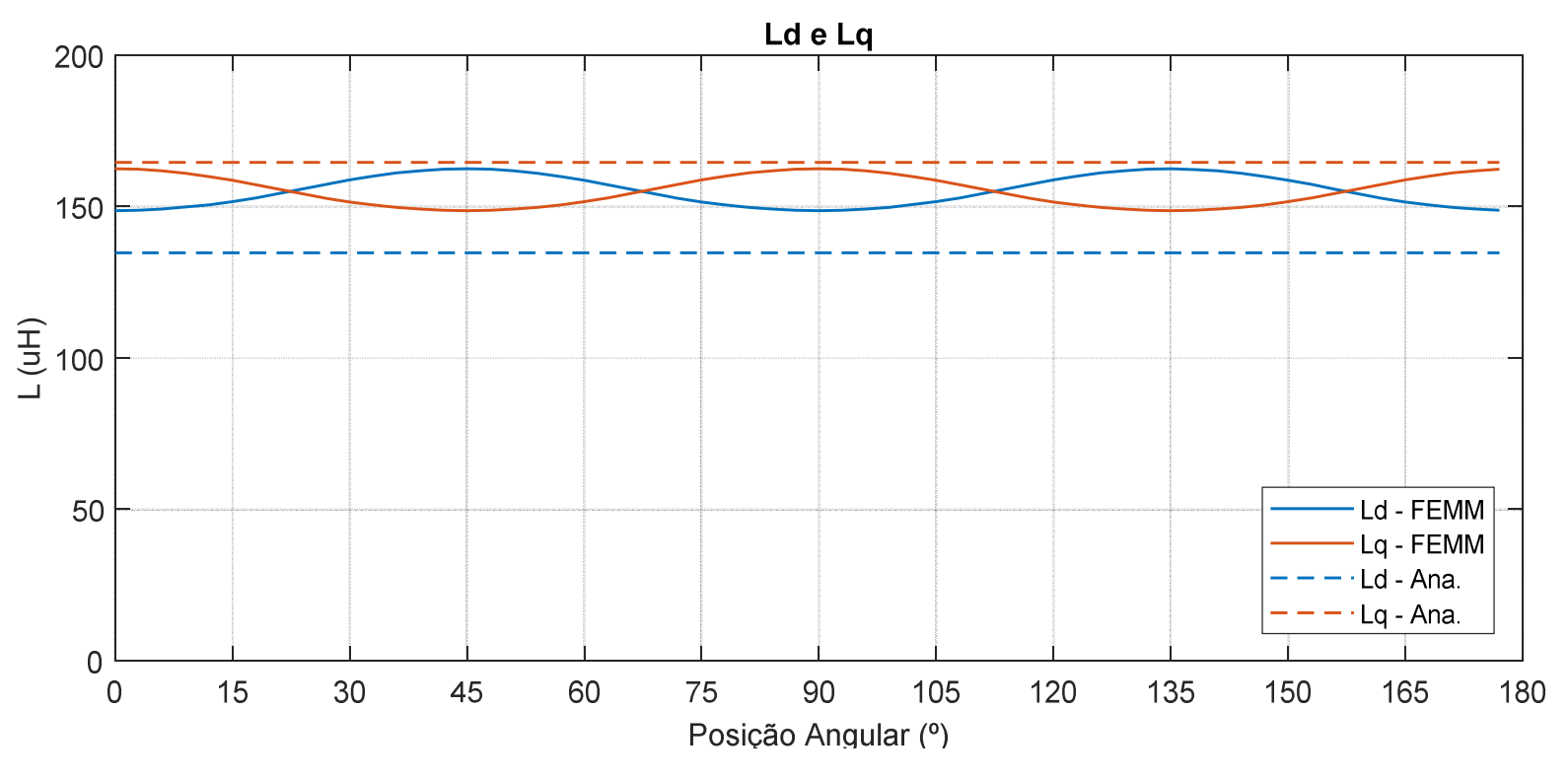

Tabela 29 - Resultados Ld, Lq em FEMM.

\begin{tabular}{|c|c|c|c|c|}
\hline Parâmetro & Método analítico & FEMM & Unidade & Diferença \\
\hline$L_{d}$ & 134,7 & 156,45 & $\mu \mathrm{H}$ & $-13,9 \%$ \\
\hline$L_{q}$ & 164,6 & 156,45 & $\mu \mathrm{H}$ & $5,19 \%$ \\
\hline
\end{tabular}

7.2.2 Variação Ld e Lq com id e iq.

Os valores das indutâncias segundo os eixos direto e de quadratura, na secção anterior, foram estimados considerando o valor nominal de corrente em apenas um dos eixos. Nesta secção, $L_{d}$ e $L_{q}$ são calculados para diferentes valores de corrente de fase em ambos os eixos, de forma a ser possível estabelecer tabelas de interpolação (lookup tables) $-L_{d}\left(i_{d}, i_{q}\right), L_{q}\left(i_{d}, i_{q}\right)$ - que são tipicamente utilizada para modelagem da máquina elétrica.

As simulações são realizadas com rotor parado, a metodologia para estimação de $L_{d}$ e $L_{q}$ é idêntica ao apresentado na secção anterior. Os dados apresentados nas tabelas a seguir foram tratados para retirar a componente de quarta harmônica. 
Tabela 30 - Ld (id,iq).

\begin{tabular}{|c|c|c|c|c|c|c|}
\hline $\boldsymbol{L}_{\boldsymbol{d}}\left(\boldsymbol{i}_{\boldsymbol{d}}, \boldsymbol{i}_{\boldsymbol{q}}\right)$ & \multicolumn{7}{|c|}{$\boldsymbol{i}_{\boldsymbol{q}}(\mathbf{p u})$} \\
\hline $\boldsymbol{i}_{\boldsymbol{d}}(\mathbf{p u})$ & $\mathbf{0 , 0 0}$ & $\mathbf{0 , 2 0}$ & $\mathbf{0 , 4 0}$ & $\mathbf{0 , 6 0}$ & $\mathbf{0 , 8 0}$ & $\mathbf{1 , 0 0}$ \\
\hline $\mathbf{0 , 0 0}$ & - & - & - & - & - & - \\
\hline $\mathbf{0 , 2 0}$ & 169,7 & 148,8 & 130,4 & 123,3 & 119,7 & 117,0 \\
\hline $\mathbf{0 , 4 0}$ & 167,6 & 158,6 & 146,6 & 139,4 & 135,0 & 132,2 \\
\hline $\mathbf{0 , 6 0}$ & 163,0 & 160,4 & 152,8 & 146,3 & 141,7 & 138,3 \\
\hline $\mathbf{0 , 8 0}$ & 159,5 & 158,2 & 154,6 & 149,9 & 145,5 & 141,7 \\
\hline $\mathbf{1 , 0 0}$ & 156,4 & 155,7 & 153,5 & 150,3 & 146,7 & 143,1 \\
\hline
\end{tabular}

Tabela 31 - Lq (id,iq).

\begin{tabular}{|c|c|c|c|c|c|c|}
\hline $\boldsymbol{L}_{\boldsymbol{q}}\left(\boldsymbol{i}_{\boldsymbol{d}}, \boldsymbol{i}_{\boldsymbol{q}}\right)$ & \multicolumn{6}{|c|}{$\boldsymbol{i}_{\boldsymbol{q}}(\mathbf{p u})$} \\
\hline $\boldsymbol{i}_{\boldsymbol{d}}(\mathbf{p u})$ & $\mathbf{0 , 0 0}$ & $\mathbf{0 , 2 0}$ & $\mathbf{0 , 4 0}$ & $\mathbf{0 , 6 0}$ & $\mathbf{0 , 8 0}$ & $\mathbf{1 , 0 0}$ \\
\hline $\mathbf{0 , 0 0}$ & - & 229,4 & 188,6 & 172,0 & 162,8 & 156,4 \\
\hline $\mathbf{0 , 2 0}$ & - & 209,0 & 185,9 & 171,2 & 162,4 & 156,2 \\
\hline $\mathbf{0 , 4 0}$ & - & 184,6 & 178,9 & 168,8 & 161,3 & 155,5 \\
\hline $\mathbf{0 , 6 0}$ & - & 162,1 & 169,0 & 164,5 & 159,1 & 154,3 \\
\hline $\mathbf{0 , 8 0}$ & - & 149,7 & 159,3 & 159,0 & 155,9 & 152,2 \\
\hline $\mathbf{1 , 0 0}$ & - & 141,7 & 152,1 & 153,5 & 151,8 & 149,2 \\
\hline
\end{tabular}

\subsubsection{Discussão dos resultados}

A estimação de $L_{d}$ e $L_{q}$ através dos métodos analíticos e, especialmente, para máquinas com excitação por imãs permanentes, dificilmente resulta em resultados precisos. Diferenças da ordem de 10 - 20\% são esperadas. A geometria de máquinas de imãs permanentes pode variar significativamente de projeto para projeto, resultando em caminhos alternativos para passagem de fluxo magnético que, em geral, não são considerados no cálculo analítico. Além disso, pelos métodos analíticos, normalmente, assume-se que o ponto de operação do ferro (em termos de saturação), tem impacto desprezível para o cálculo das indutâncias da máquina, caso isso fosse verdade $L_{d}\left(i_{d}, i_{q}\right)$ e $L_{q}\left(i_{d}, i_{q}\right)$ seriam constantes.

Considerando as limitações dos métodos analíticos, observa-se, na Tabela 29, que as indutâncias da máquina foram estimadas de forma bastante razoável, neste caso específico, com erro de $-13,9 \%$ para $L_{d}$ e de $5,19 \%$ para $L_{q}$.

Com a análise por elementos finitos, nota-se que as indutâncias da máquina não são constantes. $L_{d}$ e $L_{q}$ variam com a magnitude da corrente nos seus respectivos eixos. Além disso, observa-se que os efeitos de "saturação cruzada" (cross-coupling) são significativos. Desta forma, os pontos ótimos de operação da máquina não podem ser calculados diretamente pelas equações (4.17) e (4.18). 


\subsection{PERFORMANCE GERADOR DE 9 FASES}

Nesta secção pretende-se comparar a performance estimada pelo método analítico e através das simulações em FEMM para o gerador de nove fases (solução 3). Com a análise pelo método de elementos finitos, obteve-se um valor de fluxo magnético útil ( $\varphi_{u}$, Tabela 28) 3,9\% superior ao valor estimado pelo método analítico. Esta diferença tem impacto no parâmetro $\Psi_{p m}=N_{s f} k_{e 1} \varphi_{u}[\mathrm{~V} / \mathrm{s}]$, Apêndice D.

Os resultados apresentados no capítulo 6, assumem $L_{d}$ e $L_{q}$ constantes (134,7 e 164,6 $\mu \mathrm{H}$, respectivamente) e ponto de operação do gerador definidos pela relação (4.17). Para a análise da performance da máquina, considerando os resultados obtidos em FEMM, utiliza-se as tabelas 30 e 31, para estimar $L_{d}$ e $L_{q}$ em diferentes pontos de operação. Uma vez que as indutâncias não são constantes, a relação (4.17) não é mais válida. Desta forma, torna-se necessário estabelecer uma metodologia para definir os valores de referência de $i_{d}$ e $i_{q}$ para o controle de torque do gerador.

\subsubsection{Controle de torque}

Aplica-se o seguinte procedimento para se estabelecer os valores de $i_{d}$ e $i_{q}$ para cada nível de torque desejado:

i. Assume-se um valor específico para a corrente de fase $i_{s}$.

ii. Calcula-se $L_{d}, L_{q}$ e o torque desenvolvido para $i_{d}=0$.

iii. A magnitude de $i_{q}$ é reduzida em $1 \%$ do valor de $i_{s}$.

iv. $\quad i_{d}$ é calculado por $i_{d}=-\sqrt{i_{s}{ }^{2}-i_{q}{ }^{2}}$.

v. Calcula-se $L_{d}, L_{q}$ e o torque desenvolvido.

vi. Caso o torque aumente, repete-se os passos de 3 a 5. Caso contrário, o ponto de operação foi encontrado.

vii. Aumenta-se $i_{s}$ e repete-se o procedimento.

Esta metodologia permite encontrar pontos de operação, aproximadamente ótimos, e é semelhante ao procedimento que poderia ser desenvolvido para calibração 
da máquina durante ensaios experimentais. Os resultados são apresentados na tabela a seguir:

Tabela 32 - Pontos de operação FEMM

\begin{tabular}{|c|c|c|c|c|c|}
\hline $\boldsymbol{T}(\mathbf{p u})$ & $\boldsymbol{i}_{\boldsymbol{s}}(\mathbf{p u})$ & $\boldsymbol{i}_{\boldsymbol{d}}(\mathbf{p u})$ & $\boldsymbol{i}_{\boldsymbol{q}}(\mathbf{p u})$ & $\boldsymbol{L}_{\boldsymbol{d}}(\boldsymbol{\mu H})$ & $\boldsymbol{L}_{\boldsymbol{q}}(\boldsymbol{\mu H})$ \\
\hline 0 & 0,00 & 0 & 0 & - & - \\
\hline 0,05 & 0,05 & 0,000 & 0,050 & 163,7 & 260,1 \\
\hline 0,10 & 0,10 & 0,000 & 0,100 & 155,5 & 249,9 \\
\hline 0,21 & 0,20 & $-0,028$ & 0,198 & 140,7 & 227,0 \\
\hline 0,31 & 0,30 & $-0,042$ & 0,297 & 129,7 & 207,1 \\
\hline 0,42 & 0,40 & $-0,056$ & 0,396 & 119,3 & 188,6 \\
\hline 0,53 & 0,50 & $-0,071$ & 0,495 & 116,6 & 180,1 \\
\hline 0,63 & 0,60 & $-0,085$ & 0,594 & 114,2 & 172,1 \\
\hline 0,74 & 0,70 & $-0,099$ & 0,693 & 113,6 & 167,4 \\
\hline 0,84 & 0,80 & $-0,113$ & 0,792 & 113,1 & 162,9 \\
\hline 0,95 & 0,90 & $-0,127$ & 0,891 & 112,9 & 159,7 \\
\hline 0,97 & 0,92 & $-0,130$ & 0,911 & 112,8 & 159,1 \\
\hline 0,99 & 0,94 & $-0,133$ & 0,931 & 112,8 & 158,4 \\
\hline 1,02 & 0,96 & $-0,135$ & 0,950 & 112,8 & 157,8 \\
\hline 1,04 & 0,98 & $-0,138$ & 0,970 & 112,7 & 157,2 \\
\hline 1,06 & 1,00 & $-0,141$ & 0,990 & 112,7 & 156,6 \\
\hline
\end{tabular}

\subsubsection{Comparação dos resultados}

A Tabela 33 apresenta as condições nominais de operação estimadas pelo método analítico e pelo método de elementos finitos. Observa-se uma ligeira melhoria dos resultados, em termos de potência, fator de potência, rendimento e densidade de perdas no entreferro, após a análise detalhada em FEMM.

Com a análise por elementos finitos é possível aumentar a precisão dos parâmetros estimados pelos métodos analíticos. Para máquinas de imãs permanentes, existe vantagem significativa na estimação das indutâncias e do ponto de operação do gerador. Em todo caso, é possível afirmar que o projeto analítico foi capaz de providenciar resultados robustos e uma boa estimação para guiar o projeto detalhado do gerador. 
Tabela 33 - Condições nominais de operação

\begin{tabular}{|c|c|c|c|c|}
\hline \multicolumn{5}{|c|}{ Condições nominais de operação } \\
\hline Parâmetro & Método Analítico & FEMM & Unidade & Diferença \\
\hline$P_{n}$ & 10,711 & 10,715 & MW & $-0,04 \%$ \\
\hline$T_{n}$ & 299,9 & 299,9 & $\mathrm{kNm}$ & - \\
\hline$N_{n}$ & 343,8 & 343,8 & $R P M$ & - \\
\hline$V_{n}$ & 745,7 & 748,5 & Vrms & $-0,37 \%$ \\
\hline$E_{n}$ & 642,0 & 668,4 & Vrms & $-3,94 \%$ \\
\hline$I_{n}$ & 3,209 & 3,061 & $k A$ & $4,85 \%$ \\
\hline$f p_{\text {nom }}$ & 0,86 & 0,90 & - & $-4,30 \%$ \\
\hline$\eta_{\text {nom }}$ & $98,24 \%$ & $98,27 \%$ & $\%$ & $-0,04 \%$ \\
\hline$\eta_{\text {global }}$ & $93,81 \%$ & $93,96 \%$ & $\%$ & $-0,15 \%$ \\
\hline $\boldsymbol{K}_{\boldsymbol{j}}{ }^{*}$ & 12,830 & 11,935 & $\mathrm{~kW} / \mathrm{m} 2$ & $7,50 \%$ \\
\hline$L_{d}$ & 134,7 & 112,8 & $\mu H$ & $19,4 \%$ \\
\hline$L_{q}$ & 164,6 & 158,2 & $\mu H$ & $4,0 \%$ \\
\hline$\Psi_{p m}$ & 1,04 & 1,08 & $\mathrm{~V} / \mathrm{s}$ & $-3,94 \%$ \\
\hline
\end{tabular}

A comparação dos resultados em função da velocidade do vento é apresentada nas figuras 51, 52, 53 e 54. Devido ao maior fluxo magnético útil do que aquele esperado pelo método analítico, a corrente necessária para desenvolver o torque no entreferro é reduzida (Figura 52). Em contrapartida, a tensão induzida e a tensão de fase aumentam (Figura 51).

A redução da corrente necessária para desenvolver a mesma magnitude de torque no entreferro em conjunção com menores valores de $L_{d}$ e, especialmente, $L_{q}$ melhoram o fator de potência da máquina, como é observado na Figura 52. Estes fatores, contribuem de forma ligeiramente positiva para o rendimento do gerador, do retificador (MSC) e para o rendimento global da solução (Figura 53).

Figura 51 - Tensão induzida e tensão de fase
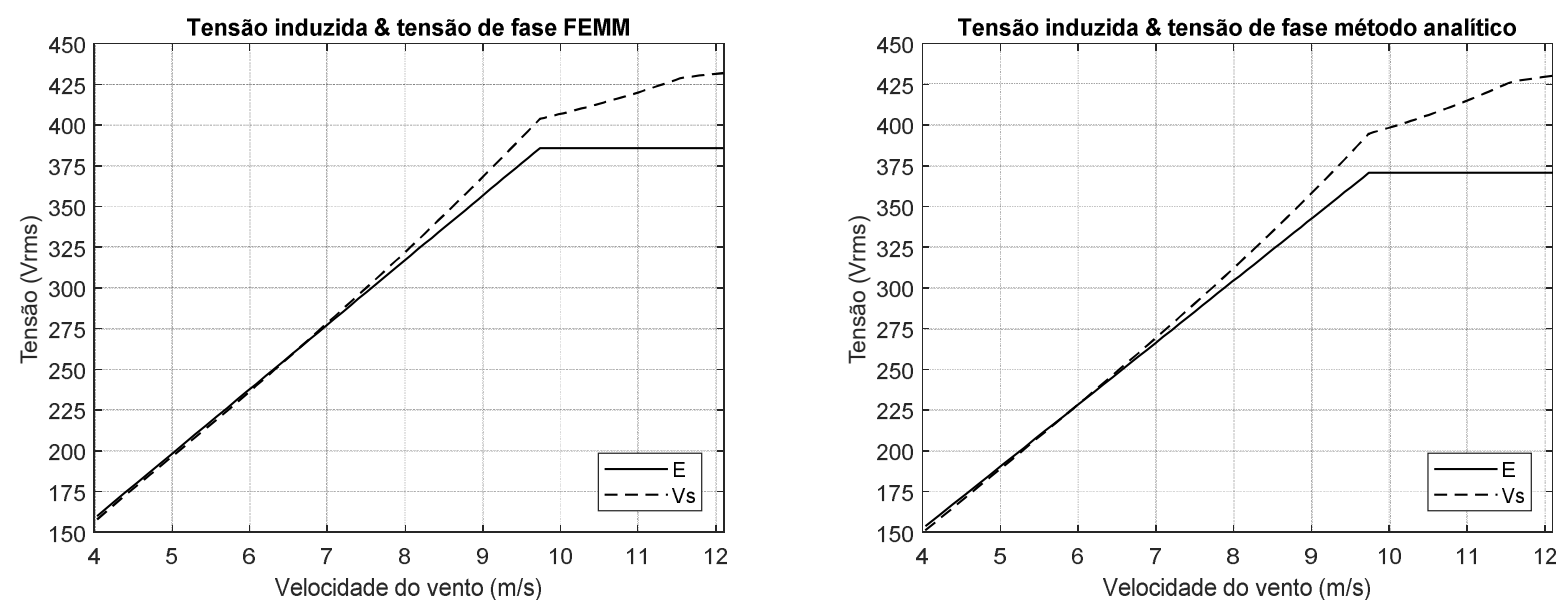
Figura 52 - Corrente de fase e fator de potência
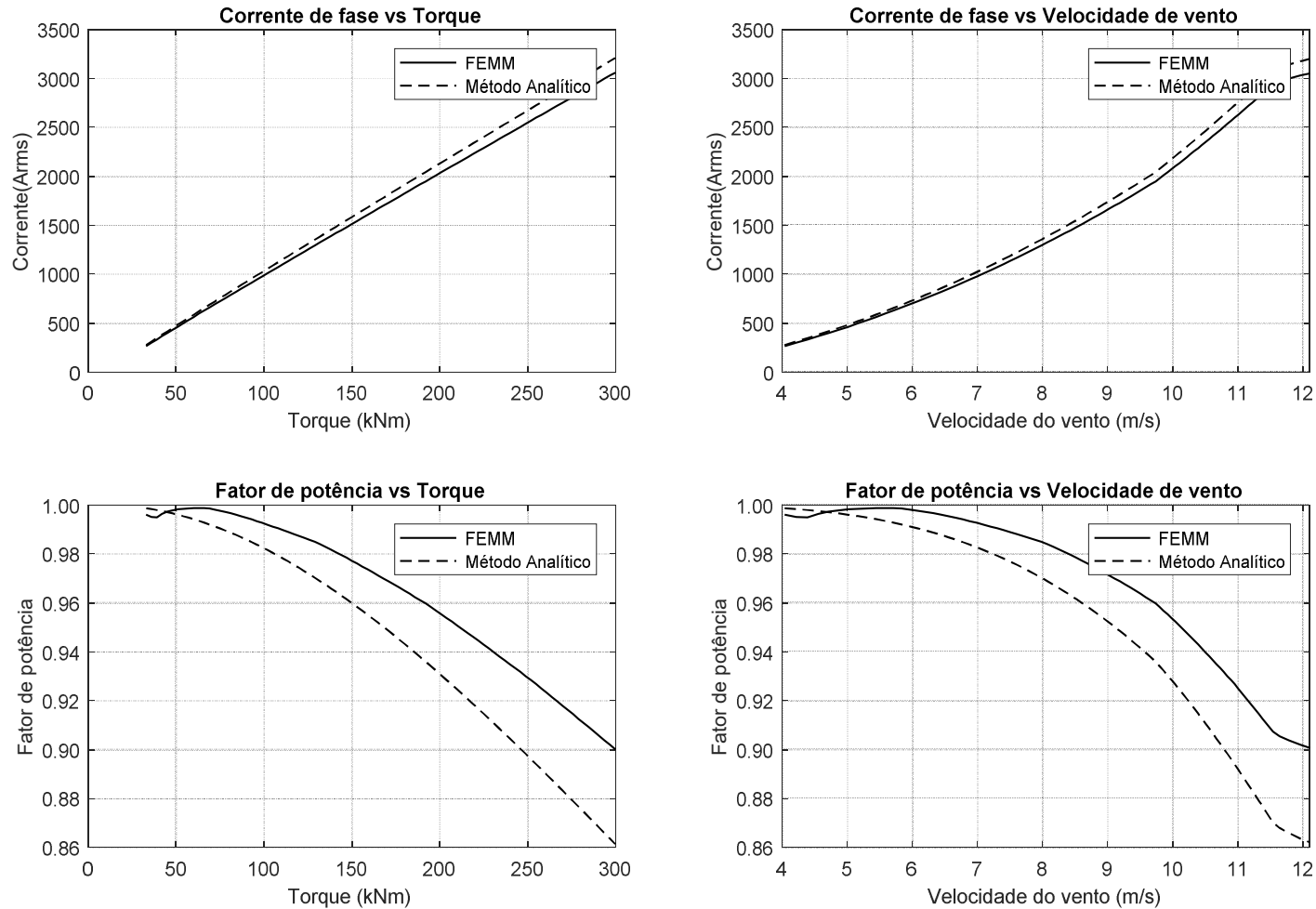

Figura 53 - Rendimentos
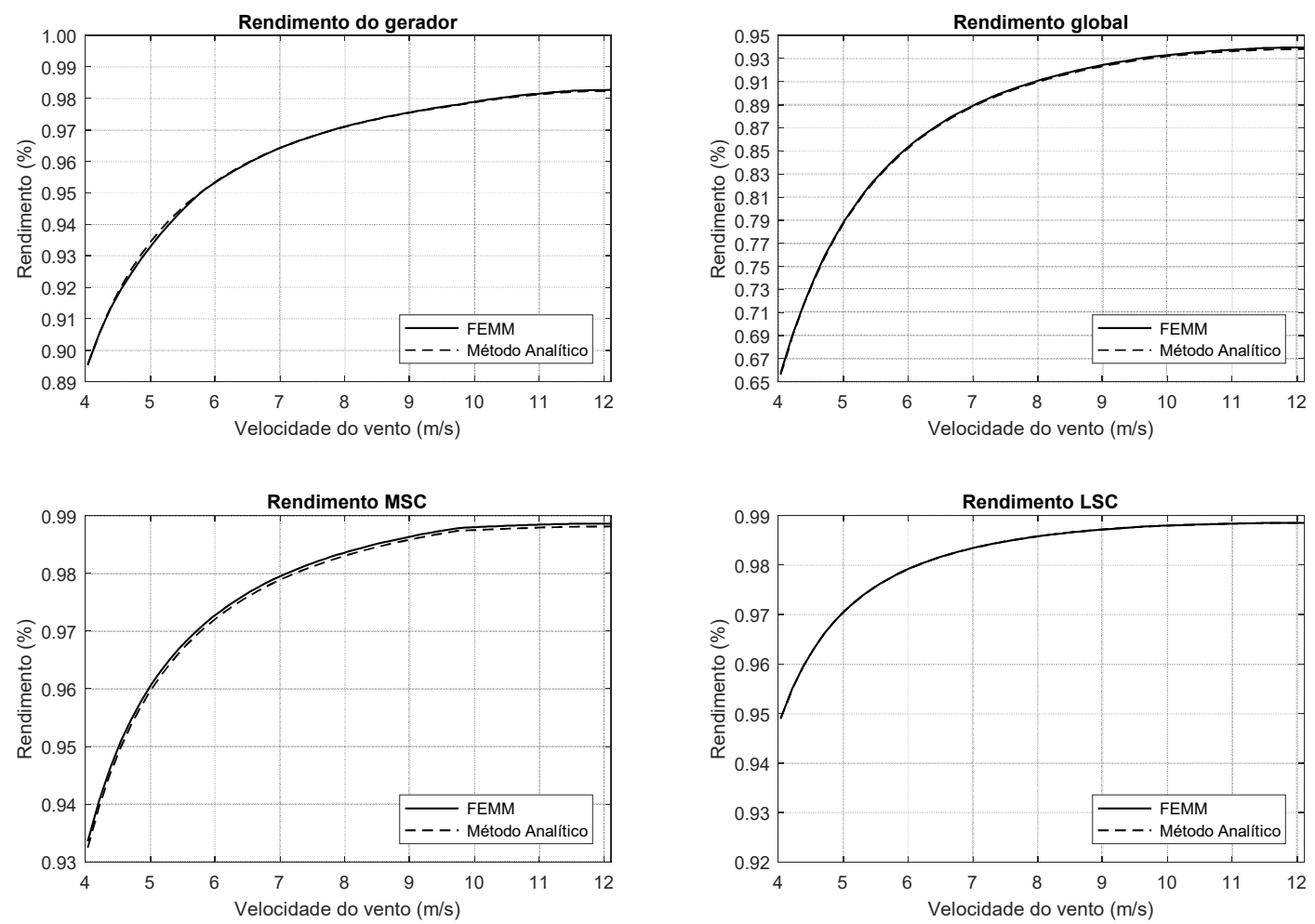

A comparação entre a potência de saída da turbina e o coeficiente de potência elétrico são apresentados na Figura 54 e Tabela 34. 
Figura 54 - Potência e Coeficiente de potência.
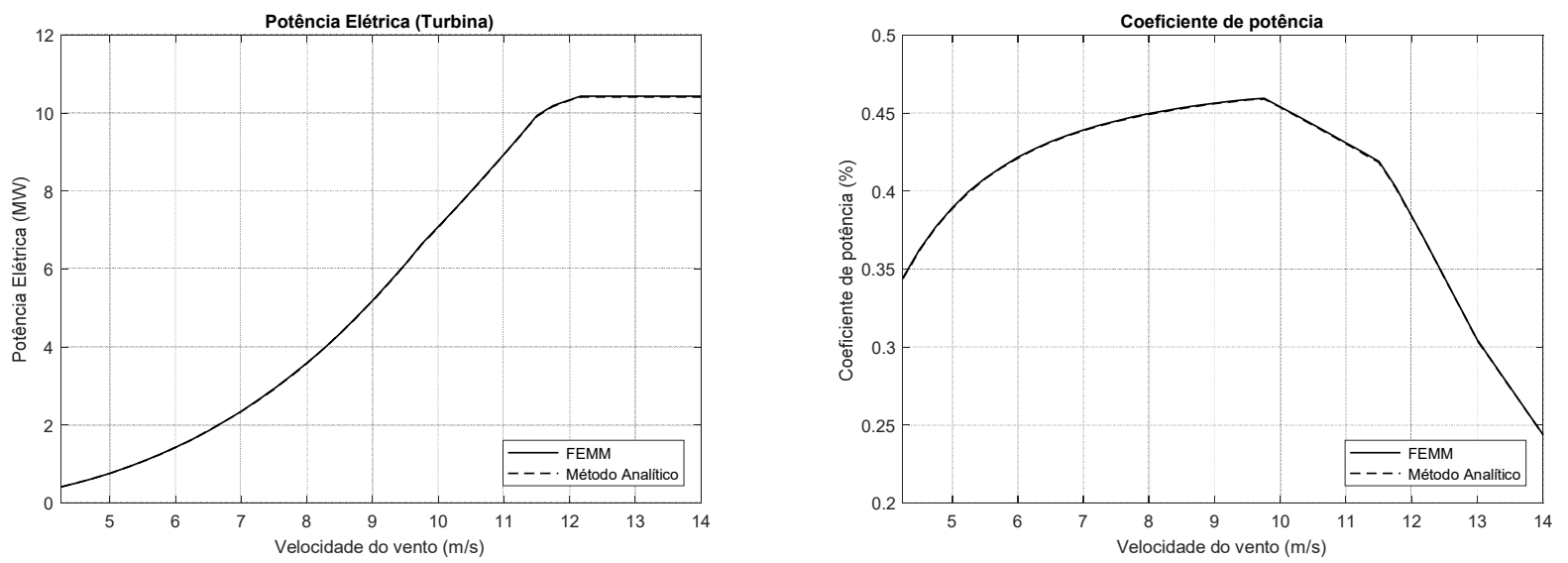

Tabela 34 - Potência e coeficiente de potência.

\begin{tabular}{|c|c|c|c|c|}
\hline \multirow{2}{*}{$U(\boldsymbol{m} / \boldsymbol{s})$} & \multicolumn{2}{|c|}{ Método Analítico } & \multicolumn{2}{c|}{ FEMM } \\
\cline { 2 - 5 } & $\boldsymbol{P}(\boldsymbol{M W})$ & $\boldsymbol{C p}$ & $\boldsymbol{P}(\boldsymbol{M W})$ & $\boldsymbol{C} \boldsymbol{p}$ \\
\hline 4,00 & 0,332 & 0,3328 & 0,332 & 0,3333 \\
\hline 4,50 & 0,514 & 0,3619 & 0,515 & 0,3623 \\
\hline 5,00 & 0,757 & 0,3886 & 0,758 & 0,3890 \\
\hline 5,50 & 1,057 & 0,4076 & 1,058 & 0,4081 \\
\hline 6,00 & 1,418 & 0,4211 & 1,419 & 0,4215 \\
\hline 6,50 & 1,845 & 0,4312 & 1,847 & 0,4316 \\
\hline 7,00 & 2,345 & 0,4386 & 2,347 & 0,4391 \\
\hline 7,50 & 2,923 & 0,4445 & 2,926 & 0,4450 \\
\hline 8,00 & 3,585 & 0,4492 & 3,589 & 0,4497 \\
\hline 8,50 & 4,335 & 0,4529 & 4,340 & 0,4534 \\
\hline 9,00 & 5,180 & 0,4559 & 5,186 & 0,4564 \\
\hline 9,50 & 6,124 & 0,4583 & 6,131 & 0,4588 \\
\hline 10,00 & 7,068 & 0,4535 & 7,076 & 0,4540 \\
\hline 10,50 & 7,976 & 0,4420 & 7,986 & 0,4426 \\
\hline 11,00 & 8,926 & 0,4303 & 8,938 & 0,4309 \\
\hline 11,50 & 9,914 & 0,4182 & 9,928 & 0,4188 \\
\hline 12,00 & 10,323 & 0,3833 & 10,339 & 0,3839 \\
\hline 12,17 & 10,410 & 0,3705 & 10,426 & 0,3711 \\
\hline 25,00 & 10,410 & 0,0483 & 10,426 & 0,0484 \\
\hline
\end{tabular}




\section{CONCLUSÃO}

Afim de diminuir a exposição do projeto aos riscos relacionados à necessidade de manutenção corretiva, para turbinas eólicas offshore, torna-se importante a utilização de tecnologias de alta confiabilidade. Este fator em conjunção com a elevada potência da aplicação, criam as condições favoráveis para a utilização de geradores elétricos multifásicos.

Em termos de confiabilidade, a maior vantagem da solução com gerador multifásico consiste na capacidade de continuar em operação caso ocorra falha em um dos enrolamentos do gerador. Além do mais, uma vez que múltiplos conversores eletrônicos de potência são necessários, a utilização de topologias multifásicas tornase uma escolha natural. Principalmente, quando é possível evitar a conexão em paralelo dos conversores. A conexão em paralelo de conversores eletrônicos de potência requer adicional complexidade no sistema de controle para mitigar o aparecimento de correntes circulantes entre os conversores e o neutro da máquina.

Para se evitar o aparecimento destas correntes circulantes, em aplicações de elevada potência, pode ser preciso projetar o gerador com um número elevado de fases - dezoito no caso analisado neste trabalho (Solução 4 - secção 4.4.4). Isso ocorre por conta das limitações dos semicondutores disponíveis no mercado.

Com o aumento do número de fases da máquina, entretanto, há uma tendência de projetar o gerador com passos polares maiores, reduzindo o número total de polos que podem ser acomodados em um certo diâmetro, conforme discutido na secção 3.9. Desta maneira, a utilização de geradores elétricos multifásicos será mais atrativa para turbinas eólicas que possuem caixa multiplicadora - devido à deterioração da performance dos conversores eletrônicos de potência em baixos valores de frequência elétrica $(<30 \mathrm{~Hz})$.

\subsection{PROJETO E MODELAGEM DE MÁQUINAS ELÉTRICAS MULTIFÁSICAS}

Para o projeto do gerador elétrico multifásico, demonstrou-se que a força magnetomotriz de reação da armadura de máquinas simétricas ou assimétricas, do tipo $N$-star, produzem apenas harmônicas espaciais de ordem $h=2 \mathrm{~km} \pm 1$, conforme discutido no Apêndice B. 
As equações analíticas tipicamente utilizadas para o projeto de máquinas elétricas trifásicas foram revisadas e escritas de forma genérica em função do número de fases do gerador. Os principais parâmetros afetados pelo arranjo multifásico são:

i. Indutância de dispersão de ranhura: A equação tipicamente utilizada para cálculo da indutância de dispersão de ranhura para máquinas trifásicas não pode ser diretamente aplicada a máquinas multifásicas. Neste trabalho, os impactos da configuração multifásica foram analisados e novas equações analíticas foram estabelecidas, conforme apresentado na secção 3.7. Estes resultados são descritos com maiores detalhes na publicação (CORDOVIL e CHABU, 2016).

ii. Indutância de dispersão de topo de dente: Para a indutância de dispersão de topo de dente, há um impacto indireto devido ao parâmetro $k_{x t}$, derivado do cálculo da indutância de dispersão de ranhura.

iii. Indutância de dispersão harmônica: Não há impacto na metodologia de cálculo, entretanto a magnitude de dispersão harmônica é reduzida devido ao menor conteúdo harmônico da força magnetomotriz de reação da armadura.

iv. Indutância de dispersão de final de enrolamento: $O$ enrolamento multifásico produz impacto no cálculo da indutância de dispersão de final de enrolamento, entretanto este assunto não é abordado neste trabalho, conforme justificado em 3.5.1.

v. Fator de distribuição: Embora não exista alteração no método analítico, para um mesmo número de ranhuras por polo e por fase $q$ a máquina multifásica terá um fator de distribuição diferente do fator de enrolamento de uma máquina trifásica. Isso acontece, pois numa máquina multifásica a defasagem angular entre ranhuras será menor do que no caso trifásico.

vi. Número de ranhuras por polo e por fase $q$ : Com o aumento do número de fases torna-se difícil a distribuição do enrolamento. Isso ocorre, pois, uma vez fixados o diâmetro e o número de polos da máquina, o passo de ranhura mínimo capaz de acomodar as bobinas estatóricas determinará o valor máximo permitido de $q$. De forma alternativa, pode-se reduzir o número de pares de polos para aumentar $q$.

Para o projeto analítico da máquina (cálculo das dimensões principais e indutâncias), adota-se o pressuposto de operação com corrente senoidal e em regime 
equilibrado. Desta forma, para a discussão deste trabalho é suficiente a aplicação da teoria geral de máquinas elétricas. As transformações genéricas que podem ser utilizadas para máquinas multifásicas simétricas ou assimétricas são apresentadas no Apêndice D. Além disso, no mesmo apêndice, apresenta-se a metodologia para cálculo da matriz de indutância para máquinas multifásicas com enrolamentos simétricos ou assimétricos. Demonstra-se que em ambas as condições a matriz de indutâncias no referencial $d q 0$ será idêntica à matriz de indutância de uma máquina trifásica.

Salienta-se que, em condições de falha em um ou mais enrolamentos do gerador, espera-se alteração nos parâmetros da máquina elétrica. O desenvolvimento de equações analíticas para cálculo dos parâmetros da máquina em condições de falha foi considerado fora do escopo deste trabalho. Recomenda-se dimensionar a máquina supondo operação em regime senoidal e equilibrado. Para avaliação detalhada da performance e modelagem do gerador, em condições de falha, recomenda-se a realização de ensaios experimentais e simulações utilizando o método dos elementos finitos.

Conforme comentado no Apêndice $E$, máquinas elétricas multifásicas são mais susceptíveis ao aparecimento de correntes harmônicas de baixa ordem. Com a finalidade de evitar o aparecimento destas correntes indesejadas, é prudente procurar minimizar as componentes harmônicas da tensão induzida e da tensão de alimentação do gerador. Em todo caso, na presença de componentes harmônicas de corrente de ordem diferente de $h=2 \mathrm{~km} \pm 1$, a teoria generalizada de componentes simétricas (ou Vector Space Decomposition) pode ser utilizada para filtrá-las.

\subsection{GERADOR DE NOVE FASES PARA TURBINA EÓLICA DE 10MW}

A modelagem da turbina eólica e de seu respectivo trem de potência é realizada no capítulo 4. Quatro diferentes configurações são analisadas para a interface entre gerador e eletrônica de potência. Nomeadamente, a Solução 1 consiste num gerador trifásico com seis conversores, também trifásicos, em paralelo. A segunda solução utiliza um gerador de seis fases com 3 conversores trifásicos em paralelo para cada grupo trifásico da máquina. A terceira solução consiste num gerador de nove fases com dois conversores trifásicos para cada grupo trifásico do gerador. Por fim, analisa- 
se o projeto de um gerador de dezoito fases que não requer conexão em paralelo de conversores trifásicos.

A performance de cada gerador estudado é calculada pelos métodos analíticos descritos neste trabalho. Com a comparação dos resultados, apresentada no capítulo 6, chega-se à conclusão que a terceira topologia, com máquina de nove fases, apresenta características mais atrativas para o projeto da turbina eólica. A solução com gerador de nove fases é capaz de desenvolver a mesma potência no entreferro que a solução de três fases com massa ativa 9,7\% inferior, aumentando de forma significativa a densidade de torque e potência do gerador elétrico. Estes resultados estão detalhados nas secções de 6.1 a 6.3 .

Com a finalidade de validar a metodologia analítica aplicada para o projeto e estimação da performance dos diferentes geradores multifásicos estudados, no capítulo 7, modela-se, em FEMM, o gerador de nove fases. Com os resultados apresentados nas secções de 7.1 a 7.3, pode-se afirmar que o método analítico foi capaz de representar de forma satisfatória as condições de operações da máquina, em termos eletromagnéticos (valores de indução e fluxo magnético nas diferentes partes da geometria do gerador) e, em termos de performance/rendimento. Salientase, entretanto, as limitações do método analítico na estimação das indutâncias de operação da máquina. Nas secções 7.2.1 e 7.2.2, observa-se variações das indutâncias $L_{d}$ e $L_{q}$ com a posição angular do rotor e em função da magnitude das correntes no referencial $d q 0$, que não são consideradas no cálculo analítico. Para máquinas de imãs permanentes, especialmente para máquinas com imãs embutidos, de geometria complexa, recomenda-se a análise através do método de elementos finitos para caracterização adequada de $L_{d}$ e $L_{q}$.

Com as condições de projeto descritas no capítulo 4, a performance esperada da turbina eólica, considerando a solução com máquina de nove fases, é apresentada na Figura 54 e Tabela 34. Nestas condições de projeto, estima-se potência nominal da turbina em torno de 10,43 MW com coeficiente de potência elétrico máximo de 0.459 .

\subsection{TEMAS PARA CONTINUAÇÃO}

Os seguintes temas são sugeridos para trabalhos futuros: 
i. Modelagem e controle de máquinas multifásicas para operação em condição de falha em uma ou mais fases.

ii. Explorar projeto de máquinas elétricas trifásicas e multifásicas com enrolamentos do tipo tooth-coil $(q<1)$. Esta solução vem sendo utilizada em diversos setores industriais, por exemplo: setor eólico (Siemens, GE), automotivo e aeroespacial.

iii. Explorar o projeto de diferentes configurações de máquinas elétricas que são tolerantes a falhas. Por exemplo, máquinas elétricas multifásicas compostas por múltiplos segmentos trifásicos - semelhante ao proposto pela Gamesa. 


\section{BIBLIOGRÁFIA}

ABB. Failure rates of IGBT modules due to cosmic rays - Application Note 5SYA 204206. Lenzburg, Switzerland. 2016.

ABB. Insulated gate bipolar transistor (IGBT) and diode modules with SPT and SPT+ chips. [S.I.]. 2017.

ABBAS, M. ; CHRISTEN, R.; JAHNS, T. M. Six-Phase Voltage Source Inverter Driven Induction Motor. IEEE Transactions on Industry Applications, v. IA-20, n. 5, p. 1251-1259, 1984.

ADKINS, B. The General Theory of Electrical Machines. London: Chapman \& Hall, 1957.

ADWEN. Adwen and Winergy present the world's biggest wind turbine gearbox. Adwen, 2016a. Disponivel em: <http://www.adwenoffshore.com>. Acesso em: 31 Janeiro 2018.

AK STEEL. Nonoriented Electrical Steels: $\mathbf{M}-15$ through $\mathbf{M}-\mathbf{4 7}$. West Chester, OH, USA. 2007.

AMSC WINDTEC SOLUTIONS. Sea Titan 10MW Wind Turbine, 2012. Disponivel em: $<$ http://www.amsc.com/documents/seatitan-10-mw-wind-turbine-data-sheet/>. Acesso em: 26 Fevereiro 2017.

ANAYA-LARA, O. et al. Offshore Wind Energy Generation: Control, Protection and Integration to Electrical Systems. West Sussex: John Wiley \& Sons, 2014.

ANDRESEN, B. Gerador para uma turbina eólica com bobinados independentes. ES2325844, 2010.

BACKLUND, B.; EBNER, S. The wind power converter for tomorrow is already here. Switzerland. 2011.

BAK, C. et al. Design and performance of a $10 \mathrm{MW}$ wind turbine. Technical University of Denmark. Lngby, Denmark, p. 111. 2013.

BANG, et al. Review of Generator Systems for Direct-Drive Wind Turbines. Delft. 2008.

BLAABJERG, F.; MA, K. Future on Power Electronics for Wind Turbine Systems. IEEE Journal of Emerging and Selected Topics in Power Electronics, v. 1, n. 3, p. 14, 2013.

BOLDEA, I. Synchronous Generators. 1st. ed. Timisoara: CRC Press, 2006.

BOULDER WIND POWER. Boulder Wind Power, 2017. Disponivel em: <http://www.boulderwindpower.com>. Acesso em: 26 Fevereiro 2017.

BRAAM, H. O\&M Aspects of the 500MW Wind Farm at NL7. [S.I.]. 2002.

BURTON, T. et al. Wind Energy Handbook. Chichester, UK: John Wiley \& Sons, 2001.

BVG ASSOCIATES. Offshore Wind Cost Reduction pathways: Technology work stream. United Kingdom. 2012.

CAUBET, O. HaliadeTM 150 Direct drive offshore wind turbine. Power Converter System description and site test results, 2014. Disponivel em:

<http://www.citcea.upc.edu/estructura/noticies/premsa.php?any=2000\&inici=all\&lang=en>. Acesso em: 22 Fevereiro 2017. 
CHAPMAN, S. J. Electric Machinery Fundamentals. 2nd. ed. Princeton: McGraw-Hill , 1991. CLIPPER WIND POWER PLC. Liberty 2.5MW Facts and Specification, United States of America, 2008. Disponivel em:

<http://geosci.uchicago.edu/ moyer/GEOS24705/Readings/Liberty_Brochure_2009_LR.pdf>

CORDOVIL, P.; CHABU, I. E. Analytical Calculation of Slot Leakage Inductance in Multiphase Electrical Machines. International Conference on Electrical Machines - ICEM. Lausanne: International Conference on Electrical Machines (ICEM) 2016. 2016.

COULTATE, J. Wind Turbine Drivetrain Technology and Cost Drivers. Romax Technology. United KIngdom, p. 29. 2011.

DET NORSKE VERITAS. Type Certificate: V164 - 8MW: TC-225602-B-1. Aarhus, p. 8. 2015.

DURAN, M. ; BARRERO, F. Recent Advances in the Design, Modeling and Control of Multiphase Machines - Part II. IEEE Transactions on Industrial Electronics, v. 63, p. 459-468, 2016.

EUROPEAN COMMISSION. 2014 JRC wind status report: technology market and economic aspects of wind energy in Europe. Joint Research Centre. Petten. 2015.

EWEA, T. E. W. E. A. The European offshore wind industry - key trends and statistics 2016. [S.I.]. 2017.

FEUP. Materiais Condutores Usados em Engenharia Electrotécnica. Faculdade de Engenharia da Universidade do Porto. Porto, Portugal, p. 23.

GAMESA. Gamesa 5.0MW technical specifications, 2016. Disponivel em: <http://www.gamesacorp.com/recursos/doc/productos-servicios/aerogeneradores/catalogog10x-45mw-eng.pdf>. Acesso em: 03 July 2016.

GE. The Temple Of Turbine: One Of These Wind Turbines Can Power 5,000 Homes, 2016. Disponivel em: <http://www.gereports.com/where-ge-makes-haliade-turbines/>.

Acesso em: 22 Fevereiro 2017.

GE. Haliade 150-6MW High Yield offshore wind turbine, 2016a. Disponivel em: $<$ https://www.gerenewableenergy.com/content/dam/gepowerrenewables/global/en_US/documents/haliade-offshore-wind-turbine.pdf>. Acesso em: 03 July 2016.

GERLING, D. Electrical Machines: Mathematical Fundamentals of Machine Topologies. Berlin: Springer, 2015.

GIERAS, J. F.; SANTINI, E.; WING, M. Calculation of Synchronous Reactances of Small Permanent Magnet Alternating-Current Motors: Comparison of Analytical Approach and Finite Element Method with Measurements. IEEE Transactions on Magnetics, v. 34, n. 5, p. 3712-3720, 1998.

GIERAS, J. F.; WING, M. Permanent Magnet Motor Technology: Design and Applications. 2nd. ed. New York: [s.n.], 2002.

GOLIATH WIND. Goliath Wind, 2016. Disponivel em: <http://www.goliath.ee>. Acesso em: 26 Fevereiro 2017.

GRAUERS, A. Design of Direct-Driven Permanent-magnet Generators dor Wind Turbines. Chalmers University of Technology. Goteborg, Sweden, p. 133. 1996. 
GUIDORIZZI, H. L. Um Curso de Cálculo: Volume 4. 5th. ed. São Paulo: LTC, v. 4, 2002.

GWEC, G. W. E. C. Global Wind Report 2015, 2016.

GWEC, G. W. E. C. Global Wind Report 2016. [S.I.]. 2017.

HEIER, S. Grid Integration or Wind Energy Conversion Systems. $2^{\circ}$. ed. Chichester, UK: John Wiley \& Sons, 2006.

HITACHI. High Voltage IGBT Module: Application Manual. Hitachi. Japão, p. 49. 2009.

HITACHI. Thermal Equivalent Model of IGBT Modules. Hitachi. Japão, p. 3. 2015.

IEA. Forecasting Wind Energy Costs \& Cost Drivers: The view of the Woeld's Leading Experts. [S.I.]. 2016.

INFINEON. Dimensioning program IPOSIM for loss and thermal calculation of Infineon IGBT modules. Infineon. Germany, p. 21. 2006.

INFINEON. 6MS30017E43W33015. [S.I.]. 2012.

INFINEON. Technical Information FZ3600R17HP4. [S.I.]: [s.n.]. 2013. p. 9.

INFINEON. IGBT Power Modules, 2017. Disponivel em: <http://www.infineon.com>. Acesso em: 13 Janeiro 2017.

JAMIESON, . Innovation in Wind Turbine Design. UK: John Willey \& Sons, 2011. Disponivel em: <http://ejurnal.bppt.go.id/digilib/sampul/9781119975441.pdf>.

JOCKEL, S. Calculation of Different Generator Systems for Wind Turbines with Particular Reference to Low-Speed Permanent-Magnet Machines. Aachen: Shaker Verlag $\mathrm{GmbH}, 2003$.

JORDÃO, R. G. Máquinas Síncronas. 2nd. ed. Rio de Janeiro: LTC, 2013.

KANG, S.-J. et al. Maximum Torque Control of IPMSM Drive with Multi-MFC. International Conference on Control, Automation and Systems, Gyeonggi-do, Korea, 27-30 Outubro 2010. 1242-1247.

KOSTENKO, M.; PIOTROVISK, L. Máquinas Elétricas: Máquinas de Corrente Alternada. Porto: Livraria Lopes da Silva, v. 2, 1979.

KRISHNAN, R. Permanent Magnet Synchronous and Brushless DC Motor Drives. Special Indian Edition. ed. Virginia: CRC Press, 2010.

LEVI, E. Polyphase Motors: A Direct Approach to Their Design. New York: John Wiley \& Sons, Inc, 1984.

LEVI, E. Advances in Converter Control and Innovative Exploitation of Additional Degrees of Freedom for Multiphase Machines. IEEE Transactions on Industrial Electronics, v. 63, n. 1, p. 433-448, 2016.

LEVI, E. et al. Multiphase Induction Motor Drives - a technology status review. IET Electric Power Applications, v. 1, n. 4, p. 489-516, 2007.

LIPO, T. A. Introduction to AC Machine Design. 3rd. ed. Madison: Wincosin Power Electronics Research Center, University of Wincosin, 2011. 
LIWSCHITZ-GARIK, M. Le Macchine Elettriche: Parte Prima - Teoria e Funcionamento. Tradução de Carlo Rossi. Prima edizione italiana. ed. Milano: [s.n.], v. Parte Prima, 1963.

LIWSCHITZ-GARIK, M. Le Macchine Elettriche: Parte Terza - Calcolo e determinazione delle dimenzioni delle macchine elettriche. Tradução de Carlo Rossi. 1st. ed. Milano: [s.n.], v. 3, 1964. Prima traduzione italiana.

LIWSCHITZ-GARIK, M.; WHIPPLE, C.. Electric Machinery Vol. I: Fundamentals and DC Machines. New York: D. Van Nostrand Company, Inc., 1947.

LIWSCHITZ-GARIK, M.; WHIPPLE, C. C. Electric Machinery Vol. II: AC Machines. New York: D. Van Nostrand Company, Inc., 1950.

MANWELL, J. F.; MCGOWAN, ; ROGERS, A. L. Wind Energy Explained. Chichester, UK: John Wiley \& Sons, 2002.

MARQUES, G. Dinâmica das Máquinas Elétricas. Lisboa: Instituto Superior Técnico, 2002.

MITTLE, V. N.; MITTAL, A. Design of Electrical Machines. New Delhi: Standard Publishers Distributors, 2009.

MONGEAU, P.; ASHAR, S.; DEMTRODER, J. Wind Turbine Power Transmission System. US 8907517 B2, 9 Dezembro 2014.

MUELLER, M.; POLINDER, H. Electrical Drives for Direct-Drive Renewable Energy Systems. United Kingdom: Woodhead Publishing, 2013.

OFFSHORE WIND JOURNAL. Siemens Gamesa pulls the plug on Adwen AD8. Offshore Wind Journal, 2017. Disponivel em: <http://www.owjonline.com>. Acesso em: 31 Janeiro 2018.

PELLEGRINO, G. Permanent Magnet Machine Design and Analysis with a Focus to Fluxswitching PM and PM-assisted Synchronous Reluctance Machines. Politecnico di Torino. Lausanne, p. 111. 2016.

POLINDER, H. et al. 10MW Wind Turbine Direct-Drive Generator Design with Pitch or Active Speed Stall Control. 2007 IEEE International Electric Machines \& Drives Conference. Antalya, Turkey: IEEE. 2007. p. 1390-1395.

PONOMAREV, P. Tooth-Coil Permanent Magnet Synchronous Machine Design for Special Applications. Lappeenranta University of Technology (LUT). Lappeenranta, p. 111. 2013.

PONOMAREV, P. et al. Inductance Calculation of Tooth-Coil Permanent-Magnet Synchronous Machines. IEEE Transactions on Industrial Electronics, v. 61, n. 11, 2014.

PYRHONEN, J.; JOKINEN, T.; HRABOVCOVÁ, V. Design of Rotating Electrical Machines. Chicester: John Wiley \& Sons, Ltd., 2014.

RENEWABLE ENERGY WORLD. Compact Drive Trains Offer New Options, 2012.

Disponivel em: <http://www.renewableenergyworld.com/articles/print/special-supplementwind-technology/volume-2/issue-1/wind-power/compact-drive-trains-offer-new-options.html>. Acesso em: 15 Janeiro 2017.

RUUSKANEN, V. Design Aspects of Megawatt-range direct-driven permanent magnet wind generators. Lappeenranta University of Technology. Lappeenranta, Finland, p. 78. 2011. 
SAY, M. G. The Performance and Design of Alternating Current Machines. Third Edition. ed. New Delhi: CBS Publishers \& Distributors Pvt. Ltd., 1983. Indian Edition.

SEMAIL, E.; BOUSCARYOL, A.; HAUTIER, J. P. Vectorial Formalism for Analysis and Design of Polyphase Synchronous Machines. The European Physical Journal - Applied Physics, v. 22, n. 3, p. 207-221, 2003.

SEMIKRON. Application Manual: Power Semiconductors. Semikron. Nuremberg, Germany, p. 464. 2015.

SHINETSU. Greases: Oil Compounds. ShinEtsu. Japan, p. 24. 2017.

SHINETSU. The Unique Properties of Silicones. ShinEtsu, 2017a. Disponivel em: <https://www.shinetsusilicone-global.com/products/type/oil/detail/about/index2.shtml>.

Acesso em: 05 Outubro 2017.

SIEMENS. Siemens 6.0MW Offshore Wind Turbine. [S.I.]. 2012.

STIESDAL, H. Direct drive generator and wind turbine. US7944076 B2, 17 Maio 2011.

STIESDAL, H. Permanent Magnet Generators for Wind Turbines: Status and Outlook. [S.I.]. 2014.

SUN \& WIND ENERGY. Siemens Gamesa launches SG 4.2-145 for onshore, SG 8.0-167 DD for offshore. Sun \& Wind Energy, 2017. Disponivel em:

<http://www.sunwindenergy.com>. Acesso em: 31 Janeiro 2018.

SWAY TURBINE. Sway Turbine, 2012. Disponivel em: <http://www.swayturbine.no>. Acesso em: 26 Fevereiro 2017.

TESSAROLO, A. Modelling and Analysis of Multiphase Electric Machines for High Power Applications. Universita degli Studi di Trieste. Trieste. 2011.

THE SWITCH. The Switch Permanent magnet generators, Finland, 2010. Disponivel em: $<$ https://www.youtube.com/watch?v=xMBOQUhoUTE>.

THE SWITCH. The Switch 8.6MW, 400RPM Permanent Magnet Generator, Finland, 11 Outubro 2013. Disponivel em: <https://www.youtube.com/watch?v=Aom59tEHdfY>. Acesso em: 15 Fevereiro 2017.

UPADHYAY, K. G. Design of Electrical Machines. New Delhi: New Age International (P) Limited, 2008.

VIZIREANU, et al. Polyphased Modular Dfrect-Drive Wind Turbine Generator. Dresden: European Conference on Power Electronics and Applications (EPE). 2005.

WALLIN, M. Measurement and Modelling of unbalanced magnetic pull in hydropower generators. Uppsala Universitet. Uppsala. 2013.

WHITE, D. C.; WOODSON, H. H. Electromechanical Energy Conversion. New York: John Wiley \& Sons, 1959.

WIND EUROPE. Wind Energy in Europe: Scenarios for 2030, Stemebro 2017.

WIND POWER MONTHLY. Close up - Vestas V164-8.0 nacelle and hub. Wind Power Monthly, 2013. Disponivel em: <https://www.windpowermonthly.com/article/1211056/closevestas-v164-80-nacelle-hub>. Acesso em: 31 Janeiro 2018. 
WIND POWER MONTHLY. Turbine of the year, 24 Dezembro 2013. Disponivel em: <http://www.windpowermonthly.com/article/1225350/turbines-year---turbines-36mw-plus>.

Acesso em: 21 Fevereiro 2017.

WIND POWER MONTHLY. Windtech: Gamesa and Areva team up for 8MW. Wind Power Monthly, 2014. Disponivel em: <https://www.windpowermonthly.com/>. Acesso em: 31 Janeiro 2018.

WIND TURBINE MODELS. Adwen AD 8-180 (Turbine), 2015. Disponivel em: <http://en.windturbine-models.com/turbines/1124-adwen-ad-8-180>. Acesso em: 21 Janeiro 2017.

WINENERGY. Winergy 8 MW gearbox selected the best wind turbine drive, 4 Janeiro 2017. Disponivel em: <https://www.winergy-group.com/root/img/pool/press/en/winergy_pr__wpm_award_8mw_en.pdf>. Acesso em: 15 Janeiro 2017.

WINENERGY. WinEnergy. https: //www.winergy-group.com, 2017a. Disponivel em: $<$ https://www.winergy-group.com/root/img/pool/downloads/en/product-brochure-multi-duoredgearbox-winergy.pdf>. Acesso em: 15 Janeiro 2017.

WU, B. et al. Power Conversion and Control of Wind Energy Systems. New Jersey: IEEE Press, 2011.

ZAVVOS, A.; MCDONALD, A. S.; MUELLER, M. Electromagnetic and Mechanical Optimization of Direct-Drive Generators for Large Wind Turbines. 5th IET International Conference on Power Electronics, Machines and Drives (PEMD 2010). Brighton: [s.n.]. 2010.

ZF, F. A. A Broad Product Range on a Global Footprint, 2017. Disponivel em:

$<$ http://www.zf.com/corporate/en_de/products/further_product_ranges/wind_power/a_broad_ product_range/global_footprint.html>. Acesso em: 26 Janeiro 2017. 


\section{APÊNDICE}

\section{APÊNDICE A - ELETRÔNICA DE POTÊNCIA}

Na primeira parte deste apêndice serão comparados conversores eletrônicos de potência com módulos IGBT de baixa e média tensão em termos de voltage stress, $k_{v}$, e capacidade de potência. Na segunda secção, procura-se validar as condições de operação adotadas para os conversores neste trabalho. Na terceira parte, comenta-se sobre os impactos da operação de conversores eletrônicos de potência em baixos valores de frequência elétrica.

\section{A.1 COMPARAÇÃO ENTRE MÓDULOS IGBT}

Uma desvantagem de semicondutores de média tensão é a sua maior suscetibilidade a falhas por conta de radiação eletromagnética (cosmic rays). Em outras palavras, ao se aumentar a tensão nominal do semicondutor, normalmente é preciso reduzir $k_{v}$ (voltage stress, $\frac{V_{d c}}{V_{I G B T}}$ ) para manter o mesmo nível de taxa de falhas. Afim de ilustrar esta questão, recorre-se ao documento (ABB, 2016), onde a seguinte expressão empírica é apresentada para cálculo da taxa de falhas de módulos IGBT por conta de radiação eletromagnética

$$
\text { FIT }=C_{3} \cdot e^{\left(\frac{C_{2}}{C_{1}-V_{D C}}\right)} \cdot e^{\left(\frac{25-T_{v j}}{47.6}\right)} \cdot e^{\left[\frac{1-\left(1-\frac{h}{44300}\right)^{5.26}}{0.143}\right]}
$$

Assume-se operação a $25^{\circ} \mathrm{C}\left(T_{v j}=25\right)$ e altitude $h=0$ (nível do mar). Estimase $V_{D C}$ em função de FIT por:

$$
V_{D C}=C_{1}+\frac{C_{2}}{\ln \left(C_{3}\right)-\ln (F I T)}
$$

O parâmetro $k_{v}$ é calculado por:

$$
k_{v}=\frac{1}{V_{I G B T}}\left(C_{1}+\frac{C_{2}}{\ln \left(C_{3}\right)-\ln (F I T)}\right)
$$

Os parâmetros $C_{1}, C_{2}$ e $C_{1}$, são apresentados em $(A B B, 2016)$ para diversos módulos IGBT, Tabela 35. A relação entre $k_{v}$ e FIT é apresentada, para cada módulo 
da Tabela 35, na Figura 55. Observa-se, na Figura 55, que para um projeto típico de um conversor trifásico de $1700 \mathrm{~V} / 3600 \mathrm{~A}$, com $k_{v}=65 \%$, FIT é igual a 10 . Para o mesmo FIT, $k_{v}$ teria que ser igual a $61 \%, 63 \%$ e $57 \%$ para os módulos de 3300,4500 e $6500 \mathrm{~V}$, respetivamente ${ }^{10}$.

Tabela 35 - Parâmetros de módulos IGBT ABB HiPak (ABB, 2016)

\begin{tabular}{|c|c|c|c|c|c|}
\hline$V_{I G B T}(\mathrm{~V})$ & $I_{I G B T}(\mathrm{~A})$ & $C_{1}$ & $C_{2}$ & $C_{3}$ & ABB - HiPak \\
\hline 1700 & 3600 & 871 & 4256 & $1.00 \mathrm{E}+09$ & 5SNA3600E170300 \\
\hline 3300 & 1500 & 1221 & 14388 & $1.00 \mathrm{E}+09$ & 5SNA1500E330305 \\
\hline 4500 & 800 & 2279 & 7222 & $7.53 \mathrm{E}+06$ & 5SNA0800J450300 \\
\hline 6500 & 750 & 2567 & 18525 & $1.00 \mathrm{E}+08$ & 5SNA0750G650300 \\
\hline
\end{tabular}

Figura 55 - FIT vs Voltage stress ABB HiPak IGBT Modules

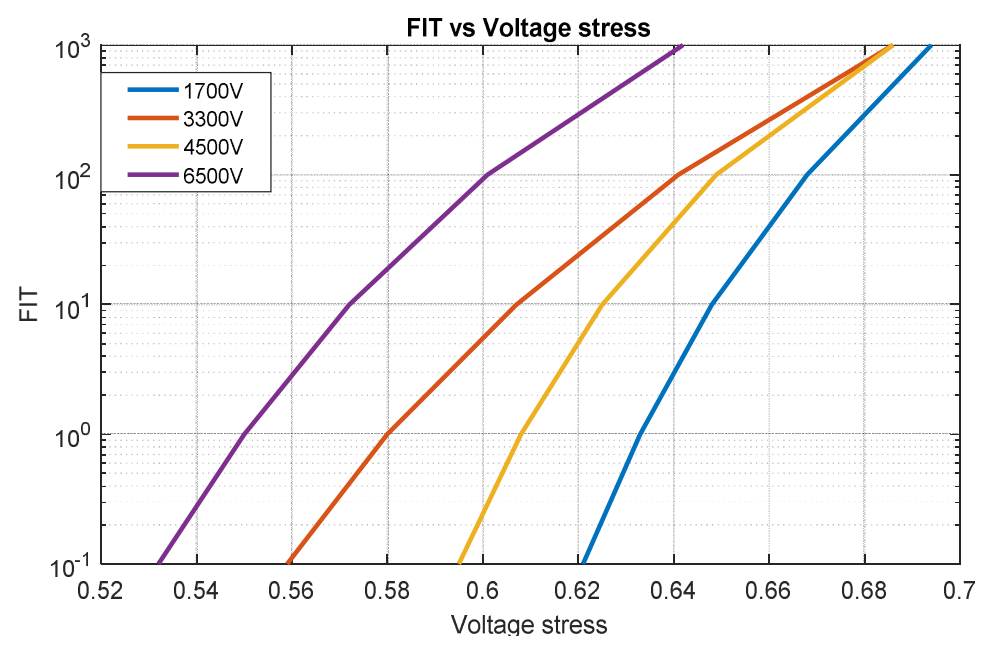

Usando como exemplo os fornecedores ABB (ABB, 2017) e Infineon (INFINEON, 2017), verifica-se que a corrente nominal máxima dos seus módulos IGBT são 3600A, 1500A, 1200A e 750A para módulos de 1700V, 3300V, 4500V e $6500 \mathrm{~V}$, respetivamente. Mantendo constante índice de modulação em amplitude $m_{a}$ = $95 \%$ e o valor de pico da corrente de fase igual a $65 \%$ do valor nominal do módulo IGBT (valor típico de projeto), é possível estimar a potência aparente máxima dos conversores para cada nível de tensão. Os resultados são apresentados na Tabela 36.

10 Observa-se que o módulo IGBT HiPak da ABB 5SNA0800J450300 de 4500V tem melhor performance do que o módulo de 3300V 5SNA1500E330305, isso acontece devido a diferente tecnologia adotada entre os módulos. 
Tabela 36 - Potência por conversor trifásico

\begin{tabular}{|c|c|c|c|c|c|c|}
\hline$V_{I G B T}(\mathrm{~V})$ & $I_{I G B T}(\mathrm{~A})$ & $k_{v}(\%)$ & $\mathrm{VDC}(\mathrm{V})$ & $\mathrm{VAC}(\mathrm{V} \mathrm{rms})$ & $\mathrm{IAC}(\mathrm{A} \mathrm{rms})$ & $\mathrm{S}(\mathrm{MVA})$ \\
\hline 1700 & 3600 & $65 \%$ & 1105 & 742 & 1655 & 2.13 \\
\hline 3300 & 1500 & $61 \%$ & 2013 & 1352 & 689 & 1.61 \\
\hline 4500 & 1200 & $63 \%$ & 2835 & 1904 & 552 & 1.82 \\
\hline 6500 & 750 & $57 \%$ & 3705 & 2489 & 345 & 1.49 \\
\hline
\end{tabular}

Com os resultados da Tabela 36, constata-se ser possível desenvolver maior potência por conversor ao se utilizar módulos IGBT de 1700V/3600A.

Uma alternativa à utilização de módulos IGBTs de média tensão, consiste na associação em série de semicondutores de baixa tensão $\left(V_{I G B T}<1700 \mathrm{~V}\right)$. Esta solução, entretanto, possui a desvantagem de aumentar a complexidade e as indutâncias parasitas do conversor. As indutâncias parasitas do conversor tem impacto negativo nos transitórios de tensão e o seu aumento, em geral, requer uma maior margem de tensão no conversor.

Em aplicações eólicas, tipicamente, quando se opta por conversores com semicondutores conectados em série, utiliza-se conversores de três níveis do tipo Neutral Point Clamped (NPC). Estes conversores usam 30 semicondutores (12 IGBTs e 18 Diodos) e operam, normalmente, com tensão AC nominal de 900V. Assumindose a mesma capacidade de corrente, conversores de três níveis e 900V são capazes de transmitir $30 \%$ mais potência que conversores de dois níveis e 690V. Entretanto, o número de semicondutores é 2.5 vezes maior.

Os limites para instalações elétricas de baixa tensão são de 1500 VDC ou 1000 VAC eficaz. Uma das vantagens de se operar os conversores em redes de 690V ou $900 \mathrm{~V}$, consiste no seu enquadramento como sistemas de baixa tensão ${ }^{11}$, reduzindo os custos da instalação elétrica em geral.

Finalmente, pode-se concluir que as principais vantagens da utilização de conversores eletrônicos de potência de 690V com módulos IGBT de 1700V/3600A para aplicações de elevada potência são:

i. Maior capacidade de converter tensão DC em AC (maior $k_{v}$ ), quando comparado com soluções de três níveis NPC ou com módulos IGBTs de média tensão.

11 Para conversores conectados à rede de 900V, a tensão do link DC é tipicamente entre 1400 e $1480 \mathrm{~V}$. 
ii. Maior potência por conversor quando comparado com conversores com módulos IGBT de média tensão.

iii. Maior potência por dispositivo semicondutor quando comparado com conversores de três níveis NPC.

iv. Enquadra-se nos limites de instalações elétricas de baixa tensão, reduzindo os custos globais da instalação elétrica.

v. Topologia padrão da indústria com diversos fornecedores disponíveis. Essas características contribuem para redução de custos (produção em escala) e riscos.

Embora a ampla maioria das turbinas eólicas utilizem conversores com módulos IGBT, é relevante comentar sobre soluções alternativas. O fabricante Enercon, por exemplo, utiliza retificador a diodos e inversor com módulos IGBT (WU, LANG, et al., 2011, p. 19). O fabricante Multibrid/Areva na sua plataforma M5000 utiliza o conversor PCS 6000 da ABB de 3.3kV com tecnologia IGCT (BACKLUND e EBNER, 2011).

A maior desvantagem da retificação passiva consiste na forma de onda não senoidal da corrente elétrica de fase do gerador e no maior volume da máquina requerido para o desenvolvimento da mesma potência ativa (uma vez que a máquina opera com menor fator de potência interno, conforme comentado na secção 3.4.1).

Conversores eletrônicos de potência com tecnologia IGCT, derivados de GTOs, tem a vantagem de conseguirem operar em níveis mais elevados de corrente. Em contrapartida, a frequência de chaveamento é muito baixa, normalmente inferior a $1500 \mathrm{~Hz}$. A operação com baixa frequência de chaveamento aumenta os custos com elementos passivos (por exemplo, capacitores e indutores de filtros), reduz a performance do sistema de controle e piora, em geral, o conteúdo harmônico injetado no sistema elétrico. 


\section{A.2 CONDIÇÕES DE OPERAÇÃO}

Os pressupostos, de operação contínua, adotados para os conversores eletrônicos de potência são: corrente de fase de $\leq 1655$ Arms, tensão de fase $\leq 445,7$ Vrms, $V_{d c}=1150 \mathrm{~V}$, frequência de chaveamento de $2,5 \mathrm{kHz}$ e frequência fundamental $\geq 40 \mathrm{~Hz}$. O módulo IGBT FZ3600R17HP4 da Infineon (INFINEON, 2013) é escolhido para este estudo de caso. Nesta secção procura-se validar que, nestas condições de operação, os semicondutores não ultrapassam os seus limites térmicos. Adota-se como limite $125^{\circ} \mathrm{C}$ para o valor máximo da temperatura da junção dos IGBTs e diodos.

\section{A.2.1 Modelo térmico.}

O modelo térmico dos semicondutores é realizado através de um circuito elétrico equivalente, onde tensão equivale à temperatura e corrente à potência. $O$ circuito térmico equivalente de um módulo IGBT é apresentado na Figura 56.

Figura 56 - Modelo térmico modulo IGBT.

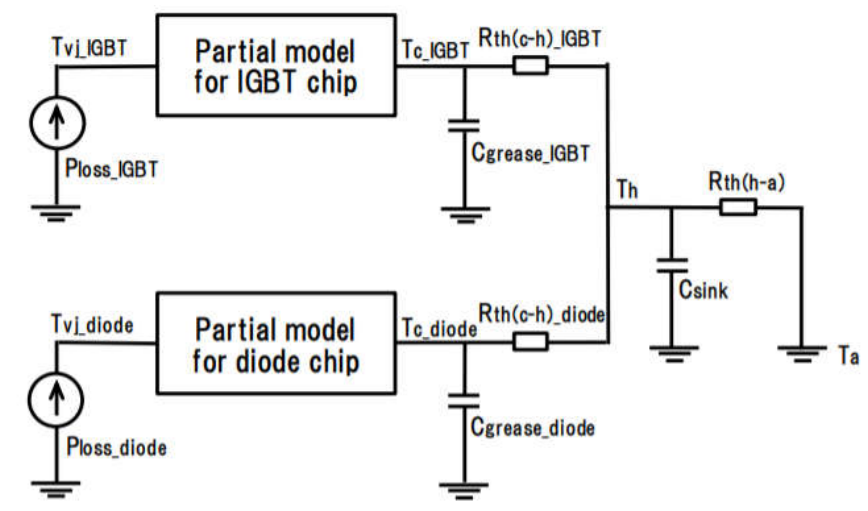

Fonte: (HITACHI, 2015).

Neste circuito elétrico equivalente, as perdas instantâneas dos dispositivos semicondutores são injetadas como uma fonte de corrente ideal. Cada semicondutor, IGBT e diodo, possui um circuito térmico que modela a sua impedância térmica entre a junção e a base (case) do módulo $-Z_{t h_{-} j c}$. Entre a base do módulo e o dissipador térmico, normalmente, utiliza-se uma pasta térmica (grease) que melhora a dissipação de calor nesta interface.

A pasta térmica é modelada por uma resistência e uma capacitância térmica, $R_{t h \_c h}$ e $C_{t h_{-} c h}$. Como será apresentado na sequência, esses valores são diferentes 
para o IGBT e para o diodo. O dissipador térmico é, também, modelado por um circuito $\mathrm{RC}$, entre a pasta térmica e o fluido de arrefecimento.

As especificações técnicas do módulo IGBT apresentam os parâmetros que devem ser adotados para se modelar $Z_{t h_{-} j c}$. Os parâmetros fornecidos no datasheet se referem à um modelo térmico do tipo Foster - apresentado Figura 57. A impedância térmica $Z_{t h \_j c}$ para o IGBT do módulo FZ3600R17HP4 é apresentada na Figura 58.

Figura 57 - Exemplo modelo térmico do tipo Foster.

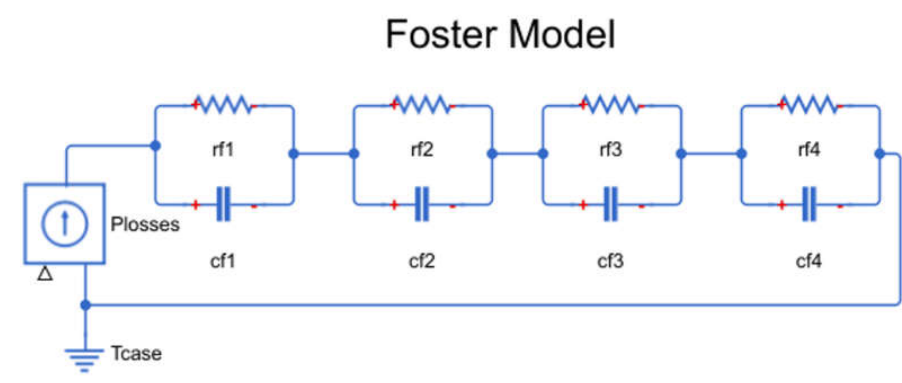

Figura 58 - Impedância térmica FZ3600R17HP4.

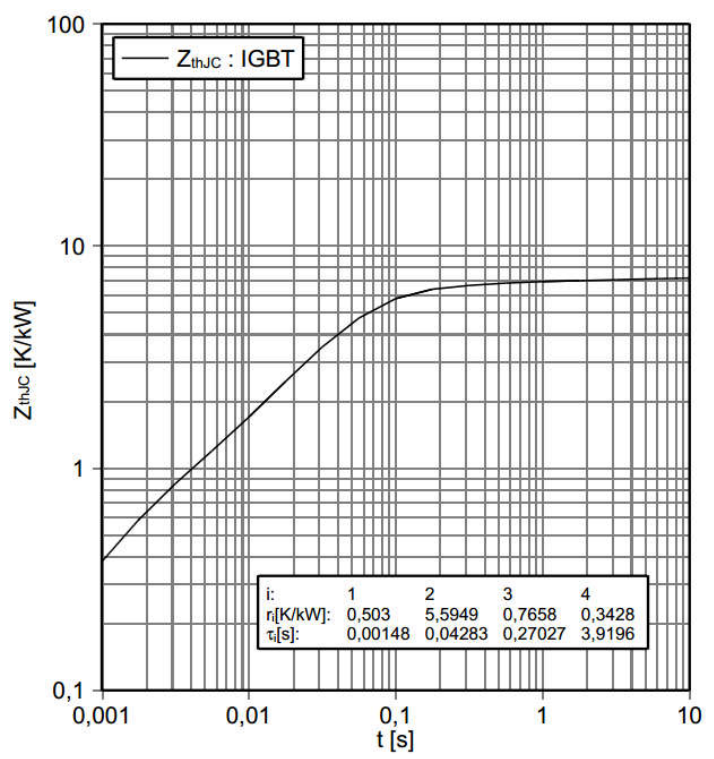

Fonte: (INFINEON, 2013).

As impedâncias térmicas, entretanto, relativas à pasta térmica e ao dissipador dependem de projeto para projeto. As hipóteses adotadas para modelagem das impedâncias térmicas da pasta e do dissipador são apresentadas na sequência. Primeiramente, é necessário definir resistência e capacitância térmicas. 


$$
\begin{aligned}
R_{t h} & =\frac{d}{k A}[K / W] \\
C_{t h} & =\rho d A h[J / K]
\end{aligned}
$$

Onde $d$ é espessura do material, $k$ é a condutividade térmica $(W / m . K), A$ é a área, $\rho$ é a massa específica $\left(g / \mathrm{cm}^{3}\right)$ e $h$ é a capacidade térmica $(J / g . K)$.

Para a pasta térmica, utiliza-se como referência a pasta G-747 da ShinEtsu com $d=100 \mu \mathrm{m}$, conforme recomendado em (HITACHI, 2009). Para este material $k=$ $0.9 \mathrm{~W} / \mathrm{m} . \mathrm{K}$ e $\rho=2,65 \mathrm{~g} / \mathrm{cm}^{3}$ (SHINETSU, 2017). A capacidade térmica da pasta G747 não é fornecida em (SHINETSU, 2017), entretanto, utiliza-se um valor típico de 1,39 J/g.K (SHINETSU, 2017a).

A área de contato total entre o case e o dissipador é estimada em $A=$ $(190-32) m m x(140-32 \mathrm{~mm})=170,64 \mathrm{~cm}^{2}$, conforme as especificações em (INFINEON, 2013). A massa total das pasta é, portanto, estimada em 4,52g.

Nas especificações técnicas fo módulo IGBT FZ3600R17HP4 (INFINEON, 2013) apresentam-se os seguintes valores de referência para a resistência térmica entre a base e o dissipador: 7,0 K/kW para o diodo e 6,3 K/kW para o IGBT. Recorrendo-se a equação (10.4), estima-se a relação entre as áreas do IGBT e a área do Diodo, $A_{d}=$ $0,9 A_{\text {Igbt }}$.

Desta forma, é possível calcular as impedâncias térmicas com as especificidades da pasta térmica assumida neste trabalho:

$$
\begin{gathered}
R_{t h \_c h D}=13,75[\mathrm{~K} / \mathrm{kW}] \\
R_{t h \_c h I}=12,37[\mathrm{~K} / \mathrm{kW}] \\
C_{t h \_c h D}=2,98[\mathrm{~J} / \mathrm{K}] \\
C_{t h \_c h I}=3,31[\mathrm{~J} / \mathrm{K}]
\end{gathered}
$$

O dissipador térmico é projetado para manter os componentes dentro de seus limites térmicos. Recorrendo-se ao circuito elétrico da Figura 56, é possível 
equacionar a relação entre a resistência térmica do dissipador e a temperatura máxima da junção dos semicondutores de acordo com as seguintes equações:

$$
\begin{aligned}
R_{t h \_h a I} & =\frac{T_{v j \_m a x}-T_{a \_ \text {max }}-\left(R_{t h \_j c I}+R_{t h \_c h I}\right) P_{i g b t}}{P_{\text {igbt }+} P_{\text {diode }}} \\
R_{\text {th_haD }} & =\frac{T_{v j \_ \text {max }}-T_{a \_m a x}-\left(R_{t h \_j c D}+R_{t h \_c h D}\right) P_{\text {diode }}}{P_{\text {igbt+ }} P_{\text {diode }}}
\end{aligned}
$$

Para resolver as equações (10.10) e (10.11), opta-se por utilizar de valores médios de $P_{\text {igbt }}$ e $P_{\text {diode }}$. Desta forma, é preciso deixar uma margem adicional em $T_{v j \_ \text {max }}$ para compensar o aumento da temperatura por conta dos picos de potência. Adotase margem de $15^{\circ} \mathrm{C}$ e, assim, nestas equações utiliza-se $T_{v j \_ \text {max }}=110^{\circ} \mathrm{C}$. Adota-se valor máximo da temperatura do fluido de arrefecimento de $T_{a \_ \text {max }}=40^{\circ} \mathrm{C}$.

Os valores médios de $P_{i g b t}$ e $P_{\text {diode }}$ são calculados pelas equações da secção 4.5.1 e são apresentados na Figura 59.

Figura 59 - Perdas médias em função do fator de potência.

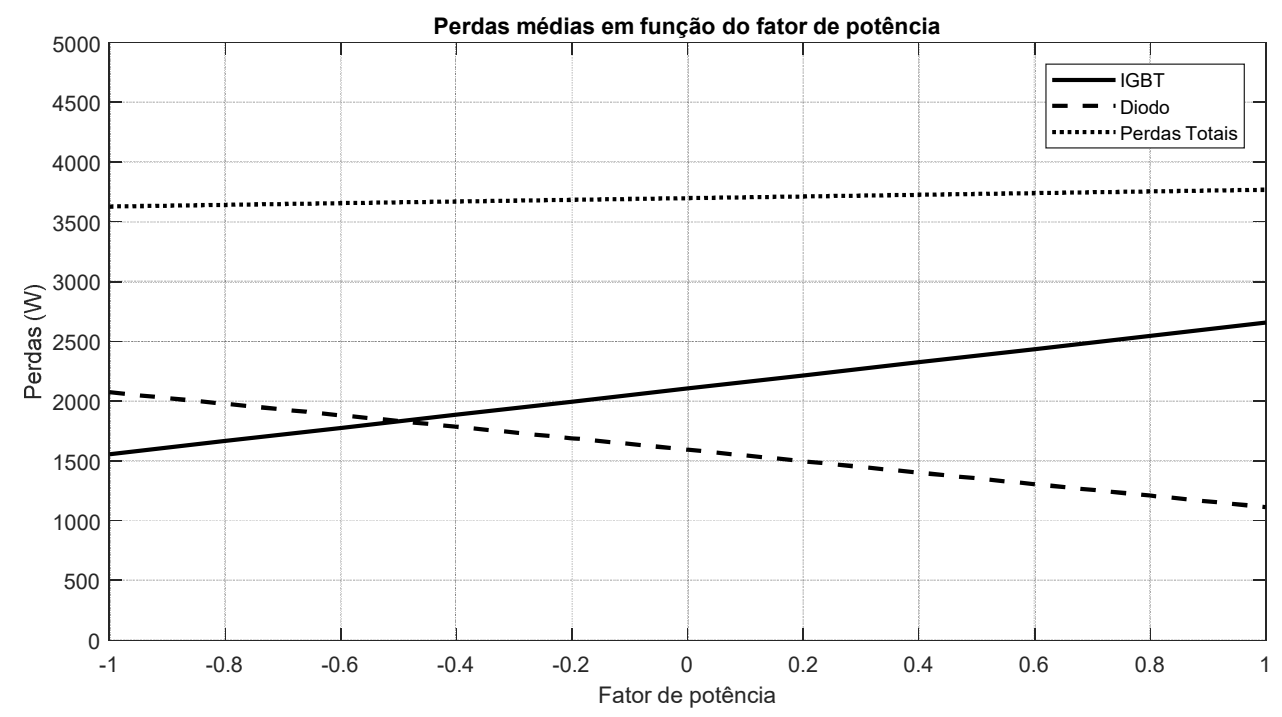

Fator de potência negativo indica operação como retificador. No caso contrário, o conversor opera como inversor. Resolvendo as equações (10.10) e (10.11), chega que $R_{t h \_h a}$ deverá ser inferior a $4 \mathrm{~K} / \mathrm{kW}$. O cenário crítico consiste na operação como retificador com fator de potência unitário, onde o diodo atinge a sua temperatura limite. Para a capacidade térmica do dissipador, assume-se que o dissipador tem constante de tempo térmica de $30 \mathrm{~s}$, desta forma $C_{t h}=7500 \mathrm{~J} / \mathrm{K}$. 
Com os parâmetros adotados para o dissipador térmico, espera-se que a temperatura média dos semicondutores seja inferior a $110^{\circ} \mathrm{C}$ nas piores condições de operação. Para avaliar as oscilações de temperatura dos semicondutores em relação ao seu valor médio, é simulado o circuito apresentado na Figura 60.

Adota-se a simplificação de se considerar que a forma de onda da potência dissipada no IGBT, ou diodo, corresponde a meia-onda senoidal com valor de pico igual a $\pi P_{a v g}$. Esta simplificação é sugerida pela Semikron e utilizada no seu programa SemiSel (SEMIKRON, 2015, p. 288), essa aproximação é exemplificada na Figura 69.

Figura 60 - Circuito térmico completo módulo IGBT.

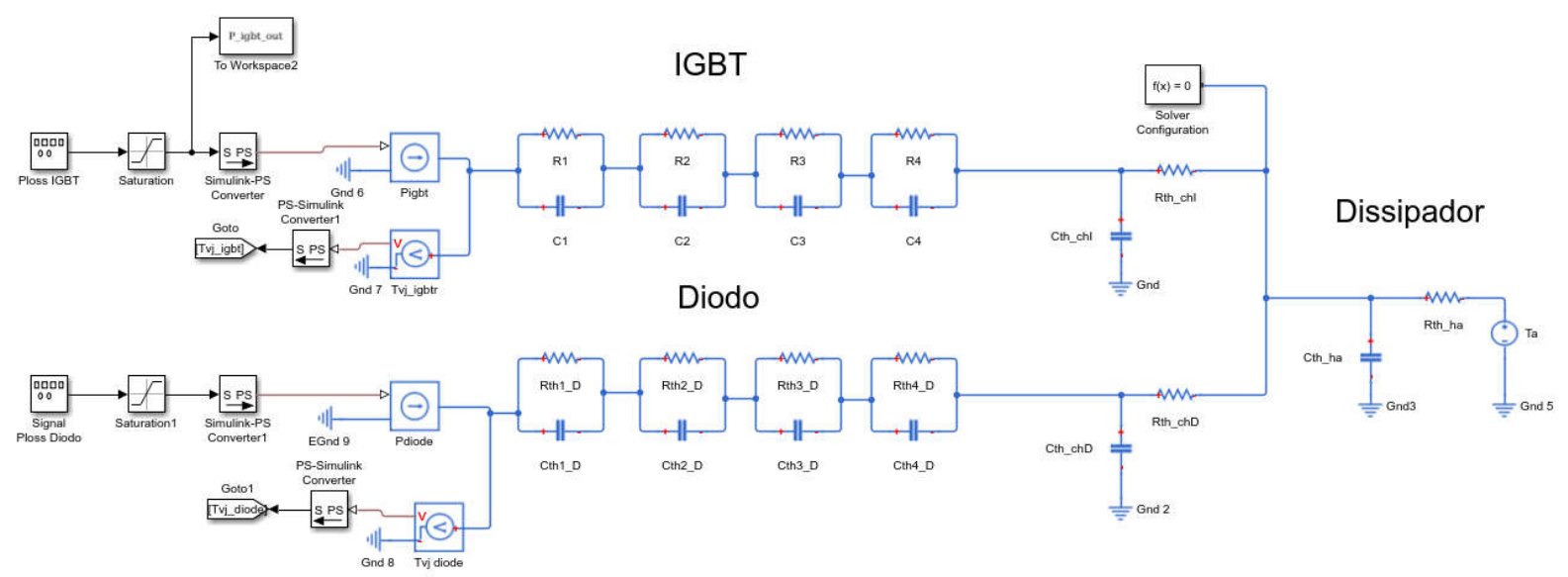

Figura 61 - Aproximação para cálculo da potência instantânea.
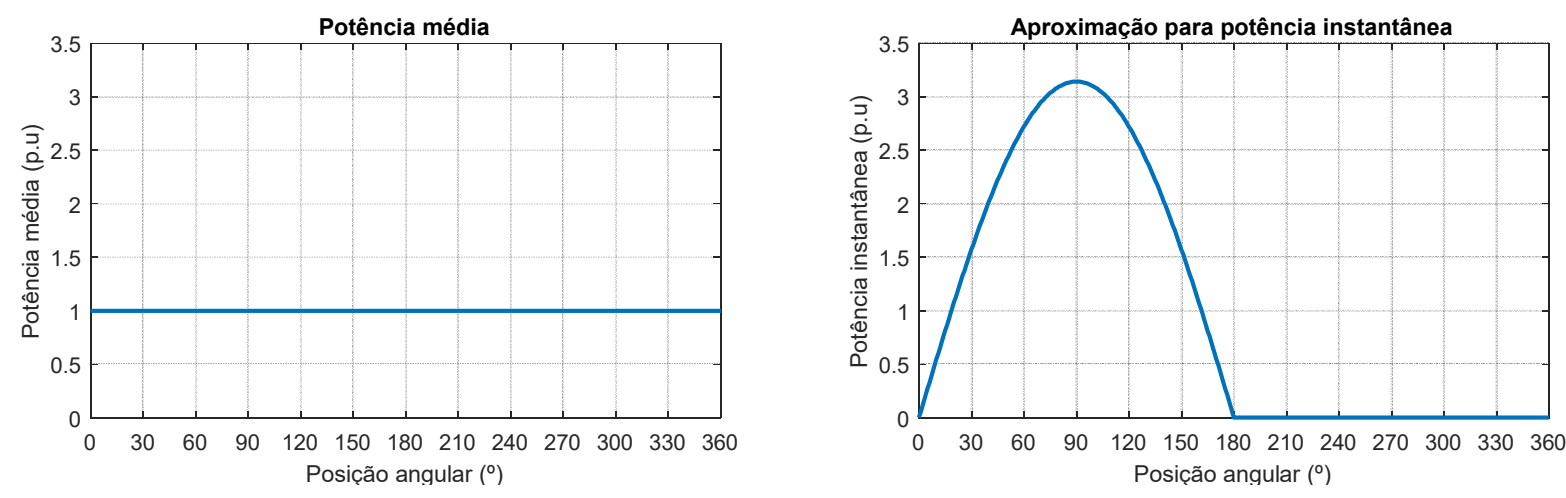

Os resultados das simulações para frequência elétrica de $40 \mathrm{~Hz}$ são apresentados nas figuras a seguir: 
Figura 62 - Retificação com fator de potência unitário.
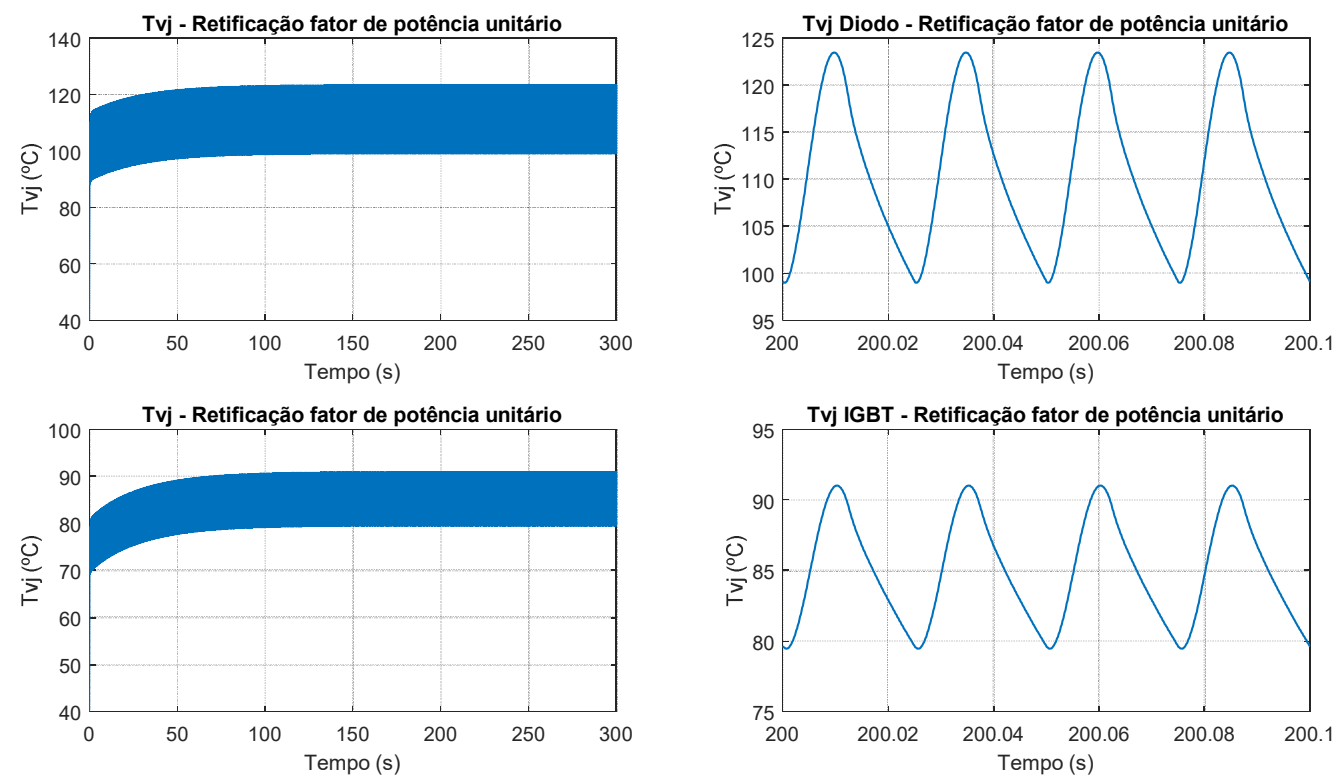

Figura 63 - Inversão com fator de potência unitário.
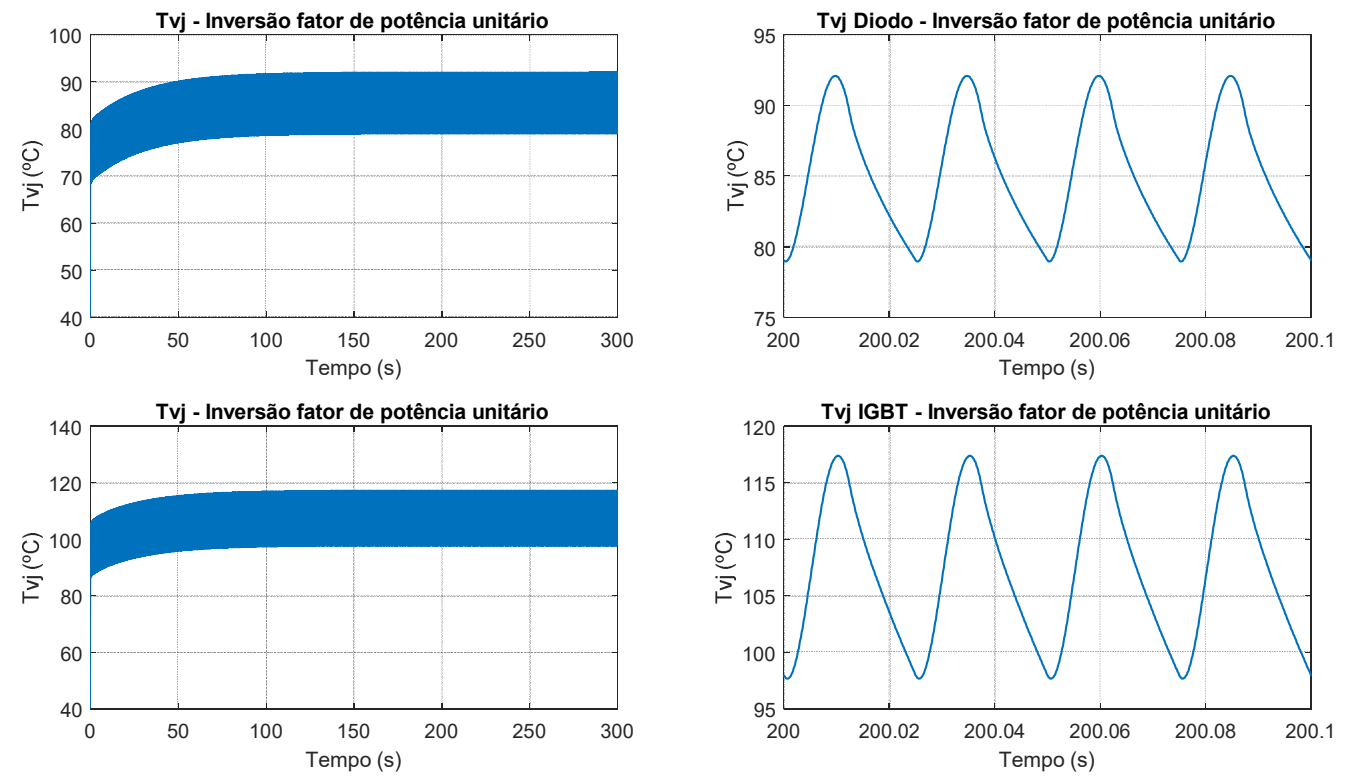

Com os resultados apresentados nas figuras Figura 62 e Figura 63, confirmase que as condições de operação dos conversores assumidas neste trabalho são factíveis. Nota-se, entretanto, que o valor da resistência térmica do dissipador pode ser otimizado pelos seguintes motivos:

- Perdas são sobrestimadas uma vez que foram sempre calculadas para $T_{v j}=125^{\circ} \mathrm{C}$. 
- O fator crítico é a temperatura do diodo para retificação com fator de potência unitário. Em condições nominais, o gerador deverá operar com fator de potência entre 0,8 e 0,9, o que melhora as condições de operação do diodo.

- Caso a frequência fundamental da máquina seja superior a $40 \mathrm{~Hz}$, a oscilação entre a temperatura média da junção e o seu valor máximo será menor. Desta forma, caso a máquina tenha mais de sete pares de polos, será possível projetar o dissipador para temperaturas médias da junção dos semicondutores superior a $110^{\circ} \mathrm{C}$.

\section{A.2.2 Operação em baixa frequência elétrica}

Conforme apresentado nas figuras 62 e 63, a oscilação da temperatura da junção dos semicondutores tem mesma frequência que a frequência fundamental da corrente elétrica. Numa primeira aproximação, a frequência fundamental da aplicação não tem impacto na potência média dissipada pelos semicondutores. Entretanto, conforme a frequência elétrica diminui, os pulsos de potência se tornam mais longos e a amplitude da oscilação de temperatura $(\Delta T)$, em relação ao seu valor médio, aumenta. Isso é exemplificado na figura a seguir:

Figura 64 - Tvj para diferentes valores de frequência.

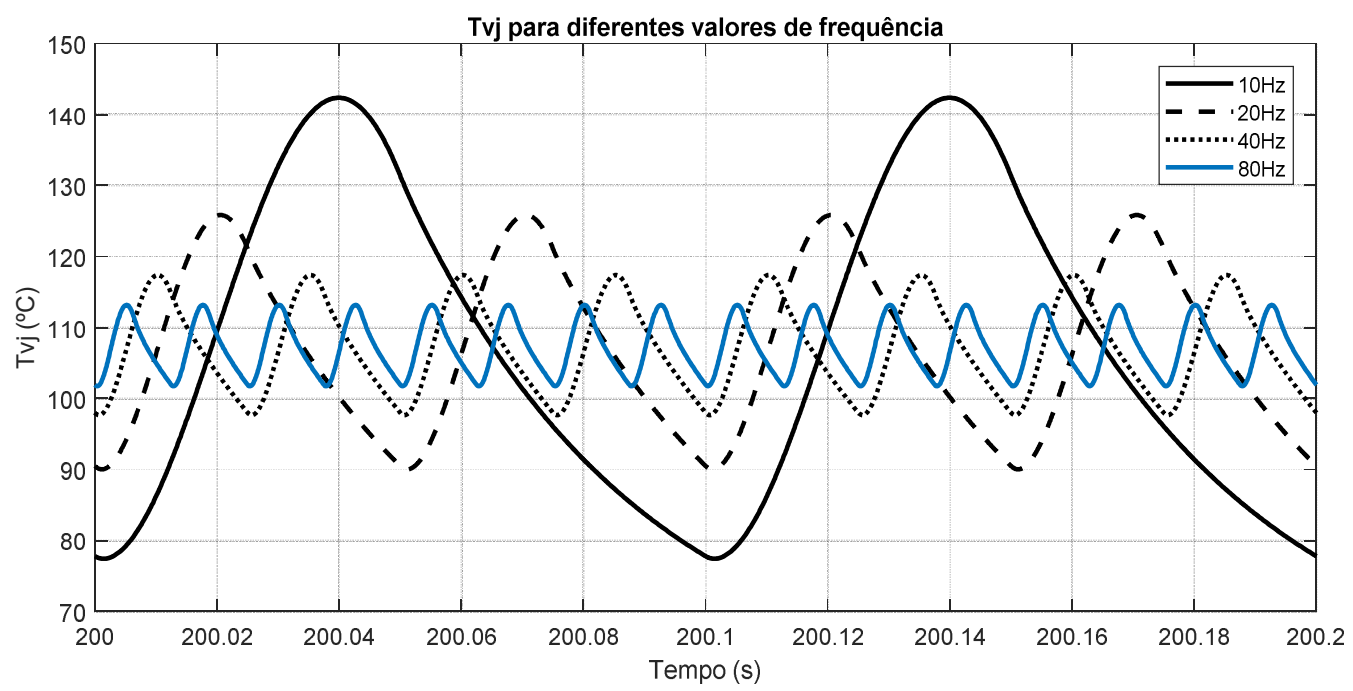

A redução da frequência elétrica, portanto, produz os seguintes impactos para o projeto do conversor eletrônico de potência: 
- Dissipador precisa ser projetado de forma a garantir menor temperatura média na junção dos semicondutores. Consequentemente, os custos com o sistema de refrigeração serão maiores.

- Para um mesmo dissipador térmico, a capacidade de corrente do conversor terá que ser reduzida para diminuir a temperatura média de operação. Isso é exemplificado com a informação disponível do inversor 6MS30017E43W33015 da Infineon para turbinas eólicas, apresentada na Figura 65.

Figura 65 - Redução da capacidade de corrente para baixos valores de frequência elétrica.

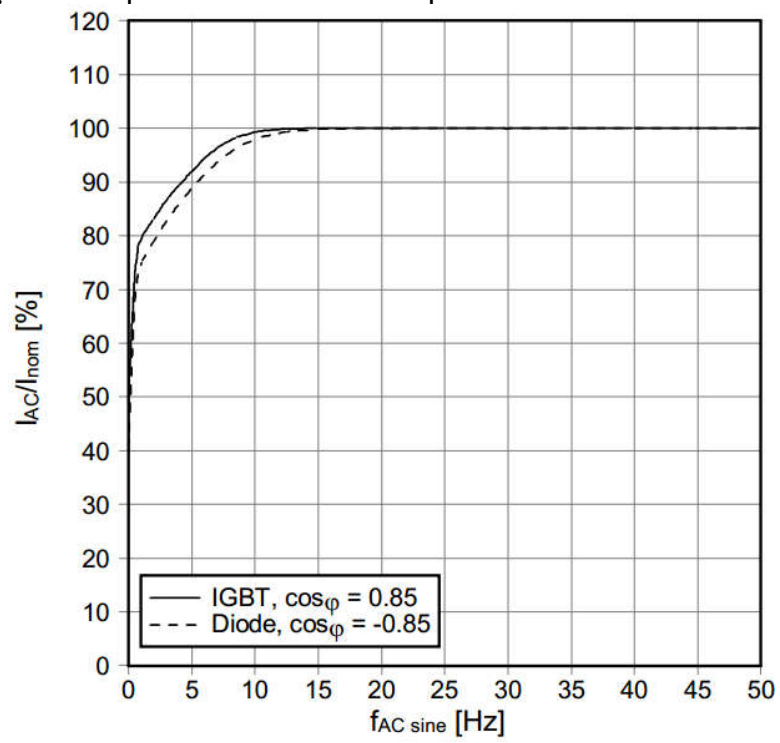

Fonte: (INFINEON, 2012).

É importante ressaltar que a operação com valores mais elevados de $\Delta T$ pode ter impactos negativos para a confiabilidade do conversor. Um dos fatores críticos para a vida útil dos semicondutores é a fadiga térmica. De acordo com (SEMIKRON, 2015, p. 127-128), o número máximo de ciclos térmicos que módulos IGBT podem ser submetidos é inversamente proporcional a $\Delta T^{4-5}$. 


\section{APÊNDICE B - FORÇA MAGNETOMOTRIZ}

\section{B.1 FORÇA MAGNETOMOTRIZ PRODUZIDA POR ENROLAMENTOS MULTIFÁSICOS PARA COMPONENTE FUNDAMENTAL}

A seguir apresenta-se a demonstração matemática da força magnetomotriz gerada por um enrolamento de $m$ fases simetricamente distribuídas no estator ou assimetricamente distribuídas em $N$ grupos simétricos.

Considerando apenas a componente fundamental de corrente, a força magnetomotriz $f_{n}$ gerada pela fase $n$ com defasagem temporal e espacial $\theta_{n}$ (LIWSCHITZ-GARIK e WHIPPLE, 1950, p. 152) é calculada por ${ }^{12}$ :

$$
\begin{gathered}
f_{n}=\frac{4}{\pi} N_{s f} \sqrt{2} I_{f} k_{e 1} \sin \left(w t-\theta_{n}\right) \cos \left(\frac{\pi}{\tau_{p}} x-\theta_{n}\right) \\
f_{n}=\frac{2}{\pi} N_{s f} \sqrt{2} I_{f} k_{e 1}\left[\left(\sin \left(w t-\frac{\pi}{\tau_{p}} x\right)+\sin \left(w t+\frac{\pi}{\tau_{p}} x-2 \theta_{n}\right)\right)\right]
\end{gathered}
$$

A força magnetomotriz que resulta do acoplamento das $m$-fases é:

$$
\begin{gathered}
F_{m m}=\frac{2}{\pi} N_{s f} \sqrt{2} I_{f} k_{e 1} \sum_{n=1}^{m}\left[\left(\sin \left(w t-\frac{\pi}{\tau_{p}} x\right)+\sin \left(w t+\frac{\pi}{\tau_{p}} x-2 \theta_{n}\right)\right)\right] \\
F_{m m}=\left(\frac{m}{2}\right) \frac{4}{\pi} N_{s f} \sqrt{2} I_{f} k_{e 1} \sin \left(w t-\frac{\pi}{\tau_{p}} x\right)+\frac{2}{\pi} N_{s f} \sqrt{2} I_{f} k_{e 1} \sum_{n=1}^{m}\left[\sin \left(w t+\frac{\pi}{\tau_{p}} x-2 \theta_{n}\right)\right] \\
F_{m m}=\left(\frac{m}{2}\right) \frac{4}{\pi} N_{s f} \sqrt{2} I_{f} k_{e 1} \sin \left(w t-\frac{\pi}{\tau_{p}} x\right)+\frac{2}{\pi} N_{s f} \sqrt{2} I_{f} k_{e 1} \sum_{n=1}^{m}\left[\operatorname{Img}\left\{e^{j w t+\frac{\pi}{\tau_{p}} x} \cdot e^{j\left(-2 \theta_{n}\right)}\right\}\right] \\
F_{m m}=\left(\frac{m}{2}\right) \frac{4}{\pi} N_{s f} \sqrt{2} I_{f} k_{e 1} \sin \left(w t-\frac{\pi}{\tau_{p}} x\right)+\frac{2}{\pi} N_{s f} \sqrt{2} I_{f} k_{e 1} \operatorname{Img}\left\{e^{j w t+\frac{\pi}{\tau_{p}} x} \cdot \sum_{n=1}^{m} e^{j\left(-2 \theta_{n}\right)}\right\}
\end{gathered}
$$

12 O fator $\frac{4}{\pi}$ corresponde à amplitude da primeira harmônica da transformada de Fourier da onda retangular. 
Considerando que os enrolamentos são distribuídos simetricamente no estator, cada fase estará defasada entre si de um ângulo $\alpha$. Considera-se a referência angular coincidente com o eixo magnético da fase 1 , portanto $\theta_{1}=0$.

$$
\alpha=\frac{2 \pi}{m}
$$

A posição angular do eixo magnético de uma fase genérica $n$, portanto, será:

$$
\theta_{n}=(n-1) \alpha
$$

Desta forma,

$$
\sum_{n=1}^{m} e^{j\left(-2 \theta_{n}\right)}=1+e^{j(-2 \alpha)}+e^{2 j(-2 \alpha)}+e^{3 j(-2 \alpha)} \ldots e^{(m-1) j(-2 \alpha)}
$$

Realizando a seguinte mudança de variável:

$$
\begin{gathered}
x=-2 \alpha \\
k=m-1 \\
\sum_{n=1}^{m} e^{j\left(-2 \theta_{n}\right)}=1+e^{j \mathrm{x}}+e^{j 2 \mathrm{x}}+e^{j 3 \mathrm{x}} \ldots e^{j \mathrm{kx}}
\end{gathered}
$$

Recorrendo-se a seguinte igualdade (GUIDORIZZI, 2002, p. 93) e para $x \neq$ $k 2 \pi:$

$$
e^{j \mathrm{x}}+e^{j 2 \mathrm{x}}+e^{j 3 \mathrm{x}} \ldots e^{j \mathrm{kx}}=\frac{e^{j k x}-1}{1-e^{-j x}}
$$

A relação (10.16) só é válida para $x \neq k 2 \pi$, para $k$ inteiro. Substituindo (10.16) em (10.15)

$$
\sum_{n=1}^{m} e^{j\left(-2 \theta_{n}\right)}=1+\frac{e^{j k x}-1}{1-e^{-j x}}
$$

Voltando às variáveis originais: 


$$
\sum_{n=1}^{m} e^{j\left(-2 \theta_{n}\right)}=1+\frac{e^{j(m-1)(-2 \alpha)}-1}{1-e^{-j(-2 \alpha)}}
$$

Colocando $\alpha$ em função do número de fases:

$$
\begin{aligned}
& \sum_{n=1}^{m} e^{j\left(-2 \theta_{n}\right)}=1+\frac{e^{j\left(\frac{4 \pi}{m}-4 \pi\right)}-1}{1-e^{j\left(\frac{4 \pi}{m}\right)}} \\
& \sum_{n=1}^{m} e^{j\left(-2 \theta_{n}\right)}=1-\frac{1-e^{j\left(\frac{4 \pi}{m}\right)}}{1-e^{j\left(\frac{4 \pi}{m}\right)}}=0
\end{aligned}
$$

No caso de enrolamentos assimétricos compostos por $N$ grupos de $\frac{m}{N}$ fases simetricamente defasadas, esse resultado permanece verdadeiro uma vez que $\sum_{n=1}^{m} e^{j\left(-2 \theta_{n}\right)}$ é nulo para cada grupo de $\frac{m}{N}$ fases. Por exemplo, para máquinas do tipo $N$-star, onde $\frac{m}{N}=3$.

$$
\sum_{n=1}^{m} e^{j\left(-2 \theta_{n}\right)}=\sum_{n=1}^{3} e^{j\left(-2 \theta_{n}\right)}+\sum_{n=4}^{6} e^{j\left(-2 \theta_{n}\right)} \ldots \sum_{n=3(\mathrm{~N}-1)+1}^{3 N} e^{j\left(-2 \theta_{n}\right)}=0
$$

Portanto, a força magnetomotriz fundamental gerada por $m$ fases distribuídas simetricamente ou em $N$ grupos de $\frac{m}{N}$ fases é descrita pela seguinte relação matemática:

$$
F_{m m}=\left(\frac{m}{2}\right) \frac{4}{\pi} N_{s f} \sqrt{2} I_{f} k_{e 1} \sin \left(w t-\frac{\pi}{\tau_{p}} x\right)
$$

Observa-se que (10.17) consiste na força magnetomotriz resultante de um enrolamento multifásico quando a defasagem temporal da corrente coincide com a defasagem espacial da respectiva fase. Em outras palavras, (10.17) é a força magnetomotriz de sequência positiva, em termos generalizados.

No caso de corrente de sequência negativa, (10.12) e (10.13), são escritas da seguinte forma: 


$$
\begin{gathered}
f_{n}=\frac{4}{\pi} N_{s f} \sqrt{2} I_{f} k_{e 1} \sin \left(w t+\theta_{n}\right) \cos \left(\frac{\pi}{\tau_{p}} x-\theta_{n}\right) \\
f_{n}=\frac{2}{\pi} N_{s f} \sqrt{2} I_{f} k_{e 1}\left[\left(\sin \left(w t-\frac{\pi}{\tau_{p}} x+2 \theta_{n}\right)+\sin \left(w t+\frac{\pi}{\tau_{p}} x\right)\right)\right]
\end{gathered}
$$

Aplicando a mesma metodologia usada para o caso de correntes de sequência positiva, obtém-se o resultado esperado, onde as forças magnetomotrizes de sequência positiva e negativa são iguais em módulo, porém com rotação em sentidos opostos, equações (10.17) e (10.20).

$$
F_{m m}=\left(\frac{m}{2}\right) \frac{4}{\pi} N_{s f} \sqrt{2} I_{f} k_{e 1} \sin \left(w t+\frac{\pi}{\tau_{p}} x\right)
$$

Para correntes de sequência zero, a força magnetomotriz produzida por uma fase genérica $f_{n}$, com fase $\theta_{0}=0$ será:

$$
\begin{gathered}
f_{n}=\frac{4}{\pi} N_{s f} \sqrt{2} I_{f} k_{e 1} \sin (w t) \cos \left(\frac{\pi}{\tau_{p}} x-\theta_{n}\right) \\
f_{n}=\frac{2}{\pi} N_{s f} \sqrt{2} I_{f} k_{e 1}\left[\left(\sin \left(w t+\frac{\pi}{\tau_{p}} x-\theta_{n}\right)+\sin \left(w t+\frac{\pi}{\tau_{p}} x+\theta_{n}\right)\right)\right]
\end{gathered}
$$

Novamente, considerando a mesma metodologia aplicada ao caso de correntes de sequência positiva chega-se que $F_{m m}=0$. Portanto, a indutância de sequência zero não terá componente de magnetização, apenas de dispersão, situação idêntica ao caso trifásico.

\section{B.2 FORÇA MAGNETOMOTRIZ PRODUZIDA POR ENROLAMENTOS MULTIFÁSICOS PARA COMPONENTES HARMÔNICAS ESPACIAIS}

Considerando apenas componente fundamental de corrente, para uma fase genérica, as equações (10.12) e (10.13) são reescritas da seguinte forma:

$$
f_{n}=\frac{4}{\pi} N_{s f} \sqrt{2} I_{f} \sin \left(w t-\theta_{n}\right) \sum_{h=1}^{\infty} \frac{k_{e h}}{h} \cos \left[h\left(\frac{\pi}{\tau_{p}} x-\theta_{n}\right)\right]
$$




$$
f_{n}=\frac{1}{2} \frac{4}{\pi} N_{s f} \sqrt{2} I_{f} \sum_{h=1}^{\infty} \frac{k_{e h}}{h}\left[\sin \left(w t-\frac{h \pi}{\tau_{p}} x+\theta_{n}(h-1)\right)+\sin \left(w t+\frac{h \pi}{\tau_{p}} x-\theta_{n}(h+1)\right)\right]
$$

A força magnetomotriz produzida por uma fase genérica só apresenta harmônicas de ordem ímpar (forma de onda simétrica).

\section{B.2.1 Força magnetomotriz resultante para máquinas simétricas}

Considerando uma componente harmônica de ordem genérica $h$, a força magnetomotriz resultante produzida pelo estator da máquina será:

$$
\begin{aligned}
& F_{h}=\frac{1}{2} \frac{4}{\pi} N_{s f} \sqrt{2} I_{f} \frac{k_{e h}}{h} \sum_{n=1}^{m}\left[\sin \left(w t-\frac{h \pi}{\tau_{p}} x+\theta_{n}(h-1)\right)+\sin \left(w t+\frac{h \pi}{\tau_{p}} x-\theta_{n}(h+1)\right)\right] \\
& F_{h}=\frac{1}{2} \frac{4}{\pi} N_{s f} \sqrt{2} I_{f} \frac{k_{e h}}{h}\left[\operatorname{Imag}\left\{e^{j w t-\frac{h \pi}{\tau_{p}} x} \cdot \sum_{n=1}^{m} e^{j \theta_{n}(h-1)}\right\}+\operatorname{Imag}\left\{e^{j w t+\frac{h \pi}{\tau_{p}} x} \cdot \sum_{n=1}^{m} e^{-j \theta_{n}(h+1)}\right\}\right]
\end{aligned}
$$

Para máquina com enrolamentos simetricamente distribuídos, tem-se: $\alpha=\frac{2 \pi}{m}$ e $\theta_{n}=(n-1) \alpha$. Desta forma:

$$
\begin{gathered}
\sum_{n=1}^{m} e^{j \theta_{n}(h-1)}=1+e^{j \alpha(h-1)}+e^{j 2 \alpha(h-1)} \ldots e^{j(m-1) \alpha(h-1)} \\
\sum_{n=1}^{m} e^{j-\theta_{n}(h+1)}=1+e^{-j \alpha(h+1)}+e^{-j 2 \alpha(h+1)} \ldots e^{-j(m-1) \alpha(h+1)}
\end{gathered}
$$

Assumindo-se

$$
\begin{gathered}
x_{1}=\alpha(h-1) \\
x_{2}=-\alpha(h+1) \\
k=m-1
\end{gathered}
$$

Para $x_{1} \neq k_{1} 2 \pi, k_{1}$ inteiro:

$$
\sum_{n=1}^{m} e^{j \theta_{n}(h-1)}=1+e^{j x_{1}}+e^{j 2 x_{1}} \ldots e^{j k x_{1}}=1+\frac{e^{j k x_{1}}-1}{1-e^{-j x_{1}}}
$$




$$
\begin{aligned}
& 1+\frac{e^{j k x_{1}}-1}{1-e^{-j x_{1}}}=1+\frac{e^{j(m-1)(h-1) \frac{2 \pi}{m}}-1}{1-e^{-j(h-1) \frac{2 \pi}{m}}} \\
& 1+\frac{e^{j k x_{1}}-1}{1-e^{-j x_{1}}}=1+\frac{e^{-j(h-1) \frac{2 \pi}{m}}-1}{1-e^{-j(h-1) \frac{2 \pi}{m}}}=0
\end{aligned}
$$

Para $x_{1}=k_{1} 2 \pi$ :

$$
\sum_{n=1}^{m} e^{j \theta_{n}(h-1)}=1+e^{j x_{1}}+e^{j 2 x_{1}} \ldots e^{j k x_{1}}=m
$$

Esta condição é satisfeita quando:

$$
h=k_{1} m+1
$$

Para $x_{2} \neq k_{1} 2 \pi, k_{1}$ inteiro:

$$
\begin{gathered}
\sum_{n=1}^{m} e^{j-\theta_{n}(h-1)}=1+e^{j x_{2}}+e^{j 2 x_{2}} \ldots e^{j k x_{2}}=1+\frac{e^{j k x_{2}}-1}{1-e^{-j x_{2}}} \\
1+\frac{e^{j k x_{2}}-1}{1-e^{-j x_{2}}}=1+\frac{e^{-j(m-1)(h+1) \frac{2 \pi}{m}}-1}{1-e^{j(h+1) \frac{2 \pi}{m}}} \\
1+\frac{e^{j k x_{2}}-1}{1-e^{-j x_{2}}}=1+\frac{e^{j(h+1) \frac{2 \pi}{m}}-1}{1-e^{j(h+1) \frac{2 \pi}{m}}}=0
\end{gathered}
$$

Para $x_{2}=k_{1} 2 \pi$ :

$$
\sum_{n=1}^{m} e^{-j \theta_{n}(h+1)}=1+e^{j x_{2}}+e^{j 2 x_{2}} \ldots e^{j k x_{2}}=m
$$

Esta condição é satisfeita quando:

$$
h=k_{1} m-1
$$


Portanto, quando $h=k_{1} m+1$, a força magnetomotriz resultante produzida pelo enrolamento multifásico será:

$$
F_{h}=\frac{m}{2} \frac{4}{\pi} N_{s f} \sqrt{2} I_{f} \frac{k_{e h}}{h}\left[\sin \left(w t-\frac{h \pi}{\tau_{p}} x\right)\right]
$$

Para $h=k_{1} m-1$ :

$$
F_{h}=\frac{m}{2} \frac{4}{\pi} N_{s f} \sqrt{2} I_{f} \frac{k_{e h}}{h}\left[\sin \left(w t+\frac{h \pi}{\tau_{p}} x\right)\right]
$$

Como a força magnetomotriz por fase apresenta apenas harmônicas de ordem ímpar, pode-se recorrer à seguinte equação para determinar as harmônicas espaciais que aparecem na força magnetomotriz resultante do enrolamento multifásico (LIWSCHITZ-GARIK e WHIPPLE, 1950, p. 497):

$$
h=2 k m+1
$$

Onde $k$ é um número inteiro positivo ou negativo. Caso $h$ possua valor positivo (10.35) está de acordo com (10.33) e a força magnetomotriz da harmônica de ordem $h$ se propaga na mesma direção da força magnetomotriz fundamental (sequencia positiva). Para $h$ negativo, quando calculado por (10.35), $F_{h}$ estará de acordo com (10.34) e se desloca no sentido contrário da componente fundamental (sequência negativa).

\section{B.2.2 Força magnetomotriz resultante para máquinas assimétricas do tipo N-star}

A máquina com enrolamentos do tipo $N$-star é composta por $\mathrm{N}$ grupos trifásicos $\left(\frac{m}{N}=3\right)$ defasados de uma faixa de fase $\frac{\pi}{m}$. Definindo:

$$
\begin{aligned}
& \qquad \alpha=\frac{2 \pi}{3} ; \beta=\frac{\pi}{m} \\
& \boldsymbol{\theta}_{\boldsymbol{n}}=[0, \alpha, 2 \alpha, \beta, \beta+\alpha, \beta+2 \alpha \ldots,(N-1) \beta,(N-1) \beta+\alpha,(N-1) \beta+2 \alpha] \\
& \text { Desta forma: }
\end{aligned}
$$




$$
\begin{aligned}
\sum_{n=1}^{m} e^{j \theta_{n}(h-1)}= & \left(1+e^{j \alpha(h-1)}+e^{j 2 \alpha(h-1)}\right)+\left(e^{j \beta(h-1)}+e^{j(\beta+\alpha)(h-1)}+e^{j(\beta+2 \alpha)(h-1)}\right) \ldots \\
& +e^{j((N-1) \beta+2 \alpha)(h-1)} \\
\sum_{n=1}^{m} e^{j \theta_{n}(h-1)}= & \left(1+e^{j \beta(h-1)}+e^{j 2 \beta(h-1)} \ldots+e^{j(N-1) \beta(h-1)}\right) \cdot\left(1+e^{j \alpha(h-1)}+e^{j 2 \alpha(h-1)}\right)
\end{aligned}
$$

Assumindo:

$$
\begin{aligned}
& x_{1}=\beta(h-1) \\
& x_{2}=\alpha(h-1) \\
& k=N-1 \\
& \sum_{n=1}^{m} e^{j \theta_{n}(h-1)}=\left(1+e^{j x_{1}}+e^{j 2 x_{1}} \ldots+e^{j k x_{1}}\right) \cdot\left(1+e^{j x_{2}}+e^{j 2 x_{2}}\right) \\
& \left(1+e^{j x_{1}}+e^{j 2 x_{1}} \ldots+e^{j k x_{1}}\right)=\left\{\begin{aligned}
1+\frac{e^{j(h-1)\left(\frac{\pi}{3}-\frac{\pi}{m}\right)}-1}{1-e^{j(h-1)\left(-\frac{\pi}{m}\right)},} & h \neq 2 m k_{1}+1 \\
N, & h=2 m k_{1}+1
\end{aligned}\right. \\
& \left(1+e^{j x_{2}}+e^{j 2 x_{2}}\right)=\left\{\begin{array}{rr}
1+\frac{e^{j 2 x_{2}}-1}{1-e^{-j x_{2}}}=0, & h \neq 3 k_{1}+1 \\
3, & h=3 k_{1}+1
\end{array}\right.
\end{aligned}
$$

Observa-se que a primeira parcela do somatório pode ter valores intermediários entre 0 e $\mathrm{N}$, diferente daquilo que acontece para máquina com enrolamentos simetricamente distribuídos no estator. Entretanto, esta diferença não tem impacto para $h$ ímpar. A figura a seguir compara o resultado do somatório (10.36) com (10.27) para $m=9$. 
Figura 66 - Harmônicas espaciais na FMM em máquinas de 9 fases, sequência positiva.
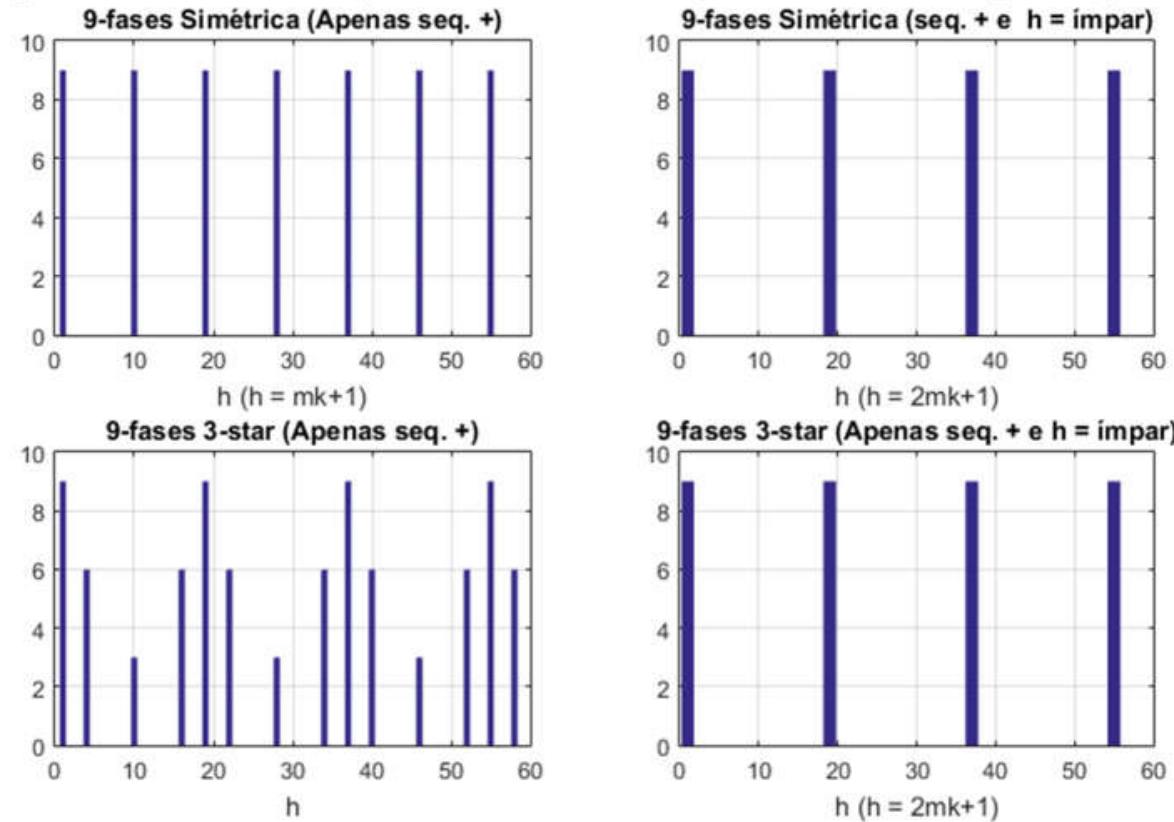

Portanto, para $h=2 k_{1} m+1$, a força magnetomotriz resultante produzida pelo enrolamento multifásico $N$-star será:

$$
F_{h}=\frac{m}{2} \frac{4}{\pi} N_{s f} \sqrt{2} I_{f} \frac{k_{e h}}{h}\left[\sin \left(w t-\frac{h \pi}{\tau_{p}} x\right)\right]
$$

De forma similar ao já apresentado, é possível provar que:

$$
\sum_{n=1}^{m} e^{j-\theta_{n}(h+1)}=\left(1+e^{j x_{1}}+e^{j 2 x_{1}} \ldots+e^{j k x_{1}}\right) \cdot\left(1+e^{j x_{2}}+e^{j 2 x_{2}}\right)
$$

Para:

$$
\begin{gathered}
x_{1}=-\beta(h+1) \\
x_{2}=-\alpha(h+1) \\
k=N-1 \\
\left(1+e^{j x_{1}}+e^{j 2 x_{1}} \ldots+e^{j k x_{1}}\right)=\left\{\begin{array}{rr}
1+\frac{e^{j(h+1)\left(\frac{\pi}{m}-\frac{\pi}{3}\right)}-1}{1-e^{j(h+1) \frac{\pi}{m}},} \quad h \neq 2 m k_{1}-1 \\
N, & h=2 m k_{1}-1
\end{array}\right.
\end{gathered}
$$




$$
\left(1+e^{j x_{2}}+e^{j 2 x_{2}}\right)=\left\{\begin{array}{rr}
1+\frac{e^{j 2 x_{2}}-1}{1-e^{-j x_{2}}}=0, & h \neq 3 k_{1}-1 \\
3, & h=3 k_{1}-1
\end{array}\right.
$$

Da mesma forma como foi apresentado anteriormente, na Figura 67 apresentase a diferença entre (10.40) e (10.30) para $m=9$.

Para $h=2 k_{1} m-1$, a força magnetomotriz resultante produzida pelo enrolamento multifásico $N$-star será:

$$
F_{h}=\frac{m}{2} \frac{4}{\pi} N_{s f} \sqrt{2} I_{f} \frac{k_{e h}}{h}\left[\sin \left(w t+\frac{h \pi}{\tau_{p}} x\right)\right]
$$

Para comparação, apresenta-se na figura a seguir a relação das harmônicas existentes (sequência positiva e negativa) para máquinas simétricas e $N$-star para $m$ $=9$.

Figura 67 - Harmônicas espaciais na FMM em máquinas de 9 fases, sequência negativa.
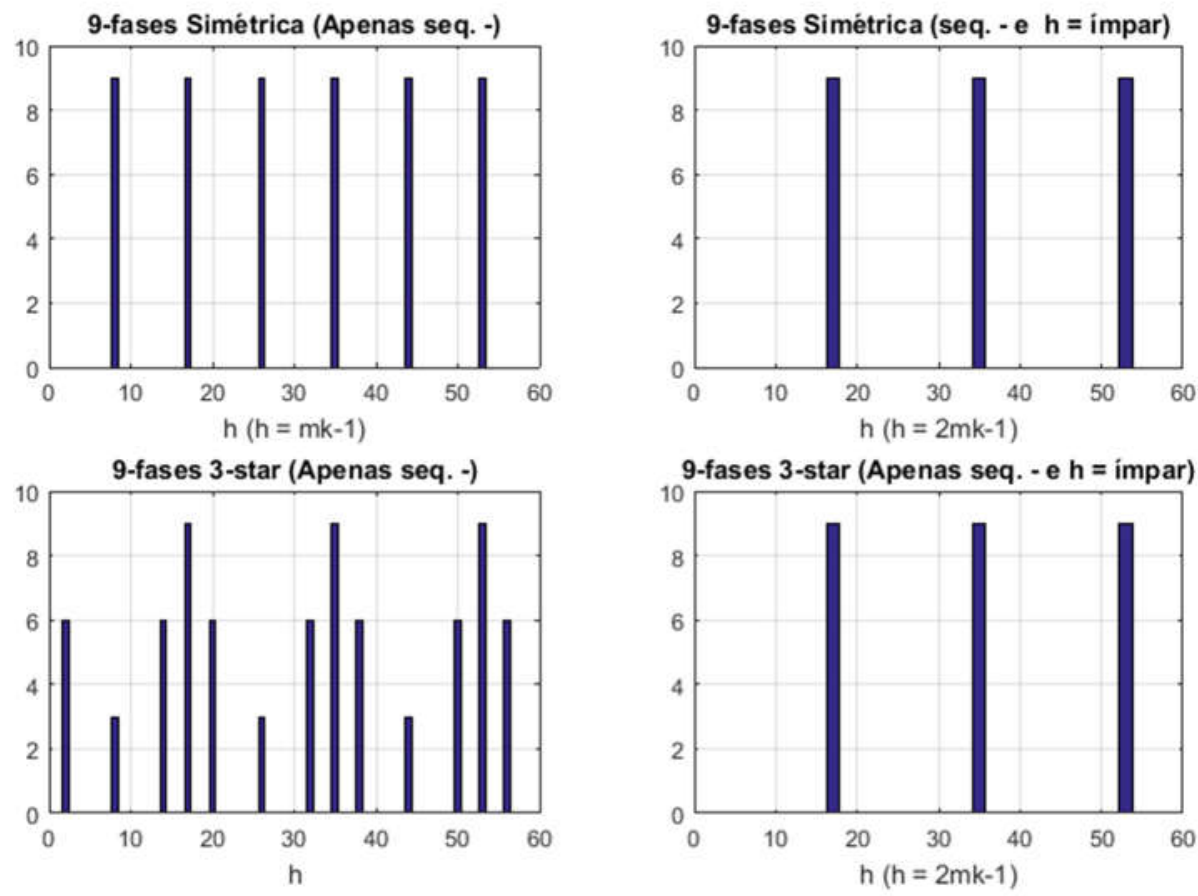
Figura 68 - Comparação entre harmônicas espaciais da FMM de máquinas simétricas e N-Star.
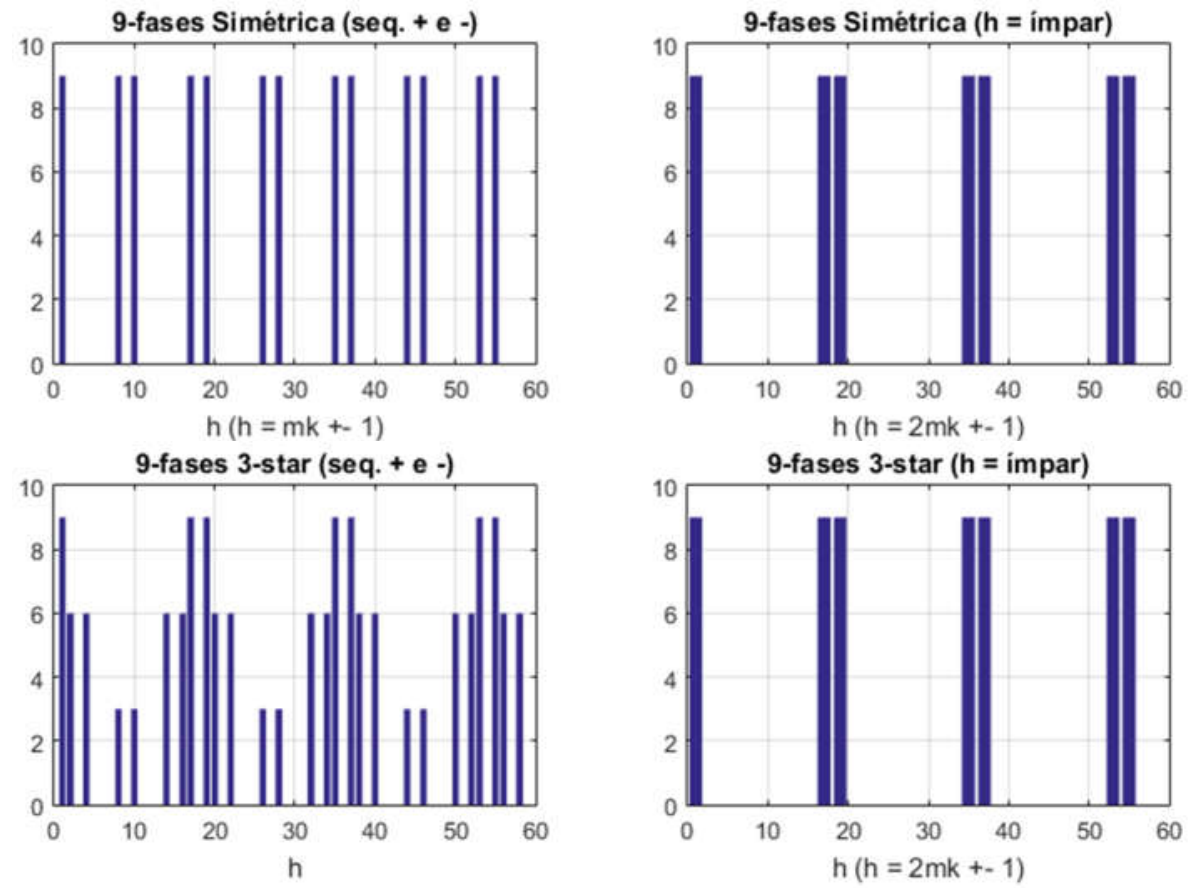

\section{B.3 FORÇA MAGNETOMOTRIZ RESULTANTE EM CASO DE FALHA EM UM CONVERSOR TRIFÁSICO PARA SOLUÇÕES 2 E 3.}

Nesta secção calcula-se a força magnetomotriz resultante no caso de falha de um conversor eletrônico de potência para as soluções 2 e 3, conforme apresentado na secção 4.4. Quando há falha em um dos conversores eletrônicos de potência, em ambos os casos, um dos grupos trifásicos do gerador terá que operar com potência reduzida, enquanto os demais grupos trifásicos podem continuar a operar em condições nominais.

Para analisar apenas a componente fundamental, recorre-se ao cálculo da força magnetomotriz por fase segundo a equação (10.13):

$$
f_{n}=\frac{2}{\pi} N_{s f} \sqrt{2} I_{f} k_{e 1}\left[\left(\sin \left(w t-\frac{\pi}{\tau_{p}} x\right)+\sin \left(w t+\frac{\pi}{\tau_{p}} x-2 \theta_{n}\right)\right)\right]
$$

Para as fases do grupo trifásico que apresenta falha em um dos conversores, a corrente elétrica precisa ser reduzida de $I_{f}$ para um certo valor $k_{i} I_{f}$, onde $0<k_{i}<$ 1. A força magnetomotriz resultante é calculada pela soma individual da força magnetomotriz produzida por cada fase da máquina. Para as fases pertencentes aos grupos trifásicos que operam sem falha, o resultado será equivalente ao apresentado 
em (10.17), uma vez que o segundo termo de (10.13) tem soma nula para cada grupo trifásico. Seja $F_{1}$ igual a força magnetomotriz resultante dos grupos trifásicos sem falha e $F_{2}$ a força magnetomotriz resultante do grupo trifásico com falha:

$$
\begin{gathered}
F_{m m}=F_{1}+F_{2} \\
F_{1}=(N-1)\left(\frac{3}{2}\right) \cdot \frac{4}{\pi} N_{s f} \sqrt{2} I_{f} k_{e 1} \sin \left(w t-\frac{\pi}{\tau_{p}} x\right) \\
F_{2}=\frac{2}{\pi} N_{s f} \sqrt{2} k_{i} I_{f} k_{e 1} \sum_{n=1}^{3}\left[\left(\sin \left(w t-\frac{\pi}{\tau_{p}} x\right)+\sin \left(w t+\frac{\pi}{\tau_{p}} x-2 \theta_{n}\right)\right)\right]
\end{gathered}
$$

Assume-se que as fases $n=1,2$ e 3 formam o grupo trifásico onde ocorreu a falha em um dos conversores eletrônicos de potência. Conforme a discussão já apresentada neste trabalho, $\sum_{n=1}^{3}\left[\sin \left(w t+\frac{\pi}{\tau_{p}} x-2 \theta_{n}\right)\right]=0$. Portanto:

$$
F_{2}=\left(\frac{3}{2}\right) \frac{4}{\pi} N_{s f} \sqrt{2} k_{i} I_{f} k_{e 1} \sin \left(w t-\frac{\pi}{\tau_{p}} x\right)
$$

Desta forma:

$$
F_{m m}=\left(N-1+k_{i}\right)\left(\frac{3}{2}\right) \frac{4}{\pi} N_{s f} \sqrt{2} I_{f} k_{e 1} \sin \left(w t-\frac{\pi}{\tau_{p}} x\right)
$$

A corrente de fase do gerador $I_{f}$ deve ser distribuída igualmente entre os conversores eletrônicos conectados em paralelo para cada grupo trifásico. Desta forma, caso exista falha em um conversor das soluções 2 e $3, k_{i}$ terá valor de $\frac{2}{3}$ e $\frac{1}{2}$ respectivamente.

\section{B.4 CONCLUSÃO}

Considerando que a forma de onda da força magnetomotriz produzida por uma fase é simétrica, demonstrou-se que a força magnetomotriz resultante terá as mesmas componentes harmônicas seja na configuração simétrica ou N-Star (apenas harmônicas de ordem ímpar, $\left.h=2 m k_{1} \pm 1\right)$. A configuração simétrica, entretanto, possui maior atenuação de harmônicas de ordem par que a configuração $N$-Star. 
Na perspectiva do autor, é mais vantajosa a aplicação de máquinas $N$-Star quando o número de fases da máquina é par. Conforme discutido na seção 3.7.3, a configuração simétrica em máquinas com número de fases par pode não permitir a utilização de faixa de fase de $\frac{\pi}{m}$, sendo normalmente utilizadas faixas de fase de $\frac{2 \pi}{m}$. Neste caso, as harmônicas da força magnetomotriz resultante serão equivalentes às harmônicas de uma máquina de $\frac{m}{2}$ fases (VIZIREANU, KESTELYN, et al., 2005, p. 3), (ABBAS, CHRISTEN e JAHNS, 1984, p. 1252).

Por fim, apresentou-se o cálculo da força magnetomotriz fundamental para máquinas elétricas multifásicas compostas por $\mathrm{N}$ grupos trifásicos quando há falha em um dos conversores eletrônicos de potência, conforme as configurações apresentadas em 4.4.2 e 4.4.3. 


\section{APÊNDICE C - FATORES DE PROJETO DE MÁQUINAS ELÉTRICAS}

\section{C.1 FATOR DE ASPECTO}

A seguir são apresentadas relações de aspecto (aspect ratio), normalmente definidas por $L_{e f} / \tau_{p}$ ou $L_{e f} / D$, típicas para geradores síncronos com mais de um pares de polos sugeridas nas referências (MITTLE e MITTAL, 2009), (PYRHONEN, JOKINEN e HRABOVCOVÁ, 2014) e (UPADHYAY, 2008).

Pyrhonen em (PYRHONEN, JOKINEN e HRABOVCOVÁ, 2014, p. 304) sugere a seguinte equação para a razão $L_{e f} / D_{g}$ para máquinas síncronas com mais de um par de polos:

$$
L_{e f} / D_{g}=\frac{\pi}{4 p} \sqrt{p}
$$

As referências (MITTLE e MITTAL, 2009, p. 483) e (UPADHYAY, 2008, p. 108109) sugerem para geradores com polos cilíndricos (Figura 69):

$$
L_{e f} / \tau_{p}=0,6-0.7
$$

Para polos retangulares:

$$
L_{e f} / \tau_{p}=0,8-4
$$

Figura 69 - Esquerda: polo cilíndrico. Direita: polo retangular.

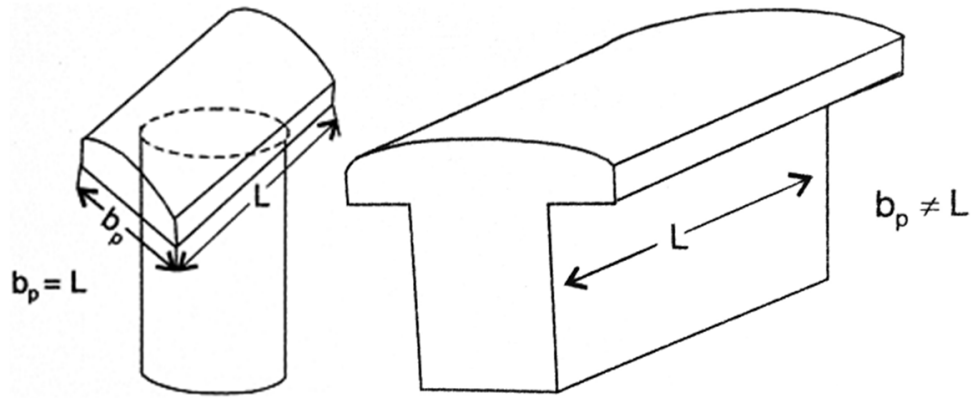

Fonte: adaptado de (UPADHYAY, 2008, p. 108).

Como é comentado em (LIPO, 2011), para máquinas de elevado diâmetro a solução ótima do gerador tende a ter forma anular (ring shape). Em outras palavras, $D_{g} \gg L_{e f}$. 


\section{C.2 FATORES DE ENROLAMENTO, CARTER E SATURAÇÃO.}

\section{C.2.5 Fator de Carter}

A existência de ranhuras para alocação dos enrolamentos do gerador provoca o efeito de espalhamento de fluxo magnético (fringing effects), nomeadamente, as linhas de indução magnética, embora se concentrem na interface entreferro/dente, parte delas atravessa a ranhura e apenas penetra no dente em posição posterior. Este efeito é modelado ao se introduzir o fator de Carter $k_{c s}$ a fim de calcular um comprimento efetivo do entreferro $l_{g}{ }^{\prime}=k_{c s} l_{g}$, capaz de incorporar estes efeitos de espalhamento de fluxo magnético no cálculo da permeância magnética do entreferro. O fator de Carter é calculado de acordo com as seguintes relações (LIPO, 2011, p. 105):

$$
\begin{gathered}
k_{c s}=\frac{\tau_{s}}{\tau_{s}-\frac{2 b_{s}}{\pi}\left\{\operatorname{atan}\left(\frac{b_{s}}{2 l_{g}}\right)-\frac{g}{b_{s}} \ln \left[1+\left(\frac{b_{s}}{2 l_{g}}\right)^{2}\right]\right\}} \\
k_{c s} \approx \frac{\tau_{s}}{\tau_{s}-\left(\frac{b_{s}{ }^{2}}{5 l_{g}-b_{s}}\right)}
\end{gathered}
$$

A equação (1.60), muitas vezes é escrita em função do fator $\delta_{c}$ :

$$
\begin{gathered}
\delta_{c}=\frac{\left(\frac{b_{s}}{l_{g}}\right)^{2}}{5+\left(\frac{b_{s}}{l_{g}}\right)} \\
k_{c s} \approx \frac{\tau_{s}}{\tau_{s}-\delta_{c} l_{g}}
\end{gathered}
$$

\section{C.2.6 Fator de Saturação}

O fator de saturação é dado pela relação entre a força magnetomotriz total do circuito magnético e a queda de força magnetomotriz no entreferro da máquina (LEVI, 1984, p. 382). 


$$
k_{s a t}=\frac{2 f_{g}+2 f_{t}+f_{s y}+f_{r y}}{2 f_{g}}
$$

\section{C.3 COMPRIMENTO EFETIVO}

Sistemas de refrigeração radiais incorporados ao longo do comprimento rotórico ou estatórico introduzem efeitos de espalhamento de campo semelhantes ao produzido pela existência de ranhuras nas interfaces entreferro rotor/estator. Desta forma, o comprimento efetivo da máquina pode ser calculado de acordo com as seguintes equações (LIPO, 2011, p. 107-111):

a) Estator de comprimento ativo $l_{a}$ (ferro) $\operatorname{com} n_{d}$ dutos de ventilação de largura $b_{v s}:$

$$
L_{e f}=l_{a}+2 l_{g}+n_{d} b_{v s}\left(\frac{5}{5+\frac{b_{v s}}{l_{g}}}\right)
$$

b) Estator e rotor de comprimento ativo $l_{a} \operatorname{com} n_{d}$ dutos de ventilação alinhados de largura $b_{v s}$ e $b_{v r}$, respectivamente:

$$
L_{e f}=l_{a}+2 l_{g}+n_{d}\left(\frac{b_{v s}+b_{v r}}{2}\right)\left(\frac{5}{5+\frac{b_{v s}}{l_{g}}}\right)\left(\frac{5}{5+\frac{b_{v r}}{l_{g}}}\right)
$$

c) Estator e rotor com ductos de ventilação desalinhados

$$
L_{e f}=l_{a}+2 l_{g}+\frac{n_{d}}{2}\left[b_{v s}\left(\frac{5}{5+\frac{b_{v s}}{l_{g}}}\right)+b_{v r}\left(\frac{5}{5+\frac{b_{v r}}{l_{g}}}\right)\right]
$$

A referência (UPADHYAY, 2008, p. 113) sugere que os ductos de ventilação sejam espaçados de $10 \mathrm{~cm}$ entre si com largura $b_{v}$ igual a $1 \mathrm{~cm}$ para máquinas de pequeno e médio porte e $1.25 \mathrm{~cm}$ em máquinas de grande porte. 


\section{C.4 INDUTÂNCIA DE DISPERSÃO DE FINAL DE ENROLAMENTO}

Três diferentes metodologias para estimação da indutância de dispersão devido ao final do enrolamento (cabeça de bobina) serão apresentadas. O primeiro método é apresentado em (LIWSCHITZ-GARIK e WHIPPLE, 1947), (LIPO, 2011) e em (LEVI, 1984) consiste numa metodologia parcialmente teórica e empírica. O segundo e terceiro métodos são empíricos apresentados respectivamente em (LIWSCHITZGARIK, 1963) e em (PYRHONEN, JOKINEN e HRABOVCOVÁ, 2014). Devido à alta complexidade para a elaboração teórica de uma formulação analítica capaz de ser suficientemente geral e precisa para máquinas com diferentes características, normalmente para cálculo da indutância de dispersão de cabeça de bobina os métodos empíricos são preferidos.

Salienta-se aqui, entretanto, que as metodologias apresentadas nesta seção foram estabelecidas através da experiência na construção de máquinas elétricas trifásicas. Faz-se, portanto, necessário, rever os parâmetros empíricos quando o número de fases é diferente de três. Embora esta limitação seja reconhecida neste trabalho, considera-se fora do escopo do mesmo realizar esta revisão. Entretanto esta atividade é recomendada para trabalhos futuros.

\section{C.4.1 Método 1}

O primeiro método consiste em considerar a geometria da cabeça da bobina conforme apresentado na Figura 16. Onde $\tau_{b(\text { ave })}$ e $\tau_{s(\text { ave })}$ correspondem, respectivamente, aos passos de bobina e de ranhura medidos na altura média da ranhura. $\mathrm{O}$ valor $b_{c}$ é a espessura da bobina e $t_{e}$ a distância entre duas bobinas adjacentes. A indutância de dispersão de cabeça de bobina por fase é calculada pela relação (10.58) (LIWSCHITZ-GARIK e WHIPPLE, 1947, p. 71-73) e (LIPO, 2011, p. 198-201).

$$
\begin{gathered}
l_{e w}=\frac{4 \mu_{0}}{2 p} N_{s f}^{2}\left(k_{d 1} k_{c 1}\right)^{2} 2.4\left[l_{e 2}+\frac{l_{e 1}}{2}\right] \\
l_{e 1}=\frac{\tau_{b(\text { ave })}\left(b_{c}+t_{e}\right)}{2 \sqrt{\tau_{s(\text { ave })}^{2}-\left(b_{c}+t_{e}\right)^{2}}}
\end{gathered}
$$




$$
\begin{gathered}
\tau_{b(\text { ave })}=\frac{\pi\left(D_{g}+h_{s}\right)}{2 p} \frac{\tau_{b}}{\tau_{p}} \\
\tau_{s(\text { ave })}=\frac{\pi\left(D_{g}+h_{s}\right)}{2 p q m}
\end{gathered}
$$

Levi em (LEVI, 1984, p. 388) sugere para uma primeira estimação de $t_{e}$

$$
t_{e} \cong\left(2,4+4,5 \cdot V_{f} 10^{-4}\right) 10^{-1}[\mathrm{~cm}]
$$

Valores de referência para $l_{e 2}$ em função da tensão do geradorsão apresentados em (LIWSCHITZ-GARIK e WHIPPLE, 1947, p. 71) e em (LEVI, 1984, p. 387). Segundo E. Levi em (LEVI, 1984, p. 387) $l_{e 2}$ pode ser estimado pela relação:

$$
l_{e 2} \cong 6 V_{f}^{0.541} \cdot 10^{-2}[\mathrm{~cm}]
$$

Onde $V_{f}$ é a tensão de fase da máquina. Os valores de referência para $l_{e 2}$ segundo (LIWSCHITZ-GARIK e WHIPPLE, 1947, p. 71) são apresentados na Tabela 37 e podem ser estimados pela equação (10.64).

$$
l_{e 2} \cong 0,0125 V_{\text {linha }}{ }^{0.7008}+0,4449[\mathrm{~cm}]
$$

Tabela 37 - Valores de Referência para $\boldsymbol{l}_{\boldsymbol{e} 2}$ (LIWSCHITZ-GARIK e WHIPPLE, 1947, p. 71)

\begin{tabular}{|c|c|}
\hline V-Linha [kV] & $l_{e 2}[\mathrm{~cm}]$ \\
\hline 0,12 & 0,635 \\
\hline 0,44 & 1,270 \\
\hline 0,60 & 1,905 \\
\hline 2,30 & 3,175 \\
\hline 6,60 & 6,350 \\
\hline 11,00 & 8,890 \\
\hline 13,20 & 10,16 \\
\hline
\end{tabular}

A comparação entre os dois métodos é apresentada na Figura 70. Nesta figura é possível observar que ambos os métodos apresentam resultados semelhantes para máquinas de baixa tensão. 
Figura 70 - Comparação entre valores de referência para $\boldsymbol{l}_{\boldsymbol{e} 2}$.

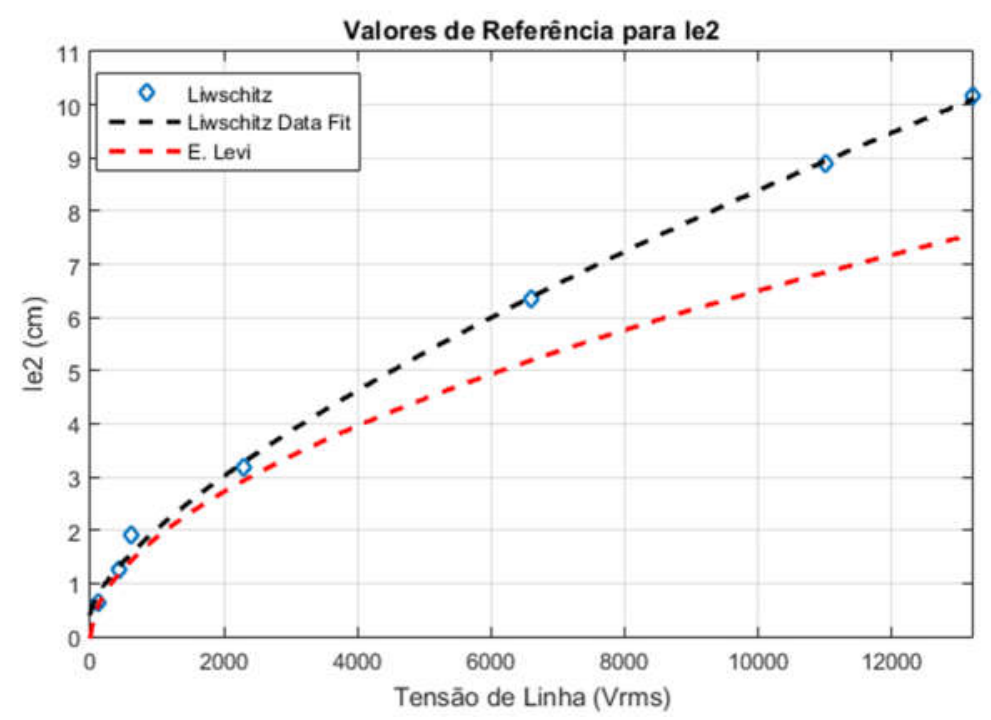

Fontes: (LIWSCHITZ-GARIK e WHIPPLE, 1947, p. 71) e (LEVI, 1984, p. 387).

\section{C.4.2 Método 2}

O segundo método consiste em aproximar a geometria da cabeça da bobina conforme apresentado na figura a baixo:

Figura 71 - Aproximação de cabeça de bobina.

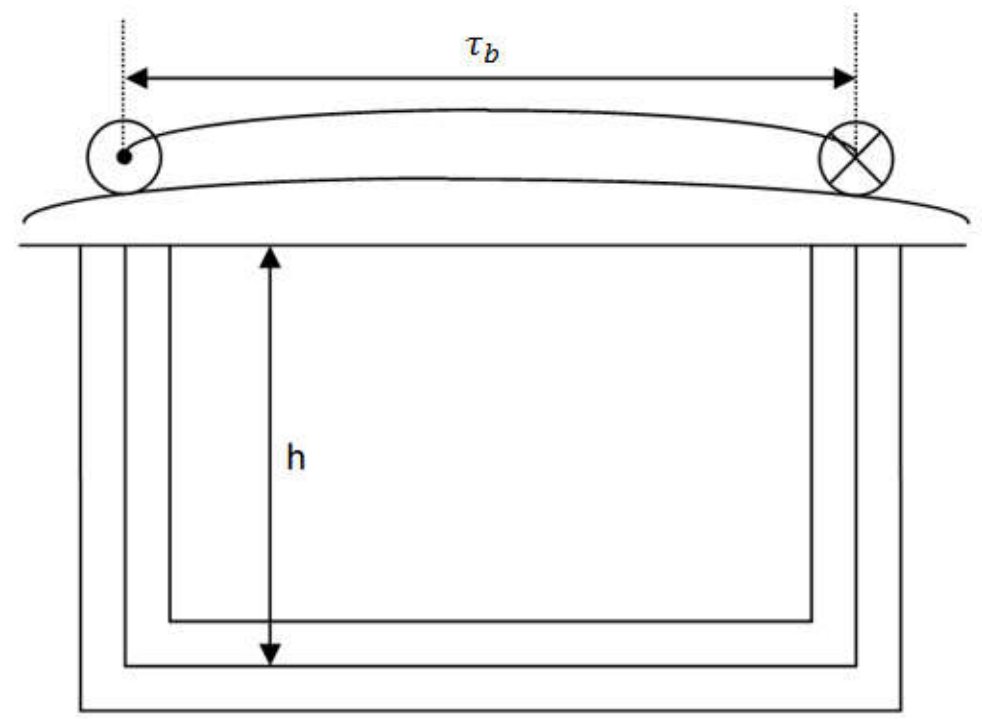

Fonte: adaptado de (LIWSCHITZ-GARIK, 1964, p. 61).

O comprimento total de cabeça $l_{e}$ de bobina é aproximado por:

$$
l_{e}=\tau_{b}+2 h
$$


A indutância de dispersão de cabeça de bobina é calculada por (LIWSCHITZGARIK, 1964, p. 65):

$$
l_{\text {ew }}=\frac{4 \mu_{0}}{2 p} N_{s}^{2}\left(k_{d 1} k_{c 1}\right)^{2} 0,43 l_{e}
$$

\section{C.4.3 Método 3}

O terceiro método utiliza a mesma simplificação do método anterior, conforme apresentado na Figura 71. Entretanto, dois fatores empíricos são considerados, $k_{1 \text { ew }}$ e $k_{2 e w}$, com valores apresentados na Figura 72. A indutância de dispersão de cabeça de bobina é calculada de acordo com (PYRHONEN, JOKINEN e HRABOVCOVÁ, 2014, p. 260-263) $)^{13}$ :

$$
l_{\text {ew }}=\frac{4 \mu_{0}}{2 p} N_{s}^{2}\left[2 h k_{1 e w}+\tau_{b} k_{2 e w}\right]
$$

\begin{tabular}{|c|c|c|c|c|}
\hline \multirow{2}{*}{$\begin{array}{l}\text { Seção Transversal de } \\
\text { Cabeça de Bobina }\end{array}$} & \multicolumn{2}{|c|}{ Máquina de Pólos Lisos } & \multicolumn{2}{|c|}{ Máquina de Pólos Salientes } \\
\hline & $k_{1 e w}$ & $k_{2 e w}$ & $k_{1 e w}$ & $k_{2 \varepsilon w}$ \\
\hline & 0.342 & 0.413 & 0.297 & 0.232 \\
\hline & 0.380 & 0.130 & 0.324 & 0.215 \\
\hline & 0.371 & 0.166 & 0.324 & 0.243 \\
\hline & 0.493 & 0.074 & 0.440 & 0.170 \\
\hline & 0.571 & 0.073 & 0.477 & 0.187 \\
\hline & 0.605 & 0.028 & 0.518 & 0.138 \\
\hline
\end{tabular}

Figura 72 - Fatores empíricos para cálculo de indutância de dispersão de cabeça de bobina.

Fonte: adaptado de (PYRHONEN, JOKINEN e HRABOVCOVÁ, 2014).

${ }^{13}$ Salienta-se que o método apresentado por Pyrhonen em (PYRHONEN, JOKINEN e HRABOVCOVÁ, 2014, p. 260-263) não inclui o fator $\left(k_{d 1} k_{c 1}\right)^{2}$, comum aos outros dois métodos apresentados previamente. 


\section{APÊNDICE D - TEORIA GERAL DE MÁQUINAS ELÉTRICAS}

Neste capítulo discute-se a modelagem de máquinas elétricas multifásicas segundo a teoria geral de máquinas elétricas. Nomeadamente, são apresentadas as transformações matemáticas que permitem a modelagem de máquinas com um número genérico de fases numa máquina equivalente de apenas duas fases - eixos direto e de quadratura.

Embora exista extensa discussão atualmente em respeito à necessidade de modelar a máquina de $m$-fases em $m$ circuitos linearmente independentes, a teoria geral de máquinas elétricas sugere que para fim de produção de potência/torque apenas dois eixos são necessários:

"In the study of rotating electromechanical energy converters, the two-phase system is the most fundamental. The importance of the two-phase system lies in the fact that, regardless of the number of phases that an energy converter may have on its rotor and on its stator, the equations of motion can always be reduced to equivalent two-phase systems on rotor and stator for considerations of torque production" (WHITE e WOODSON, 1959, p. 255)

O conceito chave para a aplicação da teoria geral de máquinas elétricas consiste em transformar as variáveis de fase da máquina para um referencial linearmente independente e capaz de produzir a mesma força magnetomotriz no entreferro da máquina (ADKINS, 1957, p. 101-102).

"The axis currents $i_{d}$ and $i_{q}$ are defined as the currents in fictitious coils, located on the axes and each having the same number of turns as a phase coil, which would set up the same M. M. F. wave as the actual currents $i_{a}, i_{b}, i_{c}$ ". (ADKINS, 1957, p. 101)

Uma vez que a onda de força magnetomotriz produzida pelo enrolamento multifásico, independentemente do número de fase, pode ser descrita nas coordenadas espaciais $(x, y, z)$ e que máquinas elétricas, em geral, possuem simetria ao longo do seu comprimento (eixo $z$ ), apenas dois eixos são necessários para representar a FMM no entreferro da máquina. 


\section{1 MODELAGEM DE MÁQUINAS ELÉTRICAS SEGUNDO EIXOS DQ}

Para a modelagem da máquina elétrica segundo os eixos direto e de quadratura, aplica-se uma transformação de variáveis. Neste trabalho, a transformação das variáveis de fase para as variáveis do referencial $d q 0$ é feita em duas etapas. Primeiramente, as variáveis de fase são convertidas para as coordenadas $\alpha \beta 0$ e, em seguida, aplica-se a transformação para o sistema $d q 0$. As transformações invariantes em potência e em amplitude serão apresentadas.

\section{D.1.1 Transformação invariante em potência}

Assume-se que o eixo $\alpha$ coincide com o eixo magnético da fase 1. A transformação generalizada $T_{\alpha \beta 0}$ de coordenadas de fase para coordenadas $\alpha \beta 0$ invariante em potência é descrita por:

$$
T_{\alpha \beta 0}=\sqrt{\frac{2}{m}}\left[\begin{array}{ccccc}
1 & \cos \left(\theta_{2}\right) & \cos \left(\theta_{3}\right) & \ldots & \cos \left(\theta_{m}\right) \\
0 & \sin \left(\theta_{2}\right) & \sin \left(\theta_{3}\right) & \ldots & \sin \left(\theta_{m}\right) \\
\sqrt{1 / 2} & \sqrt{1 / 2} & \sqrt{1 / 2} & \ldots & \sqrt{1 / 2}
\end{array}\right]
$$

Caso a máquina seja simétrica, $\operatorname{com} \alpha=2 \pi / m$ :

$$
T_{\alpha \beta 0}=\sqrt{\frac{2}{m}}\left[\begin{array}{ccccc}
1 & \cos (\alpha) & \cos (2 \alpha) & \ldots & \cos [(m-1) \alpha] \\
0 & \sin (\alpha) & \sin (2 \alpha) & \ldots & \sin [(m-1) \alpha] \\
\sqrt{1 / 2} & \sqrt{1 / 2} & \sqrt{1 / 2} & \ldots & \sqrt{1 / 2}
\end{array}\right]
$$

Observa-se que (10.68) e (10.69) são equivalentes à matriz apresentada em (ADKINS, 1957, p. 128) para a modelagem do circuito da gaiola de esquilo em coordenadas $d q 0$. A transformação $T_{\alpha \beta 0}$ possui a propriedade $T_{\alpha \beta 0} \cdot T_{\alpha \beta 0}{ }^{T}=I_{3 \times 3}$. A relação entre as variáveis em coordenas de fase $V_{1 . . . m}$ e às variáveis em coordenadas $\alpha \beta 0$ é dada por:

$$
\begin{gathered}
V_{\alpha \beta 0}=T_{\alpha \beta 0} V_{1 \ldots m} \\
V_{1 \ldots m}=T_{\alpha \beta 0}{ }^{T} V_{\alpha \beta 0}
\end{gathered}
$$


Uma vez que as variáveis estão no referencial $\alpha \beta 0$ a transformação de $\alpha \beta 0 \rightarrow$ $d q 0$ é simples e idêntica ao caso trifásico.

$$
\begin{gathered}
T_{d q 0}=\left[\begin{array}{ccc}
\cos (\theta) & \sin (\theta) & 0 \\
-\sin (\theta) & \cos (\theta) & 0 \\
0 & 0 & 1
\end{array}\right] \\
V_{d q 0}=T_{d q 0} T_{\alpha \beta 0} V_{1 \ldots m} \\
V_{1 \ldots m}=T_{\alpha \beta 0}{ }^{T} T_{d q 0}{ }^{-1} V_{d q 0}
\end{gathered}
$$

A maior desvantagem da transformação invariante em potência consiste na diferença em amplitude entre as variáveis no referencial de fase e as variáveis no referencial $\alpha \beta 0$ ou $d q 0$ pelo fator $m / 2$.

\section{D.1.2 Transformação invariante em amplitude}

A transformação invariante em amplitude ${ }^{14}$, em termos gerais, é calculada por:

$$
T_{\alpha \beta 0}=\frac{2}{m}\left[\begin{array}{ccccc}
1 & \cos \left(\theta_{2}\right) & \cos \left(\theta_{3}\right) & \ldots & \cos \left(\theta_{m}\right) \\
0 & \sin \left(\theta_{2}\right) & \sin \left(\theta_{3}\right) & \ldots & \sin \left(\theta_{m}\right) \\
\sqrt{1 / 2} & \sqrt{1 / 2} & \sqrt{1 / 2} & \ldots & \sqrt{1 / 2}
\end{array}\right]
$$

Neste caso, $T_{\alpha \beta 0} T_{\alpha \beta 0}{ }^{t}=\frac{2}{m} I_{3 \times 3}$, portanto, a matriz inversa à direita de $T_{\alpha \beta 0}$ é igual a $\frac{m}{2} T_{\alpha \beta 0}{ }^{t}$. Desta forma:

$$
\begin{gathered}
V_{\alpha \beta 0}=T_{\alpha \beta 0} V_{1 \ldots m} \\
V_{1 \ldots m}=\frac{m}{2} T_{\alpha \beta 0}{ }^{T} V_{\alpha \beta 0}
\end{gathered}
$$

De forma equivalente ao já apresentado, a relação entre as variáveis de fase e as variáveis nos eixos $d q 0$ é dada por:

$$
V_{d q 0}=T_{d q 0} T_{\alpha \beta 0} V_{1 \ldots m}
$$

${ }^{14}$ Pode ser entendido como uma generalização da transformação de Clarke (MARQUES, 2002, p. 139). 


$$
V_{1 \ldots m}=\frac{m}{2} T_{\alpha \beta 0}{ }^{T} T_{d q 0}{ }^{-1} V_{d q 0}
$$

Embora, em geral, considere-se mais conveniente trabalhar-se com a transformação invariante em amplitude, aparece o termo $\frac{m}{2}$ na transformação $d q 0 \rightarrow$ 1 ...m e nos cálculos de torque e potência (MARQUES, 2002, p. 139-141).

\section{D.1.3 Matriz de Indutâncias}

\section{D.1.3.1 Matriz de indutância em variáveis de fase}

A matriz de indutâncias relativa ao estator de uma máquina de $m$ fases é uma matriz simétrica ordem $m \times m$. A diagonal principal da matriz de indutância corresponde às indutâncias próprias de cada fase $L_{i i}$. As componentes que não fazem parte da diagonal principal representam o acoplamento mútuo entre fases $L_{i j}=L_{j i}$. De forma genérica pode-se escrever:

$$
\begin{gathered}
L_{i i}=L_{d i s}+L_{0}+L_{2} \cos \left(2 \theta+\delta_{i i}\right) \\
\delta_{i i}=-2 \theta_{i}
\end{gathered}
$$

Onde $\theta_{i}$ corresponde à defasagem espacial da fase de ordem " $i$ ". As componentes, $L_{0}$ e $L_{2}$ são calculadas por:

$$
\begin{aligned}
& L_{0}=\frac{L_{m d^{\prime}}+L_{m q}{ }^{\prime}}{2} \\
& L_{2}=\frac{L_{m d^{\prime}}-L_{m q}{ }^{\prime}}{2}
\end{aligned}
$$

Onde $L_{m d}{ }^{\prime}$ e $L_{m q}{ }^{\prime}$ correspondem às indutâncias de magnetização segundo os eixos direto e de quadratura considerando-se apenas a contribuição de uma fase.

$$
\begin{aligned}
& L_{m d^{\prime}}=\frac{2}{m} L_{m d} \\
& L_{m q}{ }^{\prime}=\frac{2}{m} L_{m q}
\end{aligned}
$$


As indutâncias $L_{m d}$ e $L_{m q}$ são definidas de acordo com (3.62) e (3.63). As indutâncias referentes ao acoplamento mútuo entre as fases $i$ e $j, L_{i j}$, são calculadas de forma genérica segundo:

$$
\begin{gathered}
L_{i j}=L_{0} \cos \left(\theta_{j}-\theta_{i}\right)+L_{2} \cos \left(2 \theta+\delta_{i j}\right) \\
\delta_{i j}=-2\left(\frac{\theta_{i}+\theta_{j}}{2}\right)
\end{gathered}
$$

As equações (10.80) e (10.86) são genéricas e podem ser utilizadas tanto para máquinas simétricas quanto para máquinas assimétricas. Resultado equivalente é apresentado em (TESSAROLO, 2011, p. 80) ${ }^{15}$.

A defasagem angular $\frac{\theta_{i}+\theta_{j}}{2}$ corresponde à posição angular do rotor para o qual a relutância magnética entre as fases $i$ e $j$ é máxima ou mínima. Assumindo-se $L_{m d}{ }^{\prime}>$ $L_{m q}{ }^{\prime}$, quando o valor médio da indutância mútua $L_{i j}$ é negativo, $L_{0} \cos \left(\theta_{j}-\theta_{i}\right)<0$, $\frac{\theta_{i}+\theta_{j}}{2}$ corresponde à posição do rotor para a qual a relutância magnética é máxima (módulo do fluxo mútuo entre fases é mínimo). Quando o valor médio de $L_{i j}$ é positivo, $\frac{\theta_{i}+\theta_{j}}{2}$ corresponde à posição angular do rotor para a qual a relutância magnética entre fases é mínima (módulo do fluxo mútuo entre fases é máximo).

Quando $L_{m d^{\prime}}<L_{m q}{ }^{\prime}$ este resultado será invertido. Por exemplo, para $L_{0} \cos \left(\theta_{j}-\theta_{i}\right)<0, \frac{\theta_{i}+\theta_{j}}{2}$ corresponderá ao ângulo para o qual a relutância magnética entre fases é mínima.

A matriz de indutâncias da máquina pode ser escrita de forma genérica por:

$$
\begin{gathered}
\boldsymbol{L}=\boldsymbol{L}_{\text {dis }}+\boldsymbol{L}_{\mathbf{0}}+\boldsymbol{L}_{\mathbf{2}} \\
\boldsymbol{L}_{\text {dis }}=L_{\text {dis }} I_{m x m} \\
\boldsymbol{L}_{\mathbf{0}}=L_{0}\left[\begin{array}{cccc}
1 & \cos \left(\theta_{2}-\theta_{1}\right) & \ldots & \cos \left(\theta_{m}-\theta_{1}\right) \\
\cos \left(\theta_{2}-\theta_{1}\right) & 1 & \ldots & \cos \left(\theta_{m}-\theta_{2}\right) \\
\vdots & \vdots & \ddots & \vdots \\
\cos \left(\theta_{m}-\theta_{1}\right) & \cos \left(\theta_{m}-\theta_{2}\right) & \ldots & 1
\end{array}\right]
\end{gathered}
$$

15 Em (TESSAROLO, 2011, p. 80) assume-se máquina com fases simetricamente distribuídas. 


$$
\boldsymbol{L}_{2}=L_{2}\left[\begin{array}{cccc}
\cos \left(2 \theta-2 \theta_{1}\right) & \cos \left[2 \theta-\left(\theta_{1}+\theta_{2}\right)\right] & \ldots & \cos \left[2 \theta-\left(\theta_{1}+\theta_{m}\right)\right] \\
\cos \left[2 \theta-\left(\theta_{1}+\theta_{2}\right)\right] & \cos \left(2 \theta-2 \theta_{2}\right) & \ldots & \cos \left[2 \theta-\left(\theta_{2}+\theta_{m}\right)\right] \\
\vdots & \vdots & \ddots & \vdots \\
\cos \left[2 \theta-\left(\theta_{1}+\theta_{m}\right)\right] & \cos \left[2 \theta-\left(\theta_{2}+\theta_{m}\right)\right] & \ldots & \cos \left(2 \theta-2 \theta_{m}\right)
\end{array}\right]
$$

D.1.3.2 Matriz de indutâncias em coordenadas $\alpha \beta 0$ e dq0

Aplicando a transformação invariante em potência, calcula-se a matriz de indutâncias no referencial $\alpha \beta 0$ por:

$$
\begin{gathered}
\boldsymbol{L}_{\boldsymbol{\alpha \beta \boldsymbol { 0 }}}=T_{\alpha \beta 0} \cdot \boldsymbol{L} \cdot T_{\alpha \beta 0}{ }^{T} \\
\boldsymbol{L}_{\boldsymbol{\alpha \boldsymbol { \beta } 0}}=L_{d i s} I_{3 \times 3}+\frac{m}{2}\left(L_{0}\left[\begin{array}{lll}
1 & 0 & 0 \\
0 & 1 & 0 \\
0 & 0 & 0
\end{array}\right]+L_{2}\left[\begin{array}{ccc}
\cos (2 \theta) & \sin (2 \theta) & 0 \\
\sin (2 \theta) & -\cos (2 \theta) & 0 \\
0 & 0 & 0
\end{array}\right]\right)
\end{gathered}
$$

Caso utilize-se a transformação invariante em amplitude, a matriz de antitransformação é igual a matriz inversa à direita de $T_{\alpha \beta 0}$ que é igual a $\frac{m}{2} T_{\alpha \beta 0}{ }^{T}$. O resultado em (10.93) mantém-se.

Transformado a matriz de indutâncias do referencial $\alpha \beta 0$ para coordenadas $d q 0$, obtém-se:

$$
\begin{gathered}
\boldsymbol{L}_{\boldsymbol{d q 0} \mathbf{0}}=T_{d q 0} \cdot \boldsymbol{L}_{\boldsymbol{\alpha} \boldsymbol{\beta} \mathbf{0}} \cdot T_{d q 0}{ }^{-1} \\
\boldsymbol{L}_{\boldsymbol{d q 0} \mathbf{0}}=L_{d i s} I_{3 \times 3}+\frac{m}{2}\left(L_{0}\left[\begin{array}{lll}
1 & 0 & 0 \\
0 & 1 & 0 \\
0 & 0 & 0
\end{array}\right]+L_{2}\left[\begin{array}{ccc}
1 & 0 & 0 \\
0 & -1 & 0 \\
0 & 0 & 0
\end{array}\right]\right)
\end{gathered}
$$

Escrevendo as variáveis $L_{0}$ e $L_{2}$ em função de $L_{m d}{ }^{\prime}$ e $L_{m q}{ }^{\prime}$ :

$$
\begin{gathered}
\boldsymbol{L}_{\boldsymbol{d q 0} \mathbf{0}}=L_{d i s} I_{3 \times 3}+\frac{m}{2}\left[\begin{array}{ccc}
L_{m d}{ }^{\prime} & 0 & 0 \\
0 & L_{m q}{ }^{\prime} & 0 \\
0 & 0 & 0
\end{array}\right] \\
\boldsymbol{L}_{\boldsymbol{d q 0} \mathbf{0}}=\left[\begin{array}{ccc}
L_{\text {disp }}+L_{m d} & 0 & 0 \\
0 & L_{d i s p}+L_{m q} & 0 \\
0 & 0 & L_{\text {disp }}
\end{array}\right]
\end{gathered}
$$




\section{D.1.4 Equações diferenciais}

Conforme discutido anteriormente, utilizando-se a abordagem tradicional para modelagem e análise de máquinas elétricas, é possível reduzir o sistema multifásico ao sistema $d q 0$ de forma equivalente à metodologia convencionalmente aplicada a máquinas trifásicas.

As relações de tensões estatóricas nos eixos direto e de quadratura e a relação do torque eletromagnético desenvolvido pela máquina são apresentadas a seguir:

$$
\begin{gathered}
\boldsymbol{v}_{d s}=r_{s} I_{d s}+\frac{d \Psi_{d s}}{d t}-w \Psi_{q s} \\
\boldsymbol{v}_{q s}=r_{s} I_{q s}+\frac{d \Psi_{q s}}{d t}+w \Psi_{d s} \\
T=\frac{m}{2} p\left(\Psi_{d s} I_{q s}-\Psi_{q s} I_{d s}\right)
\end{gathered}
$$

As equações (10.96), (10.97), (10.98) ${ }^{16}$ são gerais e não dependem da forma de excitação da máquina ou da existência ou não de enrolamentos amortecedores. Para máquinas com excitação por imãs permanentes a relação entre fluxo magnético e corrente para os eixos direto e de quadradura é dada por:

$$
\begin{gathered}
{\left[\begin{array}{c}
\Psi_{d s} \\
\Psi_{q s}
\end{array}\right]=\left[\begin{array}{cc}
L_{d} & 0 \\
0 & L_{q}
\end{array}\right]\left[\begin{array}{l}
I_{d s} \\
I_{q S}
\end{array}\right]+\left[\begin{array}{c}
\Psi_{P M} \\
0
\end{array}\right]} \\
{\left[\begin{array}{c}
I_{d s} \\
I_{q s}
\end{array}\right]=\left[\begin{array}{cc}
L_{d} & 0 \\
0 & L_{q}
\end{array}\right]^{-1}\left[\begin{array}{c}
\Psi_{d s}-\Psi_{P M} \\
\Psi_{q s}
\end{array}\right]}
\end{gathered}
$$

${ }^{16}$ Considera-se a utilização da transformação invariante em amplitude de acordo com (10.75). O termo $\frac{m}{2}$ não aparece caso utilize-se a transformação invariante em potência (10.68). 


\section{APÊNDICE E - TEORIA DE COMPONENTES SIMÉTRICAS}

Neste trabalho optou-se por modelar a máquina seguindo a teoria geral de máquinas elétricas. A metodologia adotada é válida para o pressuposto de corrente de fase senoidal e em regime balanceado. A forma mais comum apresentada na literatura para modelagem de máquinas multifásicas, entretanto, utiliza a teoria generalizada de componentes simétricas. Neste caso, transforma-se o referencial de $m$ fases num referencial de $m$ circuitos linearmente independentes. Neste caso, dois circuitos ( $d q$ ou $\alpha \beta$ ) são responsáveis pela produção de torque enquanto os outros $(m-2)$ circuitos correspondem de alguma forma à componentes de sequência zero (ADKINS, 1957, p. 128), no sentido de não contribuírem para produção de torque.

"Multiphase machines are characterized with the existence of additional degrees of freedom since independent flux and torque control of any machine always requires two independent currents, regardless of the phase number. These additional degrees of freedom can be used for various purposes." (LEVI, 2016, p. 433).

Nesse sentido, a vantagem em se utilizar a transformação de componentes simétricas generalizada com os $m$ circuitos linearmente independentes é de se explorar estes "additional degrees of freedom" para incorporar estratégias de controle. Levi em (LEVI, 2016) sumariza o estado da arte relacionado às formas de utilização destes graus de liberdade adicionais em diferentes aplicações. Como exemplo, citase a possibilidade de usar um mesmo inversor para controlar motores multifásicos em série e balancear a tensão dos bancos de capacitores em máquinas $N$-star.

E. Semail em (SEMAIL, BOUSCARYOL e HAUTIER, 2003), usa uma abordagem vetorial (Vector Space Decomposition - VSD) para a modelagem de máquinas elétricas multifásicas, analisando os espaços vetoriais criados a partir dos autovalores e autovetores da matriz de indutância da máquina. A decomposição vetorial da origem à dois subespaços vetoriais, o primeiro $P$ consiste no subespaço principal ("main"), correspondente ao sistema $d q$ ou $\alpha \beta$, o segundo, $H$, é composto por dois subespaços, um de sequência zero e o outro é chamado de secundário. Embora em (SEMAIL, BOUSCARYOL e HAUTIER, 2003) o foco do autor consista em 
apresentar ao leitor às vantagens de se utilizar o subespaço vetorial $H$ para controle da máquina, o autor deixa claro:

"We dispose of three machines to produce torque17. First, we apply the Multimachine concept to the case of a sinusoidal electromotive force. Thus, only the "main" machine will produce torque. The currents in the two other machines are then not desirable since they create only copper losses. They are parasitic currents. To cancel them we must not supply these two machines" (SEMAIL, BOUSCARYOL e HAUTIER, 2003, p. 218)

\section{E.1 TRANSFORMAÇÃO DE COMPONENTES SIMÉTRICAS GENERALIZADA}

A matriz de transformação generalizada de componentes simétricas é escrita em função do operador complexo $\alpha=e^{j \frac{2 \pi}{m}}$, esta matriz é calculada por (WHITE e WOODSON, 1959, p. 549):

$$
T=\frac{1}{\sqrt{m}}\left[\begin{array}{ccccc}
1 & 1 & 1 & \ldots & 1 \\
1 & \alpha & \alpha^{2} & \ldots & \alpha^{(m-1)} \\
1 & \alpha^{2} & \alpha^{4} & \ldots & \alpha^{2(m-1)} \\
\vdots & \vdots & \vdots & \vdots & \vdots \\
1 & \alpha^{(m-1)} & \alpha^{2(m-1)} & \ldots & \alpha^{(m-1)(m-1)}
\end{array}\right]
$$

$\mathrm{Na}$ transformação de componentes simétricas, a primeira linha da transformação da origem às variáveis de sequência zero, a segunda linha às variáveis de sequência positiva e a última linha corresponde às variáveis de sequência negativa (WHITE e WOODSON, 1959, p. 554).

Para modelagem de máquinas elétricas multifásicas, normalmente não se aplica diretamente a transformação complexa de componentes simétricas, mas a sua transformação real. A transformação real derivada de componentes simétricas é apresentada em (WHITE e WOODSON, 1959, p. 592):

\footnotetext{
17 O autor em (SEMAIL, BOUSCARYOL e HAUTIER, 2003) associa uma máquina aos circuitos linearmente independentes do subespaço $P$ e duas máquinas aos circuitos do subespaço $H$ (uma para o subespaço de sequência zero e outra para o subespaço secundário).
} 


$$
T=\sqrt{\frac{2}{m}}\left[\begin{array}{ccccc}
\sqrt{2} / 2 & \sqrt{2} / 2 & \sqrt{2} / 2 & \ldots & \sqrt{2} / 2 \\
1 & \cos (\alpha) & \cos (2 \alpha) & \ldots & \cos [(m-1) \alpha] \\
1 & \cos (2 \alpha) & \cos (4 \alpha) & \ldots & \cos [2(m-1) \alpha] \\
\vdots & \vdots & \vdots & \vdots & \vdots \\
\sqrt{2} / 2 & -\sqrt{2} / 2 & \sqrt{2} / 2 & \ldots & \pm \sqrt{2} / 2 \\
0 & \vdots & \vdots & \vdots & \vdots \\
0 & \sin (2 \alpha) & \sin (4 \alpha) & \ldots & \sin [2(m-1) \alpha] \\
0 & \sin (\alpha) & \sin (2 \alpha) & \ldots & \sin [(m-1) \alpha]
\end{array}\right]
$$

Após a conversão da transformação complexa de componentes simétricas para a "transformação real" de componentes simétricas obtém-se (10.102). A primeira linha de (10.102) corresponde à componente de sequência zero, a segunda linha corresponde à componente de sequência positiva e a última linha corresponde à componente de sequência negativa. Observa-se que estes valores serão idênticos às variáveis no referencial $\alpha \beta 0$ conforme apresentado em (10.68) e (10.69).

Levi em (LEVI, BOJOI, et al., 2007, p. 493) apresenta esta transformação de forma mais didática, conforme apresentado na figura a seguir:

Figura 73 - Transformação real derivada da transformação complexa de componentes simétricas.

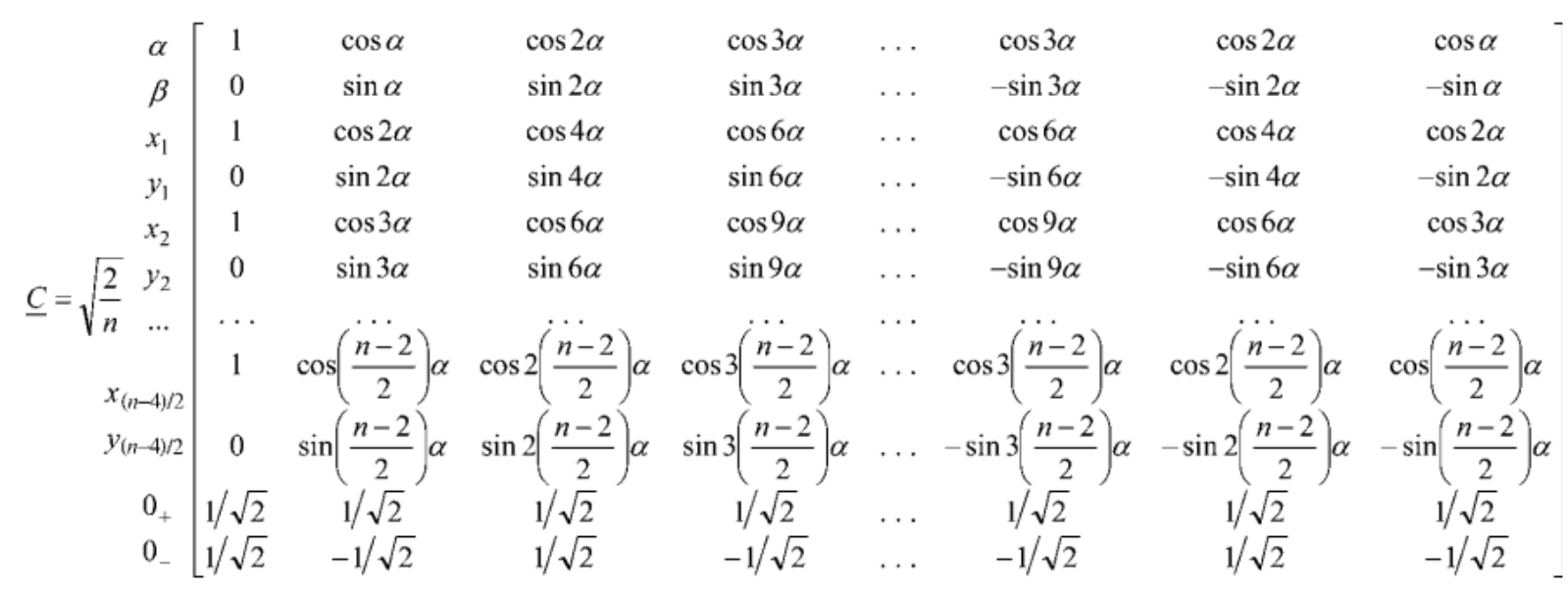

Fonte: (LEVI, BOJOI, et al., 2007)

Na transformação apresentada em (LEVI, BOJOI, et al., 2007) a relação entre as componentes de sequência direta, inversa e zero com as componentes no referencial $\alpha \beta 0$ é explicita. 
Ao se utilizar a transformação generalizada de componentes simétricas, transforma-se a matriz de indutância por fase da máquina, de ordem $m \times m$, numa matriz de indutâncias desacoplada (diagonal) também de ordem $m \times m$.

Os resultados para as componentes $\alpha \beta 0$ e $d q 0$ mantém-se conforme apresentado no Apêndice $D$. As indutâncias nos demais referenciais serão iguais a $L_{\text {disp }}$ (LEVI, BOJOI, et al., 2007, p. 493). A transformação $d q 0$ (10.72) generalisada (transformação de ordem $m \times m$ ) que deve ser aplicada quando se utiliza a transformação de componentes simétricas é apresentada em (TESSAROLO, 2011, p. 193-194).

\section{E.1.1 Harmônicas de corrente}

Para máquinas multifásicas, apenas harmônicas de ordem $h=2 \mathrm{~km} \pm 1$ aparecem no referencial $d q$ generalizado (são as únicas componentes que produzem torque). Portando, uma vantagem da topologia multifásica é que as componentes harmônicas de baixa ordem não produzem torques pulsantes no rotor. Por outro lado, para detectar e filtrar correntes harmônicas de ordem diferente de $h=2 \mathrm{~km} \pm 1$ é necessário utilizar a transformação generalizada de componentes simétricas/Vector Space Decomposition (VSD).

Conforme comentado anteriormente, a indutância equivalente da máquina para os subespaços adicionais $\left(x_{i}, y_{i}-\right.$ Figura 73$)$ é igual à indutância de dispersão. Em outras palavras, isso significa que máquinas elétricas multifásicas são mais susceptíveis ao aparecimento de correntes harmônicas de baixa ordem do que máquinas trifásicas. Quinta e sétima harmônicas são em geral as componentes mais preocupantes. Para evitar o aparecimento destas harmônicas é prudente no projeto da máquina procurar atenuar as componentes harmônicas da tensão induzida.

Caso a máquina seja alimentada por conversor eletrônico de potência com modulação do tipo PWM, recomenda-se a utilização de estratégias de controle para compensação de deadtime, com a finalidade evitar a distorção da tensão de alimentação da máquina. Em todo caso, na presença de componentes harmônicas de corrente de baixa ordem é possível utilizar os graus de liberdade adicionais da transformação generalizada de componente simétricas/VSD para filtragem das harmônicas indesejadas. 


\section{APÊNDICE F - DRIVETRAIN PARA TURBINAS EÓLICAS}

Neste apêndice são apresentados, como referência, alguns esquemas utilizados para o trem de potência em turbinas eólicas. Na figura a seguir apresentase drivetrain de baixa velocidade, direct-drive. Onde se observar que o gerador (2) compartilha o mesmo eixo mecânico da turbina eólica.

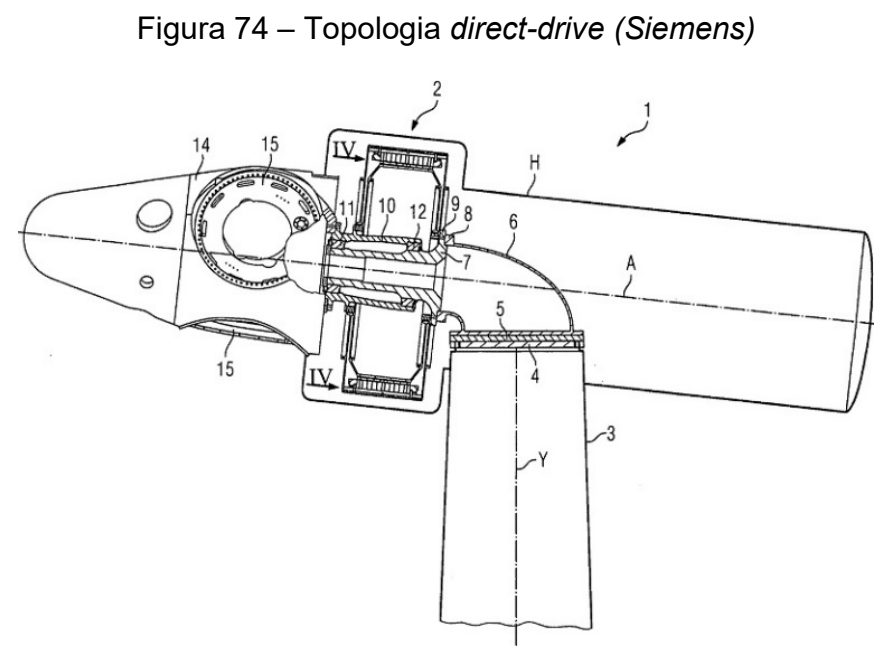

Fonte: (STIESDAL, 2011)

Na Figura 75, apresenta-se o conceito do trem de potência de média velocidade integrado da Vestas. Onde os principais componentes apresentados são: (16) o eixo principal da turbina eólica, (18) e (20) são os rolamentos que suportam o eixo principal, (24) é a caixa multiplicadora, diferencial planetária de três estágios e (28) é o gerador de imãs permanentes (MONGEAU, ASHAR e DEMTRODER, 2014).

Figura 75 - Topologia de média velocidade (Vestas)

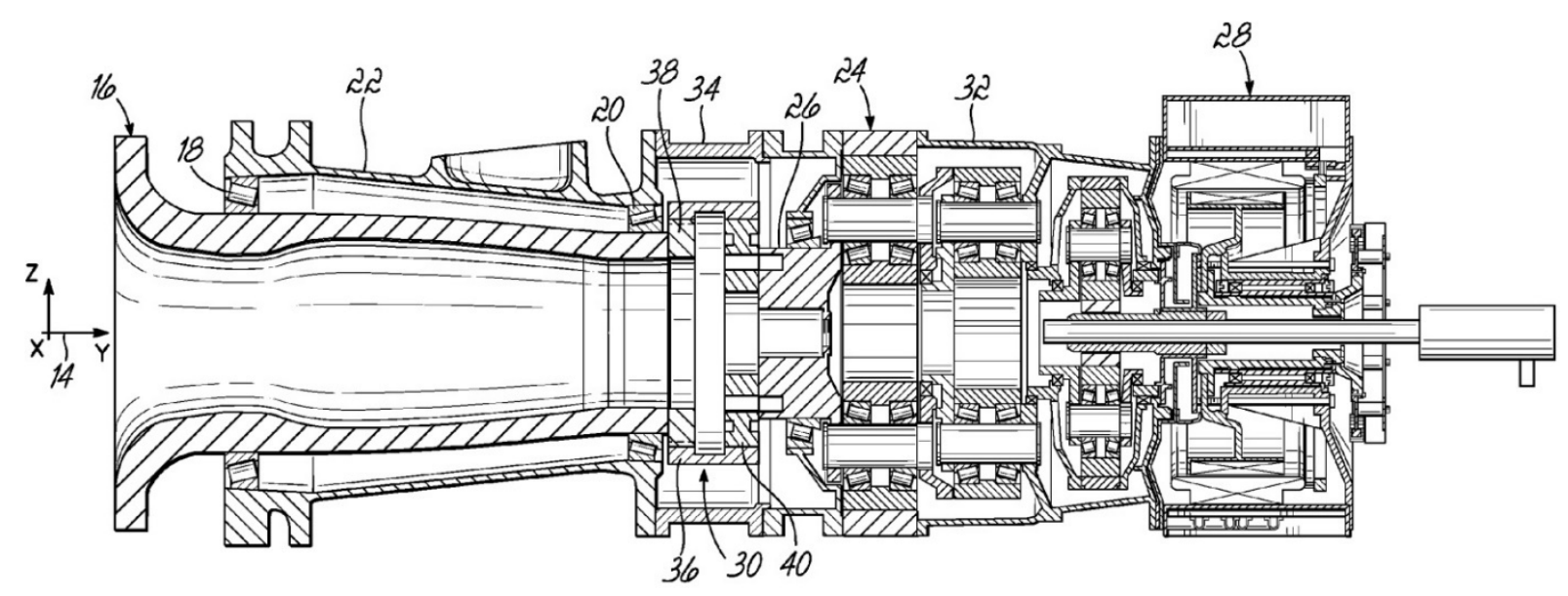

Fonte: (MONGEAU, ASHAR e DEMTRODER, 2014) 
$\mathrm{Na}$ sequência é apresentado o esquema do trem de potência de alta velocidade, convencional, tipicamente utilizado em turbinas eólicas onshore. Segundo (COULTATE, 2011), as turbinas Vestas V80 - 2MW e Gamesa G114 - 2MW tem trem de potência semelhante ao apresentado na Figura 76.

Figura 76 - Trem de potência típico de alta velocidade.

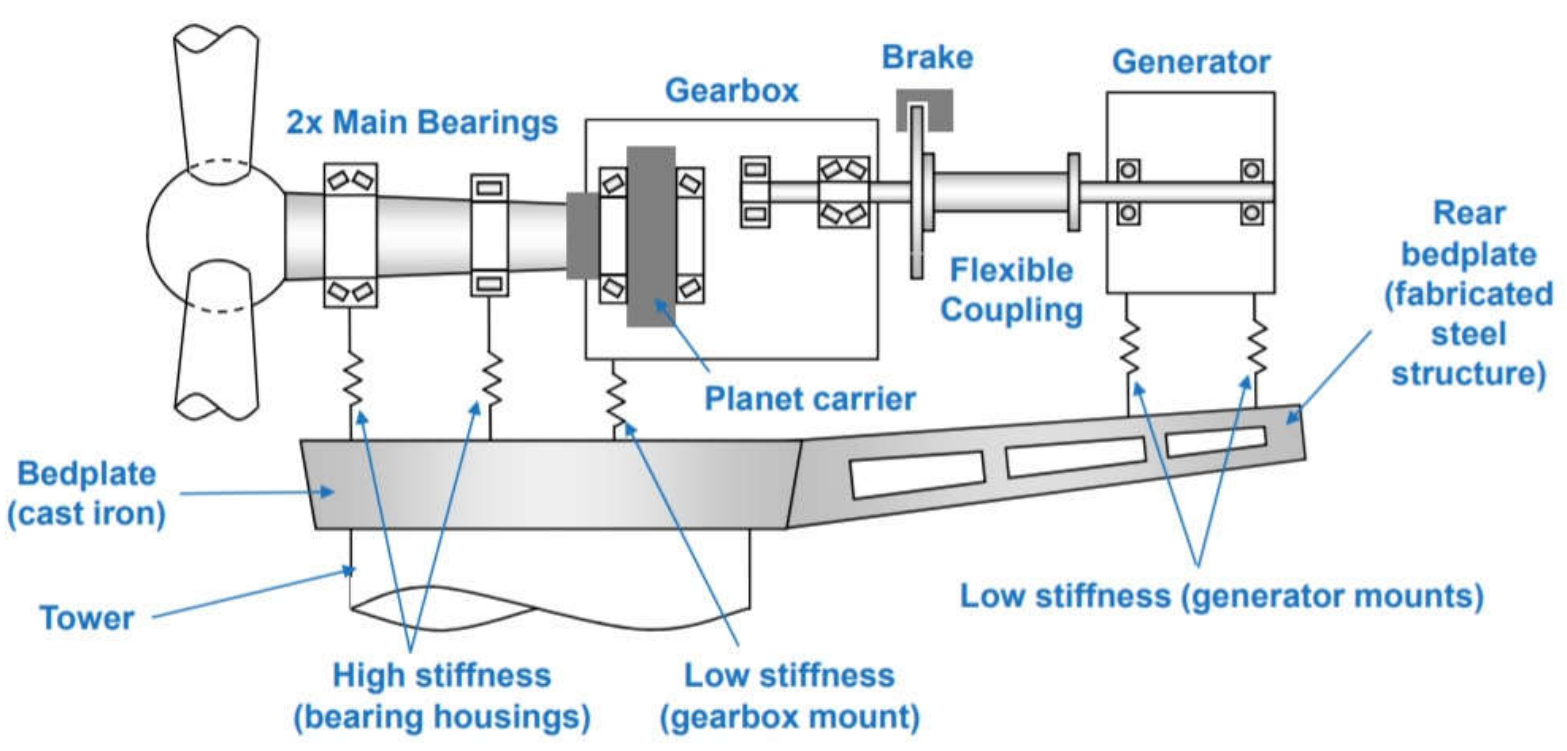

Fonte: (COULTATE, 2011) 